NBER WORKING PAPER SERIES

\title{
UNINTENDED CONSEQUENCES OF ELIMINATING TAX HAVENS
}

\author{
Juan Carlos Suárez Serrato \\ Working Paper 24850 \\ http://www.nber.org/papers/w24850 \\ NATIONAL BUREAU OF ECONOMIC RESEARCH \\ 1050 Massachusetts Avenue \\ Cambridge, MA 02138 \\ July 2018, Revised December 2019
}

I am very grateful for comments and suggestions from James Albertus, Joe Altonji, Rosanne Altshuler, Peter Arcidiacono, Alan Auerbach, Johannes Becker, Anusha Chari, Michael Devereux, Dhammika Dharmapala, Jonathan Dingel, Rafael Dix-Carneiro, John Friedman, Clemens Fuest, Tarek Hassan, Jim Hines, Niels Johannesen, Lisa Kahn, Karam Kang, Amit Khandelwal, Henrik Kleven, Wojciech Kopczuk, Brian Kovak, Adam Looney, Jon Meer, Peter Merrill, Tom Neubig, Eric Ohrn, Toan Phan, Jim Poterba, Brendan Price, Nirupama Rao, Josh Rauh, Ethan Rouen, Stephen Ryan, Nathan Seegert, Joel Slemrod, Chris Stanton, Max Todtenhaupt, Ludvig Wier, Daniel Xu, Danny Yagan, Owen Zidar, Gabriel Zucman, and Eric Zwick, as well as from seminar participants at ASSA, CESifo Venice Summer Institute, Columbia, HBS, ITFP, NBER Public Economics and Business Tax Conferences, NTA, NY Federal Reserve, Trinity University, UC Davis, UNC, University of Copenhagen, University of Michigan, University of Notre Dame Conference on Unilateralism, University of Zurich Conference on Public Finance in Developing Countries, US Treasury, Washington University (Olin), World Bank, and Yale. I am thankful to Nirupama Rao for sharing code, to Eric Ohrn for sharing data, and to John Oliver and Lin-Manuel Miranda for bringing x936 to my attention. Dan Garrett, Yamac Isik, Xian Jiang, Stephanie Karol, Ethan McClure, Linh Nguyen, Matt Panhans, Harsh Parikh, and Kevin Roberts provided outstanding research assistance. This project benefited from funding from the Kauffman Foundation and the International Tax Policy Forum and from visiting fellowships at Chicago Booth's Initiative on Global Markets and Yale University. All errors remain my own. Email: jc@jcsuarez.com; Web: www.jcsuarez.com. The views expressed herein are those of the author and do not necessarily reflect the views of the National Bureau of Economic Research.

NBER working papers are circulated for discussion and comment purposes. They have not been peerreviewed or been subject to the review by the NBER Board of Directors that accompanies official NBER publications.

(C) 2018 by Juan Carlos Suárez Serrato. All rights reserved. Short sections of text, not to exceed two paragraphs, may be quoted without explicit permission provided that full credit, including (C) notice, is given to the source. 
Unintended Consequences of Eliminating Tax Havens

Juan Carlos Suárez Serrato

NBER Working Paper No. 24850

July 2018, Revised December 2019

JEL No. F23,H25,H26,H32,J23

\begin{abstract}
$\underline{\text { ABSTRACT }}$
Eliminating firms' access to tax havens can have unintended consequences for their domestic economic activity. We study a policy that limited profit shifting by US multinationals and show it raised the tax cost of domestic investment. Firms affected by the policy responded by reducing investment and domestic employment. Firm-level responses were amplified to local labor markets through the establishment networks of profit-shifting firms. More exposed local labor markets experienced declines in employment, income, and home values and saw increases in government transfers. Policy proposals that limit profit shifting should therefore consider effects on economic activity in addition to tax revenue.
\end{abstract}

Juan Carlos Suárez Serrato

Department of Economics

Duke University

213 Social Sciences Building

Box 90097

Durham, NC 27708

and NBER

jc@jcsuarez.com 


\section{Introduction}

Profit shifting to tax havens by multinational corporations lowers tax revenues and is a key motivation for tax reform. For instance, the Tax Cuts and Jobs Act of 2017 introduced new taxes on intangible income with the aim of limiting profit shifting. While the debate over profit shifting focuses on tax revenues, this paper shows that policies that succeed at limiting profit shifting also raise the cost of domestic investment and incentivize multinationals to shift employment and investment abroad.

We show that eliminating tax havens has unintended consequences for the domestic activities of US multinationals. We study the repeal of Section 936 of the Internal Revenue Code, which limited the ability of US multinationals to shift profits to affiliates in Puerto Rico. ${ }^{1}$ Under $\S 936$, US corporations had an incentive to shift profits to Puerto Rico, since $§ 936$ essentially excluded the income of Puerto Rican affiliates from corporate taxes. This unique tax advantage allowed US multinationals to repatriate income without paying taxes. In contrast, multinationals benefit from other tax havens by deferring when they pay US taxes. After the repeal of $§ 936$, the effective tax rate of exposed multinationals rose by 4.65-6 percentage points (pp) relative to other firms.

We exploit two complementary research strategies to estimate the effects of repealing $\S 936$ on domestic economic activity. We first use firm-level data to show that $§ 936$ firms responded to the repeal by lowering domestic investment and employment. Relative to non-exposed firms, $\S 936$ firms reduced their global investment by 10\%, increased their share of investment abroad by $12 \%$, and reduced their US employment by $6.7 \%$. Our second empirical strategy uses the establishment networks of exposed firms to measure geographic exposure to the policy. We find that more exposed local labor markets saw slower growth in employment that persisted 15 years after the repeal of $\$ 936$. Moving a location from the 25 th to the 75 th percentile of the distribution of exposure to $\S 936$ reduced employment growth by $7.2 \mathrm{pp}$-about $35 \%$ of the growth in non-exposed locations. Spatial variation allows us to characterize the broader effects of the repeal. More exposed places experienced relative decreases in income, wages, and home values, and these areas also became more reliant on government transfers.

Our results reassess the view that profit shifting mainly distorts tax revenue. ${ }^{2}$ Indeed, our results show that domestic employment and investment may decrease when enforcement efforts significantly limit profit shifting. A full accounting of policies that limit profit shifting should include the intended effects of revenue collection along with unintended effects on economic activity. Our results also highlight the importance of considering the regional implications of tax

\footnotetext{
${ }^{1}$ Puerto Rico is a US possession but is treated as a foreign country for purposes of taxation. This paper studies measures of real economic outcomes in the continental US, excluding Puerto Rico.

${ }^{2}$ For instance, Gravelle (2016) argues that "profit shifting is largely a problem of lost revenue rather than inefficient location of investment," and the Tax Foundation (2016) notes "lawmakers are concerned about profit shifting because it has an impact on the amount of revenue that the corporate income tax ultimately collects." Relative to these views, effects on domestic economic activity are unintended consequences of the policy.
} 
reforms, as fiscal shocks can have long-lasting effects on local economies.

We establish these findings in three steps. We first construct a model of multinational investment and profit shifting. Since profits generated in high-tax countries may be shifted to low-tax locations, firms with access to tax havens face a lower effective cost of investing in high-tax countries. Repealing $§ 936$ raised the effective cost of investing in the US. The model predicts that multinationals respond by lowering investment and employment and by shifting economic activity to foreign affiliates. ${ }^{3}$ These predictions can be understood using the hierarchy of behavioral responses of Slemrod $(1992,2001)$. When firms can avoid policies that limit profit shifting through financial or accounting responses, they may respond merely by moving "paper profits" across tax havens. However, enforcement efforts that prevent firms from using accounting maneuvers may escalate responses down the hierarchy and may trigger adjustments to real margins of production. By analyzing production and profit-shifting behaviors jointly, the model reveals that policies that succeed in limiting the use of tax havens are subject to the standard tradeoffs between tax revenue and economic activity.

The second part of the paper tests these predictions using firm-level datasets. Our differencein-differences methodology compares the investment and employment decisions of firms exposed to $\S 936$ with those of similar control firms. Using data from Compustat, we estimate that exposed firms decreased their overall investment by 10\%. Relative to the change in effective tax rates, this investment response implies a semi-elasticity of $1.77 .{ }^{4}$ In addition to lowering overall investment, US multinationals also increased their share of investment in foreign affiliates. These investment responses were accompanied by declines in firm-level employment. Using the National Establishment Time Series (NETS) database, we find that, relative to control firms, exposed firms reduced their US employment by $6.7 \%$. The data confirm the model predictions and show that firms viewed the repeal of $\S 936$ as an increase in the effective cost of investing in the US.

This difference-in-differences approach yields unbiased estimates of the effects of repealing $\S 936$ if investment and employment in exposed firms would have been similar to that of control firms had $§ 936$ not been repealed. This parallel trends assumption is supported by four facts. First, we present graphical evidence that control firms and firms exposed to $\S 936$ were on similar trends prior to the policy change. Second, we rule out that changes in other tax policies can confound the effects of $\S 936$. Third, the estimates are robust to analyzing firm-level changes, to including firm fixed effects, and to inverse probability reweighting, which further ensures that

\footnotetext{
${ }^{3}$ The model is based on work by Hines and Rice (1994). Tax complementarities arise from profit shifting and are not due to complementarities in production or demand, as in Desai et al. (2009). Repealing $§ 936$ would lower US employment and investment if firms view the US as a high-tax country and if capital complements labor.

${ }^{4}$ Firms in more exposed industries see relative investment declines of $14-18.7 \%$, implying semi-elasticities of 2.3-3.1. By comparison, de Mooij and Ederveen (2008) conduct a meta-analysis and find a median semi-elasticity of 2.9, Zwick and Mahon (2017) find a semi-elasticity of 3.7 from bonus depreciation, Ohrn (2018) estimates a semi-elasticity of 4.7 from the domestic production activities deduction, Moon (2019) finds a semi-elasticity of 3.7 from capital gains taxes in Korea, and Chen et al. (2019) estimate a semi-elasticity of 3.2 in China.
} 
treatment and control firms are comparable. Fourth, we find similar effects when we analyze changes in industry-level investment using data from the Annual Survey of Manufactures. These facts significantly reduce the likelihood that our results are due to a spurious statistical anomaly.

In our third and final step, we show that firm-level responses had persistent effects on local labor markets. The establishment networks of firms exposed to $\S 936$ allow us to measure the degree to which each local economy was affected by this limit on profit shifting. We relate the fraction of establishments in a given county that could benefit from $\S 936$ to data on employment growth at the industry-county-year level from the Quarterly Census of Employment and Wages. We find that increasing a county's exposure to $\S 936$ from the 25 th to the 75 th percentile of the exposure distribution reduces employment growth by $7.2 \mathrm{pp}$ and income growth by $12.5 \mathrm{pp}$. Using a long-difference specification across Census years, we also find relative decreases in wage rates that are concentrated in the wages of workers without a college degree as well as decreases in housing prices and rental costs. Finally, we show that more exposed areas receive an additional $\$ 16$ in unemployment benefits per person and $\$ 30$ in income replacement programs per capita. Overall, the repeal of $\$ 936$ had long-lasting impacts on more exposed local labor markets.

As in the firm-level analysis, we provide auxiliary evidence that spatial variation identifies the regional effects of repealing $§ 936$. The key identifying assumption behind the local labor market effects is that exposure to $\S 936$ is not correlated with other shocks that could affect local labor markets. Several pieces of evidence justify this assumption. First, we show graphically that locations with different degrees of exposure have parallel trends prior to the repeal of $\S 936$. Second, the dynamic effects match the phase-out of $\S 936$, and the effects stabilize after $\S 936$ is fully phased out. Third, our preferred specification controls for industry-year fixed effects, which rule out concerns that the observed change in employment is due to industry-specific trends. Fourth, we show that exposure to $\S 936$ is not related to a battery of potential confounders and that the results are robust to including them as controls. Fifth, we find similar effects when we analyze different geographical units (counties, commuting zones, and conspumas); when we study changes in the employment-to-population ratio, which rules out the possibility that migration fully accommodates labor demand shocks; and when we use data from several different sources (QCEW, BEA, and IRS). Sixth, we conduct "placebo tests" that show that our results are not driven by exposure to firms with similar characteristics to $\S 936$ corporations, which rules out that the results are driven by changes in the firm size distribution or by exposure to industries that were heavy users of $\S 936$. In the face of these facts, the most likely scenario is that the slower economic growth in more exposed local labor markets is driven by the firm-level responses we document in this paper.

We conclude our analysis of $\S 936$ by reconciling the firm-level effects on employment with the local labor market effects. If firm-level responses to the repeal of $\S 936$ had effects on suppliers of inputs, interacted with agglomeration effects, or affected local non-tradable industries, layoffs at 
$\S 936$ corporations could have spillover effects that amplified job losses within local labor markets. Our results suggest that every $§ 936$ layoff led to the loss of an additional 3.87 jobs in the local labor market, which is consistent with employment multipliers from Moretti (2010). In addition, an event-study across industries shows that tradable employment-which included most $§ 936$ firms - was the first to decline in response to the repeal of $\S 936$ and was then followed by declines in the non-tradable and construction sectors.

This paper contributes to the public finance literature by challenging the view (e.g., in Gravelle, 2016) that profit shifting mostly affects tax revenues and is not a primary concern for real economic outcomes. While this view is prevalent in policy circles, our empirical evidence provides support for a central force in models of international taxation. ${ }^{5}$ Our results are particularly valuable for the study of international taxation, where natural experiments are few and far between. By shining a light on long-lasting effects of tax reform on local economies, this paper shows that the policy debate should also consider unequal geographic burdens from international tax reform.

To appreciate the lessons of $\S 936$, it is worth noting that Puerto Rico was a unique tax haven for US multinationals. Puerto Rico was especially desirable because of the close cultural and institutional connections with the US and, most importantly, because it allowed for the immediate repatriation of foreign profits at a zero tax rate. These benefits surpassed those of other tax havens, which allow multinationals to defer when they pay US taxes. ${ }^{6}$ For this reason, repealing $\S 936$ increased the effective tax rates of exposed firms. In a companion paper (Garrett and Suárez Serrato, 2019), we show that $§ 936$ firms did not expand to other tax havens after the repeal. We also show that the firm value of exposed firms decreased following news of the repeal of $\S 936$ (see Appendix C). These facts are consistent with the view that repealing $\S 936$ eliminated a valuable profit shifting avenue that lacked a close substitute for US multinationals. Thus, while the repeal of $§ 936$ was a unique natural experiment, the lessons from this reform provide a policy-relevant case study for when enforcement succeeds at limiting profit shifting.

This paper is related to research quantifying profit shifting by multinational corporations. Grubert and Mutti (1991) and Hines and Rice (1994) showed in pioneering work that reported pretax profits are negatively correlated with corporate tax rates. Recent papers updating seminal studies (Mutti and Ohrn, 2019) and using firm-level earnings shocks for identification (Dharmapala and Riedel, 2013) find smaller effects than earlier work. Clausing (2009) estimates that profit shifting lowers US tax revenues by $\$ 100$ billion annually. According to this methodology, $\S 936$ accounted for $10-15 \%$ of the total profits shifted out of the US at the time of its repeal. ${ }^{7}$

\footnotetext{
${ }^{5}$ This force is present in both seminal models of international tax as well as in more recent papers, including Hines and Rice (1994); Grubert and Slemrod (1998); Gordon and Hines (2002); Altshuler and Grubert (2003); Hong and Smart (2010); Slemrod and Wilson (2009); Dharmapala (2008); Auerbach and Devereux (2018).

${ }^{6}$ The massive repatriation of foreign profits during the 2004-2005 tax holiday showed that US multinationals value repatriation (at a discounted tax rate) over deferral (Blouin and Krull, 2009; Dharmapala et al., 2011).

${ }^{7}$ See Dharmapala (2014) for an in-depth review of this literature and Heckemeyer and Overesch (2013) for a meta-analysis. Recent approaches that consider non-linear models (Dowd et al., 2017), as well as recent work by
} 
Our results also contribute to the literature studying real responses of multinational corporations to international taxation. Grubert and Slemrod (1998) analyze the investment and profit-shifting decisions of $\S 936$ corporations and show that investments in Puerto Rico followed from a profit shifting strategy to avoid US taxation. Desai et al. (2009) show that foreign investment is complementary to domestic investment. Becker and Riedel (2012) find evidence of cross-border effects of taxes, such that taxation at the parent location may affect investment by affiliates. Kovak et al. (2017) show that increases in foreign employment are not associated with decreases in domestic employment. Finally, de Mooij and Liu (2018) study the effects of transfer pricing regulations and find that anti-avoidance rules lead to a decrease in domestic investment. While most papers in this literature use variation in taxes or regulations across countries, this paper exploits a natural experiment that limited access to an important tax haven for US multinationals. ${ }^{8}$

Finally, we advance the corporate and international tax literatures by using the establishment networks of multinationals to trace out the regional implications of fiscal policy. Spatial variation provides alternative identification strategies that researchers can use to evaluate fiscal policies when firm- or industry-level comparisons are not feasible. In the case of $\S 936$, the regional analysis confirms that the finding that repealing $\S 936$ affected workers in more exposed labor markets does not depend on specific firm-level comparisons. As in recent contributions that study the propagation of firm shocks across establishments (e.g., Huber, 2018; Giroud and Mueller, 2019), spatial variation complements firm-level analyses by characterizing how fiscal policy is transmitted to regional economies. For instance, in Garrett et al. (2019) we use this approach to measure how the tax incentives for investment analyzed by Zwick and Mahon (2017) impact local labor markets. Finally, spatial variation also allows us to measure the broader impacts of policies, including effects on housing values and governments transfers, as in Autor et al. (2013).

We proceed by describing $§ 936$ in Section 2, presenting the model in Section 3, and measuring exposure to $\S 936$ in Section 4. Section 5 tests the model predictions on firm-level data. Section 6 shows that more exposed local labor markets experienced slower employment growth following the repeal of $\S 936$. Section 7 concludes.

Clausing (2016) and Tørsløv et al. (2018), argue for larger estimates of profit shifting. Guvenen et al. (2017) also argue that profit shifting biases estimates of productivity growth and GDP. However, Blouin and Robinson (2019) note that correcting for differences in accounting definitions significantly lowers estimates of profit shifting.

${ }^{8}$ See Hines (1999) and Gordon and Hines (2002) for excellent reviews of this literature. Devereux and Griffith (1998) show that multinationals locate production facilities in countries with lower tax rates. Mintz and Smart (2004) show that income shifting across Canadian jurisdictions may increase investment. Overesch (2009) also finds significant effects of home country tax rates on inbound investment to Germany. Buettner et al. (2012) show that thin capitalization rules affect the choice of equity and debt at the firm level. Egger and Wamser (2015) and Albertus (2017) find that investment is hampered by controlled foreign corporation (CFC) laws. Schwab and Todtenhaupt (2019) show tax cuts can generate cross-border effects on R\&D. Bilicka et al. (2019) find that the UK worldwide debt cap also led multinationals to relocate activity away from the UK. Grubert and Altshuler (2006) show that governments may allow multinationals to engage in profit shifting to avoid reductions to their domestic operations. 


\section{The Possessions Tax Credit and the Repeal of $\S 936$}

Starting with the Revenue Act of 1921, the US government exempted US multinationals from income taxes if the income originated in affiliated corporations located in Puerto Rico. ${ }^{9}$ While the Tax Reform Act of 1976 replaced the exemption with a tax credit, possessions corporations were essentially exempted from US taxes under the new regime. The new credit was formally known as the US Possessions Corporations Tax Credit, but it was commonly referred to as $§ 936$, in reference to the relevant section of the Internal Revenue Code (26 U.S.C. §936, 1976).

$\S 936$ was especially susceptible to profit-shifting maneuvers. To see this, first consider the role of intangibles in profit shifting. A US multinational can shift tax obligations from the US to a tax haven by assigning a patent to a low-tax affiliate. The company can then use royalty payments from the US parent to the low-tax affiliate to lower its US taxable income, as well as its overall tax payments. In general, this strategy is limited by rules on the pricing of intra-group transactions as well as by taxes on the transfer of intangible assets. In the case of possessions affiliates, however, transfers of intangible assets were essentially untaxed (Eden, 1994). The Joint Committee on Taxation (2006) describes an example where a US pharmaceutical could develop a drug patent in the US, deduct labor and R\&D costs for the purposes of the federal income tax, and then assign the patent to the affiliate in Puerto Rico, where royalty income would go untaxed. ${ }^{10}$ In addition to the weak rules governing the transfer of intangible assets, relatively lax transfer pricing rules facilitated profit shifting by US multinationals operating in Puerto Rico. Finally, note that $\S 936$ allowed for the immediate repatriation of foreign profits, which was more valuable than the deferrable benefit obtained through other tax havens.

Political support for $\S 936$ rested on the belief that the tax credits benefited the economy of Puerto Rico. This support eroded with the growing concern that $§ 936$ was mainly a conduit for profit shifting. As an example of these worries, the GAO (1993) reported that the tax credits exceeded the average compensation of Puerto Rican employees in $\S 936$ firms. ${ }^{11} \S 936$ was repealed in the Small Business and Job Protection Act of $1996 .{ }^{12}$ The law allowed for a 10-year transition

\footnotetext{
${ }^{9}$ The exemption also applied to other US possessions including Guam, American Samoa, the Northern Mariana Islands, and the US Virgin Islands. However, the vast majority of exempted income originated in possessions corporations located in Puerto Rico. The government of Puerto Rico also provided tax holidays that exempted most of their income from local corporate taxes for up to 25 years (Bond, 1981).

${ }^{10}$ Even though the Tax Equity and Fiscal Responsibility Act of 1982 put an end to this particular maneuver, possessions corporations benefited from relatively lax transfer pricing rules until 1986, when $\S 936$ was harmonized with transfer pricing regulations (§482 of the IRC). Hexner and Jenkins (1995) and Eden (1998) argue that intangible assets transferred to Puerto Rico represented profit-shifting motives with little or no real investment.

${ }^{11}$ According to the GAO (1993), the tax credit per worker was about $\$ 25,000$, which was greater than the average employee compensation. The cost per employee was even higher for drug companies, who received over $\$ 70,000$ in tax credits per employee (Eden, 1998).

${ }^{12} \S 936$ was a minor provision in the law, which focused on increasing capital expense limits for small businesses and raising the minimum wage. In contrast to bills where lobbying activity affects whether a piece of legislation is enacted (Kang, 2016), this bill was passed by the House almost unanimously (414-10), had bipartisan support in the Senate (74-24), and moved from committee to final passage very quickly (HR3448, 1996). This timing
} 
period during which companies that had previously claimed $\S 936$ credits could continue to do so. While the technical details of the phase-out are complicated, many firms saw the value of their credits decrease to $40 \%$ of their original value by $1998 .^{13}$

To understand the effects of the repeal of $\S 936$, it is important to note that Puerto Rico was an especially attractive tax haven for US multinationals. First, tax havens are only able to attract foreign investment if they have strong governance (Dharmapala and Hines, 2009). Because of the strong cultural link with the US and the fact that Puerto Rico's legal system operates within the US federal system, US firms view Puerto Rico as a safe destination for their intellectual property. A second reason is that operations in Puerto Rico were essentially condoned by the US Treasury. Operations in other tax havens were more likely to raise red flags that US multinationals were pursuing aggressive tax planning strategies. Affiliates in other tax havens also faced the risk that unrepatriated earnings could be classified as passive (Subpart F) income and be subject to repatriation taxes. Finally — and most importantly — $\$ 936$ allowed US multinationals to immediately repatriate income at an effective zero US tax rate. In contrast, the benefit from shifting profits to other tax havens comes from delaying - or deferring - when US taxes are paid. ${ }^{14}$

Consider now the fiscal cost of $\S 936$. Panel A of Figure 1 displays the fiscal cost of $\S 936$ to the US Treasury at the industry level using data from the IRS (2017a). This panel shows the gradual elimination of the tax credits, starting from about $\$ 4.9$ billion in 2017 dollars and ending in their full phase-out by 2006. This graph shows large drops in the value of these credits after 1996 and 1998, which matches statutory limits on the tax credits. Panel B shows the composition of these credits by industry. In 1995, about $57 \%$ of these credits were claimed by corporations in the chemical manufacturing industry. Firms manufacturing equipment, food, beverages, and tobacco claimed about $26 \%$ of the credits, while other industries claimed the remaining $17 \%$.

Table 1 shows US and Puerto Rico employment for selected US multinationals in 1995 using

suggests the legislation was not subject to intense lobbying pressure. We find no explicit mention of this bill or $\S 936$ in lobbying expenditure data (OpenSecrets.org, 2018). Note that the 1996 reform repealed the tax credits for tax years starting after December 31, 1995 (26 U.S.C. $\$ 936,1996)$. For this reason, we use 1995 as the reference year in our empirical analysis. We also show our results are robust to defining exposure to $\S 936$ in 1993.

${ }^{13}$ Firms could elect to use an economic activity or an income credit method to compute the value of the credits (Joint Committee on Taxation, 2006). For firms using the income credit method, the credit was limited to a fraction of the pre-repeal value of the credit. This limit was set to decrease to $40 \%$ by 1998 . For firms using the economic activity method, the credits were determined by $60 \%$ of the sum of wage expenses plus a fraction of intangible property depreciation and local income taxes.

${ }^{14}$ While deferral strategies can lower the present value of taxes (Altshuler and Grubert, 2003), these avoidance schemes are costly and may reduce the profitability of domestic and foreign activities (Grubert and Altshuler, 2013; Dyreng and Markle, 2016). The American Jobs Creation Act of 2004 provides a test of the value of deferral. The act allowed US multinationals to repatriate income at a reduced tax rate for the years 2004-2005 (e.g., Blouin and Krull, 2009; Dharmapala et al., 2011). If deferral conferred the same benefit as immediate repatriation, US multinationals would not have responded to this incentive. The fact that US corporations repatriated close to $\$ 300$ billion shows that immediate repatriation is significantly more valuable than deferral. 
data from the National Establishment Time-Series (NETS). ${ }^{15}$ This table shows that just a few $\S 936$ firms accounted for about 2.3 million jobs in the US and that the 682 firms with Puerto Rican affiliates employed close to 11 million workers in the US. Many of these firms are in the chemical, food, and electronic manufacturing industries. The pharmaceutical industry established a strong presence on the island since companies like Abbott Laboratories, Wyeth, Bristol-Myers Squibb, and Merck could shift profits by locating their intellectual property in Puerto Rican affiliates. ${ }^{16}$ Several of these large firms, including Baxter International, Bristol-Myers Squibb, and General Electric, decreased their US employment significantly after the repeal of $\S 936$. These examples suggest that repealing $\S 936$ could have important implications for the domestic employment of these US multinationals.

An important question is whether the repeal impacted the effective tax rates (ETRs) of $§ 936$ firms. Using data from IRS (2017a) and NETS, we find that the ETRs of exposed firms increased by 4.65-6pp. To see this, we first compute $E T R_{i, t}^{\text {Repeal }}:$ the effective tax rate of industry $i$ during the repeal. ${ }^{17}$ Panel C of Figure 1 shows that exposed industries had a relatively stable $E T R_{i, t}^{\text {Repeal }}$ that hovered around $27 \%$ between 1996 and 2006. We make two adjustments to $E T R_{i, t}^{\text {Repeal }}$ to estimate $E T R_{i, t}^{\text {No Repeal }}$ : the effective tax rate that exposed industries would have faced absent the reform. First, we add back the credits that firms would have claimed absent the reform as a share of pretax income. Second, we allow for firms to respond to the repeal of $\S 936$ by claiming other tax credits more aggressively. ${ }^{18}$ We find that firms avoid close to $20 \%$ of the reduction in tax credits through this behavioral response. Panel $\mathrm{C}$ plots $E T R_{i, t}^{\text {No Repeal }}$ and shows that exposed US multinationals would have seen a decline in ETRs absent the repeal of $\S 936$. This pattern is remarkably consistent with results from Dyreng et al. (2017), who document a similar decline in ETRs for US corporations during this period. Therefore, $§ 936$ firms saw an increase in their tax rates relative to peer firms that experienced an overall decline in ETRs. On average, we find that by 2006, $§ 936$ firms experienced a relative increase in ETRs of 5.73pp. We also compute this relative increase for firms in sectors and industries that were prominent

\footnotetext{
${ }^{15}$ Several of these firms were identified by press accounts of firms that took advantage of $§ 936$ (Business Week, 1993; Los Angeles Times, 1993).

${ }^{16}$ In some cases the Puerto Rican operations of these large firms were not in their main industrial lines of business. For example, while Sara Lee is best known for its consolidated foods, the Puerto Rican operations focused on hosiery. Sara Lee cut employment in Puerto Rico in 2001 and then again in 2003, with no indication that these jobs would be shifted to US plants (New York Times, 2003).

${ }^{17}$ Because only eligible firms received tax credits, we divide the observed tax credits by $\hat{p}_{i}$ : the fraction of an industry's employment that is eligible for $\S 936$ credits in 1995 . We calculate $\hat{p}_{i}$ using NETS data on exposed firms (as in Table 1) to obtain: $E T R_{i, t}^{\text {Repeal }}=\frac{\text { Taxes Paid }_{i, t}-\left\{936 \text { Tax Credits }_{i, t} / \hat{p}_{i}\right.}{\text { Taxable Income }{ }_{i, t}}$.

${ }^{18}$ The mechanical loss in tax credits is $\hat{s}_{i} \times$ Taxable Income $_{i, t}$, where $\hat{s}_{i}$ is the ratio of $\S 936$ credits to taxable income prior to the repeal. The mechanical increase in ETRs is $\frac{\oint 936 \operatorname{Credits}_{i, t}-\hat{s}_{i} \times \text { Taxable Income }_{i, t}}{\hat{p}_{i} \times \text { Taxable Income }_{i, t}}$, where $\hat{p}_{i}$ is the fraction of employment eligible for $\S 936$ credits. We estimate the effect of tax credits on ETRs, $\beta$, by regressing industry-level ETRs on $\S 936$ credits. We use a value of $\hat{\beta}=0.8$, which is a mid-range of the estimates reported in Table A.1. Finally, $E T R_{i, t}^{\text {No Repeal }}=E T R_{i, t}^{\text {No Repeal }}+\hat{\beta} \times \frac{\S 936 \text { Credits }_{i, t}-\hat{s}_{i} \times \text { Taxable Income }_{i, t}}{\hat{p}_{i} \times \text { Taxable Income }_{i, t}}$. Note that the case with no accounting responses $(\beta=1)$ implies an ETR increase of $7 \mathrm{pp}$. Appendix B provides additional details.
} 
users of $\S 936$. Depending on the sector, we estimate relative increases in ETRs of 4.65-6pp. ${ }^{19}$ To complement these calculations that use aggregate data, in Section 5, we study firm-level data on taxes paid and find similar increases in ETRs. ${ }^{20}$

The effects of repealing $\S 936$ on effective tax rates suggest that US multinationals were not able to fully avoid the fiscal costs of its repeal. In Garrett and Suárez Serrato (2019), we use data on exposure to other tax havens from Dyreng and Lindsey (2009) to study whether $§ 936$ firms expanded to other tax havens after the repeal. We find that exposed firms did not respond to the repeal by expanding activities to other tax havens. We also find that firms exposed to $\S 936$ experienced declines in firm value immediately following news of the repeal of $§ 936$ (see Appendix C). ${ }^{21}$ These are positive results from the perspective of enforcement. They are also consistent with the understanding that repealing $§ 936$ eliminated a unique tax haven for US multinationals. These facts help us interpret our results as tracing out the consequences of successfully limiting the fiscal benefit of shifting profits to tax havens. While not all enforcement efforts succeed at limiting profit shifting, our results provide the policy-relevant case study for when enforcement meaningfully limits profit shifting. ${ }^{22}$

Finally, while the repeal of $\S 936$ is credited with contributing to Puerto Rico's crisis, it is worth noting that the crisis began after the full phase-out of $\S 936$. Outside of the 2001 recession, overall employment in Puerto Rico grew until the onset of the crisis in 2006 (see Figure A.1). ${ }^{23}$ Chari et al. (2017) analyze the effects of the debt crisis on growth in Puerto Rico. They argue that the cointegration of the economies of Puerto Rico and the United States broke down after 2012. This timing is convenient for our analysis as it assuages the concern that the domestic effects on employment and investment were caused by changes in Puerto Rico's economic prospects.

\footnotetext{
${ }^{19}$ Sectors identified by NAICS codes $22,31-33$, and 48-89 were major users of $\S 936$. To study industries that were major users of $\S 936$, we exclude industries that claimed less than $0.1 \%$ of tax credits: NAICS codes $321-324$, 327, 331, and 336-337. Differences in ETRs are driven by differences in $\hat{p}_{i}$ and $\hat{s}_{i}$ across industries.

${ }^{20}$ We follow recent work in accounting (Dyreng et al., 2017) and finance (Desai and Dharmapala, 2009) by focusing on the effect on ETRs. Because the marginal tax rate requires an adjustment for profit shifting (Grubert and Slemrod, 1998), we cannot compute how $§ 936$ impacts the marginal tax rate. Gruber and Rauh (2007) discuss difficulties in computing marginal tax rates using financial statement data and argue than an aggregate approach - as in Figure 1-can circumvent these drawbacks.

${ }^{21}$ Many firms continued operating in Puerto Rico after the repeal of $\S 936$. While profit shifting to Puerto Rico is an ongoing concern, this strategy only produced the more limited benefit of deferral until 2018. These facts are consistent with the loss in firm value and the lack of observed substitution to other tax havens, as well as with arguments in Bilicka (2019) that setting up tax haven affiliates involves significant fixed costs.

${ }^{22}$ In contrast, we would expect that financial or accounting responses would diminish real responses to the repeal of $\$ 936$ (Slemrod, 1992, 2001). For this reason, we would not expect to find changes in employment or investment when enforcement efforts do not meaningfully limit profit shifting, as in Bustos et al. (2019).

${ }^{23}$ While this paper does not study the effects of $\S 936$ on the Puerto Rican economy, Feliciano and Green (2017) use industry-level data to show that the repeal of $\S 936$ led to a decline in manufacturing establishments. Mora et al. (2017) provide an in-depth study of the origins of the crisis. La crisis boricua had manifold causes including new sales taxes in Puerto Rico; demographic trends related to population control policies that started in the 1930s; high costs of living due to increased trade costs from the Jones Act; increased public indebtedness; and a reliance on imported oil for electricity generation, which deeply affected the economy as oil prices doubled between 2005 and 2012. In 2006, these conditions coalesced into the "perfect storm" behind Puerto Rico's crisis.
} 


\section{$3 \quad$ A Model of Profit Shifting with Tax Complementarities}

This section builds on the frameworks of Hines and Rice (1994) and Grubert and Slemrod (1998) to show theoretically that profit shifting lowers the cost of capital in other countries. These tax complementarities generate empirical predictions that answer the question: How would the repeal of $\S 936$ affect investment and employment in the US?

Suppose a firm is located in Puerto Rico, the United States, and a third country $C$ and has after-tax profits given by:

$$
\left(1-t_{C}\right) f_{C}\left(K_{C}\right)+\left(1-t_{U S}\right)\left(f_{U S}\left(K_{U S}\right)+f_{P R}\left(K_{P R}\right)\right)+t_{U S} f_{P R}\left(K_{P R}\right)-\rho\left(K_{C}+K_{U S}+K_{P R}\right),
$$

where $\rho$ is the nondeductible opportunity cost of equity capital and $f_{j}(\cdot)$ is a firm's production function in country $j$, which is increasing in capital, $f_{j}^{\prime}(K)>0$, and exhibits decreasing returns to investment, $f_{j}^{\prime \prime}(K)<0$. The possessions tax credit is $t_{U S} f_{P R}\left(K_{P R}\right)$, which gives a zero tax rate on profits from operations in Puerto Rico. ${ }^{24}$ Our analysis generalizes beyond the three-country case, where global after-tax profits are given by $\sum_{j}\left[\left(1-t_{j}\right) f_{j}\left(K_{j}\right)-\rho K_{j}\right]$.

Firms make two sequential decisions. They first decide where to locate their capital. In the second period, firms choose a profit shifting strategy. Firms engage in profit shifting by misreporting their profitability as $r_{j}$, which may deviate from their actual profitability $\bar{f}_{j}=$ $f_{j}\left(K_{j}\right) / K_{j}$ in country $j$. Misreporting is costly to the firm since it may face penalties, litigation costs resulting from challenges from tax authorities, and real costs of transferring intangible assets. ${ }^{25}$ We assume misreporting costs are proportional to local capital, are convex in the degree of misreporting, and take the form:

$$
C\left(r_{j}, \bar{f}_{j}, K_{j}\right)=\frac{K_{j}\left(r_{j}-\bar{f}_{j}\right)^{2}}{2 a} .
$$

The parameter $a$ modulates these costs with high values of $a$ implying low misreporting costs. ${ }^{26}$

We start by analyzing profit shifting in the second period. Given a capital allocation $\left\{K_{j}\right\}$, firms solve the tax planning problem:

$$
\max _{\left\{r_{j}\right\}} \sum_{j} K_{j}\left[\left(1-t_{j}\right) r_{j}-\rho-\frac{\left(r_{j}-\bar{f}_{j}\right)^{2}}{2 a}\right], \quad \text { subject to: } \sum_{j} \bar{f}_{j} K_{j}=\sum_{j} r_{j} K_{j},
$$

\footnotetext{
${ }^{24}$ We assume that corporations in Puerto Rico would pay the US corporate rate absent $\S 936$ and that profits from country $C$ would be reinvested in the country $C$ in the case that $t_{C}<t_{U S}$. While Puerto Rico has positive corporate taxes, their magnitude is negligible in practice, and we omit them from the analysis. As in Hines and Rice (1994), we assume firms reinvest profits abroad. Finally, we assume the cost of capital $\rho$ is not affected by small changes in tax rates.

${ }^{25}$ This analysis takes the network of affiliates as given. As we show in Garrett and Suárez Serrato (2019), §936 firms do not expand to other tax havens after the repeal of $\S 936$. For analyses of the extensive margin of operating in a tax haven, see Grubert and Slemrod (1998), Desai et al. (2006), and Gumpert et al. (2016).

${ }^{26}$ This formulation of misreporting costs follows general features of evasion costs, as in Slemrod (2001). While the closed-form results depend on this formulation, we obtain similar qualitative patterns from alternative functional forms that capture convex misreporting costs that are proportional to the firm's activity in the country.
} 
where the constraint implies that the firm must report total profits truthfully but may shift the location of its profits.

Proposition 1 (Optimal Profit Shifting). Firms over-report (under-report) profits in countries where the corporate tax rate is below (above) the capital-weighted average:

$$
r_{j}=\bar{f}_{j}+a\left(\tilde{t}-t_{j}\right)
$$

where the capital-weighted average tax rate $\tilde{t}$ is given by $\tilde{t}=\frac{\sum_{j} t_{j} K_{j}}{\sum_{j} K_{j}}$.

See Appendix D for detailed proofs of the results in this section. Proposition 1 states our version of the result in Hines and Rice (1994) that reported profitabilities are negatively correlated with the country's tax rate. ${ }^{27}$ Panel A in Figure 2 describes this result graphically. Firms overreport profits in countries with low taxes $\left(\tilde{t}>t_{j}\right)$ and under-report in countries with high taxes $\left(\tilde{t}<t_{j}\right)$. The degree of misreporting depends on the cost of profit shifting: the relationship between $r_{j}$ and the tax differential is relatively flat (solid line) when $a$ is low (high cost of misreporting) and is steeper (dashed line) when $a$ is large (low cost of misreporting).

In the first period, firms foresee their profit-shifting strategies and invest across countries to maximize a combination of economic and profit-shifting incentives. Substituting the optimal profit-shifting strategies into the objective function and rearranging, we obtain:

$$
\max _{\left\{K_{j}\right\}} \underbrace{\sum_{j}\left[\left(1-t_{j}\right) f_{j}\left(K_{j}\right)-\rho K_{j}\right]}_{\text {Economic Incentives }}+a \sum_{j} K_{j} \underbrace{\left[\left(1-t_{j}\right)\left(\tilde{t}-t_{j}\right)-\frac{\left(\tilde{t}-t_{j}\right)^{2}}{2}\right]}_{\text {Net Benefit from Profit Shifting }} .
$$

Firms' optimal investment plans trade off economic and profit-shifting incentives in Equation 1. This tradeoff includes the "avoidance-facilitating effect" (Slemrod and Gillitzer, 2013) whereby real activity in a given country enables profit shifting. In addition, the firm takes into account how its capital allocation affects the capital-weighted average tax, $\tilde{t}$.

Proposition 2 (Profit Shifting Lowers the User Cost of Capital (UCC)). Profit shifting (weakly) lowers the UCC in all countries. The decline is largest in countries with tax rates that are most different from $\tilde{t}$. UCCs can be observed from the first-order condition of Equation 1:

$$
\left(1-t_{j}\right) f_{j}^{\prime}\left(K_{j}\right)=\rho-\frac{a\left(\tilde{t}-t_{j}\right)^{2}}{2} \equiv \tilde{\rho} \leq \rho
$$

The effective cost of capital $\tilde{\rho}$, which Grubert and Slemrod (1998) call the "income shifting adjusted user cost of capital," is reduced by the net marginal benefit from profit shifting. ${ }^{28}$ Panel

\footnotetext{
${ }^{27}$ As in Huizinga and Laeven (2008), misreporting for a given firm depends on its capital-weighted mean tax, $\tilde{t}$.

${ }^{28}$ Given the quadratic misreporting costs in the model, the net marginal benefit is given by: $\frac{a\left(\tilde{t}-t_{j}\right)^{2}}{2}=\frac{\left(r_{j}-\bar{f}_{j}\right)^{2}}{2 a}$. Gordon and Hines (2002) discuss a similar expression in their presentation of Hines and Rice (1994). See also Overesch (2009) and Mintz and Smart (2004). Note that this result relies on the assumption that the production function does not exhibit complementarities across countries. Since employment in Puerto Rican affiliates accounted for about $1.6 \%$ of employment in $\S 936$ firms, we view this as an innocuous simplifying assumption in this application. See Desai et al. (2009) and Becker and Riedel (2012) for models with such complementarities.
} 
B in Figure 2 describes the intuition of this result. Without profit shifting, the firm sets capital so that the after-tax marginal product of capital equals the cost of equity $\rho^{N P S}$ (dotted line). When firms can shift profits, the income-shifting adjusted user cost of capital $\tilde{\rho}_{0}$ (dashed line) is below $\rho^{N P S}$, which results in a higher level of investment $K_{j}^{0}>K_{j}^{N P S}$.

While Proposition 2 shows profit shifting lowers the effective cost of capital in all countries, the mechanism for this effect is different across high- and low-tax countries. Affiliates in high-tax countries know the returns from investment will be partly shifted to tax havens, which lowers the required return on investment. Multinationals have an incentive to invest in tax havens as real investment lowers the cost of profit shifting. When a country increases its tax rate, tax havens see additional investment as the higher tax rate increases the returns from profit shifting. In contrast, high-tax countries see a decrease in investment as the returns from investment will now be taxed at a higher rate. The main result of the model formalizes this intuition by characterizing which countries are tax complements and tax substitutes with tax havens.

Proposition 3 (Profit Shifting Generates Tax Complements and Substitutes).

- Investment in high-tax countries $\left(t_{j}>\tilde{t}\right)$ is decreasing in $t_{i}$ for all $j \neq i$;

- Investment in low-tax countries $\left(t_{j}<\tilde{t}\right)$ is increasing in $t_{i}$ for all $j \neq i$; and, formally,

$$
\operatorname{sign}\left(\frac{\partial K_{j}}{\partial t_{i}}\right)=\operatorname{sign}\left(\tilde{t}-t_{j}\right)
$$

To clarify the intuition behind Proposition 3, note that the repeal of $\S 936$ can be viewed as Puerto Rico introducing a corporate tax, $t_{P R}$. Differentiating the expression in Proposition 2, we see that repealing $\S 936$ would increase the effective cost of capital and reduce US investment:

$$
\frac{\partial K_{U S}}{\partial t_{P R}}=\frac{a\left(\tilde{t}-t_{U S}\right)}{\underbrace{-f_{U S}^{\prime \prime}}_{>0}\left(1-t_{U S}\right)} \underbrace{\frac{\partial \tilde{t}}{\partial t_{P R}}}_{>0}=\frac{r_{U S}-\bar{f}_{U S}}{-f_{U S}^{\prime \prime}\left(1-t_{U S}\right)} \frac{\partial \tilde{t}}{\partial t_{P R}}<0 \Leftrightarrow r_{U S}<\bar{f}_{U S} .
$$

In Appendix D, we show that increasing $t_{P R}$ raises the firm's average rate $\tilde{t}$ even after firms reallocate capital across countries. The second equality substitutes the optimal profit-shifting rule from Proposition 1, which shows that repealing $§ 936$ would lower US investment as long as profits are under-reported in the US, $r_{U S}<\bar{f}_{U S}$. We show this graphically in Panel B of Figure 2 , where the dot-dashed line shows that a tax increase in a tax haven raises the cost of investing in a high-tax country, $\tilde{\rho}_{1}$, which lowers domestic investment: $K_{j}^{0}>K_{j}^{1}>K_{j}^{N P S}$.

Proposition 4 (Profit Shifting and Labor Demand). Suppose production depends on capital and labor and that capital complements labor in country $j$. Then:

- Employment in high-tax countries $\left(t_{j}>\tilde{t}\right)$ is decreasing in $t_{i} \forall j \neq i$; 
- Employment in low-tax countries $\left(t_{j}<\tilde{t}\right)$ is increasing in $t_{i} \forall j \neq i$; and, formally,

$$
\operatorname{sign}\left(\frac{\partial L_{j}}{\partial t_{i}}\right)=\operatorname{sign}\left(\left(\tilde{t}-t_{j}\right) \times \frac{\partial^{2} f_{j}\left(K_{j}, L_{j}\right)}{\partial K_{j} \partial L_{j}}\right) .
$$

Proposition 4 shows that when labor and capital are complements, the tax complementarities in Proposition 3 also extend to the labor market. Panel C of Figure 2 shows the effects of profit shifting on the labor market. Since capital and labor are complements, labor demand depends on the cost of capital $\left(L^{D}(w, \rho)\right)$, and it shifts outward when firms can shift profits to tax havens: $L^{D}\left(w, \tilde{\rho}_{1}\right)>L^{D}\left(w, \rho^{N P S}\right)$. Conversely, labor demand shifts inward when there is a tax increase in the low-tax country: $L^{D}\left(w, \tilde{\rho}_{0}\right)<L^{D}\left(w, \tilde{\rho}_{1}\right)$. This figure shows that there is more domestic employment when tax havens reduce the effective cost of capital: $E_{j}^{N P S}<E_{j}^{1}<E_{j}^{0}$.

Overall, the model shows that profit shifting to tax havens complements economic activity in high-tax countries and has the following empirical predictions for the repeal of $\S 936$ :

Empirical Predictions. Assuming the US is a high-tax country, $\tilde{t} \leq t_{U S}$, and that capital complements labor in the US, repealing $§ 936$ would:

- Decrease profit shifting toward Puerto Rico and increase reported profitability in the US;

- Lower global investment and employment for exposed firms; and

- Shift investment and employment from the US toward low-tax countries.

While most of the literature focuses on the first empirical prediction, the contribution of this paper is to provide empirical evidence that profit shifting has real effects on the economy by using variation from $\S 936$ to test the last two predictions of the model. ${ }^{29}$

\section{Measuring Exposure to $§ 936$}

This section summarizes the data we use to test the predictions of the model and to quantify the effects of the repeal of $\S 936$ on local labor markets. Appendix A provides further details.

\subsection{Firm-Level Exposure and Outcomes}

We measure firm-level exposure to $§ 936$ using the National Establishment Time-Series (NETS, Walls \& Associates, 2012), which links the universe of US establishments to firm headquarters. There are 682 US firms that had establishments in Puerto Rico in 1995 and that could have benefited from $\S 936$. These firms had broad networks of establishments and many employees.

\footnotetext{
${ }^{29}$ OECD (2018) confirms the US was a high-tax country in 1996. We do not test the first model prediction as we cannot measure affiliate-level profitability in our data. Appendix D discusses extensions of the model and shows that Propositions 1-4 are robust to allowing for heterogeneous costs of profit shifting across countries.
} 
In Appendix A, we validate this measure of exposure by showing that it is close to estimates of take-up of $\S 936$ based on tax data and that it identifies firms with similar characteristics to $\S 936$ firms. As we discuss below, we conduct a number of tests to ensure that our results are robust to our definition of exposure.

We use data from Compustat (Capital IQ, 1980-2014) on firm-level (global) investment. ${ }^{30}$ In 1995, $\S 936$ firms were responsible for $16.1 \%$ of all capital investment reported by Compustat firms. ${ }^{31}$ We also use the geographic segments variables to analyze whether repealing $\S 936$ led to offshoring of investment as predicted in our model in Section 3. While these data allow us to measure the effects of repealing $§ 936$ on offshoring of investment, one drawback of these data is that the fraction of firms with missing observations is higher than in the overall investment data series. $^{32}$ Compustat data on taxes paid also allow us to study the effects of repealing $\S 936$ on effective tax rates. Following Dyreng et al. (2017), we define effective tax rates (ETRs) as federal taxes paid divided by global pretax income. This definition ensures that changes in ETRs are not driven by where firms report their income. As in Figure 1, $§ 936$ firms had an average ETR of $26 \%$ in Compustat data. ${ }^{33}$

We complement the firm-level analysis by using data from the Annual Survey of Manufacturers (1997, ASM) to measure the effects of repealing $§ 936$ on investment at the state-industry level. These data measure investment in US plants owned by both public and private firms. The relative benefit of using these data over the geographic segments data is that they avoid issues of missing values as well as potential reporting issues related to FASB (1997).

\subsection{Geographic Exposure and Outcomes}

To assess the effects of the repeal of $\S 936$ on local labor markets, we create a geographic measure of exposure. We begin by linking the exposed firms to their network of establishments in the US. Our measure of exposure is the fraction of establishments in each US county that belongs to firms that were exposed to $§ 936$. Figure 3 plots the distribution of this measure across the US. Panel A shows that labor market exposure varies from $0 \%$ to $5 \%$. Panel $\mathrm{B}$ shows that there is

\footnotetext{
${ }^{30}$ We merge the list of exposed firms by name, confirm and extend the merge manually, and further crawl the SEC's EDGAR database to confirm that we include all firms related to Puerto Rico or $\S 936$. There are 219 exposed firms in Compustat, which are responsible for $69.5 \%$ of the total employment of $\S 936$ firms. Grubert and Slemrod (1998) note that in their data, $96 \%$ of the tax credits were claimed by 214 firms.

${ }^{31}$ We restrict our data to firms with at least three observations before and after the repeal of $\S 936$. Our sample starts after 1990 to avoid missing data problems in earlier years. To avoid outliers, we winsorize investment-tocapital ratios at the $5 \%$ level.

${ }^{32}$ Geographic segments data divide global investment into US and foreign segments. It is generally not possible to separate investment by individual countries. To avoid potential issues related to changes in reporting due to FASB (1997), we include non-identified segments in the foreign category and we restrict the sample to firms that report foreign segments three years prior and three years after the repeal.

${ }^{33}$ To avoid negative ETRs, our analyses on ETRs restrict estimation samples to firms with non-negligible pretax income. Appendix A provides additional detail on data sources, and Table A.2 reports summary statistics.
} 
substantial variation across counties within a given state by plotting a standardized measure of exposure that subtracts state averages and divides by the national standard deviation.

Figure 3 shows that the regional exposure to $\S 936$ is not geographically clustered. Nonetheless, one may be concerned that exposure to $\S 936$ is correlated with demographic characteristics, industrial compositions, state policies, or other economic shocks that may confound the effect of $\S 936$. Figure 4 shows that exposure to $\S 936$ is generally not correlated with minimum wages and right-to-work laws (Valletta and Freeman, 1988; Meer and West, 2016); state taxes and tax revenues (Suárez Serrato and Zidar, 2017); R\&D tax credits (Wilson, 2009); exposure to competition through trade with China (Autor et al., 2016) and NAFTA (Hakobyan and McLaren, 2016); the share of routine labor (Autor and Dorn, 2013); demographic and industry employment (US Census); or capital stocks (BEA). The only statistically significant correlation is a positive one with the fraction of workers with a college education (Table A.4 reports these correlations). In Section 6, we confirm that our results are robust to controlling for these potential confounders.

In addition to the baseline measure of exposure in Figure 3, we show our results are robust to using alternative measures of exposure. While our main measure of exposure is based on the fraction of establishments in exposed firms, we show similar results when we use a measure of exposure based on the fraction of workers in exposed firms. ${ }^{34}$ We also find similar results when we study different geographical levels of aggregation including commuting zones and conspumas, when we define the shock two additional years before the repeal of $\S 936$, and when we focus on exposure to public firms and those with very high employment. ${ }^{35}$

Our main dataset on labor market outcomes is the Quarterly Census of Employment and Wages (QCEW, 2017). These data are constructed mostly from administrative sources, with unemployment insurance systems providing highly reliable data on employment and earnings. These data are available at the 3-digit-NAICS industry-by-county level. This is important for our study since it allows us to control for industry-by-year fixed effects, which rule out the concern that $§ 936$ firms faced industry-specific shocks that may confound the effect of repealing $\S 936$.

We use three additional datasets on labor market outcomes at the county level. First, we use BEA data on personal employment and income, which include other forms of employment and income, including proprietor's income (Bureau of Economic Analysis, 2018). Second, we use data from IRS tabulations at the county level on the number of filers and total taxable income

\footnotetext{
${ }^{34}$ Barnatchez et al. (2017) evaluate the properties of the NETS data. They show the NETS measures firm-level employment and establishment location very well, but that establishment-level employment is imputed for some firms. Figure A.2 compares the establishment- and employment-based measures of exposure. These metrics are highly correlated. Table A.3 displays the counties with the largest and smallest exposure for both measures. For this reason-to avoid problems related to imputation of establishment-level employment-our main measure of exposure is the fraction of exposed establishments in industries that were major users of $\S 936$.

${ }^{35}$ Figure A. 3 plots the exposure to $\S 936$ for counties, states, commuting zones, and conspumas. The conspuma level is an aggregation of counties that respects state boundaries and is the smallest consistently identifiable geographic unit that can be traced between the 1980 and 2010 US Censuses.
} 
(IRS, 2017b). Third, we use data from the BEA on public transfers, such as unemployment insurance payments. While the BEA and IRS data have broader definitions of income, they are not available at the industry-county level.

Finally, we use data from the 1980-2000 US Censuses and the 2009 American Community Survey (Ruggles et al., 2010) to construct average wage rates at the conspuma-decade level that control for changes in workers' demographic characteristics. We construct these measures for all workers and for workers with and without a four-year college education. We also use these data to construct indexes of rental costs and home values.

These different datasets allow us to measure the exposure to $\S 936$ for firms and local labor markets, how exposed firms may have responded by adjusting employment and investment, and how these responses affected local labor markets.

\section{$5 \quad$ Firm-Level Effects of Repealing $§ 936$}

This section tests the predictions of the model and shows that exposed firms responded to the repeal of $\S 936$ by adjusting the scale and location of their investment and employment.

\subsection{Effects of Repealing $§ 936$ on Firm Investment}

We begin by showing that the repeal of $\S 936$ led to a decline in the investment of exposed firms. We use data from Compustat to estimate the following regression:

$$
\frac{\mathrm{I}_{c t}}{\mathrm{~K}_{c, 1990-1995}}=\gamma_{t}+\beta^{t} \text { Exposure } \S 936_{c}+X_{i t}^{\prime} \Gamma+\varepsilon_{i c t},
$$

where $\frac{\mathrm{I}_{c t}}{\mathrm{~K}_{c, 1990-1995}}$ is the ratio of capital investment to the pre-reform capital of the firm, and where we allow the firm-level indicator of Exposure $\S 936_{c}$ to have year-specific effects, $\beta^{t}$. We control for firm size in $X_{i t}$ and cluster $\varepsilon_{i c t}$ at the firm level. The identifying assumption of this regression is that firms that took advantage of $\S 936$ were not on a differential trend from other firms and that exposed firms were not subject to other shocks or policy changes that coincided with the repeal $\S 936 .{ }^{36}$ Figure 5 reports the results of this regression with $95 \%$ confidence intervals. Exposed

\footnotetext{
${ }^{36}$ While the assumption that exposed firms were not affected by unobserved, time-varying shocks that coincide with the repeal of $\S 936$ is fundamentally untestable, there are no other tax reforms that could confound the effect of $\S 936$. For instance, the 2003 dividend tax cut studied by Yagan (2015) affects all of the firms in the sample equally since they are all C-corporations. Similarly, periods of bonus depreciation in 2001 and 2008 have differential effects across industries that rely on assets with different tax lives, as studied by Zwick and Mahon (2017). We rule this out by comparing exposed firms to control firms in similar industries and by including sector-by-year fixed effects. Finally, other changes such as the adoption of "check-the-box" regulations by the IRS in 1997 would not confound the effect of $\S 936$. "Check-the-box" allows multinationals to avoid paying foreign taxes by limiting Subpart F regulations on income transferred between related closely held corporations. Since these transactions are between affiliates in third-party countries and tax havens, they would not interact with $\S 936$, and they would not differentially affect $\S 936$ firms.
} 
and non-exposed firms had similar trends in investment before the repeal of $\S 936$. After the reform, exposed firms saw a decline in investment relative to control firms. ${ }^{37}$

Table 2 reports the average effect of exposure after the repeal and shows that the decline in investment is robust across a number of specifications. Columns (2) and (3) show that this result is not affected by including sector-by-year fixed effects or firm fixed effects. Columns (1)-(3) imply that, by 2006, $\S 936$ firms reduced investment by $9.9-11.1 \%$ relative to other firms. Column (4) restricts the sample to firms in sectors that were major users of $\S 936$, and column (5) further restricts the sample to firms in the main industries that used $\S 936 .{ }^{38}$ Finally, the last column of Table 2 follows Yagan (2015) by using the methods of DiNardo et al. (1996, DFL, henceforth) to weight observations so that exposed and unexposed firms have similar observable characteristics. $^{39}$ Columns (4)-(6) show that firms that were heavy users of $\S 936$ experienced larger investment declines of $14-18.7 \%$. These estimates confirm the model prediction that firms respond to limits on profit shifting by lowering their investment. ${ }^{40}$

The results of Table 2 are comparable to previous estimates of the effects of corporate taxes on investment. de Mooij and Ederveen (2008) conduct a meta-analysis of studies that analyze the effects of corporate taxes on investment and find a median semi-elasticity of investment of 2.9 with respect to the tax rate. Given our calculations in Section 2 that $\S 936$ raised ETRs by 4.65-6pp, the median estimate from de Mooij and Ederveen (2008) would predict a decline in investment of $13.5-17.4 \%$, which is consistent with the upper range of our estimates.

To allow further interpretation of our estimates, Table 2 compares the percentage change in investment to the change in ETRs using data from IRS (2017a). For column (3), the estimated increase in ETR of 5.73pp implies a semi-elasticity of investment of 1.77. Columns (5)-(6) imply semi-elasticities of 2.33-3.11 for the firms that were most exposed to $\S 936$. As an alternative approach to quantifying the responsiveness of investment to tax changes, we use Compustat data to measure the effect of the reform on ETRs. Table 3 shows that relative to non-exposed firms, the post-reform ETRs of exposed firms increased by 3.5pp for all firms (column 3) and by 5.4pp for the most affected firms (column 6). ${ }^{41}$ Together with estimates from Table 2, these data imply

\footnotetext{
${ }^{37}$ Figure A.4 plots average investment rates. This graph is consistent with panel $\mathrm{C}$ of Figure 1, since unexposed firms see a decline in ETRs and an increase in investment. In contrast, exposed firms have a flat ETR and a more moderate growth in investment. The relatively slower growth in investment rates for exposed firms results in the negative $\beta^{t}$ coefficients for Equation 2 displayed in Figure 5.

${ }^{38}$ We define major sectors and industries as in Section 2 (footnote 18) to match data from IRS (2017a).

${ }^{39}$ As in Yagan (2015), these weights ensure that exposed and control firms receive equal weight across 3-digit industries and 20 bins of firm size. Appendix A.4 discusses the construction of these weights in detail.

${ }^{40}$ The results in Table 2 are robust to using alternative measures of investment or controls. We obtain similar results when the dependent variable is the percentage change in investment (Table A.5 and Figure A.5) or when the investment-to-capital ratio is winsorized at the $1 \%$ level instead of the $5 \%$ level (Table A.6 and Figure A.6). Table A.7 shows that we obtain similar results when we use different controls for firm size or 3-digit NAICS-by-year fixed effects. Finally, Figure A.7 shows similar investment trends using other specifications in Table 2.

${ }^{41}$ Because the denominator in the ETR is global income, the effects in Table 3 are lower bounds on the ETR on domestic profits. In Table A.8, we approximate the share of income that originates in the US using data on
} 
semi-elasticities of 2.89 (column 3) and 2.59 (column 6). ${ }^{42}$ By both accounts, the changes in ETRs imply elasticities that are comparable to the median value from de Mooij and Ederveen (2008). These semi-elasticities are also in the lower range of estimates from more recent papers. For example, Zwick and Mahon (2017) find a semi-elasticity of 3.7 when studying depreciation deductions, Ohrn (2018) estimates a semi-elasticity of 4.7 in response to tax breaks for domestic manufacturing, Moon (2019) finds a semi-elasticity of 3.7 with respect to the capital gains tax rate in Korea, and Chen et al. (2019) estimate a semi-elasticity of 3.2 for Chinese firms.

We now test the model's prediction that, in addition to lowering investment, exposed firms would decrease domestic investment relative to investment in other low-tax affiliates. We use two complementary strategies to test this prediction. First, we use geographic segments data from Compustat to show that $§ 936$ firms shifted investment to foreign affiliates. We follow Rao (2015) by analyzing the effects of the repeal on the share of foreign investment, ForInvShare ${ }_{c t}=\frac{I_{c t}^{F}}{I_{c t}^{F}+I_{c t}^{U S}}$, and we estimate the following specification:

$$
\frac{\text { ForInvShare }_{c t}-\text { ForInvShare }_{c 1995}}{\text { ForInvShare }_{c 1995}}=\gamma_{t}+\beta^{t} \text { Exposure } \S 936_{c}+X_{i t}^{\prime} \Gamma+\varepsilon_{i c t} \text {. }
$$

Figure 6 reports the results of this specification. This figure shows that exposed and non-exposed firms were on a similar trend before the repeal of $\S 936$ and that, consistent with the model, exposed firms increased the share of investment conducted abroad after the reform.

Table 4 quantifies the size of this effect using similar specifications as in Table $2 .{ }^{43}$ Column (3) shows that the foreign investment share increased by $12.3 \%$, and column (6) shows an increase of $15.1 \%$ for the most affected firms. Since the average of ForInvShare ${ }_{c 1995}$ was about 43 pp, columns (3) and (6) imply an increase of 5.3-6.5pp to about 48.3-49.5pp. Using the evidence in Figures 5-6, we can estimate the decrease in US investment. The combined effect of the decrease in global investment and the shift to foreign investment implies a decrease in domestic investment by exposed firms of $19.3-25.7 \% .^{44}$

the (fixed) share of US revenue multiplied by global income as the denominator. This approximates the ETR on domestic profits and - as in Table 3 - is not sensitive to where firms report profits. This table shows that $\S 936$ increased ETRs on US income by 4.6pp for all firms (column 3) and by 7.2pp for the most affected firms (column 6). Table A.9 shows that the point estimates of Table 3 are robust to including foreign taxes in the ETR.

${ }^{42}$ While we obtain quantitatively similar semi-elasticities using aggregate and firm-level data, there are several benefits to relying on aggregate data for our baseline. First, as noted by Gruber and Rauh (2007), financial statement data and tax data can differ substantially. Dyreng et al. (2017) discuss other limitations of using financial statement data to measure ETRs. Second, Compustat data show patterns of sticky reporting of taxes over time. Third, to obtain well-behaved ETRs, we need to restrict the analysis to firms with non-negligible profits. Finally, because multinational corporations can inter-temporally optimize their tax liabilities by not repatriating income or by deferring certain credits, changes to tax payments in financial statement data may not line up with when companies respond to tax incentives. Thus, while Figure A.8 presents an event study on ETRs from Compustat, we rely on Figure 1 as the baseline picture describing the impact on the ETRs of exposed firms.

${ }^{43}$ Since the percentage change specification absorbs the firm fixed effect, column (2) controls for industry fixed effects. Table A.5 shows that we obtain similar effects on investment when we use this specification.

${ }^{44}$ The percentage change in domestic investment is $\beta^{\text {Inv }}-\beta^{\text {ForInvShare }} \times \frac{\text { ForInvShare }}{1-\text { ForInvShare }}$, where $\beta^{\text {Inv }}$ and $\beta^{\text {ForInvShare }}$ come from Tables 2 and 4, respectively. 
As a complementary strategy to measure the effects on domestic investment, we use data from the Annual Survey of Manufactures. Because these data are available at the industry-year level, we generate a measure of exposure to $\S 936$ by collapsing the data in Figure 3 to estimate the following specification:

$$
\frac{\mathrm{CAPX}_{i s t}-\mathrm{CAPX}_{i s 1995}}{\mathrm{CAPX}_{i s 1995}}=\alpha_{i}+\gamma_{t}+\beta^{t} \text { Exposure } \S 936_{i s}+\varepsilon_{i s t} .
$$

We include industry and year fixed effects and allow for arbitrary correlation of standard errors at the state level. The continuous exposure measure is fixed in 1995, but we allow the effects of exposure to $\S 936$ to vary over time by estimating the year-specific coefficients $\beta^{t}$. We normalize the exposure measure by its inter-quartile range (IQR), so the interpretation of $\beta^{t}$ is the effect of increasing exposure to $\$ 936$ from the 25 th percentile to the 75 th percentile of the distribution. The identifying assumption of Equation 4 is that exposure to $§ 936$ is not correlated with other trends or omitted variables that may also affect capital investment. Figure 7 plots the results of this estimation and shows that Exposure $\S 936_{i s}$ is not correlated with investment growth prior to the reform. Following the reform, however, we see a persistent decline in the flow of investment.

Table 5 reports the average effect of Exposure $\S 936_{i s}$ by pooling the years after the repeal. This table shows that the decline in investment is robust to including state fixed effects, stateby-industry fixed effects, year-by-industry fixed effects, and year-by-state trends. These specifications show that the effects of Exposure $\S 936_{i s}$ are not driven by trends at the industry or state level that are somehow correlated with investment patterns. The last column in Table 5 suggests that going from the 25 th to the 75 th percentile of the distribution results in a decline in investment of $66 \%$ of the capital expenditures in $1995 .{ }^{45}$

The results of Figures 5-7 provide compelling evidence that investment responded to the repeal of $\S 936$. One notable feature of these graphs is that investment responds very quickly. This dynamic is consistent with the forward-looking nature of investment decisions (e.g., Auerbach and Hines, 1987). Thus, even though the tax credits were phased out over time, firms adjust investment immediately if they expect that they will not be able to shift their profits in the future. ${ }^{46}$ Additionally, even though Figures 5-7 show a sharp decrease in the flow of investment, the stock of capital decreases gradually and more smoothly. Relative to a steady state where investment replaces depreciating capital, a decrease in investment allows the stock of capital to adjust over time to its new long-run level. ${ }^{47}$

These results show that efforts to limits profit shifting - such as the repeal of $\S 936$ - can

\footnotetext{
${ }^{45}$ Since the mean $\mathrm{CAPX}_{i s 1995}$ was about $\$ 349,000$, this effect represents a decline of about $\$ 230,000$.

${ }^{46}$ Consistent with this view, we show in Garrett and Suárez Serrato (2019) and Appendix C that exposed firms experienced a decrease in value following the repeal of $\S 936$.

${ }^{47}$ We discuss numerical examples in Figure A.9 and Appendix E. For example, for capital assets with an economic depreciation rate of 0.069 - as in the case of industrial machinery - a $25.7 \%$ reduction in investment would result in a $13.2 \%$ reduction in the capital stock over 10 years.
} 
increase the cost of domestic investment and cause multinational firms to reduce their domestic investment or to shift investment abroad.

\subsection{Effects of Repealing $§ 936$ on Firm Employment}

This section tests the model prediction that exposed firms would reduce their employment in the US in response to an increase in the income-shifted adjusted cost of capital. We test this hypothesis using data from NETS on the domestic employment of firms exposed to $\S 936$. As discussed in Section 4, we have data on 682 firms that had an establishment in Puerto Rico before the repeal of $\S 936$. We match these firms to firms that were not exposed to $\S 936$ but that operated in the same industry, were headquartered in the same Census region, and had a similar number of employees and establishments in $1995 .^{48}$

We measure the effect of the repeal of $\S 936$ on the US employment of exposed firms by estimating the following regression:

$$
\frac{\operatorname{Emp}_{c t}-\operatorname{Emp}_{c 1995}}{\operatorname{Emp}_{c 1995}}=\gamma_{t}+\beta^{t} \text { Exposure } \S 936_{c}+\varepsilon_{c t},
$$

where the exposure measure is a firm-level indicator, we control for year fixed effects, and the standard errors are clustered at the firm level. ${ }^{49}$ The identifying assumption is that firms with exposure to $\S 936$ had similar trends to the matched control firms. Figure 8 presents estimates of this regression and shows a lack of differential pre-trends between exposed and control firms. The figure also shows that exposed firms gradually reduced employment during the phase-out of §936. As discussed in the previous section, while investment responded shortly after the repeal, capital stocks likely declined over time. The dynamics in Figure 8 are consistent with a decline in employment that matches the gradual decline in capital stocks. ${ }^{50}$

Figure 8 shows that exposed firms saw a relative decrease in employment of $6.7 \%$ by $2006 .{ }^{51}$ One way to grasp the magnitude of this effect is to compare the change in employment to the change in investment using our merged Compustat-NETS data. The data show that a $1 \%$ increase in capital expenditures is associated with a $0.39 \%$ increase in US employment (Figure A.12). The 10-18.7\% reduction in capital expenditures from Table 2 would then be consistent with a 3.9$7.3 \%$ decrease in employment, which brackets the estimate from Figure 8. In contrast to the effect of corporate taxes on investment, there is scant evidence on how corporate taxes affect

\footnotetext{
${ }^{48}$ See Appendix A.3 for details of the matching procedure used to identify the control firms.

${ }^{49}$ Because the dependent variable is the firm-level change in employment, this regression absorbs firm fixed effects. Figure A.10 and Table A.10 report similar effects across the specifications used in other tables.

${ }^{50}$ In Figure A.11, we plot a figure similar to Figure 8 except that the dependent variable is the change in the number of US establishments. This figure shows that the change in US establishments lagged that of US employment. This is consistent with a dynamic where downsizing firms first lay off workers across locations and then incur the fixed costs of consolidating establishments.

${ }^{51}$ Table A.11 shows the employment decline was concentrated in industries that were heavy users of $\S 936$ (e.g., chemicals and electronic device manufacturing).
} 
labor demand. ${ }^{52}$ The repeal of $\S 936$ provides a valuable opportunity to estimate this important parameter. Compared to the tax increase of $4.65-6 \mathrm{pp}$, the $6.7 \%$ reduction in employment implies a labor semi-elasticity between 1.2 and 1.44 over a 10-year period.

These results confirm the model prediction that limiting profit shifting can incentivize US multinationals to reduce domestic employment.

\section{Effects of Repealing $§ 936$ on Local Labor Markets}

We now study whether the firm-level responses to $§ 936$ documented in the previous section also affected the communities exposed to $\S 936$ firms. This approach has three main benefits. First, spatial variation in exposure to $\S 936$ provides an alternative identification strategy to measure the effects of repealing $§ 936$. By comparing outcomes across local labor markets that differed in their exposure to the network of establishments of $\S 936$ firms, we can measure the effects of repealing $\S 936$ without relying on firm-level comparisons. A second benefit of this approach is that it allows us to measure whether firm-level responses are absorbed or amplified within local labor markets. Finally, this approach also allows us to characterize the broader impacts of tax policy, including effects on housing markets and transfers from the government.

\subsection{Effects of Repealing $§ 936$ on Employment Growth}

We now use the geographic measure of exposure to $\S 936$ in Figure 3 , Exposure $\S 936_{c}$, to estimate the relative effect of the repeal of $\$ 936$ on employment growth at the industry-county level..$^{53}$ Our main outcome of interest is the employment growth between 1995 and a given year $t$ :

$$
\frac{\mathrm{Emp}_{i c t}-\mathrm{Emp}_{i c 1995}}{\mathrm{Emp}_{i c 1995}}
$$

where the unit of observation is employment at the industry $(i)$, county $(c)$, year $(t)$ level. Figure 9 provides a non-parametric comparison of places with different degrees of exposure by plotting the average employment growth for counties in the top and bottom terciles of Exposure $\$ 936_{c}$. This figure shows that while county-industries in the top and bottom terciles of Exposure $\$ 936_{c}$ had similar trends before 1995, more exposed counties (top tercile) grew relatively more slowly after the repeal of $\S 936$. By the end of the phase-out in 2006, places in the bottom tercile (low exposure) experienced employment growth above $20 \%$ relative to 1995, while places in the top tercile (high exposure) had an average growth rate below $10 \%$.

We build on Figure 9 by estimating a regression model that separates the effects of $\S 936$ from

\footnotetext{
${ }^{52}$ One exception is Bilicka et al. (2019), who estimate a labor semi-elasticity of 2.5.

${ }^{53}$ As discussed in Section 4, Exposure $\S 936_{c}$ is the fraction of the county's establishments that could have taken advantage of $\S 936$ in 1995.
} 
time trends. Consider the following regression:

$$
\frac{\operatorname{Emp}_{i c t}-\operatorname{Emp}_{i c 1995}}{\operatorname{Emp}_{i c 1995}}=\alpha_{i c}+\gamma_{i t}+\beta^{t} \text { Exposure } \S 936_{c}+\varepsilon_{i c t} .
$$

This regression includes industry-year fixed effects, $\gamma_{i t}$, and industry-county fixed effects, $\alpha_{i c}$. Since industry-county pairs vary in the number of jobs they represent, we weight these regressions by the share of national employment in each industry-county in 1995 . The variable Exposure $\S 936_{c}$ is normalized to allow interpretation of $\beta^{t}$ as the effect of increasing the Exposure $\S 936_{c}$ from the 25 th to the 75 th percentile of the distribution. Finally, the standard errors are clustered to allow for two-way arbitrary correlations at both the state and industry levels.

Panel A of Figure 10 shows estimates of $\beta^{t}$ for $t=1990, \cdots, 2012$. The main result is that more exposed counties saw slower employment growth starting with the repeal of $\S 936$. This decline in employment growth persisted even after the end of the phase-out. For 2006, the graph shows that increasing the exposure to $\S 936$ from the 25 th to the 75 th percentile would decrease employment growth by 7.8pp. The decline in employment growth stabilizes after the full phaseout of $\S 936$ in $2006 .{ }^{54}$ Panel B of Figure 10 plots the fitted values of this regression for different levels of exposure. This figure shows that going from almost zero exposure (5th percentile) to the mean level of exposure would decrease employment growth by $7 \mathrm{pp}$ from about $23 \%$ to $16 \%$ in 2006, which is a change in employment growth of about $30 \%\left(\approx \frac{7}{23}\right)$. This graph provides compelling evidence that networks of establishments can propagate the effects of fiscal policy and have persistent effects on regional employment.

\subsection{Robustness Checks and Placebo Tests}

The identifying assumption of Equation 6 is that Exposure $\S 936_{c}$ is independent of time-varying shocks that could explain the pattern in Figure 10. This section presents evidence that severely limits the likelihood that this assumption is violated in the data.

A useful check of the validity of this research design is to test for trends in employment growth prior to the repeal of $\S 936$. Panel A of Figure 10 shows that prior to the repeal of $\S 936$, exposure to $§ 936$ is not predictive of employment growth, which is consistent with the differencein-differences assumption. Table 6 presents alternative specifications of this regression. The first column includes industry-by-year fixed effects, which ensures that the results are not driven by differential exposure to industries that are growing or declining during this time period. The second column adds county fixed effects. Column (3) includes county-by-industry fixed

\footnotetext{
${ }^{54}$ Notably, the graph is relatively stable during Puerto Rico's debt crisis, which started in 2006 . The fact that the effects stabilize after 2006 also rules out other policy changes that could be potential confounders. Specifically, the hypothesis that "check-the-box" regulations that were adopted in 1997 are responsible for these effects is inconsistent with this dynamic pattern since profit shifting under check-the-box continued to grow between 2006 and 2012 (e.g., Wright and Zucman, 2018).
} 
effects, which ensure that the estimated $\beta^{t}$ s are not confounded by differential growth rates in employment at the industry-county level. Columns (4)-(5) explore the robustness of the results to using alternative weights. In Column (4), we winsorize the weights to limit the influence of large counties on the results. In Column (5), we drop county-industries with less than 1000 employees in 1995. The pattern of results is consistent across these specifications.

These results are robust to using alternative geographic definitions of local labor markets and data sources. Panel A of Figure 11 plots the last two columns of Table 6, which show that we obtain similar results when we study employment at the conspuma or commuting zone level. These results rule out the concern that our main results are driven by very local geographic spillovers. Table 8 summarizes these results by estimating the effect for the years 1990-1995 and 2004-2008. The first row of results shows that we obtain similar estimates at the conspuma or commuting zone level and when we use data on employment from the IRS or the BEA. ${ }^{55}$ The last columns of Table 8 report effects on income growth. Consistent with the effects on employment, we also find that more exposed areas have slower income growth and that this result is robust across different data sources and different definitions of local labor markets. ${ }^{56}$

As we discuss in Section 4, our main measure of exposure to $§ 936$ is based on the fraction of establishments in a county that could have taken advantage of $\S 936$. Panel B of Figure 11 shows the results of an estimation where we measure Exposure $\S 936_{c}$ as the fraction of the county's employment that could have benefited from $\S 936$ in 1995. To avoid bias from measurement error, we instrument exposure to $\S 936$ with our establishment-based measure of exposure. This figure and column (1) of Table 7 show that we obtain similar results when we use the employment-based measure of exposure. ${ }^{57}$

The results in Figure 10 are also robust to using alternative measures of exposure to $\S 936$. The first alternative measure excludes large retailers that are likely located in most counties in the US and Puerto Rico. A second alternative measure excludes firms with uncertain headquarters locations. Panel B of Figure 11 and columns (2)-(4) of Table 7 show that we obtain similar results when we use these measures of exposure. These results rule out the concern that our main results are driven by secular trends in the retail industry or by errors in the coding of the headquarters location. Because $\S 936$ credits were concentrated on a small number of large firms (Joint Committee on Taxation, 2006), we now explore whether the results are robust to focusing on exposure to large firms. In panel B of Figure 11, we obtain similar results when exposure is defined to include only firms in Compustat. Panel $\mathrm{C}$ of Figure 11 shows similar results when we restrict exposure to firms with more than 50,000 employees. Finally, panel $\mathrm{C}$ also shows that

\footnotetext{
${ }^{55}$ Since IRS and BEA data are not available at the country-industry level, we only control for year fixed effects.

${ }^{56}$ Note that the definitions of income vary across data sources. While QCEW data report wage earnings, BEA data include proprietor's income, and IRS data correspond to total adjusted gross income in a county. These differences may explain the larger effects on income growth in IRS and BEA data.

${ }^{57}$ Table A.12 provides additional estimates using the employment measure of exposure.
} 
our results are robust to defining exposure at two years prior to the repeal of $\S 936$. We do this in two ways. We first use firms that had an establishment in Puerto Rico in 1993 to construct a measure of exposure. We then construct an additional measure that only uses firms that had employment in Puerto Rico in both 1993 and 1995. These results show that our results are not sensitive to how we construct the measure of exposure. ${ }^{58}$

We also explore the robustness of these results to using alternative measures of employment growth. If workers left counties that saw declines in employment after the repeal of $\S 936$, we might see no effects on the employment to population ratio. Panel A of Figure 11 (column (5) of Table 7) shows results when the dependent variable is the percentage change in the employment to working age population ratio, which shows similar if slightly smaller effects. This suggests that, while some workers do relocate in response to the shock, local workers are affected by the repeal of $\S 936$, since the effect on per-capita employment sees a significant decline (e.g., Yagan, 2017). Column (6) focuses on the ratio of manufacturing employment to the working age population, as in Autor et al. (2013), and finds slightly larger effects. Finally, panel C of Figure 11 shows that our results are robust to also including state-specific trends. ${ }^{59}$

We now rule out the concern that our results are driven by exposure to firms with certain characteristics by conducting placebo tests that isolate potential confounding channels. One concern is that our results are driven by exposure to large firms that may have already been in decline. In Panel A of Figure 12, we use the set of control firms in Section 6.1 to generate a "fake shock." Since these firms have a similar size, are headquartered in a similar location, and have similar industrial characteristics, this test rules out that our exposure measure is picking up employment trends in large firms that had similar characteristics as exposed firms. Since a large fraction of $\S 936$ tax credits were claimed by the pharmaceutical industry, a second concern is that the exposure measure is picking up industry-specific trends that are not related to $\S 936$. Panel B of Figure 12 defines exposure as the fraction of employment in the pharmaceutical industry and shows that this is not the case. Both of these "placebo tests" show that these alternative mechanisms are not driving our main result. ${ }^{60}$

In our final robustness check, we explore the possibility that the exposure to $§ 936$ is correlated

\footnotetext{
${ }^{58}$ The estimates used to plot these graphs are presented in the Appendix. Table A.13 provides estimates for the measure that drops retailers, Table A.14 provides estimates for the measure that drops firms with an uncertain headquarters location, and Table A.15 provides estimates for the measure that relies solely on Compustat firms. Figure A.15 and Table A.16 show that results using the exposure of large firms are robust to using different cutoffs to define large firms. Table A.17 reports results using the 1993 networks of firms to define exposure. Table A.18 defines exposure using firms with operations in Puerto Rico in both 1993 and 1995.

${ }^{59}$ We obtain similar results when we use specifications close to those of Autor et al. (2013). Panel A of Figure A.13 (Table A.19) plots the event study on manufacturing jobs per capita and panel B of Figure A.13 (Table A.20) presents results on the level change in the ratio of manufacturing jobs to the working age population. Figure A.14 and Table A.21 provide additional results controlling for state-specific trends.

${ }^{60}$ Table A.22 provides estimates for the placebo test using the fraction of employment in the control firms. Table A.23 provides estimates for the placebo test using the fraction of employment in the pharmaceutical industry.
} 
with a shock that could confound the effects of the policy. Our base specification in column (3) of Table 8 shows an effect in years 2004-2008 of -7.2\%. Figure 13 plots this baseline result as well as robustness checks that control for local incentives for job creation and worker training (Bartik, 2017); right-to-work laws and minimum wage rates (Valletta and Freeman, 1988; Meer and West, 2016); state R\&D and investment tax credits (Wilson, 2009); state tax revenue and state taxes for personal income, corporate income, sales and property (Suárez Serrato and Zidar, 2017); measures of exposure to trade from NAFTA and China (Autor et al., 2016; Hakobyan and McLaren, 2016); and the share of routine workers (Autor and Dorn, 2013). The last specification includes all controls and further controls for changes in the local firm size distribution. ${ }^{61}$

The litany of robustness checks and placebo tests in this section show that the effects of $\S 936$ on local labor markets are not confounded by other shocks, are not sensitive to how we measure exposure to $\S 936$, and do not depend on the data we use to measure labor market outcomes. These facts strongly support the conclusion that the local labor market results are caused by the firm-level responses we document in Section 5.

\subsection{Spillovers and Heterogeneous Effects of Repealing $§ 936$}

The results from the previous section provide strong evidence that more exposed local labor markets experienced a diminished rate of growth that persisted years after the repeal of $\S 936$. In this section, we consider the role of local spillovers as a mechanism that can amplify firm-level changes in employment. We might expect to find spillover effects if the reduction in economic activity in $\S 936$ corporations reduced the demand for locally sourced material inputs, if it affected the supply of inputs to competitors, or if the reduction in employment in $\S 936$ firms affected local non-tradable sectors.

To compute an estimate of job spillovers, we first calculate the expected number of layoffs in $§ 936$ firms in the county with the average level of exposure. Using the firm-level estimates from Figure 8, we calculate that the average county experienced a loss of 283 jobs in $\S 936$ firms. We now compare this number to the total number of jobs lost in the county with the average level of exposure. Using the average estimate between 2004 and 2008 from Table 8, going from no exposure to the average level of exposure results in a loss of 1,293 jobs for the average county. This implies that, for every layoff in $\S 936$ firms, the county also lost an additional $3.57\left(\approx \frac{1,293-283}{283}\right)$ jobs. Moretti $(2010)$ studies local employment multipliers and finds similar estimates. ${ }^{62}$ This suggests that the firm-level changes in employment and investment in $\S 936$ firms

\footnotetext{
${ }^{61}$ We control for the percentage growth in establishments of different sizes in each location using data from County Business Patterns (Census Bureau, 2018). Tables A.24-A.25 report the full results of these 18 regressions.

${ }^{62}$ Moretti (2010) finds that when a local labor market loses a skilled job in the tradable sector, this results in a loss of about 2.5 jobs in the non-tradable sector, in addition to about 0.26 jobs in the tradable sector. Moretti (2010) reports considerable heterogeneity across industries, including a loss of 4.9 jobs in the non-tradable sector for every layoff in the electronic manufacturing industry (which was represented among $\S 936$ firms).
} 
were not absorbed by other firms in the same county and that these job losses had multiplier effects for other workers in the local labor market.

An additional implication of the spillover hypothesis is that jobs in the tradable sector should be the first to be affected by the repeal of $\$ 936$. Moreover, as argued by Moretti (2010), we would expect workers in tradable industries to be more mobile, so that the long-term effect on tradable jobs should be smaller than that on service jobs. We test these hypotheses by estimating heterogeneous effects of the repeal of $\$ 936$ across sectors, as in Mian and Sufi (2014). ${ }^{63}$ Figure 14 tests these hypotheses and shows that tradable jobs were the first to decline and were followed by a decline in non-tradable jobs and construction. In addition, the decline in tradable jobs is the first to stabilize, while other sectors decline for a longer period of time. ${ }^{64}$ These results suggests that local employment multipliers amplified the firm-level effects of the repeal of $\S 936$.

\subsection{Effects of Repealing $§ 936$ on Wage Rates, Costs of Living, and Government Transfers}

We now study whether the repeal of $\S 936$ impacted local wage rates and costs of living. We use data on wage rates and rental cost data from the Census. While these data are only available every 10 years, they allow us to examine effects on skilled (college-educated) and non-skilled workers and to adjust for changes in observable characteristics. We estimate regressions of the form:

$$
\Delta y_{c, t}=\alpha_{s}+\gamma_{t}+\beta \text { Exposure } \oint 936_{c}+\varepsilon_{c t},
$$

where $\Delta y_{c, t}$ is the 10-year percentage change in wage rates, rental costs, or home values in a given conspuma. These regressions include state and year fixed effects, and the standard errors are clustered at the conspuma level.

Table 9 reports the results of estimating the parameter $\beta$ as a stacked difference for the years 1990-2000 and 2000-2010. We find that more exposed conspumas saw a decline in wage growth after the repeal of $\S 936$. Going from the 25 th to the 75 th percentile of exposure reduced wages by $1.0 \%$. Figure 15 plots these results and shows that exposure to $\S 936$ was not correlated with wage growth before the repeal of $\S 936$.

The results of the previous section show that non-tradable employment faced a larger reduction in labor demand. If low-skilled workers are concentrated in non-tradable sectors, we would expect to see a larger decrease in their wages. Column (3) of Table 9 shows that the wages of

\footnotetext{
${ }^{63}$ Mian and Sufi (2014) show local shocks to demand were an important driver of the employment drop in the great recession. We use their sectoral definitions and find evidence of a supply-side response to the repeal of $\S 936$.

${ }^{64}$ Figure A.16 shows these estimates with confidence intervals, and Table A.26 provides more details. Note that while the biggest decline is in construction, this sector usually experiences higher volatility. Moreover, while the tradable sector declined by $10 \%$ nationally from 1995 to 2006, the construction industry grew overall by $49 \%$.
} 
low-skilled workers fall by $1.4 \%{ }^{65}$ Consistent with the broad decline in employment, income, and wages, we also find reductions of $1.8 \%$ and $2.5 \%$ in rental costs and home values, respectively.

Finally, we consider the possibility that decreases in employment and income increased workers' reliance on government transfers. Table 10 estimates a similar specification on government transfers per capita at the county level using data from the Bureau of Economic Analysis (2018). Panel A shows the effects of an IQR increase in Exposure $\S 936_{c}$ on the percentage change in transfers per capita relative to the 1995 level. We find that, in 2004-2008, compensation from unemployment insurance increased by $25.7 \%$ for every IQR increase in exposure. We also find an effect of $10.2 \%$ on transfers from income replacement programs. ${ }^{66}$ However, we do not find significant changes for other forms of transfers, including retirement, disability, Medicare, and public medical benefits. Panel B shows the effect of Exposure $\$ 936_{c}$ on the dollar change in transfers per capita relative to 1995. Since income replacement programs are larger than unemployment insurance programs, we see that an IQR increase in Exposure $\S 936_{c}$ would raise income maintenance transfers by $\$ 30$ per person and unemployment insurance transfers by $\$ 16$ per person. Panel $\mathrm{B}$ also shows a positive effect of $\$ 6$ per person in education benefits. This effect is not statistically significant in Panel A. These results show that, while repealing $\S 936$ increased corporate tax revenue, the repeal also increased government expenditures in the form of transfers to affected workers.

This section shows that regions that were exposed to $\S 936$ through the establishment networks of multinational firms experienced slower growth after the repeal of $\S 936$. The regional effects on employment suggest that firm-level shocks were not dissipated within local labor markets and were instead amplified. The persistent effects of employment growth as well as the broader impacts on wages, costs of living, and government transfers show that changes to the tax code can have more geographically concentrated effects than previously thought.

\section{Conclusion}

This paper studies the repeal of $\S 936$ as a natural experiment that limited the ability of firms to shift profits to affiliates in Puerto Rico. We use two complementary research strategies to test theoretical predictions that limits to profit shifting raise the effective cost of capital and reduce the domestic activities of exposed firms. Exploiting firm-level exposure to $\S 936$, we show that exposed firms lowered their investment and employment in the US. The establishment networks

\footnotetext{
${ }^{65}$ The larger decline in the wages of low-skilled workers is also consistent with relatively higher mobility costs. Table A.27 provides estimates on wages and costs of living that do not adjust for observable characteristics.

${ }^{66}$ According to the Bureau of Economic Analysis (2018), income replacement programs include Supplemental Security Income (SSI) benefits, the Earned Income Tax Credit (EITC), Supplemental Nutrition Assistance Program (SNAP), welfare payments (Aid to Families with Dependent Children (AFDC), previously Temporary Assistance for Needy Families (TANF)), and nutrition programs for Women, Infants, and Children (WIC). Table A.28 shows that Exposure $\$ 936_{c}$ is uncorrelated with growth in government transfers prior to the repeal.
} 
of these firms give rise to spatial variation in exposure to $§ 936$. This variation reveals that firmlevel effects were amplified into persistent declines in employment growth for more exposed local labor markets. Overall, we find that reducing the attractiveness of Puerto Rico as a tax haven also reduced employment and investment in firms and regions exposed to $\S 936$.

The effects of the repeal on the domestic economy were unintended consequences for policymakers who did not consider these potential repercussions when repealing $§ 936$. Our analysis shows that cost-benefit analyses of policies that aim to limit profit shifting should account for these unintended consequences in addition to the intended consequences of raising tax revenue. The persistent effects on local labor markets also suggest that policymakers should be particularly mindful of the regional consequences of changes in tax policy.

When considering the lessons of this natural experiment, it is worth bearing in mind that Puerto Rico was an especially desirable tax haven for US multinationals. This was primarily because $\S 936$ allowed for the immediate repatriation of profits at an effective zero tax rate. Tight cultural and institutional connections between the US and Puerto Rico also lowered the cost of setting up and operating affiliates on the island, and these operations were essentially condoned by the US Treasury. In a companion paper (Garrett and Suárez Serrato, 2019), we study whether $\S 936$ corporations increased their exposure to other tax havens after the repeal. Consistent with the view that firms did not have access to a tax haven with the same tax benefits as those bestowed by $\S 936$, we do not find that firms expand to other tax havens. The decrease in stock prices of $\S 936$ firms following the repeal also shows that investors viewed the repeal as the loss of a unique tax haven (see Appendix C). While the lessons of any natural experiment depend on the specific context, the repeal of $\$ 936$ informs the international tax literature by providing a valuable case study where limits to profit shifting significantly affect the operations of multinational corporations.

Understanding the repeal of $\S 936$ as a case study that significantly limited profit shifting informs the effects of potential reforms to the international tax system (e.g., Zucman, 2015; Devereux et al., 2019). If firms are able to escape enforcement by substituting across methods of profit shifting (e.g., Saunders-Scott, 2015; Bustos et al., 2019), we may not expect to see real effects on economic activity. Following the hierarchy of behavioral responses to taxation of Slemrod $(1992,2001)$, limits to profit shifting that cannot be averted through accounting or financial responses may trigger real changes in investment and employment. While it is hard to know which efforts will succeed in policing profit shifting, our results show that efforts that do succeed at limiting profit shifting can also affect domestic employment and investment. We view these results as motivation for researchers and practitioners to design policies that best balance tax revenue gains with such unintended consequences on economic activity. 


\section{References}

26 U.S.C. §936, "Tax Reform Act of 1976," 1976. Tax Reform Act of 1976, Pub. L. 94-455, 90 stat. 1643 , codified as amended at title 26 U.S.C. $§ 936$.

_ , "Small Business Job Protection Act of 1996," 1996. Pub. L. 104-188, 110 stat. 1832, codified as amended at title 26 U.S.C. $§ 936$.

Acemoglu, Daron and Pascual Restrepo, "Robots and Jobs: Evidence from US Labor Markets," Working Paper 23285, National Bureau of Economic Research March 2017.

Albertus, James F., "The Real Effects of U.S. Tax Arbitrage by Foreign Multinational Firms," SSRN (February 1, 2017). 2017.

Altshuler, Rosanne and Harry Grubert, "Repatriation taxes, repatriation strategies and multinational financial policy," Journal of Public Economics, 2003, 87 (1), 73 - 107. Proceedings of the Trans Atlantic Public Economics Seminar on "Taxation of Financial Incomet" 22-24 May, 2000.

Annual Survey of Manufacturers, "Report Series (Volume 1)," November 1997.

Auerbach, Alan J., "Tax Reform and Adjustment Costs: The Impact on Investment and Market Value," International Economic Review, 1989, 30 (4), 939-962.

- and James Hines, "Anticipated Tax Changes and the Timing of Investment," in "Taxes and Capital Formation," National Bureau of Economic Research, Inc, 1987, pp. 85-88.

- and Michael P. Devereux, "Cash-Flow Taxes in an International Setting," American Economic Journal: Economic Policy, August 2018, 10 (3), 69-94.

Autor, David H. and David Dorn, "The Growth of Low-Skill Service Jobs and the Polarization of the US Labor Market," American Economic Review, August 2013, 103 (5), 1553-97.

_, _, and Gordon H. Hanson, "The China Syndrome: Local Labor Market Effects of Import Competition in the United States," American Economic Review, October 2013, 103 (6), 2121-68.

_ , _ , and _, "The China Shock: Learning from Labor Market Adjustment to Large Changes in Trade," WP 21906, NBER 2016.

Barnatchez, Keith, Leland Crane, and Ryan Decker, "An Assessment of the National Establishment Time Series (NETS) Database," Finance and Economics Discussion Series 2017110, Board of Governors of the Federal Reserve System (U.S.) November 2017.

Bartik, Timothy J., "A New Panel Database on Business Incentives for Economic Development Offered by State and Local Governments in the United States," Technical Report, W.E. Upjohn Institute 2017.

BEA, "BEA Depreciation Estimates," Technical Report https://bea.gov/national/pdf/ BEA_depreciation_rates .pdf (Accessed: June 28, 2018), Bureau of Economic Analysis 2018.

Becker, Johannes and Nadine Riedel, "Cross-border tax effects on affiliate investmentEvidence from European multinationals," European Economic Review, 2012, 56 (3), 436 450 .

Bilicka, Katarzyna Anna, "Comparing UK Tax Returns of Foreign Multinationals to Matched Domestic Firms," American Economic Review, August 2019, 109 (8), 2921-53.

_ , Yaxuan Qi, and Jing Xing, "Real responses to anti-tax avoidance policies: Evidence from UK's worldwide debt cap," Working Paper, 2019. 
Blouin, Jennifer and Leslie Robinson, "Double Counting Accounting: How Much Profit of Multinational Enterprises Is Really in Tax Havens?," Working Paper SSRN, 2019.

_ and Linda K. Krull, "Bringing It Home: A Study of the Incentives Surrounding the Repatriation of Foreign Earnings under the American Jobs Creation Act of 2004," Journal of Accounting Research, 2009, 47 (4).

Bond, Eric, "Tax Holidays and Industry Behavior," The Review of Economics and Statistics, 1981, 63 (1), 88-95.

Buettner, Thiess, Michael Overesch, Ulrich Schreiber, and Georg Wamser, "The impact of thin-capitalization rules on the capital structure of multinational firms," Journal of Public Economics, 2012, 96 (11), 930-938. Fiscal Federalism.

Bureau of Economic Analysis, "State Personal Income and Employment: Methodology," Technical Report, Washington, D.C. 2010.

_ , "National Data: Private Fixed Assets by Industry," Web Site, Washington, D.C. 2017.

_, "Local Area Personal Income Accounts, CA35," Web Site, Washington, D.C. 2018.

Business Week, "A Hurricane Heads for Puerto Rico," in "Eden (1994)," Vol. 54 1993, p. 52.

Bustos, Sebastián, Dina Pomeranz, Juan Carlos Suárez Serrato, José Vila-Belda, and Gabriel Zucman, "Monitoring Tax Compliance by Multinational Firms: Evidence from a Natural Experiment in Chile," December 2019. Working Paper.

Capital IQ, "Compustat Segments (Annual Data)," Available: Standard \& Poor's/Compustat 1980-2014. Retrieved from Wharton Research Data Services http://wrds-web.wharton. upenn.edu/wrds/connect/ (Accessed: March 14, 2016).

Census Bureau, "County Business Patterns," Web Site (Accessed: July 11, 2018), https: //www. census.gov/programs-surveys/cbp.html 2018.

Chari, Anusha, Ryan Leary, and Toan Phan, "The Costs of (sub)Sovereign Default Risk: Evidence from Puerto Rico," Working Paper 24108, National Bureau of Economic Research December 2017.

Chen, Zhao, Xian Jiang, Zhikuo Liu, Juan Carlos Suárez Serrato, and Daniel Xu, "Tax Policy and Lumpy Investment Behavior: Evidence from China's VAT Reform," Working Paper 26336, National Bureau of Economic Research October 2019.

Clausing, Kimberly A., "Multinational Firm Tax Avoidance and Tax Policy," National Tax Journal, 2009, 62 (4), 703-725.

_ , "The Effect of Profit Shifting on the Corporate Tax Base in the United States and Beyond," National Tax Journal, 2016, 69 (4), 905-934.

CRSP Stocks, "The Center for Research in Security Prices Stock / Security Files," Available: The Center for Research in Security Prices 1990-1996. Retrieved from Wharton Research Data Services http://wrds-web. wharton. upenn.edu/wrds/connect/ (Accessed: December 1, 2017).

de Mooij, Ruud A. and Li Liu, "At A Cost: the Real Effect of Transfer Pricing Regulations on Multinational Investment," 2018.

- and Sjef Ederveen, "Corporate tax elasticities: a reader's guide to empirical findings," Oxford Review of Economic Policy, winter 2008, 24 (4), 680-697. 
Desai, Mihir A. and Dhammika Dharmapala, "Corporate Tax Avoidance and Firm Value," Review of Economics and Statistics, August 2009, 91 (3), 537-546.

_ and James R. Hines, "Expectations and Expatriations: Tracing the Causes and Consequences of Corporate Inversions," National Tax Journal, September 2002, LV (3).

_ , C. Fritz Foley, and James R. Hines, "The demand for tax haven operations," Journal of Public Economics, 2006, 90 (3), 513-531. Special issue published in cooperation with the National Bureau of Economic Research: Proceedings of the Trans-Atlantic Public Economics Seminar on Fiscal Federalism 20-22 May 2004.

_ , _, and _, "Domestic Effects of the Foreign Activities of US Multinationals," American Economic Journal: Economic Policy, February 2009, 1 (1), 181-203.

Devereux, Michael P., Alan Jeffrey Auerbach, Michael Keen, Paul Oosterhuis, Wolfgang Sch on, and John Vella, "Residual Profit Allocation by Income," Oxford University Centre for Business Taxation Working Paper WP19/01, 2019.

_ and Rachel Griffith, "Taxes and the location of production: evidence from a panel of US multinationals," Journal of Public Economics, 1998, 68 (3), 335 - 367.

Dharmapala, Dhammika, "What problems and opportunities are created by tax havens?" Oxford Review of Economic Policy, 2008, 24 (4), 661-679.

_, "What Do We Know about Base Erosion and Profit Shifting? A Review of the Empirical Literature," Fiscal Studies, 2014, 35 (4), 421-448.

- and James R. Hines, "Which countries become tax havens?," Journal of Public Economics, 2009, 93 (9), $1058-1068$.

_ and Nadine Riedel, "Earnings shocks and tax-motivated income-shifting: Evidence from European multinationals," Journal of Public Economics, 2013, 97 (Supplement C), 95 - 107.

_ , C. Fritz Foley, and Kristin J. Forbes, "Watch What I Do, Not What I Say: The Unintended Consequences of the Homeland Investment Act," Journal of Finance, June 2011, $66(3), 753-787$.

DiNardo, John, Nicole M. Fortin, and Thomas Lemieux, "Labor Market Institutions and the Distribution of Wages, 1973-1992: A Semiparametric Approach," Econometrica, 1996, 64 (5), 1001-1044.

Dowd, Tim, Paul Landefeld, and Anne Moore, "Profit shifting of U.S. multinationals," Journal of Public Economics, 2017, 148 (Supplement C), 1-13.

Dube, Arindrajit, Ethan Kaplan, and Suresh Naidu, "Coups, Corporations, and Classified Information," Quarterly Journal of Economics, 2011, 126 (3), 1375-1409.

Dyreng, Scott D. and Bradley P. Lindsey, "Using Financial Accounting Data to Examine the Effect of Foreign Operations Located in Tax Havens and Other Countries on U.S. Multinational Firms' Tax Rates," Journal of Accounting Research, 2009, 47 (5), 1283-1316.

- and Kevin S. Markle, "The Effect of Financial Constraints on Income Shifting by U.S. Multinationals," The Accounting Review, 2016, 91 (6), 1601-1627.

_, Michelle Hanlon, Edward L. Maydew, and Jacob R. Thornock, "Changes in corporate effective tax rates over the past 25 years," Journal of Financial Economics, 2017, 124 (3), $441-463$.

Eden, Lorraine, "Puerto Rican Transfers and Section 936," Tax Notes International, 1994, 9, $37-45$. 
_, Taxing Multinationals: Transfer Pricing and Corporate Income Taxation in North America, University of Toronto Press, 1998.

Egger, Peter H. and Georg Wamser, "The impact of controlled foreign company legislation on real investments abroad. A multi-dimensional regression discontinuity design," Journal of Public Economics, 2015, 129 (Supplement C), 77 - 91.

Fajgelbaum, Pablo D., Eduardo Morales, Juan Carlos Suárez Serrato, and Owen M. Zidar, "State Taxes and Spatial Misallocation," Working Paper 21760, National Bureau of Economic Research November 2015.

Fama, Eugene and Kenneth French, "Common Risk Factors in the Returns on Stocks and Bonds," Journal of Financial Economics, 1993, 33 (1), 3-56.

FASB, "Statement of Financial Accounting Standards No. 131: Summary Disclosures about Segments of an Enterprise and Related Information," Financial Accounting Standards Board Financial Accounting Foundation, June 1997.

Feliciano, Zadia M. and Andrew Green, "US Multinationals in Puerto Rico and the Repeal of Section 936 Tax Exemption for U.S. Corporations," Working Paper 23681, National Bureau of Economic Research August 2017.

GAO, "Puerto Rico and the Section 936 Tax Credit," Technical Report GAO/GGD-93-109, Government Accountability Office June 1993.

_, "Puerto Rico Fiscal Relations with the Federal Government and Economic Trends during the Phaseout of the Possessions Tax Credit," Technical Report GAO-06-541, Government Accountability Office May 2006.

Garrett, Daniel and Juan Carlos Suárez Serrato, "How Elastic is the Demand for Tax Havens? Evidence from the US Possessions Corporations Tax Credit," AEA Papers and Proceedings, May 2019, 109, 493-99.

_, Eric Ohrn, and Juan Carlos Suárez Serrato, "Tax Policy and Local Labor Market Behavior," American Economic Review: Insights (forthcoming), July 2019.

Giroud, Xavier and Holger M. Mueller, "Firms' Internal Networks and Local Economic Shocks," American Economic Review, October 2019, 109 (10), 3617-49.

Gordon, Roger H. and James R. Hines, "International Taxation," in "in," Vol. 4 of Handbook of Public Economics, Elsevier, 2002, pp. 1935-1995.

Gravelle, Jane, "Policy Options to Address Profit Shifting: Carrots or Sticks," Tax Notes, 2016, 121, 121-134.

Gruber, Jonathan and Joshua Rauh, "How Elastic is the Corporate Income Tax Base," in Alan Auerbach, James R. Hines, and Joel Slemrod, eds., Taxing Corporate Income in the 21st Century, Cambridge University Press, 2007.

Grubert, Harry and Joel Slemrod, "The Effect of Taxes on Investment and Income Shifting to Puerto Rico," Review of Economics and Statistics, 1998, 80 (3), 365-373.

- and John Mutti, "Taxes, Tariffs and Transfer Pricing in Multinational Corporate Decision Making," The Review of Economics and Statistics, 1991, 73 (2), 285-293.

- and Rosanne Altshuler, "The Three Parties in the Race to the Bottom: Host Governments, Home Governments and Multinational Corporations," Florida Tax Review, 2006, 7 (3), 137209. 
_ and _ , "Fixing the System: An Analysis of Alternative Proposals for the Reform of International Tax," National Tax Journal, September 2013, 66 (3), 671-712.

Gumpert, Anna, James R. Hines, and Monika Schnitzer, "Multinational Firms and Tax Havens," The Review of Economics and Statistics, 2016, 98 (4), 713-727.

Guvenen, Fatih, Jr. Raymond J. Mataloni, Dylan G. Rassier, and Kim J. Ruhl, "Offshore Profit Shifting and Domestic Productivity Measurement," Working Paper 23324, National Bureau of Economic Research April 2017.

Hakobyan, Shushanik and John McLaren, "Looking for Local Labor Market Effects of NAFTA," The Review of Economics and Statistics, 2016, 98 (4), 728-741.

Heckemeyer, Jost H. and Michael Overesch, "Multinationals? Profit Response to Tax Differentials: Effect Size and Shifting Channels," 2013.

Hexner, J. Tomas and Glenn P. Jenkins, "Puerto Rico and Section 936: A Costly Dependence," Tax Notes International, 1995, 10, 235-254.

Hines, James R., "Lessons from Behavioral Responses to International Taxation," National Tax Journal, 1999, 52 (2), 305-322.

- and Eric M. Rice, "Fiscal Paradise: Foreign Tax Havens and American Business," The Quarterly Journal of Economics, 1994, 109 (1), 149-182.

Hong, Qing and Michael Smart, "In Praise of Tax Havens: International Tax Planning and Foreign Direct Investment," European Economic Review, 2010, 54 (1), 82-95.

HR3448, "H.R.3448 - Small Business Job Protection Act of 1996," Technical Report https: //www. congress.gov/bill/104th-congress/house-bill/3448/ (Accessed: June, 28, 2018) 1996.

Huber, Kilian, "Disentangling the Effects of a Banking Crisis: Evidence from German Firms and Counties," American Economic Review, March 2018, 108 (3), 868-98.

Huizinga, Harry and Luc Laeven, "International profit shifting within multinationals: A multi-country perspective," Journal of Public Economics, 2008, 92 (5), 1164 - 1182.

IRS, "SOI Tax Stats - Corporation Complete Report," Web Site https://www.irs. gov/statistics/soi-tax-stats-corporation-complete-report (Accessed: December 1, 2017), U.S. Internal Revenue Service 2017.

_, "SOI Tax Stats - County Data," Web Site https://www.irs.gov/statistics/ soi-tax-stats-county-data (Accessed: December 1, 2017), U.S. Internal Revenue Service 2017.

Johannesen, Niels and Tim B.M. Stolper, "The Deterrence Effect of Whistleblowing An Event Study of Leaked Customer Information from Banks in Tax Havens," Max Planck Institute for Tax Law and Public Finance, 2017.

Joint Committee on Taxation, "An Overview of the Special Tax Rules Related to Puerto Rico and an Analysis of the Tax and Economic Policy Implications of Recent Legislative Options," June 23, 20062006.

Kang, Karam, "Policy Influence and Private Returns from Lobbying in the Energy Sector," The Review of Economic Studies, 2016, 83 (1), 269-305.

Kovak, Brian K., Lindsay Oldenski, and Nicholas Sly, "The Labor Market Effects of Offshoring by U.S. Multinational Firms: Evidence from Changes in Global Tax Policies," Working Paper 23947, National Bureau of Economic Research October 2017. 
Los Angeles Times, "Hazy Forecast for Puerto Rico: Taxes: Clinton's Budget Will Phase Out Most Tax Breaks for U.S. firms. The Commonwealth May Try New Incentives," Olmos, David R., 1993.

MacKinlay, A. Craig, "Event Studies in Economics and Finance," Journal of Economic Literature, March 1997, 35 (1), 13-39.

Meer, Jonathan and Jeremy West, "Effects of the Minimum Wage on Employment Dynamics," Journal of Human Resources, 2016, 51 (2), 500-522.

Mian, Atif and Amir Sufi, "What Explains the 2007-2009 Drop in Employment?," Econometrica, 2014, 82 (6), 2197-2223.

Mintz, Jack and Michael Smart, "Income shifting, investment, and tax competition: theory and evidence from provincial taxation in Canada," Journal of Public Economics, 2004, 88, $1149-1168$.

Moon, Terry, "Capital Gains Taxes and Real Corporate Investment," Working Paper, 2019.

Mora, Marie T., Alberto Dávila, and Havidán Rodríguez, Population, Migration, and Socioeconomic Outcomes among Island and Mainland Puerto Ricans: La Crisis Boricua, Lexington Books, 2017.

Moretti, Enrico, "Local Multipliers," American Economic Review, May 2010, 100 (2), 373-77.

Mutti, John and Eric Ohrn, "Taxes and the Location of U.S. Business Activity Abroad," National Tax Journal, March 2019, 72 (1), 165-192.

New York Times, "Sara Lee to Cut 1,200 Jobs in Puerto Rico," 2003.

OECD, "Tax Database," 2018.

Ohrn, Eric, "The Effect of Tax Incentives on U.S. Manufacturing: Evidence from State Accelerated Depreciation Policies," September 2017. Mimeo.

_ , "The Effect of Corporate Taxation on Investment and Financial Policy: Evidence from the DPAD," American Economic Journal: Economic Policy, May 2018, 10 (2), 272-301.

OpenSecrets.org, "Bulk Lobbying Data," Web Site http://www.opensecrets.org/ (Accessed: June, 28, 2018) 2018.

Overesch, Michael, "The Effects of Multinationals' Profit Shifting Activities on Real Investments," National Tax Journal, 2009, 62 (1), 5-23.

QCEW, "Bureau of Labor Statistics: Quarterly Census of Employment and Wages," Web Site (Accessed: December 1, 2017), https://www.bls.gov/cew/ 2017.

Rao, Nirupama, "Corporate Inversions and Economic Performance," National Tax Journal, 2015, 68 (4), 1073-1097.

Ruggles, Steven et al., "Integrated Public Use Microdata Series: Version 5.0," [Machinereadable database], Minneapolis: University of Minnesota 2010.

Saunders-Scott, Molly J., "Substitution Across Methods of Profit Shifting," National Tax Journal, 2015, 68 (4), 1099-1120.

Schwab, Thomas and Maximilian Todtenhaupt, "Thinking Outside the Box: The Crossborder Effect of Tax Cuts on R\&D," Technical Report, WU International Taxation Research Paper Series No. 2016-07 September 2019. 
Slemrod, Joel, "Do Taxes Matter? Lessons from the 1980's," The American Economic Review, 1992, 82 (2), 250-256.

- , "A general model of the behavioral response to taxation," International Tax andPublic Finance, 2001, 8 (2), 119-128.

_ and Christian Gillitzer, Tax Systems, MIT Press, 2013.

- and John D. Wilson, "Tax competition with parasitic tax havens," Journal of Public Economics, 2009, 93 (11), 1261-1270.

Suárez Serrato, Juan Carlos and Owen Zidar, "Who Benefits from State Corporate Tax Cuts? A Local Labor Markets Approach with Heterogeneous Firms," American Economic Review, 2016.

_ and _, "The Structure of State Corporate Taxation and its Impact on State Tax Revenues and Economic Activity," Working Paper, Duke University May 2017.

- and Philippe Wingender, "Estimating the Incidence of Government Spending," December 2014. Mimeo.

_ and _, "Estimating Local Fiscal Multipliers," Working Paper 22425, National Bureau of Economic Research July 2016.

Tax Foundation, "What Does Research on Profit Shifting Tell Us?," Web Site https: //taxfoundation.org/what-does-research-profit-shifting-tell-us/ (Accessed: July, 5, 2018) 2016.

Tørsløv, Thomas, Ludvig Wier, and Gabriel Zucman, "The Missing Profits of Nations," Working Paper 2018.

Valletta, R.G. and R.B. Freeman, "The NBER Public Sector Collective Bargaining Law Data Set," in Richard B. Freeman and Casey Ichniowski, eds., When Public Employees Unionize, Chicago: NBER and University of Chicago Press, 1988, chapter Appendix B.

Walls \& Associates, "NETS: National Establishment Time-Series Database," 2012.

Wilson, Daniel J, "Beggar Thy Neighbor? The In-State, Out-of-State, and Aggregate Effects of R\&D Tax Credits," Review of Economics and Statistics, 2016/02/22 2009, 91 (2), 431-436.

Wright, Thomas and Gabriel Zucman, "The Exorbitant Tax Privilege," working paper, 2018.

Yagan, Danny, "Capital Tax Reform and the Real Economy: The Effects of the 2003 Dividend Tax Cut," American Economic Review, December 2015, 105 (12), 3531-63.

_ , "Employment Hysteresis from the Great Recession," Journal of Political Economy, forthcoming., 2017.

Zucman, Gabriel, The Hidden Wealth of Nations, The University of Chicago Press, 2015.

Zwick, Eric and James Mahon, "Tax Policy and Heterogeneous Investment Behavior," American Economic Review, January 2017, $10^{r}$ (1), 217-48. 
Figure 1: Fiscal Cost of $\S 936$ : US Possessions Corporations Tax Credit

A. Total Tax Credits from $§ 936$

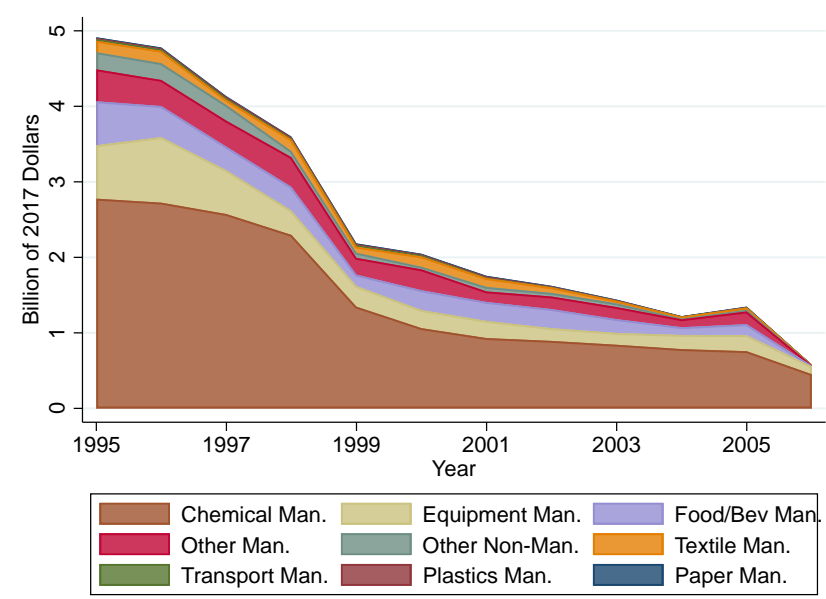

B. Share of $\S 936$ Credits By Industry

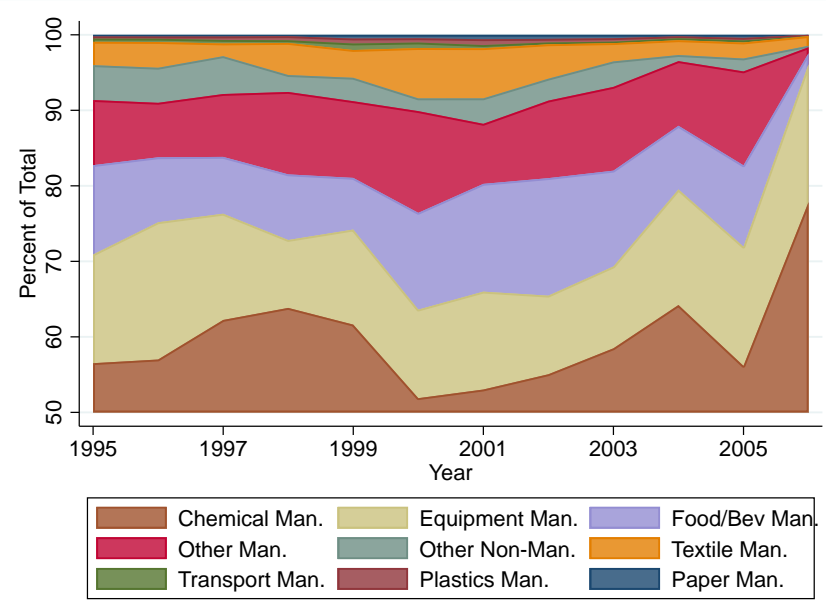

\section{Counterfactual Effective Tax Rates for Affected Firms}

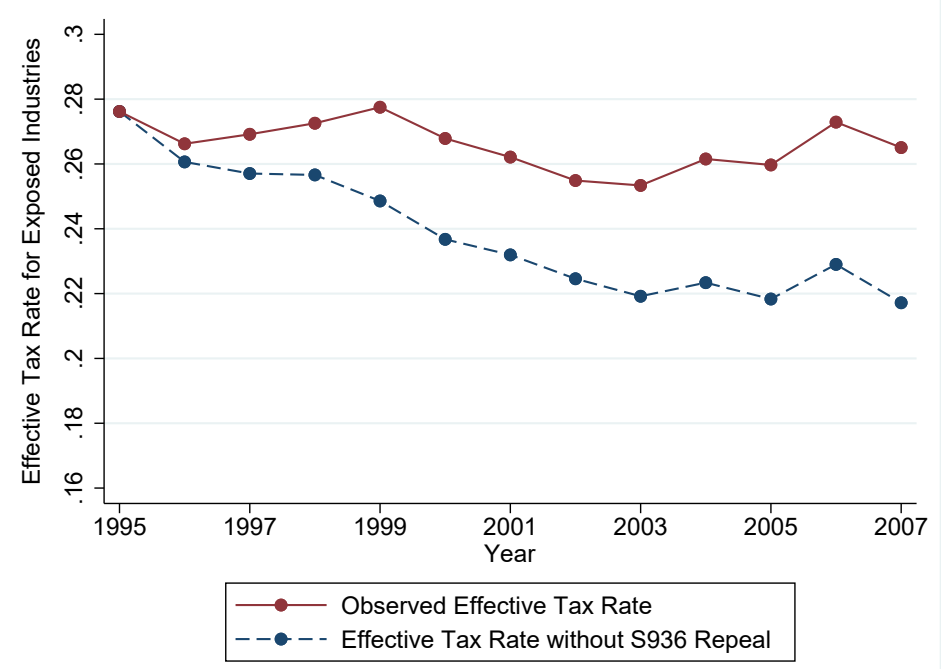

Notes: This figure displays the fiscal cost of $\S 936$ to the US Treasury. Panel A tabulates claims of US Corporations' Possessions Tax Credits from 1995 to 2006 by industry using data from the IRS (2017a) "Statistics of Income" series. This graph shows that the largest drops in the value of these credits happen after 1996 and 1998, years that correspond to statutory limits on the tax credits. Panel B shows the composition of these credits by industry. In 1995, about $55 \%$ of these credits are claimed by corporations in the chemical manufacturing industry. Firms manufacturing equipment, food, beverages, and tobacco claimed about $26 \%$ of the credits, while other industries claimed the remaining $17 \%$. Panel $\mathrm{C}$ plots the effective tax rates for exposed firms as well as a counterfactual assuming that $\S 936$ was not repealed. See Section 2 for more details. 


\section{Figure 2: Effects of Profit Shifting on Investment and Employment}

A. Optimal Profit Shifting Strategy

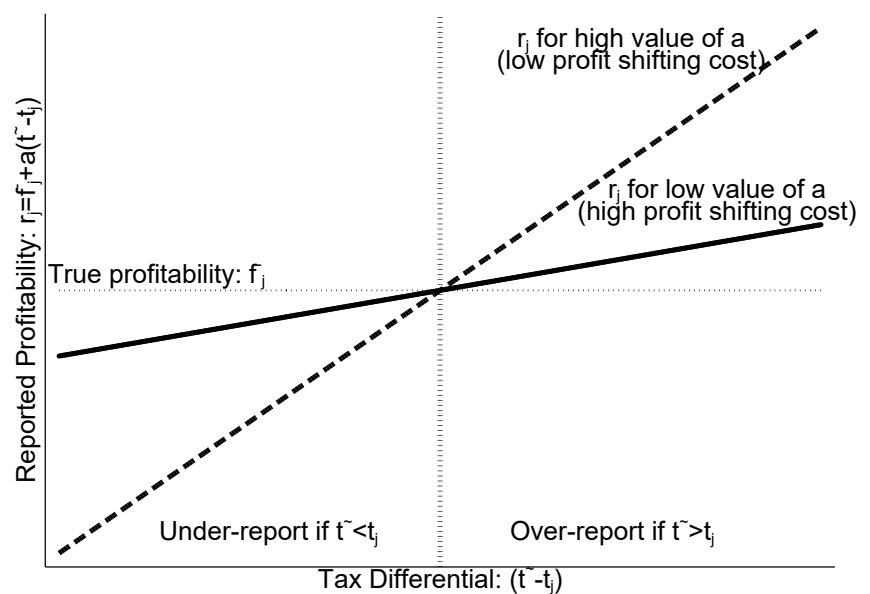

B. Profit Shifting and Domestic Investment

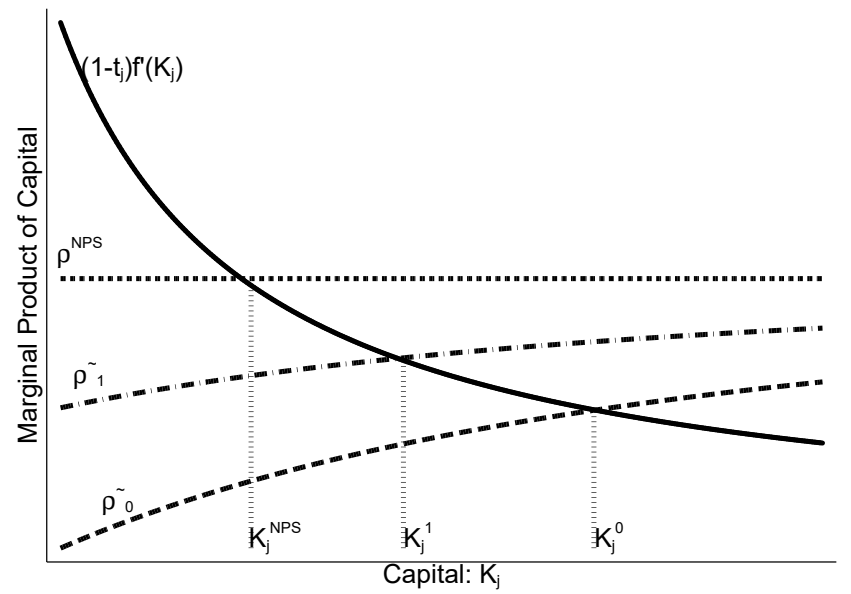

C. Profit Shifting and Domestic Employment

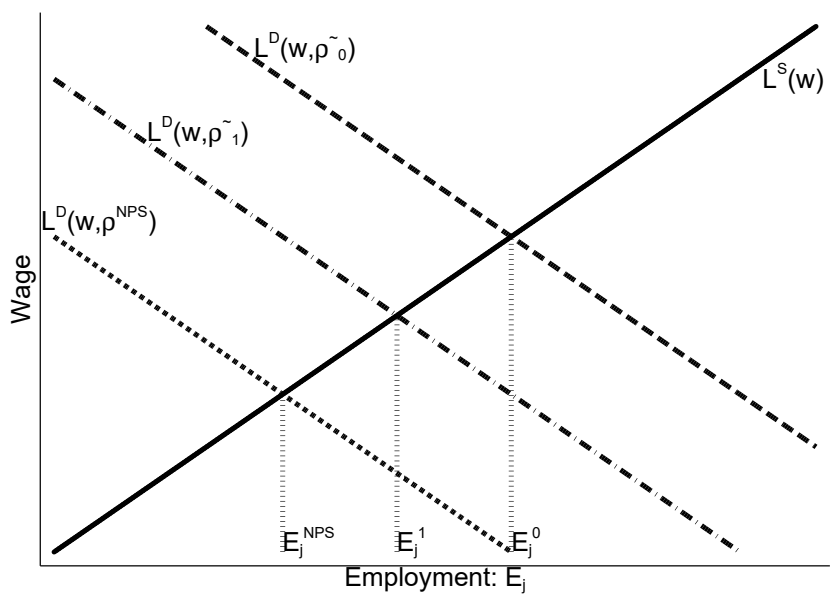

Notes: This figure displays the predictions of the model in Section 3. Panel A shows that reported profitabilities $r_{j}$ depend on true profitability $\bar{f}_{j}$, the tax differential $\left(\tilde{t}-t_{j}\right)$, and the parameter governing the cost of profit shifting, $a$. Firms over-report profits in countries with low taxes $\left(\tilde{t}>t_{j}\right)$ and underreport in countries with high taxes $\left(\tilde{t}<t_{j}\right)$. The degree of over-reporting depends on the cost of profit shifting. If $a$ is low (high cost of misreporting), the relationship between $r_{j}$ and the tax differential is relatively flat (solid line). If $a$ is large (low cost of misreporting), the slope is steeper (dashed line). Panel $\mathrm{B}$ shows the implications of profit shifting for domestic investment. Without profit shifting, the firm sets capital so that the after-tax marginal product of capital equals the cost of equity $\rho^{N P S}$ (dotted line). When profit shifting is allowed, the income-shifting adjusted user cost of capital $\tilde{\rho}_{0}$ (dashed line) is below $\rho^{N P S}$ and is increasing in $K_{j}$. This results in a higher level of investment $K_{j}^{0}>K_{j}^{N P S}$. The dot-dashed line labeled $\tilde{\rho}_{1}$ shows the effect of a tax increase in a tax haven on the user cost in a high-tax country. Reducing the tax gains from the tax haven results in lower domestic investment $K_{j}^{0}>K_{j}^{1}>K_{j}^{N P S}$. Panel $\mathrm{C}$ shows the effects of these tax changes on domestic employment, assuming that capital and labor are complements, in country $j$. This graph shows that the demand for labor depends on the cost of capital $L^{D}(w, \rho)$. Labor demand shifts out when profit shifting is allowed $L^{D}\left(w, \tilde{\rho}_{1}\right)>L^{D}\left(w, \rho^{N P S}\right)$ and shifts in when there is a tax increase in the low-tax country, $L^{D}\left(w, \tilde{\rho}_{1}\right)>L^{D}\left(w, \tilde{\rho}_{0}\right)$. Therefore, there is more domestic employment when tax havens reduce the income-shifted adjusted cost of capital: $E_{j}^{N P S}<E_{j}^{1}<E_{j}^{0}$. 
Figure 3: Distribution of Exposure to $§ 936$ at the County Level in 1995

A. Raw Exposure to $§ 936$

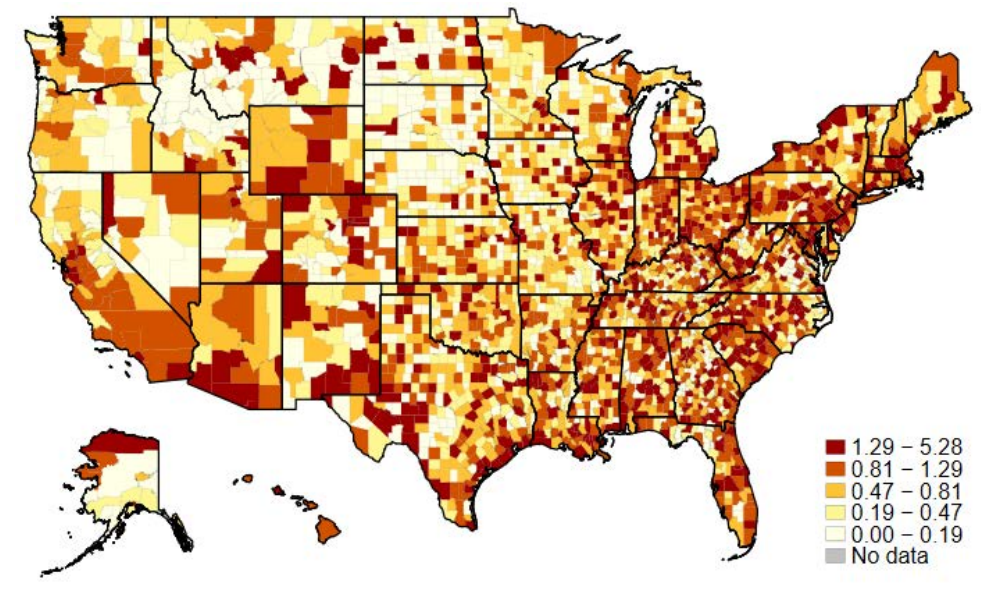

B. Standardized Exposure to $§ 936$

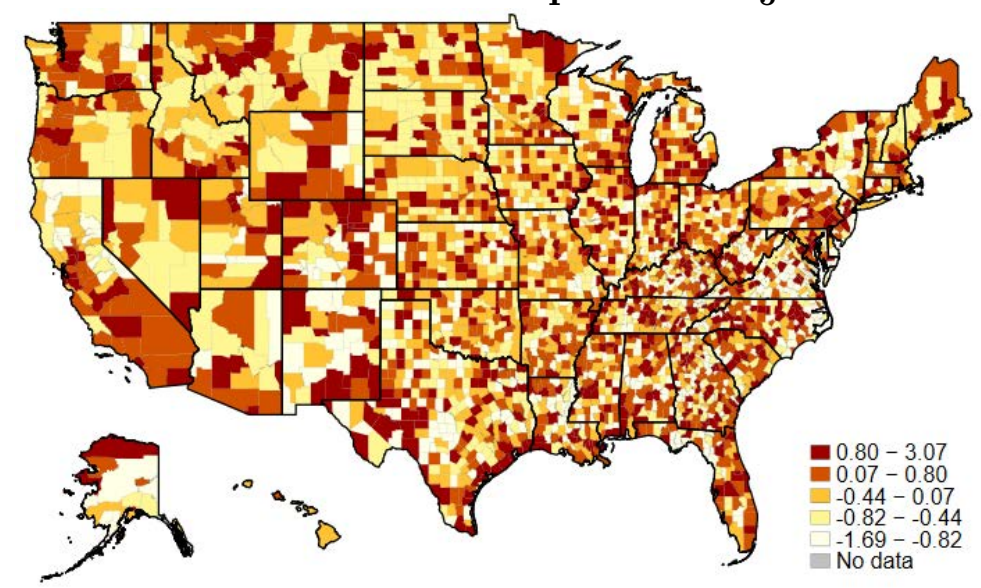

Notes: Author's calculations using data from NETS. This figure plots the distribution of the percent of establishments in each county that are part of firms with exposure to $§ 936$. Panel A shows that the fraction of labor market exposure varies from $0 \%$ to $5 \%$. Panel B shows a measure of the exposure that is standardized within states and shows that there is substantial variation across counties within any given state. See Section 4 and Appendix A for more information about the data and measurement. 
Figure 4: Exposure to §936, Demographic Characteristics, and Economic Polices
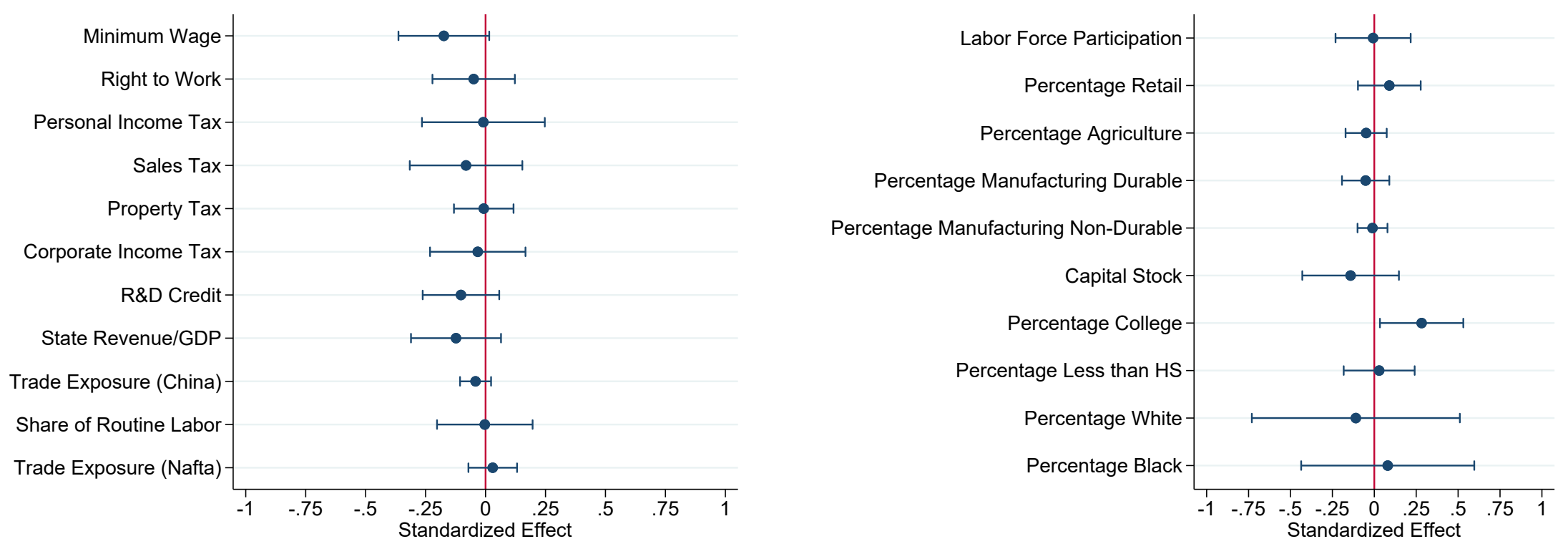

Notes: This graph shows the correlation of the exposure to $\S 936$ at the county level and various policies, economic indicators, and other shocks. Blue lines span a 95\% confidence interval. Author's calculations using data from NETS and various other sources. See Valletta and Freeman (1988); Meer and West (2016) for data on minimum wage and right-to-work laws, Suárez Serrato and Zidar (2016) for data on state taxes and tax revenues, Wilson (2009) for data on R\&D tax credits, Autor et al. (2016) and Hakobyan and McLaren (2016) for data on exposure to trade, and Autor and Dorn (2013) for data on the share of routine labor. Demographic and industry employment data are from the US Census, and data on capital stocks are from the BEA. See Appendix A for more details on data sources. 


\section{Figure 5: Repealing §936 Reduced the Investment-to-Capital Ratios of Exposed}

Firms

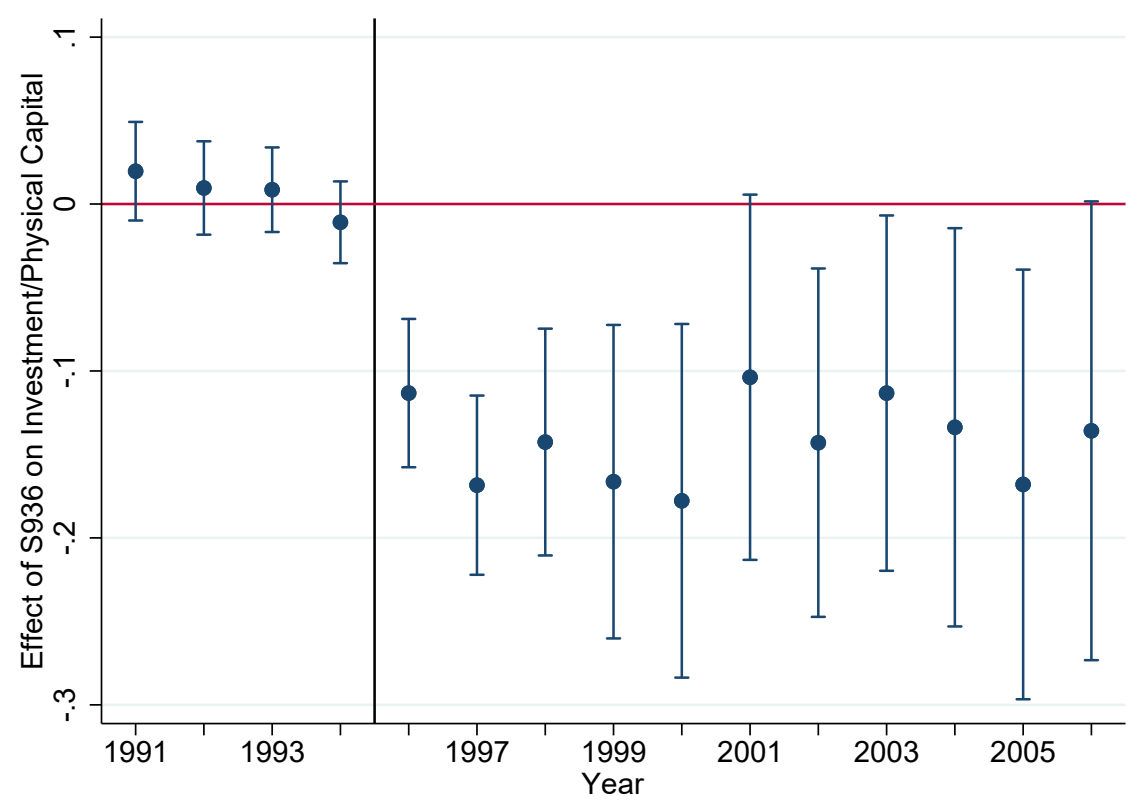

Notes: Author's calculations using data from COMPUSTAT. This figure shows estimates of Equation 2 where the dependent variable is investment divided by average capital in 1990 to 1995 and exposure to $\S 936$ is an indicator at the firm level. Investment is defined as capital expenditures, and capital is defined as plants, property, and equipment. Blue lines span a 95\% confidence interval. Consistent with the hypothesis that multinationals decreased investment, we see that exposed firms saw a decrease in investment following the repeal of $\S 936$ relative to non-exposed firms. Point estimates and additional specifications are shown in Table 2. Standard errors are clustered at the firm level. 


\section{Figure 6: Repealing $§ 936$ Increased the Foreign Share of Investment of Exposed}

Firms

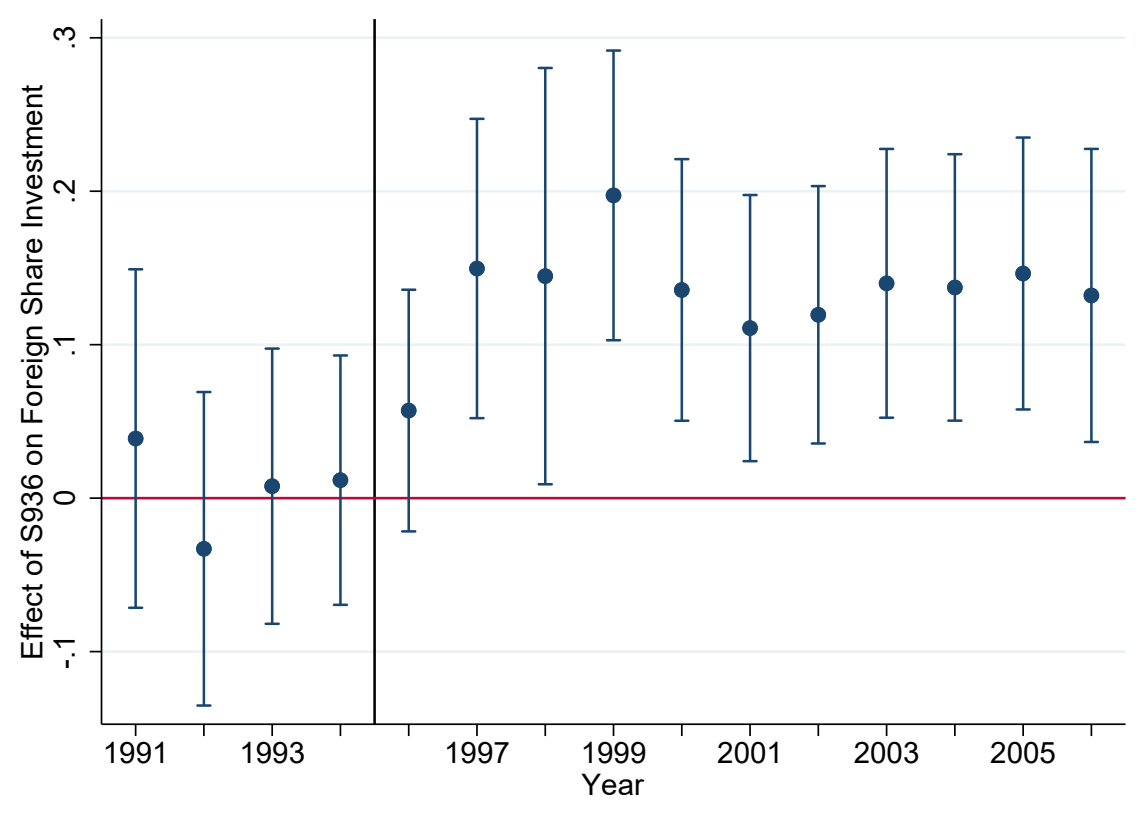

Notes: Author's calculations using data from COMPUSTAT Historical Segments. This figure shows estimates of Equation 3 where the dependent variable is the share of investment based in foreign affiliates and exposure to $\S 936$ is an indicator at the firm level. Blue lines span a $95 \%$ confidence interval. Consistent with the hypothesis that multinationals shifted investment abroad, we see that exposed firms saw an increase in the fraction of foreign investment following the repeal of $\S 936$. Coefficient estimates and additional specifications are shown in Table 4. See Section 5 for more discussion. Standard errors are clustered at the firm level. 


\section{Figure 7: Repealing $§ 936$ Reduced CAPX Investment in Exposed Industries}

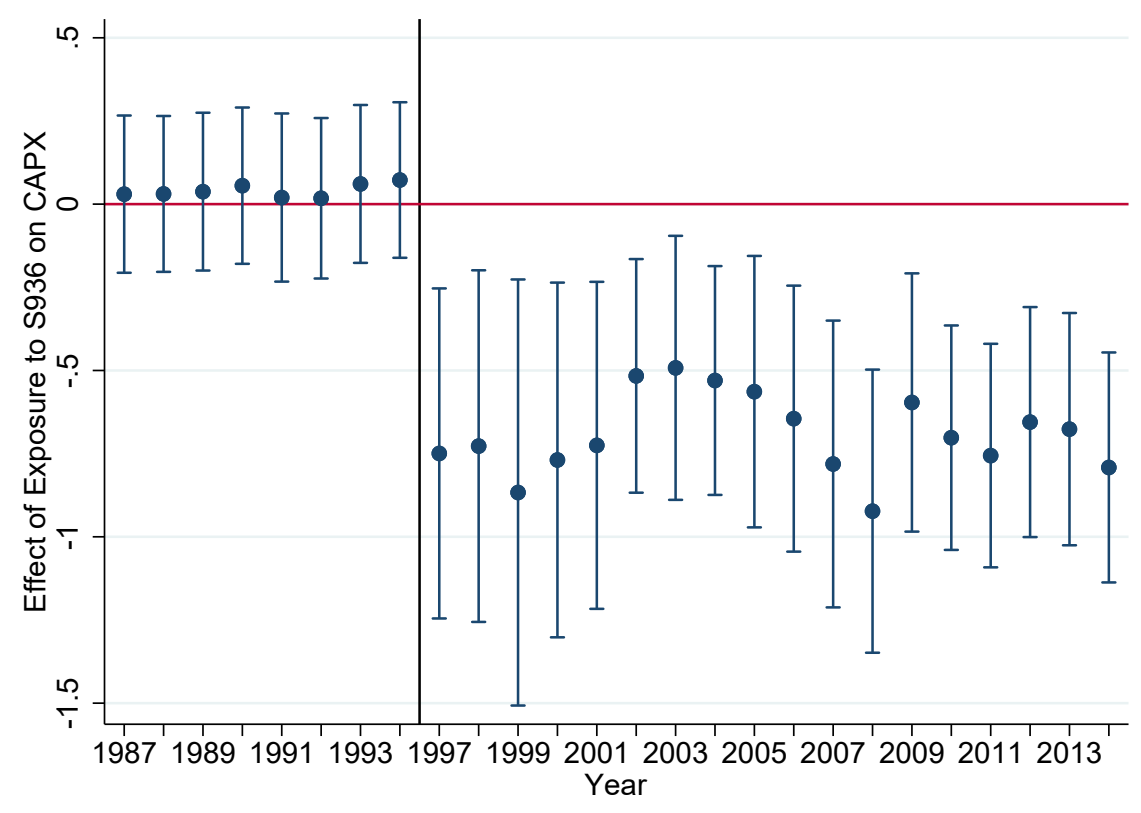

Notes: Author's calculations using data from NETS and the Annual Survey of Manufactures. This figure plots estimates of Equation 4 where exposure to $\S 936$ is the proportion of establishments in each state-industry divided by the interquartile range. Blue lines span a $95 \%$ confidence interval. Following the repeal of $\S 936$, we see a persistent decline in the flow of investment in state-industries with more exposure to $§ 936$. Coefficient estimates and additional specifications are shown in Table 5. See Section 5 for more information. Standard errors are clustered at the state level. 


\section{Figure 8: Firm-Level Employment Effects of Repealing of $\S 936$}

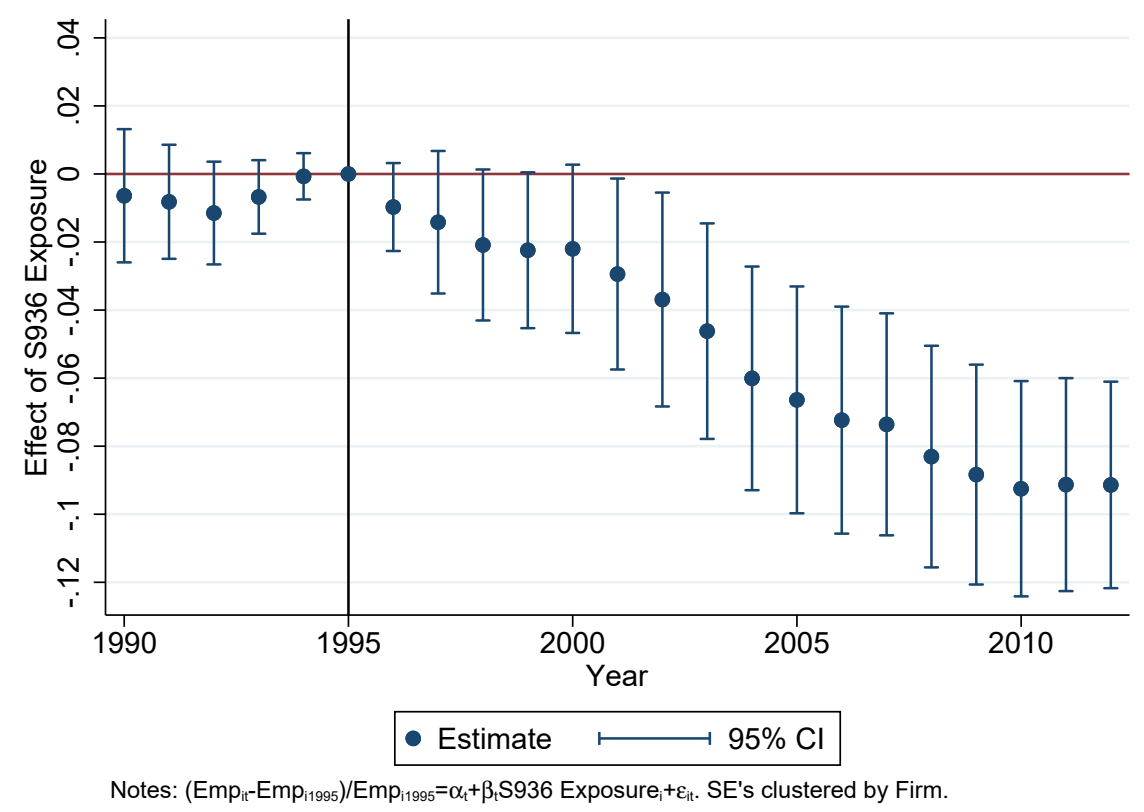

Notes: Author's calculations using data from NETS. This figure shows the decline in employment at $\S 936$ exposed firms relative to similar control firms without exposure to $\S 936$, where exposure to $\S 936$ is an indicator at the firm level. See Appendix A.3 for a description of the procedure used to identify the comparison firms. Point estimates are displayed in Table A.10. See Section 5 for additional discussion. Standard errors are clustered at the firm level. 


\section{Figure 9: Employment Effects of Repealing of $\S 936$ by Tercile of Exposure}

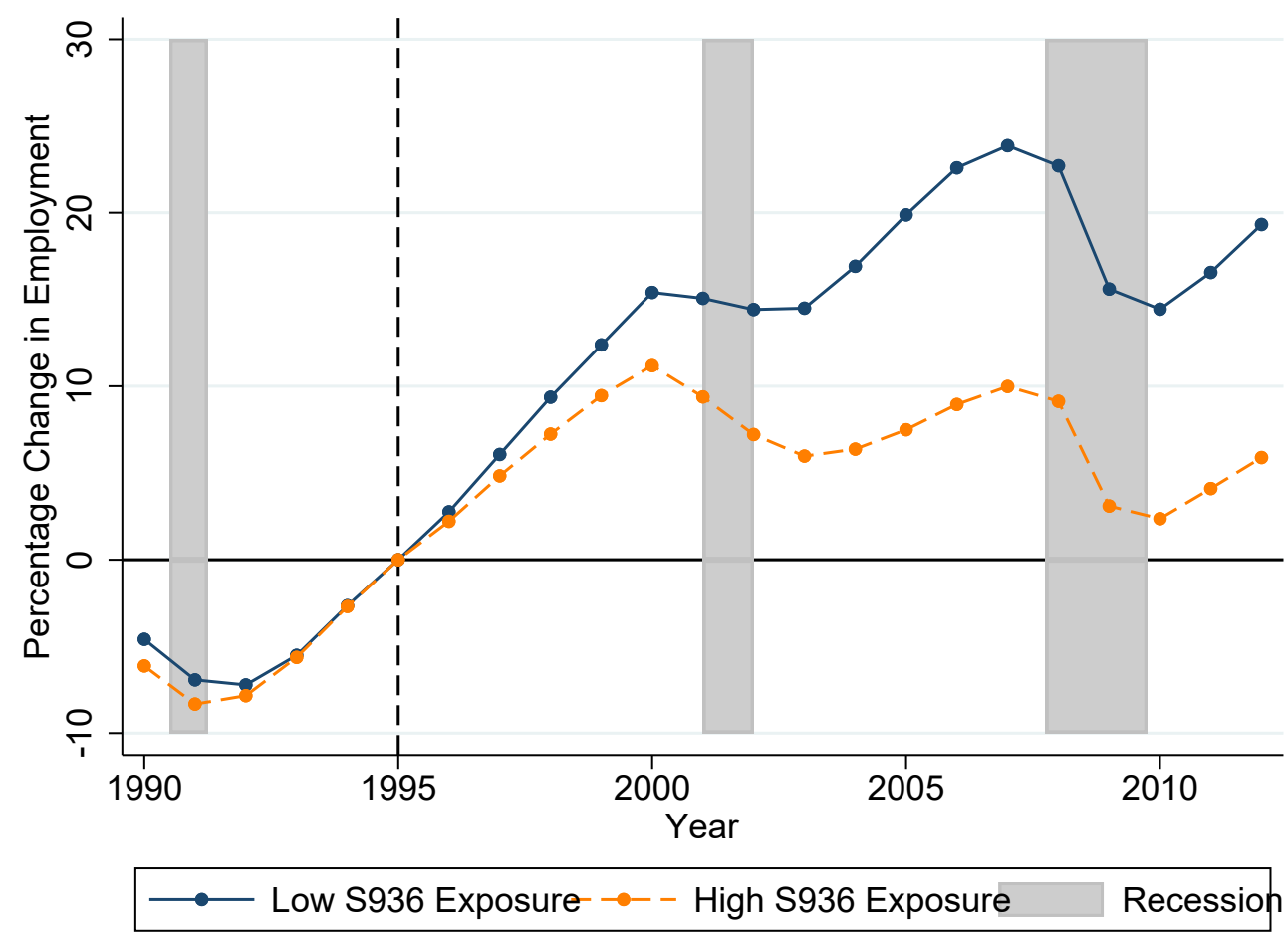

Notes: Author's calculations using data from NETS and QCEW. This figure plots average employment growth for counties in the top tercile of $\S 936$ exposure (High S936 Exposure) relative to the employment growth in counties in the bottom tercile (Low S936 Exposure). This graph shows that counties with a greater exposure to $\S 936$ experienced a relative decrease in employment growth during the 10 years that correspond to the phase-out of $\S 936$. For a parametric analysis of the effect of exposure to $\S 936$ on employment growth, see Figure 10. See Appendix A for a discussion of the data and Section 6 for more discussion. Average employment growth is weighted according to county-by-industry employment in 1995. 
Figure 10: Effects of Exposure to $§ 936$ on Employment Growth

\section{A. Estimated Coefficients for $§ 936$ Exposure (IQR Adjusted)}

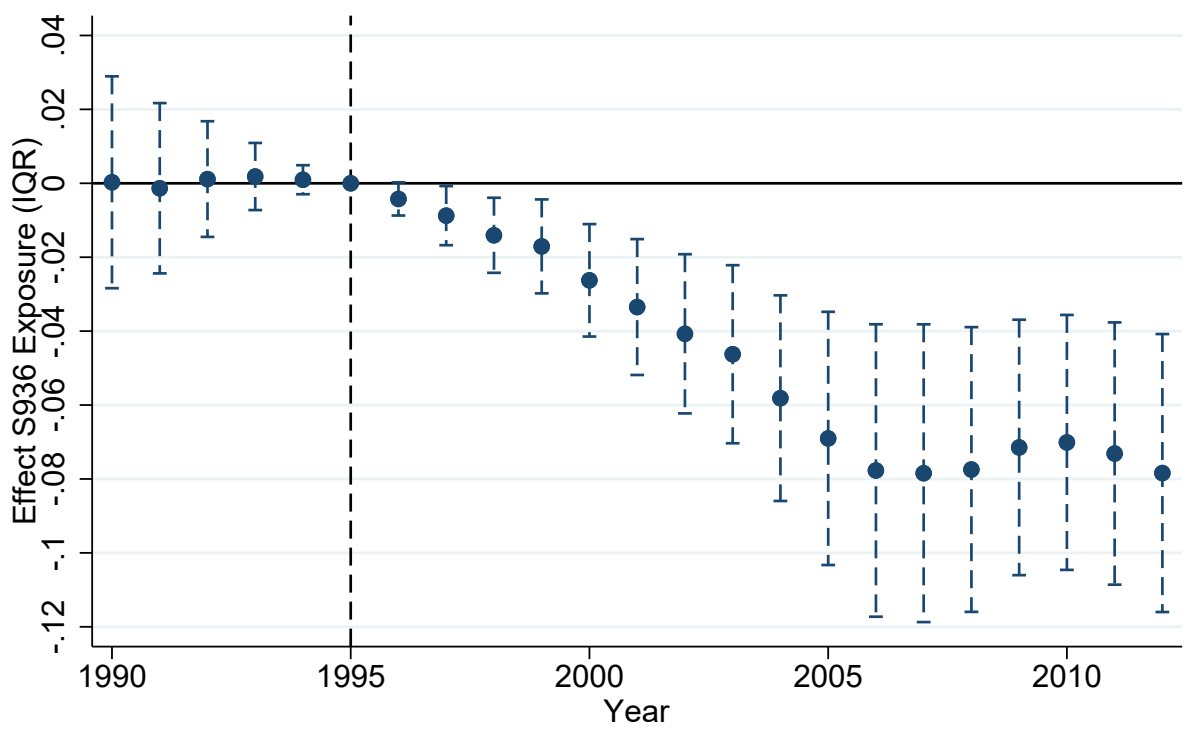

- Estimate $\vdash---\dashv 95 \% \mathrm{Cl}$

Notes: $\left(\mathrm{Emp}_{\mathrm{ict}}-\mathrm{Emp}_{\mathrm{ic} 1995}\right) / \mathrm{Emp}_{\mathrm{ic} 1995}=\alpha_{\mathrm{c}}+\gamma_{\mathrm{tt}}+\beta_{\mathrm{t}} \mathrm{S} 936$ Exposure $_{\mathrm{c}}+\varepsilon_{\mathrm{ict}}$. SE's clustered by State and Industry.

\section{B. Implied Employment Growth at Selected Quantiles}

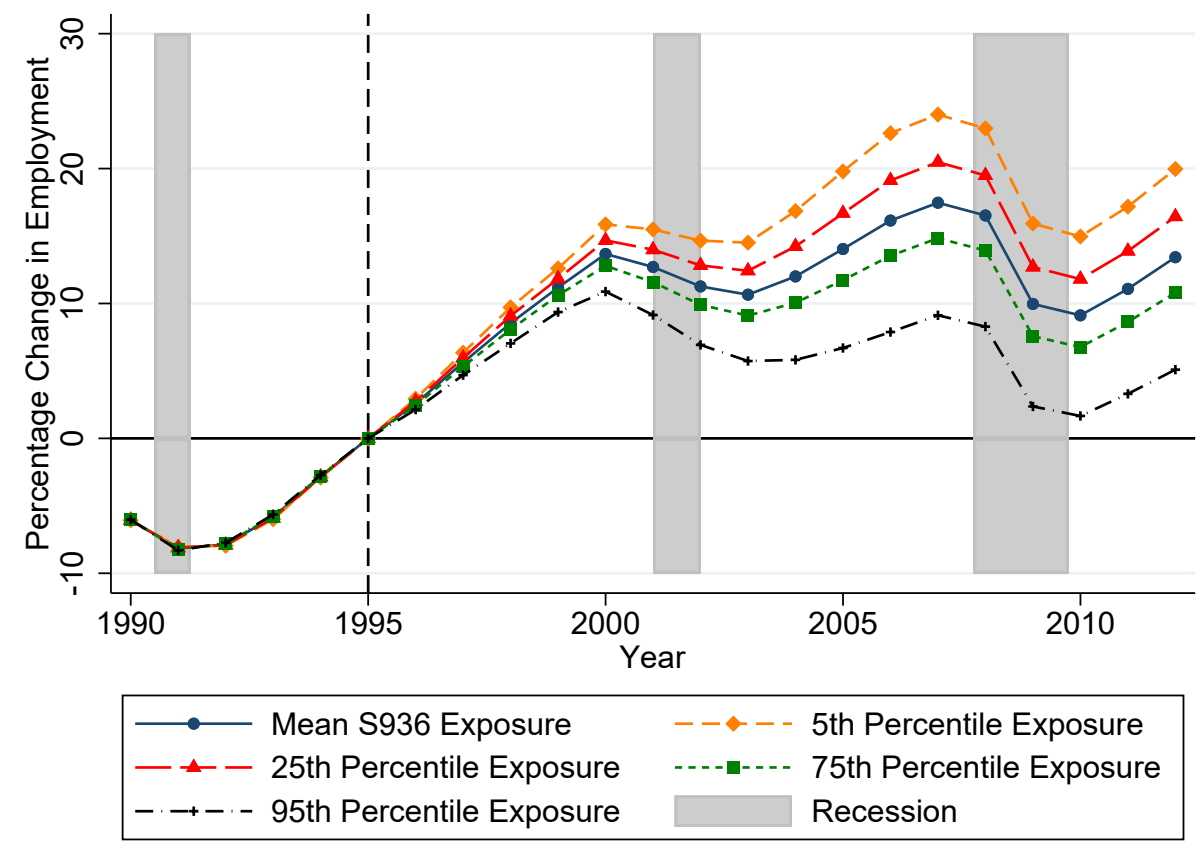

Notes: Author's calculations using data from NETS and QCEW. This figure shows estimates of $\beta^{t}$ for $t=1990, \cdots, 2012$ in Equation 6. Exposure is measured as the percent of establishments exposed to $\S 936$ divided by the interquartile range. This graph shows that, prior to the repeal of $\S 936$, exposure to $\S 936$ is not predictive of employment growth, which is consistent with the parallel trends assumption. The graph shows that counties with greater exposure to $\S 936$ experienced a relative decrease in employment growth during the 10 years that correspond to the phase-out of $\S 936$. For 2006, Panel A shows that increasing the exposure to $\S 936$ from the 25 th percentile to the 75 th percentile decreases employment growth by $7.2 \%$. Moreover, the decline in employment growth stabilizes after the full phase-out of $\S 936$ in 2006. See Appendix A for a discussion of the data and Section 6 for a discussion of the results. Coefficients are displayed in Table 6. Standard errors are clustered at the state and industry levels. Observations at the industry-45unty level are weighted by employment in 1995 . 
Figure 11: Effects of Exposure to $§ 936$ on Employment Growth: Alternative Specifications

A. Robustness to Geography and Per Capita

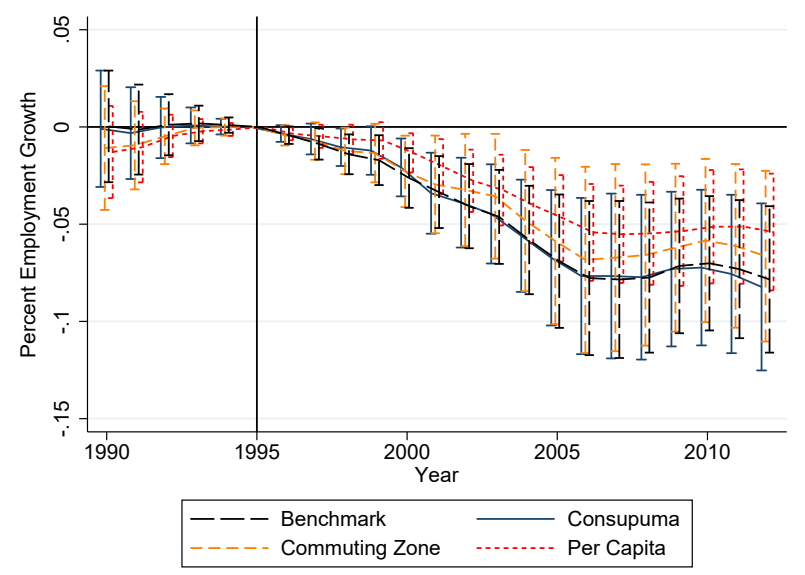

B. Robustness of Exposure Measure

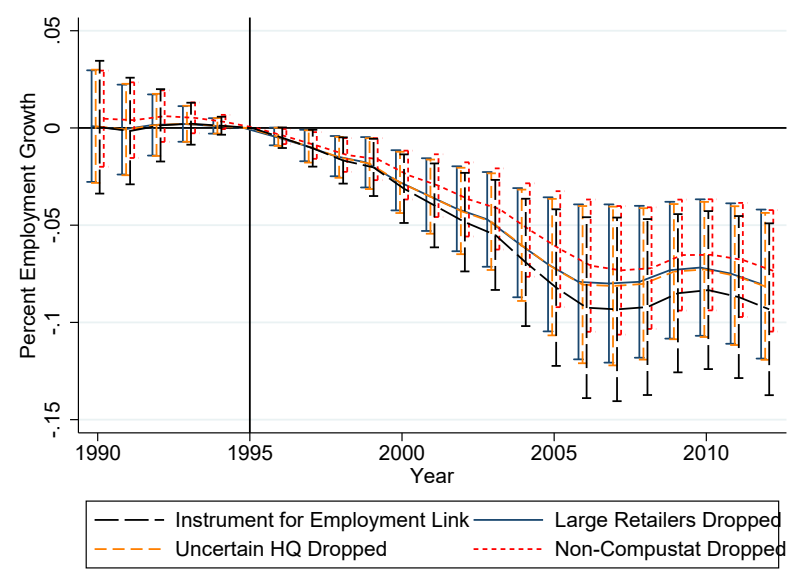

\section{Robustness to Network of Establishment Links Definition}

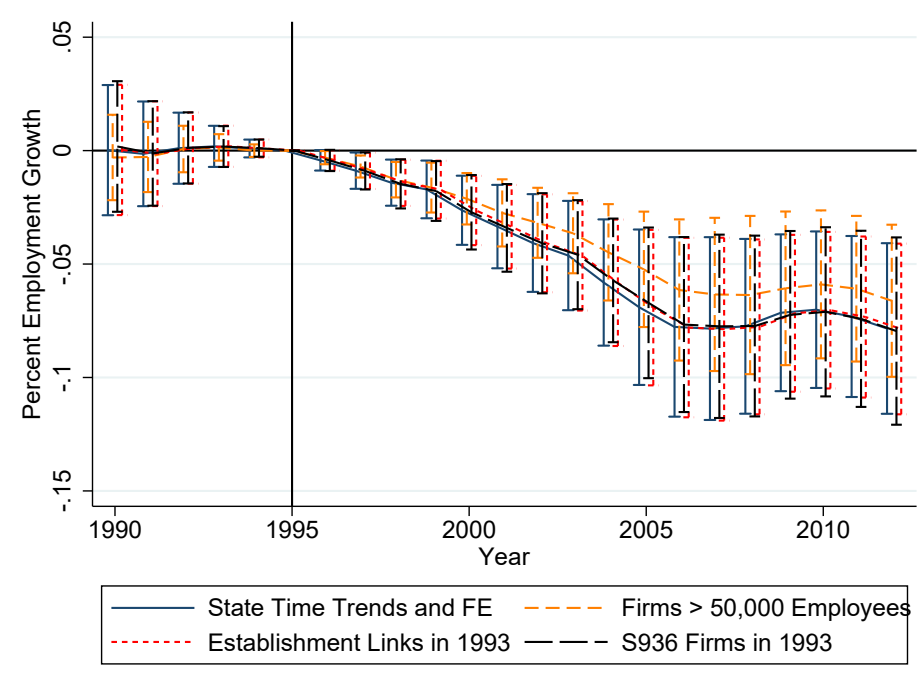

Notes: Author's calculations using data from NETS and QCEW. This figure shows estimates of $\beta^{t}$ for $t=1990, \cdots, 2012$ from Equation 6. The top panel shows results from regressions using a different measurement for the geography of interest and for population-adjusted employment growth. Coefficient estimates and additional specifications are displayed in Tables 6 and 7. Panel B shows alternative specifications of the sample of firms that are considered as potential links. Exposure is calculated from the NETS in terms of both employment and establishments, and the establishments' exposure is used to instrument for the employment exposure in the first specification. The second specification in the lower panel manually excludes large retailers from links, the third specification excludes those firms for which NETS does not report a headquarters, and the fourth excludes firms that are not part of the Compustat Database from the links. Coefficient estimates for Panel B are displayed in Tables A.12, A.13, A.14, and A.15, respectively. Panel C shows further alternative specifications for the sample of firms that are considered as potential links. First, the estimate of equation 6 with state fixed effects and state time trends is shown. Second, the same regression restricting links to firms with more than 50,000 employees is shown. The final two specifications define links in 1993 using either the full set of firms in Puerto Rico or the set of firms in Puerto Rico from the original 1995 sample that are also in Puerto Rico in 1993. Coefficient estimates for Panel C are displayed in Tables A.21, A.16, A.17, and A.18, respectively. Standard errors are clustered at the state and industry levels. Observations at the industry-county level are weighted by employment in 1995. 
Figure 12: Effects of Exposure to $§ 936$ on Employment Growth: Placebo Tests

\section{A. Placebo Test for Matched, Non-exposed Firms}

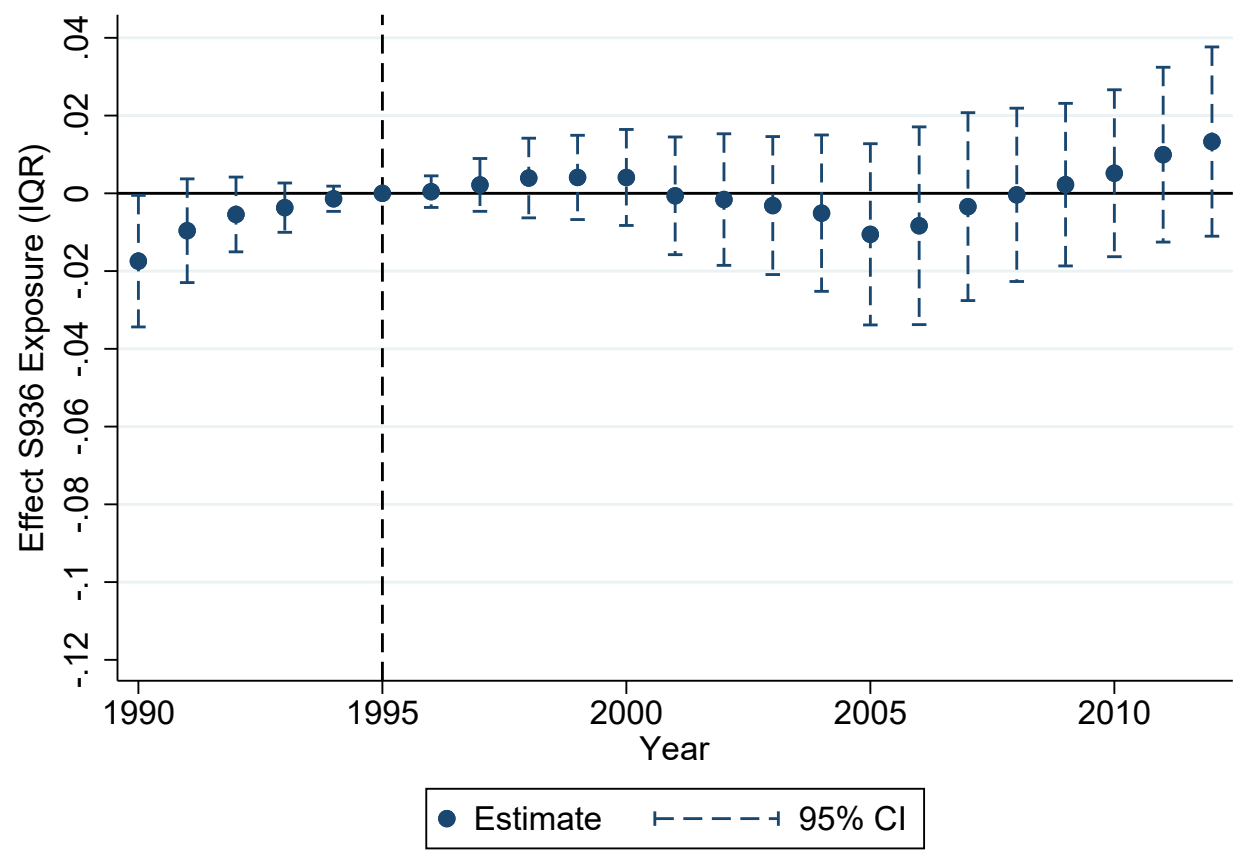

Notes: $\left(E p_{\mathrm{ict}}-\mathrm{Emp}_{\mathrm{ic} 1995}\right) / \mathrm{Emp}_{\mathrm{ic1995}}=\alpha_{\mathrm{c}}+\gamma_{\mathrm{it}}+\beta_{\mathrm{t}} \mathrm{S} 936$ Exposure $_{\mathrm{c}}+\varepsilon_{\mathrm{ict}}$. SE's clustered by State and Indust

\section{B. Placebo Test for Exposure to Pharmaceuticals}

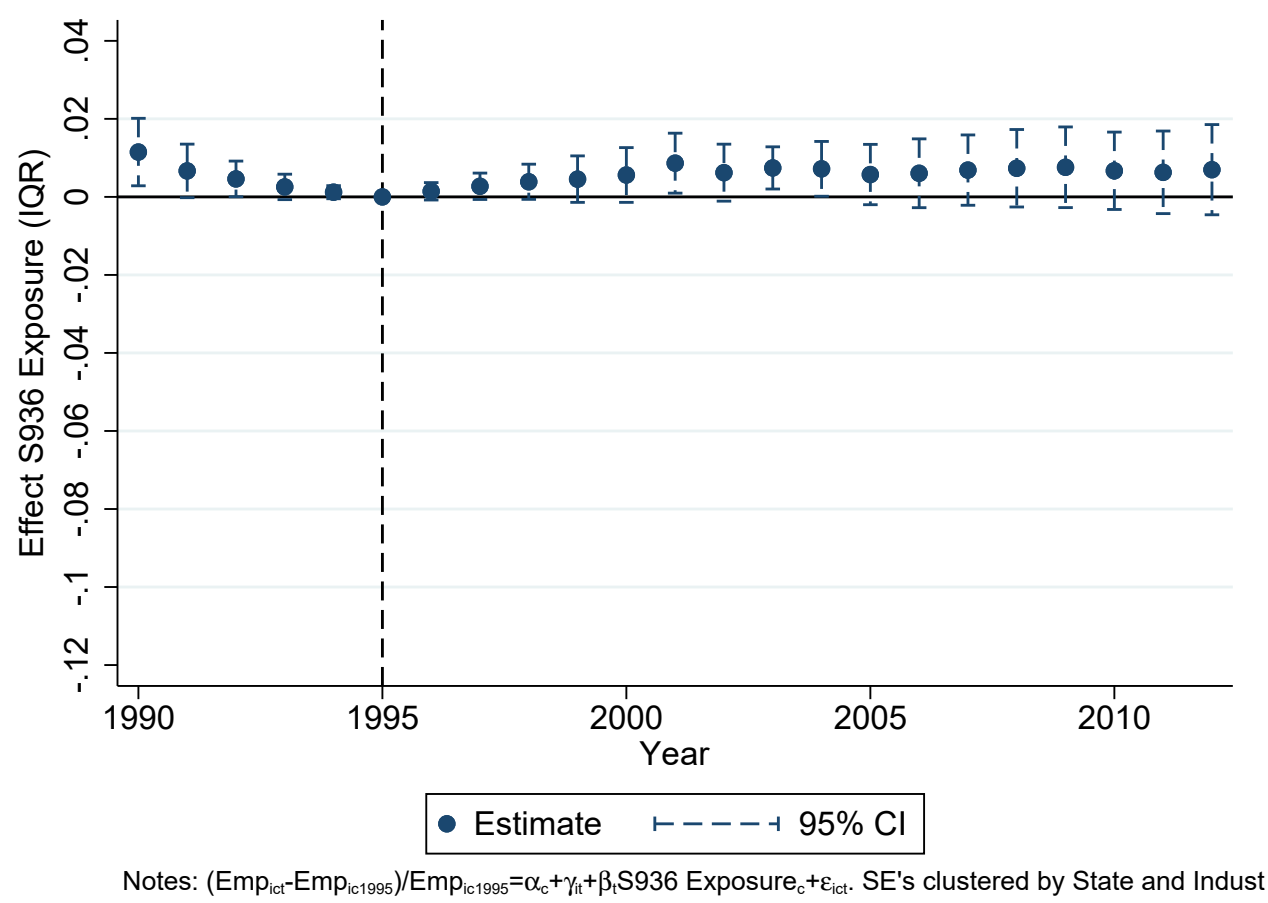

Notes: Author's calculations using data from NETS and QCEW. This figure shows estimates of $\beta^{t}$ for $t=1990, \cdots, 2012$ in Equation 6 using other measures of "exposure" that could be correlated with exposure to $\S 936$. The top panel shows results from regressions using fake $\S 936$ exposure from a sample of unlinked firms that are similar to linked firms. See Appendix A.3 for a description of the procedure used to identify the set of counterfactual firms for the Panel A shock. The lower panel replaces the exposure to $\S 936$ with exposure to the pharmaceuticals industry, NAICS 3254. See Appendix A for a discussion of the data and Section 6 for a discussion of the results. Both of these placebo exercises fail to find any evidence of a negative effect on local employment growth. Coefficient estimates and additional specifications are displayed in Tables A.22 and A.23, respectively. Standard errors are clustered at the state and industry levels. Observations at the ind Gistry-county level are weighted by employment in 1995. 


\section{Figure 13: Effects of Exposure to $§ 936$ on Employment Growth: Robustness}

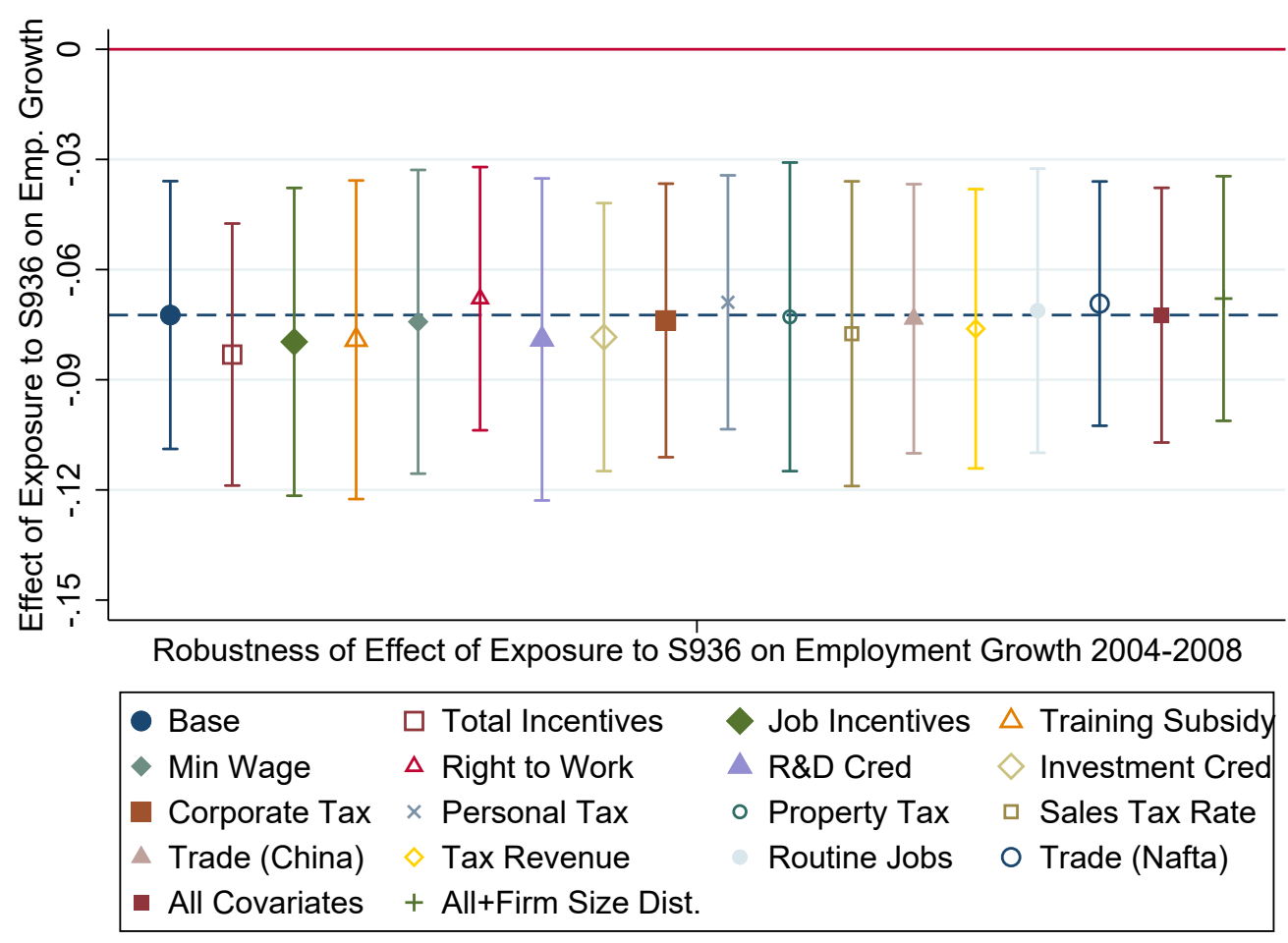

Notes: This figure shows the robustness of the coefficients shown in Table 8 to controlling for various county- and state-level characteristics. The coefficients represent the effect of increasing $\S 936$ exposure from the 25 th to the 75 th percentile. In 2004-2008 the average change in employment growth due to an IQR increase in $\S 936$ exposure is $-7.2 \%$. Controlling for other state and county characteristics yields estimates between $-6.8 \%$ and $-8.3 \%$. The coefficients and standard errors are displayed in Tables A.24 and A.25. See Appendix A for a discussion of the data and Section 6 for a discussion of the results. Standard errors are clustered at the state and industry levels. Observations at the industry-county level are weighted by employment in 1995 . 


\section{Figure 14: Heterogeneous Effects of Exposure to $\S 936$ on Employment Growth by Sector}

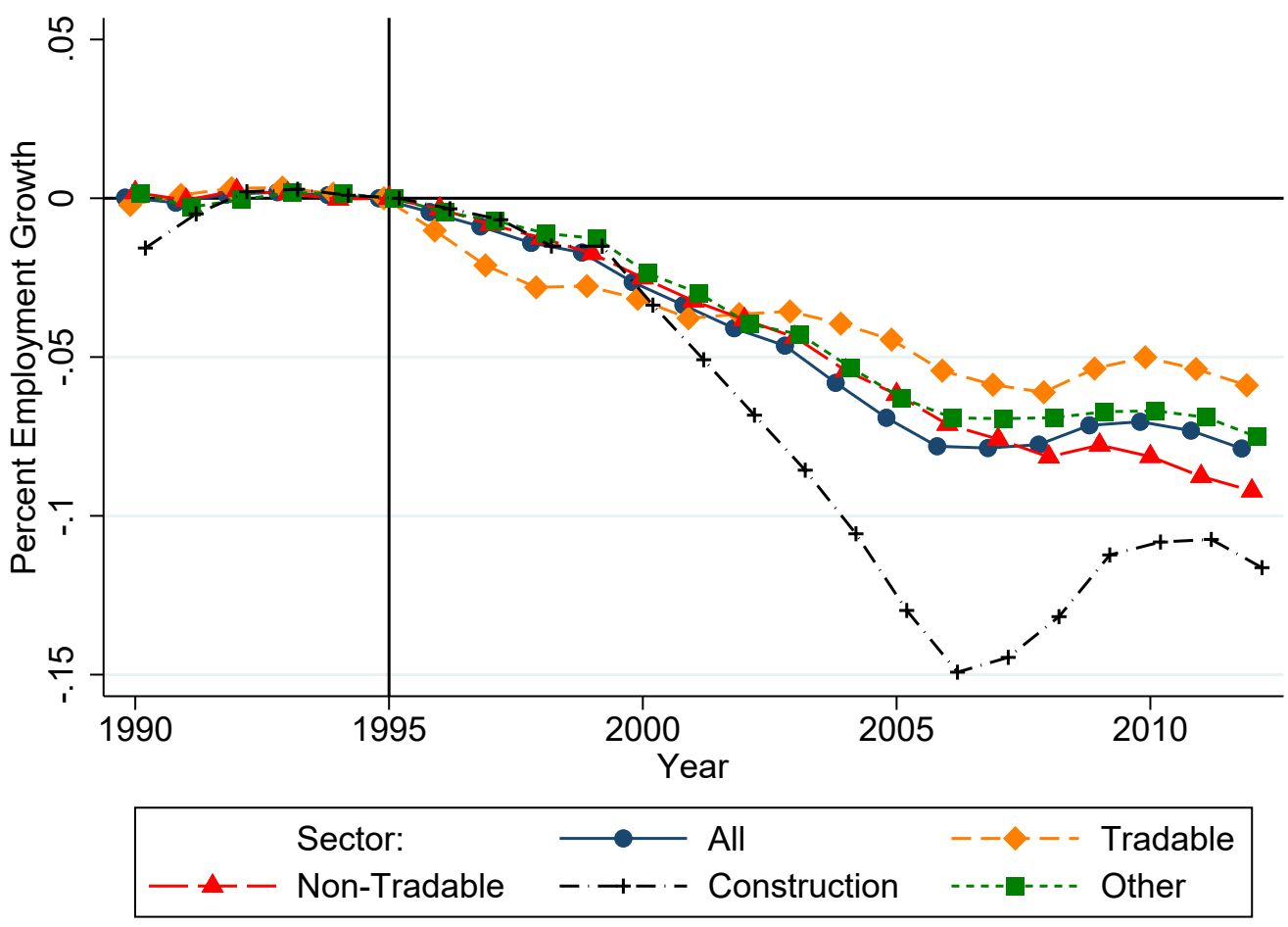

Notes: Author's calculations using data from NETS and QCEW and sector definitions from Mian and Sufi (2014). This figure shows the average effect and heterogeneous effects by sector. Estimates and standard errors are displayed in Table A.26 and Figure A.16. This figure highlights that the tradable sector sees a decline in employment growth before any of the other sectors. See Appendix A for a discussion of the data and Section 6 for a discussion of the results. Standard errors are clustered at the state and industry levels. Observations at the industry-county level are weighted by employment in 1995. 
Figure 15: Effects of Exposure to $§ 936$ on Wages and Rental Costs

A. Wage Growth After 1990

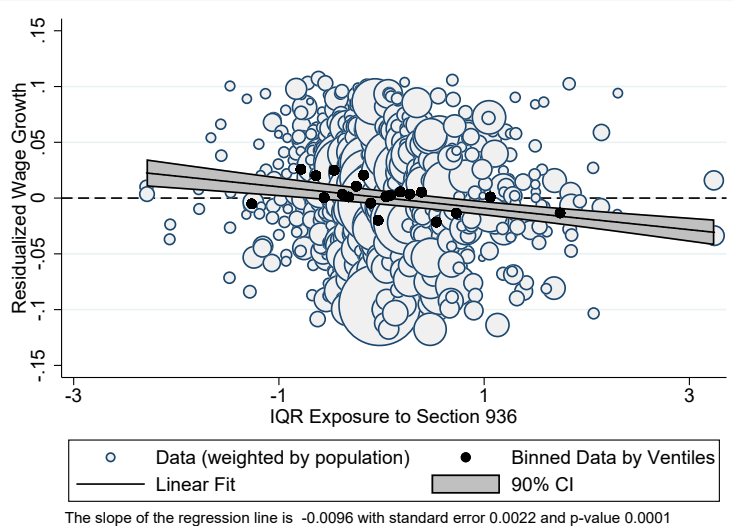

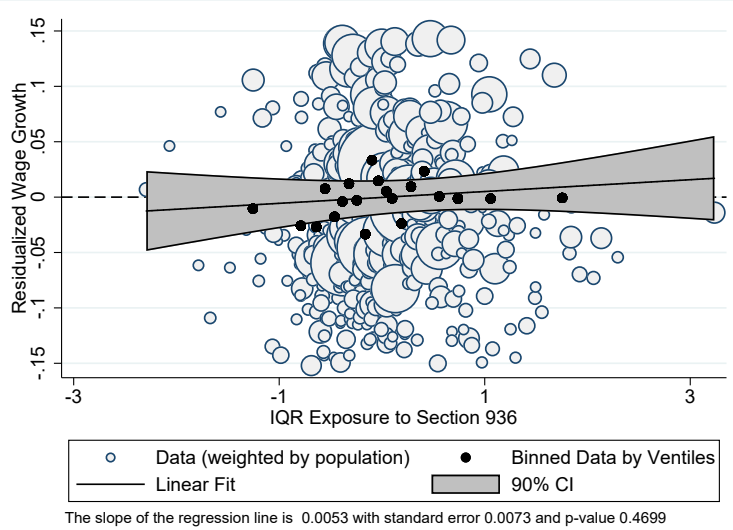

B. Low-Skill Wage Growth After 1990

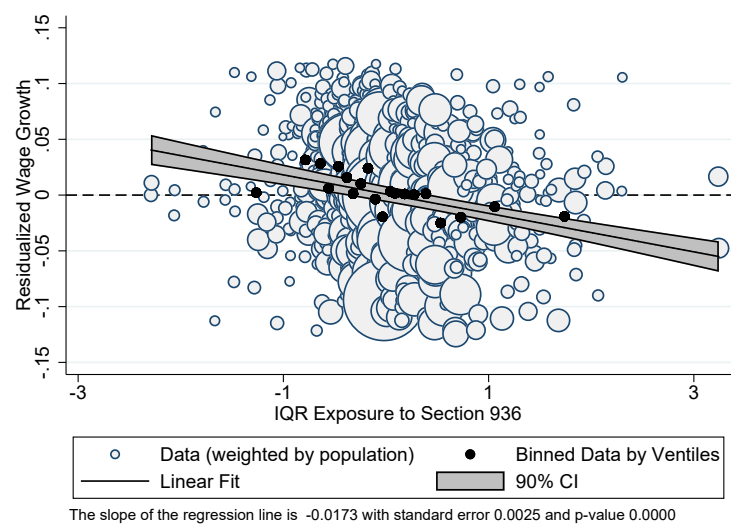

E. Low-Skill Wage Growth Before 1990

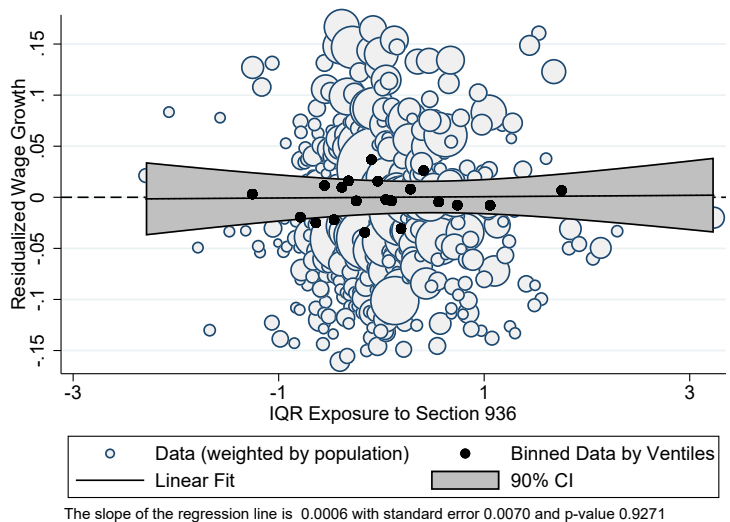

C. Rent Growth After 1990

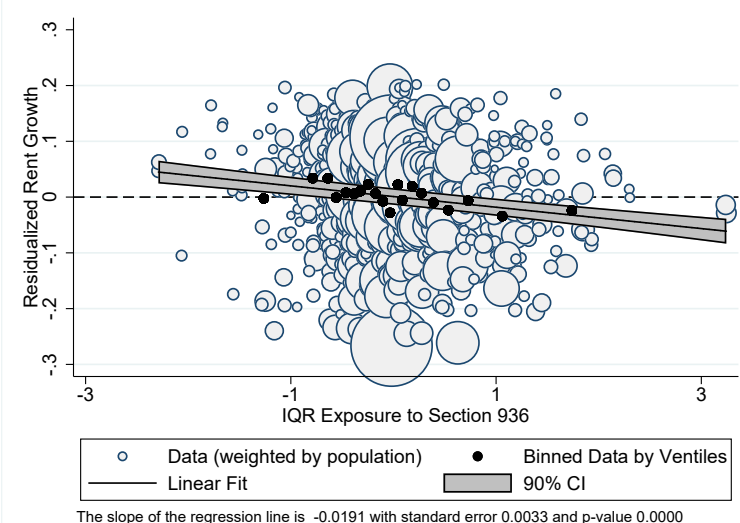

F. Rent Growth Before 1990

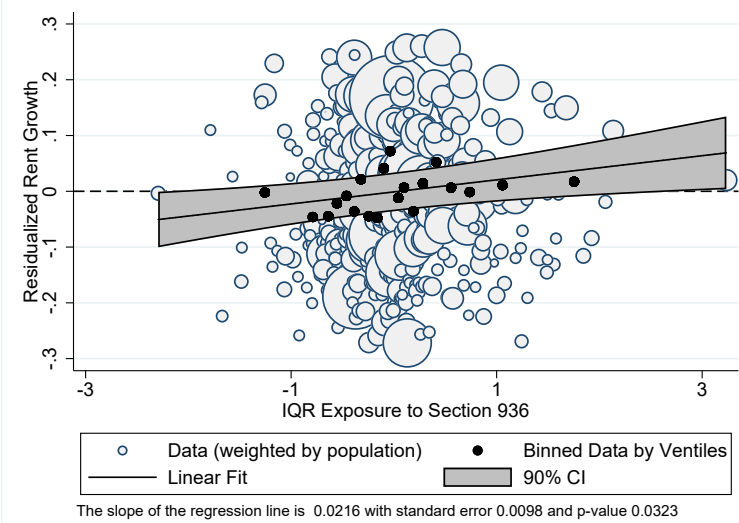

Notes: Author's calculations using data from NETS and Census. Exposure to $\S 936$ is residualized. This figure shows that exposure to $\S 936$ was not correlated with wage and rent growth before the repeal of $\S 936$. See Appendix A for a discussion of the data and Section 6 for a discussion of the results. 
Table 1: US and Puerto Rico Employment at Large NETS Companies in 1995

\begin{tabular}{lccc}
\hline Company & US & PR & Industry \\
\hline ABBOTT LABORATORIES & 47,357 & 6,786 & Chemicals \\
BAXTER INTERNATIONAL INC & 54,373 & 6,027 & Wholesale and Retail \\
JOHNSON \& JOHNSON & 45,526 & 5,115 & Other Mfg \\
WESTINGHOUSE (LATER CBS) & 144,550 & 4,775 & Other Non-Mfg \\
GENERAL ELECTRIC COMPANY & 434,310 & 4,736 & Electrical Equipment \\
PEPSICO INC & 225,575 & 4,537 & Beverages \\
WYETH LLC & 41,960 & 4,217 & Chemicals \\
SARA LEE CORPORATION & 103,664 & 3,706 & Food Mfg \\
H J HEINZ COMPANY & 21,259 & 3,263 & Food Mfg \\
BRISTOL-MYERS SQUIBB COMPANY & 42,080 & 3,082 & Chemicals \\
KMART CORPORATION & 401,217 & 2,483 & Wholesale and Retail \\
BERKSHIRE HATHAWAY INC & 175,799 & 2,336 & Other Non-Mfg \\
DIGITAL EQUIPMENT CORPORATION & 55,917 & 2,305 & Other Mfg \\
MERCK \& CO INC & 14,476 & 2,173 & Chemicals \\
SEARS ROEBUCK AND CO & 365,901 & 1,606 & Wholesale and Retail \\
AMR CORPORATION & 112,955 & 1,515 & Other Mfg \\
\hline Sub Total & $2,286,919$ & 58,662 & \\
\hline Total & $10,675,679$ & 170,350 & \\
\hline
\end{tabular}

Notes: This table lists US companies with employment in Puerto Rico greater than 1,500 according to the NETS (Walls \& Associates, 2012). The first column shows the company name, the second column shows US employment in 1995, and the third column shows Puerto Rico employment in 1995. The last column includes an industry category derived from NAICS classification. The sub total row is the sum of the 14 companies displayed here. The total row includes all 682 firms with establishments in Puerto Rico. 
Table 2: Effects of Repealing $§ 936$ on the Investment-to-Capital Ratio of Exposed Firms

\begin{tabular}{lcccccc}
\hline Change in Investment: $\frac{I}{K_{-1990-1995}}$ & $(1)$ & $(2)$ & $(3)$ & $(4)$ & $(5)$ & $(6)$ \\
\hline \multicolumn{1}{c}{ Exposure to Section 936 X Post } & -0.116 & -0.130 & -0.119 & -0.155 & -0.183 & -0.142 \\
& $(0.053)$ & $(0.052)$ & $(0.043)$ & $(0.047)$ & $(0.057)$ & $(0.052)$ \\
& 0.029 & 0.012 & 0.006 & 0.001 & 0.001 & 0.007 \\
\hline Observations & 79393 & 79376 & 79376 & 42734 & 36089 & 34821 \\
Sample Average I/K in 2006 & 1.174 & 1.174 & 1.174 & 0.931 & 0.981 & 1.018 \\
Percent of 2006 Average & $9.9 \%$ & $11.1 \%$ & $10.1 \%$ & $16.6 \%$ & $18.7 \%$ & $14.0 \%$ \\
Change in Effective Tax Rate & 5.727 & 5.727 & 5.727 & 4.653 & 6.010 & 6.010 \\
Semi-elasticity of Investment & 1.73 & 1.93 & 1.77 & 3.57 & 3.11 & 2.33 \\
\hline Year Fixed Effects & $\mathrm{Y}$ & $\mathrm{Y}$ & $\mathrm{Y}$ & $\mathrm{Y}$ & $\mathrm{Y}$ & $\mathrm{Y}$ \\
NAICS-by-Year Fixed Effects & & $\mathrm{Y}$ & $\mathrm{Y}$ & $\mathrm{Y}$ & $\mathrm{Y}$ & $\mathrm{Y}$ \\
Firm Fixed Effects & & & $\mathrm{Y}$ & $\mathrm{Y}$ & $\mathrm{Y}$ & $\mathrm{Y}$ \\
S936 Exposed Sector & & & & $\mathrm{Y}$ & $\mathrm{Y}$ & $\mathrm{Y}$ \\
S936 Exposed Industry & & & & & $\mathrm{Y}$ & $\mathrm{Y}$ \\
DFL Weights & & & & & & $\mathrm{Y}$ \\
\hline \hline
\end{tabular}

Notes: Author's calculations using data from COMPUSTAT. This table shows estimates of Equation 2 where the dependent variable is the change in investment divided by average capital in 1990-1995 winsorized at the 5\% level. The estimates in this table correspond to a pooled version of the regression displayed in Figure 5 where Exposure to Section 936 X Post is an indicator at the firm level for exposed firms interacted with an indicator for years after 1995. The coefficient in column (5) means that firms exposed to $\S 936$ decrease investment by $18 \%$ after 1995, which implies a semi-elasticity of 3.11. Additional results are displayed in Tables A.5 and A.6 to show robustness. See Section 5 for discussion and Appendix A for more information about the data and variables. Standard errors clustered at the firm level are shown in parentheses with p-values below. 
Table 3: Effect of Repealing $§ 936$ on Federal Taxes Paid as a Percent of Global Pretax Income

\begin{tabular}{lcccccc}
\hline \hline Change in Federal Taxes Paid as a Percent of Pretax Income & & \\
& $(1)$ & $(2)$ & $(3)$ & $(4)$ & $(5)$ & $(6)$ \\
\hline \multicolumn{1}{c}{ Exposure to Section 936 X Post } & 3.144 & 3.656 & 3.507 & 5.874 & 4.962 & 5.436 \\
& $(1.600)$ & $(1.589)$ & $(1.716)$ & $(2.465)$ & $(2.767)$ & $(2.538)$ \\
& 0.049 & 0.021 & 0.041 & 0.017 & 0.073 & 0.032 \\
\hline Observations & 33097 & 33074 & 33074 & 17314 & 14065 & 13187 \\
Change in Effective Tax Rate & 5.727 & 5.727 & 5.727 & 4.653 & 6.010 & 6.010 \\
\hline Year Fixed Effects & $\mathrm{Y}$ & $\mathrm{Y}$ & $\mathrm{Y}$ & $\mathrm{Y}$ & $\mathrm{Y}$ & $\mathrm{Y}$ \\
NAICS-by-Year Fixed Effects & & $\mathrm{Y}$ & $\mathrm{Y}$ & $\mathrm{Y}$ & $\mathrm{Y}$ & $\mathrm{Y}$ \\
Firm Fixed Effects & & & $\mathrm{Y}$ & $\mathrm{Y}$ & $\mathrm{Y}$ & $\mathrm{Y}$ \\
S936 Exposed Sector & & & & $\mathrm{Y}$ & $\mathrm{Y}$ & $\mathrm{Y}$ \\
S936 Exposed Industry & & & & $\mathrm{Y}$ & $\mathrm{Y}$ \\
DFL Weights & & & & & $\mathrm{Y}$ \\
\hline \hline
\end{tabular}

Notes: Author's calculations using data from COMPUSTAT. This table estimates a version of Equation 2 where the dependent variable is cash federal taxes paid divided by global pretax income. These estimates reflect the percent change in federal taxes paid as a percent of pretax income at firms exposed to Section 936 after 1995. The last column shows that federal taxes paid as a percent of global pretax income increased by 5.44pp at exposed firms after the repeal of $\S 936$. The sample is restricted to those firms with non-trivial pretax income. The estimated change in the effective tax rate is similar to the tax increase estimates of 4.5-5.9pp discussed in Appendix B. See Section 5 and Appendix B for additional discussion and Appendix A for more information about the data and variables. Clustered standard errors at the firm level are shown in parentheses with p-values below. 
Table 4: Effects of Repealing $§ 936$ on the Foreign Share of Investment of Exposed Firms

\begin{tabular}{lcccccc}
\hline \hline Change in Foreign Share of Investment & & & & & \\
& $(1)$ & $(2)$ & $(3)$ & $(4)$ & $(5)$ & $(6)$ \\
\hline \multicolumn{1}{c}{ Exposure to Section 936 X Post } & 0.127 & 0.126 & 0.123 & 0.190 & 0.178 & 0.151 \\
& $(0.045)$ & $(0.044)$ & $(0.044)$ & $(0.048)$ & $(0.055)$ & $(0.057)$ \\
& 0.005 & 0.004 & 0.005 & 0.000 & 0.001 & 0.008 \\
\hline Observations & 15697 & 15695 & 15671 & 7416 & 6315 & 5613 \\
\hline Year Fixed Effects & $\mathrm{Y}$ & $\mathrm{Y}$ & $\mathrm{Y}$ & $\mathrm{Y}$ & $\mathrm{Y}$ & $\mathrm{Y}$ \\
NAICS-by-Year Fixed Effects & & $\mathrm{Y}$ & $\mathrm{Y}$ & $\mathrm{Y}$ & $\mathrm{Y}$ & $\mathrm{Y}$ \\
Industry Fixed Effects & & & $\mathrm{Y}$ & $\mathrm{Y}$ & $\mathrm{Y}$ & $\mathrm{Y}$ \\
S936 Exposed Sector & & & $\mathrm{Y}$ & $\mathrm{Y}$ & $\mathrm{Y}$ \\
S936 Exposed Industry & & & & $\mathrm{Y}$ & $\mathrm{Y}$ \\
DFL Weights & & & & & $\mathrm{Y}$ \\
\hline \hline
\end{tabular}

Notes: Author's calculations using data from COMPUSTAT Historical Segments. This table shows estimates of Equation 3 where Exposure to Section 936 X Post is an indicator at the firm level for exposed firms interacted with an indicator for years after 1995. Consistent with the hypothesis that multinationals shifted investment abroad, we see that exposed firms saw an increase in the fraction of foreign investment following the repeal of $\S 936$. Yearly coefficients are shown graphically in Figure 6. See Section 5 for more discussion. Standard errors clustered at the firm level are shown in parentheses with p-values below.

\section{Table 5: Effects of Exposure to $§ 936$ on Industry-State-Level Capital Expenditures}

\begin{tabular}{lccccc}
\hline \hline Growth in Capital Expenditures & $(1)$ & $(2)$ & $(3)$ & $(4)$ & $(5)$ \\
\hline \multicolumn{1}{c}{ Exposure to Section 936 X Post } & -0.735 & -0.736 & -0.726 & -0.684 & -0.659 \\
& $(0.209)$ & $(0.207)$ & $(0.212)$ & $(0.188)$ & $(0.285)$ \\
& 0.001 & 0.001 & 0.001 & 0.001 & 0.025 \\
\hline Observations & 10694 & 10694 & 10694 & 10694 & 10694 \\
Year Fixed Effects & Yes & Yes & Yes & & \\
Industry Fixed Effects & Yes & Yes & & & \\
State Fixed Effects & & Yes & & & \\
State X Industry Fixed Effects & & & Yes & Yes & Yes \\
Year X State Fixed Effects & & & & Yes & \\
Year X Industry Fixed Effects & & & & & Yes \\
\hline \hline
\end{tabular}

Notes: Author's calculations using data from NETS and the Annual Survey of Manufactures. This table displays the estimates of Equation 4 where exposure to $\S 936$ is the proportion of establishments in each state-industry divided by the interquartile range. Exposure to Section $936 \mathrm{X}$ Post is an indicator at the firm level for exposed firms interacted with an indicator for years after 1995. Following the repeal of $\S 936$, we see a persistent decline in the flow of investment in state-industries with more exposure to $§ 936$. The yearly estimates are shown graphically in Figure 5. See Section 5 for more information. Standard errors clustered at the state level are shown in parentheses with p-values below. 
Table 6: Event Study on Employment Growth

\begin{tabular}{|c|c|c|c|c|c|c|c|}
\hline Exposure to Section 936 & $(1)$ & $(2)$ & $(3)$ & $(4)$ & $(5)$ & $(6)$ & $(7)$ \\
\hline \multirow[t]{2}{*}{ X 1990} & 0.000 & 0.000 & 0.000 & 0.007 & -0.007 & -0.001 & -0.011 \\
\hline & $(0.015)$ & $(0.015)$ & $(0.015)$ & $(0.011)$ & $(0.019)$ & (0.015) & $(0.016)$ \\
\hline \multirow[t]{2}{*}{ X 1991} & -0.001 & -0.001 & -0.001 & 0.004 & -0.008 & -0.003 & -0.009 \\
\hline & $(0.012)$ & $(0.012)$ & $(0.012)$ & (0.009) & $(0.016)$ & $(0.012)$ & $(0.012)$ \\
\hline \multirow[t]{2}{*}{ X 1992} & 0.001 & 0.001 & 0.001 & 0.005 & -0.003 & -0.000 & -0.005 \\
\hline & $(0.008)$ & (0.008) & (0.008) & $(0.006)$ & (0.011) & (0.008) & $(0.007)$ \\
\hline \multirow{2}{*}{ X 1993} & 0.002 & 0.002 & 0.002 & 0.003 & -0.001 & 0.001 & -0.000 \\
\hline & $(0.005)$ & $(0.005)$ & $(0.005)$ & $(0.004)$ & $(0.006)$ & $(0.005)$ & $(0.005)$ \\
\hline \multirow[t]{2}{*}{ X 1994} & 0.001 & 0.001 & 0.001 & 0.002 & 0.000 & 0.000 & -0.000 \\
\hline & $(0.002)$ & $(0.002)$ & $(0.002)$ & $(0.002)$ & $(0.003)$ & $(0.002)$ & $(0.002)$ \\
\hline \multirow[t]{2}{*}{ X 1996} & -0.004 & -0.004 & -0.004 & -0.004 & -0.005 & -0.003 & -0.004 \\
\hline & $(0.002)$ & $(0.002)$ & $(0.002)$ & $(0.002)$ & $(0.003)$ & $(0.002)$ & $(0.003)$ \\
\hline \multirow[t]{2}{*}{ X 1997} & $-0.009^{*}$ & $-0.009^{*}$ & $-0.009^{*}$ & $-0.008^{*}$ & -0.009 & -0.006 & -0.007 \\
\hline & $(0.004)$ & $(0.004)$ & $(0.004)$ & $(0.003)$ & $(0.005)$ & $(0.004)$ & $(0.005)$ \\
\hline \multirow[t]{2}{*}{ X 1998} & $-0.014^{* *}$ & $-0.014^{* *}$ & $-0.014^{* *}$ & $-0.013^{* *}$ & $-0.015^{*}$ & $-0.010^{*}$ & $-0.012^{*}$ \\
\hline & $(0.005)$ & $(0.005)$ & $(0.005)$ & $(0.005)$ & $(0.007)$ & $(0.005)$ & $(0.006)$ \\
\hline \multirow[t]{2}{*}{ X 1999} & $-0.017^{*}$ & $-0.017^{*}$ & $-0.017^{*}$ & $-0.017^{* *}$ & $-0.018^{*}$ & -0.012 & -0.013 \\
\hline & $(0.006)$ & $(0.007)$ & $(0.006)$ & $(0.006)$ & $(0.008)$ & $(0.006)$ & $(0.008)$ \\
\hline \multirow[t]{2}{*}{ X 2000} & $-0.026^{* *}$ & $-0.026^{* *}$ & $-0.026^{* *}$ & $-0.025^{* *}$ & $-0.029^{* *}$ & $-0.021^{* *}$ & $-0.023^{*}$ \\
\hline & $(0.008)$ & $(0.008)$ & $(0.008)$ & $(0.007)$ & $(0.010)$ & $(0.008)$ & $(0.009)$ \\
\hline \multirow[t]{2}{*}{ X 2001} & $-0.033^{* * *}$ & $-0.033^{* * *}$ & $-0.033^{* * *}$ & $-0.032^{* * *}$ & $-0.039^{* *}$ & $-0.034^{* *}$ & $-0.030^{*}$ \\
\hline & $(0.009)$ & (0.009) & $(0.009)$ & (0.009) & $(0.012)$ & $(0.011)$ & $(0.013)$ \\
\hline \multirow[t]{2}{*}{ X 2002} & $-0.041^{* * *}$ & $-0.041^{* * *}$ & $-0.041^{* * *}$ & $-0.039^{* * *}$ & $-0.045^{* *}$ & $-0.039^{* *}$ & $-0.032^{*}$ \\
\hline & $(0.011)$ & $(0.011)$ & $(0.011)$ & $(0.011)$ & $(0.014)$ & $(0.012)$ & $(0.015)$ \\
\hline \multirow[t]{2}{*}{ X 2003} & $-0.046^{* * *}$ & $-0.046^{* * *}$ & $-0.046^{* * *}$ & $-0.044^{* * *}$ & $-0.051^{* *}$ & $-0.045^{* *}$ & $-0.036^{*}$ \\
\hline & $(0.012)$ & $(0.012)$ & $(0.012)$ & $(0.012)$ & $(0.016)$ & $(0.013)$ & $(0.016)$ \\
\hline \multirow[t]{2}{*}{ X 2004} & $-0.058^{* * *}$ & $-0.058^{* * *}$ & $-0.058^{* * *}$ & $-0.055^{* * *}$ & $-0.065^{* * *}$ & $-0.056^{* * *}$ & $-0.048^{*}$ \\
\hline & (0.014) & $(0.014)$ & $(0.014)$ & (0.014) & (0.018) & $(0.015)$ & $(0.019)$ \\
\hline \multirow[t]{2}{*}{ X 2005} & $-0.069^{* * *}$ & $-0.069^{* * *}$ & $-0.069^{* * *}$ & $-0.065^{* * *}$ & $-0.078^{* * *}$ & $-0.067^{* * *}$ & $-0.059^{* *}$ \\
\hline & (0.017) & $(0.018)$ & $(0.017)$ & (0.017) & $(0.022)$ & $(0.018)$ & $(0.022)$ \\
\hline \multirow[t]{2}{*}{ X 2006} & $-0.078^{* * *}$ & $-0.078^{* * *}$ & $-0.078^{* * *}$ & $-0.073^{* * *}$ & $-0.087^{* *}$ & $-0.077^{* * *}$ & $-0.068^{* *}$ \\
\hline & $(0.020)$ & $(0.020)$ & $(0.020)$ & $(0.019)$ & $(0.026)$ & $(0.020)$ & $(0.024)$ \\
\hline \multirow[t]{2}{*}{ X 2007} & $-0.078^{* * *}$ & $-0.078^{* * *}$ & $-0.078^{* * *}$ & $-0.073^{* * *}$ & $-0.087^{* *}$ & $-0.077^{* * *}$ & $-0.067^{* *}$ \\
\hline & $(0.021)$ & $(0.021)$ & $(0.021)$ & $(0.019)$ & $(0.026)$ & $(0.022)$ & $(0.025)$ \\
\hline \multirow[t]{2}{*}{ X 2008} & $-0.077^{* * *}$ & $-0.077^{* * *}$ & $-0.077^{* * *}$ & $-0.072^{* * *}$ & $-0.085^{* *}$ & $-0.077^{* * *}$ & $-0.066^{* *}$ \\
\hline & $(0.020)$ & $(0.020)$ & $(0.020)$ & $(0.018)$ & $(0.025)$ & $(0.022)$ & $(0.024)$ \\
\hline \multirow[t]{2}{*}{ X 2009} & $-0.071^{* * *}$ & $-0.071^{* * *}$ & $-0.071^{* * *}$ & $-0.066^{* * *}$ & $-0.078^{* *}$ & $-0.073^{* * *}$ & $-0.062^{* *}$ \\
\hline & (0.018) & $(0.018)$ & $(0.018)$ & $(0.016)$ & $(0.023)$ & $(0.020)$ & $(0.022)$ \\
\hline X 2010 & $-0.070^{* * *}$ & $-0.070^{* * *}$ & $-0.070^{* * *}$ & $-0.065^{* * *}$ & $-0.076^{* *}$ & $-0.072^{* * *}$ & $-0.058^{* *}$ \\
\hline & $(0.018)$ & $(0.018)$ & $(0.018)$ & $(0.016)$ & $(0.023)$ & $(0.020)$ & $(0.021)$ \\
\hline X 2011 & $-0.073^{* * *}$ & $-0.073^{* * *}$ & $-0.073^{* * *}$ & $-0.069^{* * *}$ & $-0.080^{* *}$ & $-0.076^{* * *}$ & $-0.061^{* *}$ \\
\hline & (0.018) & (0.018) & $(0.018)$ & $(0.016)$ & $(0.024)$ & $(0.021)$ & $(0.021)$ \\
\hline X 2012 & $-0.078^{* * *}$ & $-0.078^{* * *}$ & $-0.078^{* * *}$ & $-0.073^{* * *}$ & $-0.087^{* * *}$ & $-0.082^{* * *}$ & $-0.066^{* *}$ \\
\hline & $(0.019)$ & $(0.019)$ & $(0.019)$ & $(0.018)$ & $(0.025)$ & $(0.022)$ & $(0.022)$ \\
\hline Year by Industry Fixed Effects & $\mathrm{Y}$ & $\mathrm{Y}$ & $\mathrm{Y}$ & $\mathrm{Y}$ & $\mathrm{Y}$ & $\mathrm{Y}$ & $\mathrm{Y}$ \\
\hline Location Fixed Effects & & Y & & & & & \\
\hline Industry-by-County Fixed Effects & & & Y & & & & \\
\hline Winsorized Weights & & & & $\mathrm{Y}$ & & & \\
\hline Drops Small County-Industries $(<1000)$ & & & & & Y & & \\
\hline Conspuma Geography & & & & & & Y & \\
\hline Commuting Zone Geography & & & & & & & Y \\
\hline
\end{tabular}

Notes: This table displays estimates of Equation 6, which are shown in Figure 11. Observations are county-industries in each year. Exposure to Section 936 comes from the NETS, and employment growth comes from QCEW (2017). See Section 5 for discussion and Appendix A for more information about the data. Standard errors clustered at the state and industry levels are shown in parentheses. Observations are weighted by employment in $1995 .{ }^{*} p<0.05,{ }^{* *}$ $p<0.01,{ }^{* * *} p<0.001$. 
Table 7: Event Study on Employment Growth: Additional Specifications

\begin{tabular}{|c|c|c|c|c|c|c|}
\hline Exposure to Section 936 & $\overline{(\overline{(1)}}$ & (2) & $(3)$ & (4) & $(5)$ & (6) \\
\hline \multirow[t]{2}{*}{ X 1990} & 0.000 & 0.001 & 0.001 & 0.005 & -0.013 & -0.011 \\
\hline & $(0.017)$ & $(0.015)$ & $(0.015)$ & $(0.013)$ & $(0.012)$ & $(0.013)$ \\
\hline \multirow[t]{2}{*}{ X 1991} & -0.002 & -0.001 & -0.001 & 0.004 & -0.010 & -0.000 \\
\hline & $(0.014)$ & $(0.012)$ & $(0.012)$ & $(0.010)$ & $(0.009)$ & $(0.009)$ \\
\hline \multirow{2}{*}{ X 1992} & 0.001 & 0.001 & 0.001 & 0.006 & -0.005 & 0.001 \\
\hline & $(0.010)$ & $(0.008)$ & $(0.008)$ & $(0.007)$ & $(0.005)$ & $(0.006)$ \\
\hline \multirow[t]{2}{*}{ X 1993} & 0.002 & 0.002 & 0.002 & 0.005 & -0.002 & -0.000 \\
\hline & $(0.006)$ & $(0.005)$ & $(0.005)$ & $(0.004)$ & $(0.003)$ & $(0.005)$ \\
\hline \multirow{2}{*}{ X 1994} & 0.001 & 0.001 & 0.001 & 0.003 & -0.001 & -0.002 \\
\hline & $(0.002)$ & $(0.002)$ & $(0.002)$ & $(0.002)$ & $(0.002)$ & $(0.004)$ \\
\hline \multirow[t]{2}{*}{ X 1996} & -0.005 & -0.004 & -0.005 & $-0.004^{*}$ & $-0.004^{*}$ & $-0.009^{*}$ \\
\hline & $(0.003)$ & $(0.002)$ & $(0.002)$ & $(0.002)$ & $(0.002)$ & $(0.004)$ \\
\hline \multirow[t]{2}{*}{ X 1997} & $-0.011^{*}$ & $-0.009^{*}$ & $-0.010^{*}$ & $-0.009^{*}$ & -0.005 & $-0.015^{* *}$ \\
\hline & $(0.005)$ & $(0.004)$ & $(0.004)$ & $(0.003)$ & $(0.003)$ & $(0.005)$ \\
\hline \multirow[t]{2}{*}{ X 1998} & $-0.017^{* *}$ & $-0.015^{* *}$ & $-0.015^{* *}$ & $-0.014^{* *}$ & -0.006 & $-0.019^{* *}$ \\
\hline & $(0.006)$ & $(0.005)$ & $(0.005)$ & $(0.004)$ & $(0.004)$ & $(0.006)$ \\
\hline \multirow[t]{2}{*}{ X 1999} & $-0.020^{* *}$ & $-0.018^{* *}$ & $-0.018^{* *}$ & $-0.016^{* *}$ & -0.007 & $-0.021^{* *}$ \\
\hline & $(0.008)$ & $(0.007)$ & $(0.007)$ & $(0.005)$ & $(0.005)$ & $(0.007)$ \\
\hline \multirow[t]{2}{*}{ X 2000} & $-0.031^{* *}$ & $-0.027^{* *}$ & $-0.028^{* * *}$ & $-0.024^{* * *}$ & $-0.013^{*}$ & $-0.023^{*}$ \\
\hline & $(0.009)$ & $(0.008)$ & $(0.008)$ & $(0.006)$ & $(0.005)$ & $(0.009)$ \\
\hline \multirow[t]{2}{*}{ X 2001} & $-0.040^{* * *}$ & $-0.034^{* * *}$ & $-0.035^{* * *}$ & $-0.030^{* * *}$ & $-0.020^{* *}$ & $-0.026^{*}$ \\
\hline & $(0.011)$ & $(0.009)$ & $(0.010)$ & $(0.008)$ & $(0.007)$ & $(0.010)$ \\
\hline \multirow[t]{2}{*}{ X 2002} & $-0.048^{* * *}$ & $-0.042^{* * *}$ & $-0.043^{* * *}$ & $-0.037^{* * *}$ & $-0.028^{* *}$ & $-0.029^{* *}$ \\
\hline & $(0.013)$ & $(0.011)$ & $(0.011)$ & $(0.010)$ & $(0.008)$ & $(0.009)$ \\
\hline \multirow[t]{2}{*}{ X 2003} & $-0.055^{* * *}$ & $-0.047^{* * *}$ & $-0.048^{* * *}$ & $-0.042^{* * *}$ & $-0.032^{* * *}$ & $-0.034^{* * *}$ \\
\hline & $(0.014)$ & $(0.012)$ & $(0.013)$ & $(0.011)$ & $(0.009)$ & $(0.009)$ \\
\hline \multirow[t]{2}{*}{ X 2004} & $-0.069^{* * *}$ & $-0.059^{* * *}$ & $-0.060^{* * *}$ & $-0.052^{* * *}$ & $-0.040^{* * *}$ & $-0.045^{* * *}$ \\
\hline & $(0.017)$ & $(0.014)$ & $(0.015)$ & $(0.012)$ & $(0.010)$ & $(0.009)$ \\
\hline \multirow[t]{2}{*}{ X 2005} & $-0.082^{* * *}$ & $-0.070^{* * *}$ & $-0.072^{* * *}$ & $-0.062^{* * *}$ & $-0.047^{* * *}$ & $-0.049^{* * *}$ \\
\hline & $(0.021)$ & $(0.018)$ & $(0.018)$ & $(0.015)$ & $(0.011)$ & $(0.011)$ \\
\hline \multirow[t]{2}{*}{ X 2006} & $-0.092^{* * *}$ & $-0.079^{* * *}$ & $-0.081^{* * *}$ & $-0.071^{* * *}$ & $-0.054^{* * *}$ & $-0.066^{* * *}$ \\
\hline & $(0.024)$ & $(0.020)$ & $(0.021)$ & $(0.017)$ & $(0.013)$ & $(0.013)$ \\
\hline \multirow[t]{2}{*}{ X 2007} & $-0.093^{* * *}$ & $-0.080^{* * *}$ & $-0.081^{* * *}$ & $-0.073^{* * *}$ & $-0.055^{* * *}$ & $-0.067^{* * *}$ \\
\hline & $(0.024)$ & $(0.021)$ & $(0.021)$ & $(0.017)$ & $(0.013)$ & $(0.014)$ \\
\hline \multirow[t]{2}{*}{ X 2008} & $-0.092^{* * *}$ & $-0.079^{* * *}$ & $-0.080^{* * *}$ & $-0.072^{* * *}$ & $-0.055^{* * *}$ & $-0.065^{* * *}$ \\
\hline & $(0.023)$ & $(0.020)$ & $(0.020)$ & $(0.016)$ & $(0.013)$ & $(0.014)$ \\
\hline \multirow[t]{2}{*}{ X 2009} & $-0.085^{* * *}$ & $-0.073^{* * *}$ & $-0.074^{* * *}$ & $-0.065^{* * *}$ & $-0.053^{* * *}$ & $-0.059^{* * *}$ \\
\hline & $(0.021)$ & $(0.018)$ & $(0.018)$ & $(0.015)$ & $(0.014)$ & $(0.012)$ \\
\hline X 2010 & $-0.083^{* * *}$ & $-0.072^{* * *}$ & $-0.073^{* * *}$ & $-0.065^{* * *}$ & $-0.051^{* *}$ & $-0.058^{* * *}$ \\
\hline & $(0.021)$ & $(0.018)$ & $(0.018)$ & $(0.015)$ & $(0.015)$ & $(0.012)$ \\
\hline X 2011 & $-0.087^{* * *}$ & $-0.075^{* * *}$ & $-0.076^{* * *}$ & $-0.068^{* * *}$ & $-0.051^{* *}$ & $-0.060^{* * *}$ \\
\hline & $(0.021)$ & $(0.018)$ & $(0.018)$ & $(0.015)$ & $(0.015)$ & $(0.013)$ \\
\hline X 2012 & $-0.093^{* * *}$ & $-0.080^{* * *}$ & $-0.081^{* * *}$ & $-0.073^{* * *}$ & $-0.054^{* * *}$ & $-0.063^{* * *}$ \\
\hline & $(0.023)$ & $(0.020)$ & $(0.019)$ & $(0.016)$ & $(0.015)$ & $(0.014)$ \\
\hline Year Fixed Effects & $\mathrm{Y}$ & $\mathrm{Y}$ & $\mathrm{Y}$ & $\mathrm{Y}$ & $\mathrm{Y}$ & $\mathrm{Y}$ \\
\hline Year by Industry Fixed Effects & Y & Y & Y & Y & & \\
\hline Employment Instrument & Y & & & & & \\
\hline Large Retailers Dropped from Links & & Y & & & & \\
\hline No US Headquarter Dropped from Links & & & Y & & & \\
\hline Only Compustat Sample Links & & & & Y & & \\
\hline Employment Growth Per Capita & & & & & Y & \\
\hline Manufacturing Employment Per Capita & & & & & & Y \\
\hline
\end{tabular}

Notes: This table displays estimates of Equation 6, which are shown in Figure 11. Observations are county-industries in each year. Exposure to Section 936 comes from the NETS, and employment growth comes from QCEW (2017). See Section 5 for discussion and Appendix A for more information about the data. Standard errors clustered at the state and industry levels are shown in parentheses. ${ }^{*} p<0.05,{ }^{* *} p<0561,{ }^{* * *} p<0.001$. Observations are weighted by employment in 1995. 
Table 8: Effects of Repealing $§ 936$ on Employment and Income Growth

\begin{tabular}{|c|c|c|c|c|c|c|c|c|c|c|}
\hline \multirow{3}{*}{$\begin{array}{l}\text { Geography } \\
\text { Data Source } \\
\text { Years: 2004-2008 }\end{array}$} & \multicolumn{5}{|c|}{ Employment Growth } & \multicolumn{5}{|c|}{ Income Growth } \\
\hline & \multicolumn{3}{|c|}{ County } & \multirow{2}{*}{$\begin{array}{l}\text { Conspuma } \\
\text { QCEW } \\
(4)\end{array}$} & \multirow{2}{*}{$\begin{array}{l}\text { C-Zone } \\
\text { QCEW } \\
(5)\end{array}$} & \multicolumn{3}{|c|}{ County } & \multirow{2}{*}{$\begin{array}{c}\text { Conspuma } \\
\text { QCEW } \\
(9)\end{array}$} & \multirow{2}{*}{$\begin{array}{c}\text { C-Zone } \\
\text { QCEW } \\
(10)\end{array}$} \\
\hline & IRS & BEA & $\overline{\mathrm{QCEW}}$ & & & IRS & $\mathrm{BEA}$ & $\overline{\mathrm{QCEW}}$ & & \\
\hline \multirow[t]{3}{*}{ Exposure to Section 936} & -0.057 & -0.092 & -0.072 & -0.071 & -0.062 & -0.133 & -0.111 & -0.125 & -0.121 & -0.124 \\
\hline & $(0.012)$ & $(0.015)$ & $(0.018)$ & $(0.019)$ & $(0.022)$ & $(0.025)$ & $(0.024)$ & $(0.033)$ & $(0.033)$ & $(0.039)$ \\
\hline & 0.000 & 0.000 & 0.000 & 0.001 & 0.007 & 0.000 & 0.000 & 0.000 & 0.001 & 0.002 \\
\hline \multirow[t]{3}{*}{ Exposure to Section 936} & 0.005 & 0.006 & 0.000 & -0.001 & -0.004 & -0.000 & -0.003 & -0.004 & -0.005 & -0.009 \\
\hline & $(0.004)$ & $(0.004)$ & $(0.007)$ & $(0.007)$ & $(0.007)$ & $(0.006)$ & $(0.004)$ & $(0.007)$ & $(0.007)$ & $(0.007)$ \\
\hline & 0.197 & 0.148 & 0.952 & 0.932 & 0.527 & 0.994 & 0.541 & 0.569 & 0.504 & 0.198 \\
\hline Year Fixed Effects & Yes & Yes & Yes & Yes & Yes & Yes & Yes & Yes & Yes & Yes \\
\hline
\end{tabular}

Notes: This table shows county, conspuma, and commuting zone level regression estimates of the effect of exposure to Section 936 on employment growth in (1) to (5) and income growth in (6) to (10) before and after the rollback of Section 936 in the upper and lower panels, respectively. Exposure to Section 936 comes from the NETS, while employment and income growth come from the IRS SOI, the BEA, and QCEW (2017) for columns (1) and (6), (2) and (7), and (3) to (5) and (8) to (10). See Section 5 for discussion and Appendix A for more information about the data. The QCEW regressions also include industry fixed effects in addition to the year fixed effects in all columns. Standard errors clustered at the state and industry levels are shown in parentheses with p-values displayed below. The independent variable of interest is the IQR-adjusted exposure to $\S 936$ at the county level, so the estimates mean that an IQR increase in exposure to $\$ 936$ is associated with a $7.2 \%$ decrease in employment and a $12.5 \%$ decrease in income according to columns (3) and (8). The lower panel fails to find evidence of any pre-trends using conventional levels of statistical significance. 
Table 9: Effects of Repealing $§ 936$ on Wages, Rental Costs, and Home Values

\begin{tabular}{|c|c|c|c|c|c|}
\hline & (1) & $(2)$ & $(3)$ & $(4)$ & $(5)$ \\
\hline \multicolumn{6}{|c|}{ Stacked Differences After 1990} \\
\hline & \multicolumn{3}{|c|}{ Wages } & & \\
\hline & All & High Skill & Low Skill & Rent & Home Value \\
\hline \multirow[t]{3}{*}{ Exposure to Section 936} & -0.010 & -0.006 & -0.014 & -0.018 & -0.025 \\
\hline & $(0.002)$ & $(0.002)$ & $(0.002)$ & $(0.004)$ & $(0.008)$ \\
\hline & 0.000 & 0.003 & 0.000 & 0.000 & 0.002 \\
\hline Observations & 984 & 984 & 984 & 984 & 984 \\
\hline Year Fixed Effects & Yes & Yes & Yes & Yes & Yes \\
\hline State Fixed Effects & Yes & Yes & Yes & Yes & Yes \\
\hline \multicolumn{6}{|l|}{ Differences Before 1990} \\
\hline & \multicolumn{3}{|c|}{ Wages } & & \\
\hline & All & High Skill & Low Skill & Rent & Home Value \\
\hline \multirow[t]{3}{*}{ Exposure to Section 936} & 0.006 & 0.005 & 0.004 & 0.032 & 0.034 \\
\hline & $(0.008)$ & $(0.005)$ & $(0.008)$ & $(0.012)$ & $(0.024)$ \\
\hline & 0.475 & 0.376 & 0.660 & 0.012 & 0.160 \\
\hline Observations & 492 & 492 & 492 & 492 & 492 \\
\hline Year Fixed Effects & Yes & Yes & Yes & Yes & Yes \\
\hline State Fixed Effects & Yes & Yes & Yes & Yes & Yes \\
\hline
\end{tabular}

Notes: Estimates in this table come from regressions of economic outcomes at the conspuma level on the exposure to Section 936 scaled by the IQR. Exposure to Section 936 comes from the NETS, and conspuma-level outcomes are from the Census (Ruggles et al., 2010). These regressions use the adjusted values of the outcomes. See Section 5 for discussion and Appendix A for more information about the data. Standard errors clustered at the state level are shown in parentheses with p-values displayed below. Additional specifications are shown in Table A.27. Observations are weighted according to population. 
Table 10: Effects of Repealing $§ 936$ on Government Transfer Payments Per Capita, 2004-2008

\begin{tabular}{|c|c|c|c|c|c|c|c|}
\hline & $\begin{array}{c}\text { Total } \\
\text { Transfers } \\
(1)\end{array}$ & $\begin{array}{c}\text { Unem- } \\
\text { ployment } \\
\text { Benefits } \\
(2)\end{array}$ & $\begin{array}{c}\text { Income } \\
\text { Replace- } \\
\text { ment } \\
(3)\end{array}$ & $\begin{array}{c}\text { Educ- } \\
\text { ation } \\
\text { Benefits } \\
(4)\end{array}$ & $\begin{array}{l}\text { Retire- } \\
\text { ment and } \\
\text { Disability } \\
(5)\end{array}$ & $\begin{array}{c}\text { Medicare } \\
\text { Benefits } \\
(6)\end{array}$ & $\begin{array}{c}\text { Public } \\
\text { Medical } \\
\text { Benefits } \\
(7)\end{array}$ \\
\hline \multicolumn{8}{|c|}{ Panel A. Percent change in transfers per capita relative to 1995} \\
\hline \multirow[t]{2}{*}{ Exposure to Section 936} & $\begin{array}{c}0.025 \\
(0.016)\end{array}$ & $\begin{array}{c}0.254 \\
(0.066)\end{array}$ & $\begin{array}{c}0.101 \\
(0.030)\end{array}$ & $\begin{array}{c}0.075 \\
(0.062)\end{array}$ & $\begin{array}{c}0.005 \\
(0.016)\end{array}$ & $\begin{array}{l}-0.007 \\
(0.026)\end{array}$ & $\begin{array}{c}0.014 \\
(0.029)\end{array}$ \\
\hline & 0.128 & 0.000 & 0.001 & 0.232 & 0.777 & 0.780 & 0.638 \\
\hline \multicolumn{8}{|c|}{ Panel B. Dollar change in transfers per capita relative to 1995} \\
\hline \multirow[t]{2}{*}{ Exposure to Section 936} & $\begin{array}{c}6.426 \\
(41.776)\end{array}$ & $\begin{array}{l}15.883 \\
(3.289)\end{array}$ & $\begin{array}{l}30.214 \\
(5.449)\end{array}$ & $\begin{array}{c}6.439 \\
(2.995)\end{array}$ & $\begin{array}{c}1.527 \\
(19.083)\end{array}$ & $\begin{array}{l}-14.324 \\
(13.078)\end{array}$ & $\begin{array}{l}-26.040 \\
(40.346)\end{array}$ \\
\hline & 0.878 & 0.000 & 0.000 & 0.037 & 0.937 & 0.279 & 0.522 \\
\hline Sample Proportion of Transfers & $97.2 \%$ & $1.9 \%$ & $9.6 \%$ & $1.7 \%$ & $38.5 \%$ & $25.1 \%$ & $18.6 \%$ \\
\hline Sample Transfers Per Capita & $6,040.1$ & 114.1 & 596.6 & 103.7 & $2,358.8$ & $1,570.5$ & $1,176.6$ \\
\hline Year Fixed Effects & Yes & Yes & Yes & Yes & Yes & Yes & Yes \\
\hline
\end{tabular}

Notes: Estimates in this table come from regressions of government transfers in each category at the county level on the exposure to Section 936. The upper panel shows the results with the dependent variable measured in percent change per capita, while the lower panel shows results with the dependent variable measured in change in dollars per capita. Exposure to Section 936 comes from the NETS, and county-level transfers come from the BEA local area personal income accounts (Bureau of Economic Analysis, 2018). Column (1) includes all transfers in columns (2) to (7), which do not include veteran's benefits, and covers $97.2 \%$ of all personal income transfers reported in Bureau of Economic Analysis (2018). Column (2) shows a positive effect on the dependent variable of unemployment insurance compensation, while Columns (3) and (4) show positive effects on income maintenance payments, including SSI and the Earned Income Tax Credit, and education and training assistance programs. Columns (5)-(7) show statistically insignificant effects on retirement and disability benefits programs, which includes most Social Security Administration payments except for Supplemental Security Income (SSI), Medicare payments, or public assistance medical benefits. See Appendix A for more information about the data. Clustered standard errors are shown in parentheses with p-values displayed below. Analogous regressions for the 1990-1995 period in Table A.28 show statistically insignificant pre-trends. 


\section{Online Appendix: Not For Publication}

This appendix includes supplemental information and additional analyses. Appendix A describes the data sources. Appendix B describes how the repeal of $\S 936$ affected the effective tax rates of US firms. Appendix $\mathrm{C}$ shows that exposed firms experienced a decline in firm value following news of the repeal of $\S 936$. Appendix D proves the propositions of the model. Appendix E describes how changes in investment accumulate into changes in capital stocks over time. Appendix F characterizes heterogeneous effects of the repeal of $\S 936$ on local employment growth.

\section{A Data Appendix}

\section{A.1 Data Sources}

The size of the actual tax expenditure incurred by 26 U.S.C. $\S 936$ (1976) is provided at the three-digit NAICS code level by the IRS (IRS, 2017a). The SOI reports for corporations include the aggregate expenditure for the "US Possessions Tax Credit" up until the end of the phaseout in 2007. These data also include total revenues, net income, tax liabilities before and after deductions and credits, and several other enumerated federal corporate tax credits.

The primary data on the location of business establishments and employment comes from the National Establishment Time-Series (NETS) database from 1990-2010 (Walls \& Associates, 2012). NETS contains the Duns and Bradstreet historical establishment data that is transformed into a time-series database. Of particular interest for this project, the data include the location of business establishments, employment at the establishment level, and links to firm headquarters. Other information includes relocations, estimated firm sales, counts of establishments, credit scores, active years, industries, and other indicators. The NETS data are supplemented with information about counties in the US.

This paper uses firm-specific data to measure the response of businesses and equity markets to the repeal. The firms with establishments in Puerto Rico that are identified in NETS are merged with information from the Compustat Historical Segments databases (Capital IQ, 19802014). Compustat data comes from public filings for publicly traded firms and includes values reported in annual 10-Ks regarding segment operation and financial statements. The financial information is reported on an annual basis. As in Rao (2015), we exploit the fact that the data allow investment to be separated into domestic and foreign segments. Stock returns surrounding the repeal of Section 936 come from CRSP Stocks (1990-1996) and other market indicators for use in an event study methodology come from Fama and French (1993). The CRSP data 
include daily returns for every publicly traded stock in the US for each active trading day. The Fama-French data includes weighted portfolios of returns to capture different types of market risk.

Data on manufacturing investment come from the Annual Survey of Manufacturers (ASM) through the Census Bureau. Data for 1997-2010 come from Ohrn (2017) while data for 19871995 come from Annual Survey of Manufacturers (1997). We combine data from the 1987-2006 surveys at the NAICS three digit level. We use the Census crosswalk between SIC codes and NAICS codes for years 1987-1995.

This paper uses data gathered by Suárez Serrato and Wingender (2016) from the Bureau of Economic Analysis, the Bureau of Labor Statistics, and the Internal Revenue Service. For each county, data on personal income and employment come from the Bureau of Economic Analysis' Regional Economic Information System (REIS) (Bureau of Economic Analysis, 2010). Employment and earnings at the industry and county level come from the Quarterly Census of Employment and Wages (QCEW) produced by the Bureau of Labor Statistics (BLS). The QCEW is made up of the universe of jobs covered by state unemployment insurance systems (QCEW, 2017). It accounts for more than $94 \%$ of total wages reported by the Bureau of Economic Analysis. Income by source comes from the IRS Statistics of Income (SOI) publications from 1989-2009 (IRS, 2017b). The SOI data include a breakdown of income at the county level into gross incomes, salaries, dividends, and interest, which allows changes in county income to be connected to the source of the income. This project also uses data from the Census Bureau. Skill specific outcomes including wages and rents come from calculations done by Suárez Serrato and Wingender (2014) using IPUMS (Ruggles et al., 2010). This includes skill specific values of log-wages, log-rents, and log-housing values. Other information from IPUMS includes aggregate values of population, employment, income, and earnings.

In order to calculate capital stock at the county level, we use the local QCEW earnings data at the industry level in conjunction with aggregate capital stock in the US by industry from the Bureau of Economic Analysis (Bureau of Economic Analysis, 2017). We then use two digit NAICS codes to distribute each industry's national capital stock across counties to match the distribution of employment across counties in the QCEW. The total capital stock for each county is then computed by summing across all of the industries in that county.

Data on the local import exposure from China comes from Autor et al. (2016). The main variable is import exposure per worker. The share of labor in "routine jobs" was gathered by Autor and Dorn (2013). An indicator of whether a state is a "right to work" state in 1984 is collected from Valletta and Freeman (1988). Data regarding income transfers from governments to individuals come from the Bureau of Economic Analysis Local Area Personal Income Accounts 
(Bureau of Economic Analysis, 2018). These data include county level transfers disaggregated by program. We use the following categories: Retirement and disability insurance benefits, Medicare benefits, public assistance medical care benefits, Income maintenance benefits, Unemployment insurance compensation, and Education and training assistance, which amount to over $95 \%$ of total transfers in the data.

\section{A.2 Validity of the Firm-Level Exposure Measure}

Our measure of firm-level exposure is close to estimates of take-up of $\S 936$ based on tax data. There are 682 firms that could have taken advantage of $§ 936$ in our data. ${ }^{67}$

The GAO (2006) found that a total of 656 firms ever claimed $\S 936$ credits, while Grubert and Slemrod (1998) find that 419 manufacturing firms claimed $\S 936$ credits in 1987. Similarly, GAO (1993) shows that $§ 936$ firms had 105,000 workers in Puerto Rico in 1989, which is comparable to our estimate of 140,000 in 1990. To the extent that our measure of exposure to $\S 936$ is a slight upper bound, our estimates may be considered an intent-to-treat, and would represent a lower bound on the true effect. As we discuss in the paper, we conduct a number of tests to ensure that our results are robust to our definition of exposure.

We merge NETS with Compustat by firm name and then confirm and extend the merge manually. We further crawled the SEC's EDGAR database and searched for terms related to Puerto Rico, §936, and US Possessions Corporations Tax Credit in 10-K filings. We also note that a number of firms with operations in Puerto Rico are private. Overall, there are 219 exposed firms in Compustat, and we find that these firms are responsible for $69.5 \%$ of the total employment in $§ 936$ firms. It is also likely that the Compustat firms are responsible for the bulk of the $\S 936$ tax credits. The Joint Committee on Taxation (2006) notes that $\S 936$ credits were highly concentrated within $\S 936$ firms, and Grubert and Slemrod (1998) note that, in their data, $96 \%$ of the tax credits were claimed by 214 firms.

We use this matched sample from the NETS and Compustat to replicate the results of Grubert and Slemrod (1998), who study characteristics of $\S 936$ firms, and confirm that our measure of exposure captures the types of firms that actually received $\S 936$ credits. Specifically, we estimate a probit model of the likelihood that a firm is exposed to $§ 936$. Table A.29 shows that firms in the pharmaceutical industry, firms with more assets, more gross profits, and with R\&D investment were more likely to be exposed to $\S 936$. Note that, while pharmaceutical firms were more likely to claim $\S 936$ credits, only $4.2 \%$ of pharma firms in Compustat were exposed to $\S 936$.

Finally, in Appendix $\mathrm{C}$ we show that news of the repeal of $\S 936$ had negative effects on

\footnotetext{
${ }^{67}$ We conduct additional checks on our measure of exposure to $\S 936$ by manually excluding establishments in the public sector or non-profit sector.
} 
the stock prices of exposed firms. This result confirms that our firm-level measure of exposure correctly identifies firms that took advantage of $\S 936$.

\section{A.3 Matching Exposed Firms to Controls in NETS}

In order to measure the employment response of firms exposed to Section 936, we match exposed firms to a set of control firms that capture the counterfactual of how employment in these firms would have evolved if they were not exposed to the repeal of Section 936. Since the exposed firms are much larger than the average firm in the NETS, using any random set of companies as a control group is likely to lead to selection bias. For this reason, we create a matched sample of firms in NETS that are not exposed to Section 936 but are observably similar to the exposed firms.

We use the following procedure to find matches. We first identify the census region, industry defined by three digit NAICS code, employment quintile, and establishment quintile for each US-headquartered firm with at least one establishment in Puerto Rico in 1995. Since the NETS contains the universe of all firms, we are not able to run a matching algorithm on the entire

dataset. We therefore restrict the set of potential matches to include every US-headquartered firm in the NETS from the same census region and industry classification as at least one of the exposed firms. Of these firms, we restrict the sample further to match the employment and establishment quintile of the relevant exposed firm. This procedure yields a list of 21,504 firms that are headquartered in the same census region, have the same 3-digit industry, and are in the same quintile of employment and number of establishments. This ensures that we match these characteristics perfectly. For each exposed firm, we select up to 10 control firms that match these characteristics to create the control data set of 2,000 firms. We use this control sample of matched firms to identify firm level employment effects in Figure 8 and to run the placebo test on local employment outcomes in Panel A of Figure 12.

\section{A.4 Construction of DFL Weights}

To improve the comparability of firms exposed to $§ 936$ and control firms, we follow Yagan (2015) by weighting regressions according to the methods of DiNardo et al. (1996). To implement this procedure, we first estimate the probability that a firm is in Puerto Rico in 1995. We estimate this probability, $\hat{p}_{i}$, using a logit regression that controls for three digit industry fixed effects and indicators for 20 bins of firms revenue. We then use the following weights:

$$
D F L_{i}=\left(P R+(1-P R) * \frac{\hat{p}_{i}}{1-\hat{p}_{i}}\right) .
$$


These weights are equal to one for all firms in the treated sample and are larger for control firms that are more similar to the treatment firms. We use these weights as a robustness check in our regression tables.

\section{B The Effect of Repealing $§ 936$ on Effective Tax Rates}

This appendix describes how we compute the effect of repealing $§ 936$ on effective tax rates (ETRs). Gruber and Rauh (2007) and Dyreng et al. (2017) describe the numerous challenges involved in using financial statement data to compute firm-level tax rates. First, financial statement data is only available for the corporate sector. Second, reported income in financial statements can differ in important ways from taxable income. Third, firms with losses present a problem for empirical analyses and are often excluded from empirical analyses to avoid data points with negative ETRs. To avoid these problems, we follow the recommendation in Gruber and Rauh (2007) to use aggregate data from IRS (2017a) to calculate the effects on ETRs of exposed firms. As we discuss in Section 5, we obtain comparable results when analyzing the effects of the repeal on ETRs using data from financial statements.

The counterfactual question we want to answer is the following: what would the effective tax rate be for exposed firms if $\S 936$ had not been repealed? We need to solve two challenges to answer this question. First, to compute the effect on ETRs of treated firms, we need to approximate the fraction of firms that was exposed to $\S 936$. We use data on employment from NETS to calculate the fraction, $p_{i}$, of employment in a given industry that was eligible for $\S 936$ credits in 1995. Using this credit assumes that the fraction of employment is commensurate with the fraction of credits received by $\S 936$. Because larger firms were more likely to claim $\S 936$ credits (Grubert and Slemrod, 1998), this assumption likely results in a good approximation of the fraction of firms that was exposed to $\S 936$.

The second challenge to computing counterfactual ETRs is that the path of actual credits is not observed. We make two assumptions to estimate the counterfactual credits. First, we assume that the possessions tax credits would have been a constant ratio, $s_{i}$, of taxable income if $§ 936$ had not been repealed. ${ }^{68}$ Second, one possibility is that firms responded to the repeal of $\S 936$ by claiming other tax credits or deductions more aggressively. We test this hypothesis by running the following regression:

$$
E T R_{i t}=\alpha_{t}+\xi_{i}+\beta U S P_{i t}+\gamma X_{i t}+\varepsilon_{i t}
$$

The subscripts $i$ and $t$ denote industry and year, respectively. $\alpha_{t}$ is a year fixed effect and $\xi_{i}$ is an industry fixed effect. $E T R_{i t}$ is defined as corporate income taxes after credits divided by taxable

\footnotetext{
${ }^{68}$ In $1995, \S 936$ tax credits equalled $0.54 \%$ of taxable income, on average.
} 
income. $U S P_{i t}$ stands for $\S 936$ credits divided by taxable income and $X_{i t}$ includes controls for aggregate net income and sales at the industry level.

Table A.1 displays estimates of $\beta$ using data from IRS (2017a). The first three columns show specifications with and without the controls, $X_{i t}$, and that weight regressions by net income or taxable income. The latter 3 columns show the same estimates after taking first differences of the regression equation. The estimates of these regressions range from 0.718 to 0.943 , which can be interpreted as tax payments increasing by 71.8 to 94.3 cents for every dollar of $\S 936$ credits that is taken away.

Using these two assumptions, we then calculate a stream of $\S 936$ credits that would have been given to firms had the law not been repealed. Taking Taxable Income $i, t$ as observed taxable income, potential credits are credits holding the share of credits as a percent of taxable income constant are given by $\hat{s}_{i} *$ Taxable Income $_{i, t}$. Subtracting the observed $\S 936$ credits, $\S 936$ Tax Credits $_{i, t}$, and adjusting for accounting responses, the counterfactual difference in tax credits is: $\hat{\beta}\left(\S 936\right.$ Credits $_{i, t}-\hat{s}_{i} \times$ Taxable Income $\left._{i, t}\right) . \beta$ is the share of $\S 936$ credits that are not shifted to other tax credits after the repeal. We assume $\hat{\beta}=0.8$, which is in the middle of the range 0.718-0.943 shown in Table A.1. Because these credits accrue to a share of firms given by $\hat{p}_{i}$, the effect on the ETR is therefore: $\frac{\hat{\beta}\left(\S 936 \mathrm{Credits}_{i, t}-\hat{s}_{i} \times \text { Taxable Income }_{i, t}\right)}{\hat{p}_{i} \text { Taxable Income }_{i, t}}$. These calculations allow us to compute:

$$
E T R_{i, t}^{\text {Repeal }}=\frac{{\text { Taxes } \text { Paid }_{i, t}-\S 936 \text { Tax }_{\text {Credits }}, t} / \hat{p}_{i}}{\text { Taxable Income }_{i, t}}
$$

and

$$
E T R_{i, t}^{\text {No Repeal }}=E T R_{i, t}^{\text {No Repeal }}+\hat{\beta} \times \frac{\oint 936 \text { Credits }_{i, t}-\hat{s}_{i} \times \text { Taxable Income }_{i, t}}{\hat{p}_{i} \times \text { Taxable Income }_{i, t}} .
$$

We calculate the change in effective tax rates separately for three groups. We first consider the effect on all industries. Panel $\mathrm{C}$ of Figure 1 displays these counterfactual tax rates. We then compute the change in effective tax rates for "Major Sectors." These sectors included in this category are those with US Possessions Tax Credits making up more than $0.1 \%$ of taxable income (NAICS 22, 31-33, and 48-49). Finally, we also compute this quantity for "Major Industries." These industries are a subset of major sectors that omit industries within manufacturing with US Possessions Tax Credits making up less than 0.1\% of taxable income (NAICS 22, 31-33, and 48-49 omitting 321-324, 327, 331, and 336-337). We use IRS (2017a) data to estimate $s_{i}$ and NETS data to estimate $p_{i}$ for each of these subgroups. On average, we find that exposed firms saw a relative increase in ETRs of 5.727 percentage points. Across major sectors and industries, we find relatives increases in ETRs ranging from 4.653 to 6.010 percentage points. ${ }^{69}$

\footnotetext{
${ }^{69}$ Note that it is possible for the effect on ETRs to decrease in more narrow categories of industries since both $s_{i}$ and $p_{i}$ change. When restricting to major sectors, $s_{i}$ decreases by a smaller amount than $p_{i}$ so the estimator
} 


\section{Effects of Repealing $\S 936$ on Firm Value}

In this section we discuss an additional set of analyses that looks at the effects of news surrounding the repeal of $\S 936$ on market value. If investors believe the repeal of $\S 936$ will increase a firm's tax obligations, news of the repeal may reduce the stock price of exposed firms. ${ }^{70}$ We look at the initial proposal to eliminate $§ 936$ as well as the date when the drafting of the legislation was announced. President Clinton first announced on February 16, 1993 that he wanted to limit the use of $\S 936$. Since this is the first mention of repeal, it is likely to have the largest effect on expectations. The US House of Representatives started writing the final bill to eliminate $\S 936$ on October 12, 1995.

We use an event study methodology (MacKinlay, 1997), where we estimate a regression explaining the return of firm $f$ at date $t, R_{f t}$ :

$$
R_{f t}=X_{t} \beta_{f}+\gamma E_{f t}(k)+\epsilon_{f t}
$$

where $X_{t} \beta_{f}$ includes market returns minus the risk free rate. $\gamma$ is the parameter of interest and is equal to the Cumulative Abnormal Return (CAR) of firms exposed to $§ 936 .{ }^{71}$ Table A.30 reports results of this regression. Figure A.18 plots the results of this estimation where we pool both event dates. The graph shows that firms exposed to $\S 936$ saw CAR of $-1.4 \%$ between days $(0,12)$.

While we find a negative CAR on average, it is likely that more intangible intensive firms experience larger declines in values, as these are the kinds of firms that can benefit from profit shifting. Grubert and Slemrod (1998) suggest that firms with higher R\&D intensity, advertising expenditures, and gross profits to sales are more likely to benefit from profit shifting. The intuition for the first two ratios is that firms that rely more on intangible capital will spend more on $R \& D$ and advertising. The intuition for the gross profits ratio is that a firm must first be profitable in order to shift its profits to low tax locations.

Table A.31 analyzes heterogeneous effects on firm value by regressing the CAR measures between 0-10 days on firm characteristics. The constant in this regression measures the average

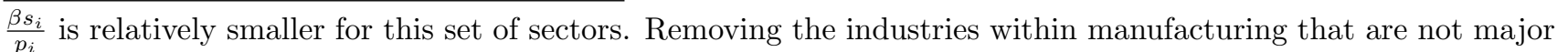
users of US Possessions Tax Credits has the opposite effect on the estimate because $p_{i}$ decreases relatively more than $s_{i}$.

${ }^{70}$ Consistent with this hypothesis, Desai and Hines (2002) find that firms experience an increase in stock prices in response to the announcement that a firm will perform a corporate inversion. Note that Desai and Dharmapala (2009) argue that agency problems complicate the relation between tax planning and firm value. In addition, Johannesen and Stolper (2017) find that announcements that a firm has engaged in facilitating tax evasion have negative effects on stock prices.

${ }^{71} E_{f t}(k)$ is an adjusted indicator for the event period that is $k$ days long, so that $E_{f t}(k)=\frac{1}{k}$ for each of the $k$ days following the event. We follow the event study implementation in Dube et al. (2011) to estimate all relevant parameters in one step. We use a period of 100 days before each event to establish the relationship between individual stock returns and the covariates in normal times.
} 
effect and the coefficient for each variable corresponds to an interaction term. Column (1) shows that R\&D intensive firms saw a larger decline in firm value following these news events. This ratio is standardized so that a firm with a $R \& D$ intensity that is one standard deviation above the mean saw a CAR that was lower than the average by -0.47 percentage points, which is close to one third of the average effect. We do not find evidence that more profitable firms decreased in value following these news events; indeed we find the opposite. We include an indicator for having had any advertising expenses and we find that this measure of intangible intensity has a negative effect on the CAR. We also control for the change in the effective tax rate at the firm level and for the fraction of employment in Puerto Rico, and we do not find significant interactions. Finally, the last column of this table shows that, as expected, the initial announcement that $\S 936$ would be repealed had a larger effect on firm values. ${ }^{72}$

Overall, these estimates suggest that investors viewed the repeal of $\S 936$ as an indication that firms' US tax obligations would increase, which would reduce stock prices. These results also speak to the degree to which investors view tax havens as substitutes. In a world where firms are able to shift profits across multiple tax havens and can substitute between them when one of them is eliminated, we would not expect to see any effects on firm value. Thus, our results suggest that firms are not able to switch between tax havens seamlessly.

\section{Model Appendix}

This appendix proves the results in Propositions 1-4. We then extend the results to allow for heterogeneous costs of profit shifting across countries.

\section{D.1 Proposition 1}

Form the Lagrangean of the profit shifting problem:

$$
\sum_{j} K_{j}\left[\left(1-t_{j}\right) r_{j}-\rho-\frac{\left(r_{j}-\bar{f}_{j}\right)^{2}}{2 a}\right]+\lambda\left\{\sum_{j} K_{j}\left(\bar{f}_{j}-r_{j}\right)\right\} .
$$

The first order condition with respect to $r_{j}$ implies:

$$
r_{j}-\bar{f}_{j}=a\left(\left(1-t_{j}\right)-\lambda\right) .
$$

The first order condition with respect to $\lambda$ implies:

$$
0=\sum_{j} K_{j}\left(\bar{f}_{j}-r_{j}\right)=\sum_{j} a K_{j}\left(\lambda-\left(1-t_{j}\right)\right) \Leftrightarrow \lambda=1-\tilde{t},
$$

\footnotetext{
${ }^{72}$ We report additional results that show that these patterns are robust to controlling for the Fama and French (1993) 3 factors and momentum. Figure A.19 plots a similar graph to Figure A.18 and shows a smaller CAR of $-.8 \%$, and Table A.32 shows that heterogeneous results are robust to controlling for these four factors.
} 
where $\tilde{t}=\frac{\sum_{j} t_{j} K_{j}}{\sum_{j} K_{j}}$. Substituting Equation D.2 into D.1 yields the result in Proposition 1.

\section{D.2 Proposition 2}

Substituting the result of Proposition 1 into the objective function and rearranging we obtain

$$
\max _{\left\{K_{j}\right\}} \underbrace{\sum_{j}\left[\left(1-t_{j}\right) f_{j}\left(K_{j}\right)-\rho K_{j}\right]}_{\text {Economic Incentives }}+a \sum_{j} K_{j} \underbrace{\left[\left(1-t_{j}\right)\left(\tilde{t}-t_{j}\right)-\frac{\left(\tilde{t}-t_{j}\right)^{2}}{2}\right]}_{\text {Net Benefit from Profit Shifting }} .
$$

The first summation of Equation D.3 is the firm's objective in the absence of profit shifting opportunities. The second summation expresses the net-benefit from profit shifting across all locations. For country $j$, the benefit from profit shifting is captured by

$$
K_{j}\left(1-t_{j}\right)\left(r_{j}-\bar{f}_{j}\right)=a K_{j}\left(1-t_{j}\right)\left(\tilde{t}-t_{j}\right)
$$

where the profit shifting term is substituted by the term in Proposition 1. Similarly, the cost from profit shifting is captured by:

$$
C\left(r_{j}, \bar{f}_{j}, K_{j}\right)=K_{j} \frac{\left(r_{j}-\bar{f}_{j}\right)^{2}}{2 a}=a K_{j} \frac{\left(\tilde{t}-t_{j}\right)^{2}}{2} .
$$

Firms' optimal investment plans thus trade-off the economic and tax incentives in Equation D.3. In addition, firms' capital allocations also impact their capital-weighted average tax: $\tilde{t}$. Note that the base-shifting effect $\frac{\partial \tilde{t}}{\partial K_{i}}$ is given by:

$$
\frac{\partial \tilde{t}}{\partial K_{i}}=\frac{-\left(\tilde{t}-t_{i}\right)}{\sum_{k} K_{k}}
$$

A similar effect arises in analyses of formulary apportionment, as in Suárez Serrato and Zidar (2016) and Fajgelbaum et al. (2015).

The first order condition of Equation 1 with respect to $K_{i}$ is:

$$
\begin{aligned}
\left(1-t_{i}\right) f_{i}^{\prime}\left(K_{i}\right)-\rho+a\left[\left(1-t_{i}\right)\left(\tilde{t}-t_{i}\right)-\frac{\left(\tilde{t}-t_{i}\right)^{2}}{2}\right]+a(1-\tilde{t}) \frac{\partial \tilde{t}}{\partial K_{i}} \sum_{k} K_{k} & =0 \\
\left(1-t_{i}\right) f_{i}^{\prime}\left(K_{i}\right)-\rho+a[\underbrace{\left(1-t_{i}\right)\left(\tilde{t}-t_{i}\right)}_{(1-\tilde{t})\left(\tilde{t}-t_{i}\right)+\left(\tilde{t}-t_{i}\right)^{2}}-\frac{\left(\tilde{t}-t_{i}\right)^{2}}{2}]-a(1-\tilde{t})\left(\tilde{t}-t_{i}\right) & =0 \\
\left(1-t_{i}\right) f_{i}^{\prime}\left(K_{i}\right)-\rho+a \frac{\left(\tilde{t}-t_{i}\right)^{2}}{2} & =0,
\end{aligned}
$$

where the second line substituted the base-shifting term and the third simplifies the middle term. Solving Equation D.4 yields the result in Proposition 2. 


\section{D.3 Proposition 3}

Following Proposition 2, write the effect of changing tax $t_{j}$ in country $i$ as:

$$
\frac{\partial K_{i}}{\partial t_{j}}=\frac{a\left(\tilde{t}-t_{i}\right)}{\mathbb{I}\{i=j\} f_{i}^{\prime}\left(K_{i}\right)-\left(1-t_{i}\right) f_{i}^{\prime \prime}\left(K_{i}\right)}\left(\frac{\partial \tilde{t}}{\partial t_{j}}-\mathbb{I}\{i=j\}\right) .
$$

Taking the derivative of $\tilde{t}$ we obtain:

$$
\begin{aligned}
\frac{\partial \tilde{t}}{\partial t_{j}} & =\frac{K_{j}}{\sum_{k} K_{k}}-\frac{1}{\sum_{k} K_{k}} \sum_{k}\left[\left(\tilde{t}-t_{k}\right) \frac{\partial K_{k}}{\partial t_{j}}\right] \\
& =\frac{K_{j}}{\sum_{k} K_{k}}-\frac{1}{\sum_{k} K_{k}} \sum_{k} \frac{a\left(\tilde{t}-t_{k}\right)^{2}\left(\frac{\partial \tilde{t}}{\partial t_{j}}-\mathbb{I}\{k=j\}\right)}{\mathbb{I}\{k=j\} f_{k}^{\prime}\left(K_{k}\right)-\left(1-t_{k}\right) f_{k}^{\prime \prime}\left(K_{k}\right)},
\end{aligned}
$$

where we substitute Equation D.5 for all countries in the second line. Solving Equation D.6 for $\frac{\partial \tilde{t}}{\partial t_{j}}$, we obtain:

$$
\frac{\partial \tilde{t}}{\partial t_{j}}=\frac{K_{j}+\frac{a\left(\tilde{t}-t_{j}\right)^{2}}{f_{j}^{\prime}\left(K_{j}\right)-\left(1-t_{j}\right) f_{j}^{\prime \prime}\left(K_{j}\right)}}{\sum_{k} K_{k}+\sum_{k} \frac{a\left(\tilde{t}-t_{k}\right)^{2}}{\mathbb{I}\{k=j\} f_{k}^{\prime}\left(K_{k}\right)-\left(1-t_{k}\right) f_{k}^{\prime \prime}\left(K_{k}\right)}}
$$

Since $f_{k}^{\prime}\left(K_{k}\right)>0$ and $-\left(1-t_{k}\right) f_{k}^{\prime \prime}\left(K_{k}\right)>0$, we know $0<\frac{\partial \tilde{t}}{\partial t_{j}}<1$. For $i \neq j$, Equation D.5 then implies:

$$
\operatorname{sign}\left(\frac{\partial K_{i}}{\partial t_{j}}\right)=\operatorname{sign}\left(\tilde{t}-t_{i}\right)
$$

\section{D.4 Profit Shifting and Labor Demand}

We now explore the implications of Propositions 1-3 for labor demand. The tax planning problem in the second period is now as follows:

$$
\sum_{j} K_{j}\left[\left(1-t_{j}\right)\left(r_{j}-w_{j} \frac{L_{j}}{K_{j}}\right)-\rho-\frac{\left(r_{j}-\bar{f}_{j}\right)^{2}}{2 a}\right]+\lambda\left\{\sum_{j} K_{j}\left(\bar{f}_{j}-r_{j}\right)\right\} .
$$

Since including the tax-deductible cost of labor in this expression does not affect Equation D.1, the result from Proposition 1 is unaffected.

In the first period, the choice of capital and labor inputs follow from maximizing:

$$
\max _{K_{j}, L_{j}} \sum_{j}\left[\left(1-t_{j}\right)\left(f_{j}\left(K_{j}, L_{j}\right)-w_{j} L_{j}\right)-\rho K_{j}\right]+a \sum_{j} K_{j}\left[\left(1-t_{j}\right)\left(\tilde{t}-t_{j}\right)-\frac{\left(\tilde{t}-t_{j}\right)^{2}}{2}\right] .
$$

The first order condition for capital in this problem is identical to Equation D.4, which implies that the result from Proposition 2 is also unaffected. The first order condition for labor is:

$$
\frac{\partial f_{j}}{\partial L_{j}}\left(K_{j}, L_{j}\right)=w_{j},
$$


which is not directly affected by $t_{j}$ since labor costs are deductible.

To proceed, we introduce some convenient notation. First, we write $f_{12}^{k}=\frac{\partial^{2} f_{k}}{\partial K_{j} \partial L_{j}}$ to denote second derivatives with respect to inputs $1, K_{k}$, and $2, L_{k}$. We also write $\frac{\partial w_{k}}{\partial t_{j}}=\kappa_{k j} \frac{\partial L_{k}}{\partial t_{j}}$ to denote the equilibrium relation between labor demand and a country's wage rate. Since changes in labor demand will trace the country's labor supply curve, we assume $\kappa_{k j}>0$. We now totally differentiate this equation as well as Equation D.4:

$$
\left[\begin{array}{cc}
f_{11}^{k}-\mathbb{I}(j=k) \frac{f_{1}^{k}}{\left(1-t_{k}\right)} & f_{12}^{k} \\
f_{21}^{k} & f_{22}^{k}-\kappa_{k j}
\end{array}\right]\left[\begin{array}{c}
\frac{\partial K_{k}}{\partial t_{j}} \\
\frac{\partial L_{k}}{\partial t_{j}}
\end{array}\right]=\left[\begin{array}{c}
-\frac{a\left(\tilde{t}-t_{k}\right)}{\left(1-t_{k}\right)} \times\left(\frac{\partial \tilde{t}}{\partial t_{j}}+\mathbb{I}(j=k)\right) \\
0
\end{array}\right] .
$$

The determinant of the first matrix is given by:

$$
\Omega_{k j}=\left(f_{11}^{k}-\mathbb{I}(j=k) \frac{f_{1}^{k}}{\left(1-t_{k}\right)}\right) \times\left(f_{22}^{k}-\kappa_{k j}\right)-f_{21}^{k} f_{12}^{k}>0 .
$$

Inverting Equation D.8 yields:

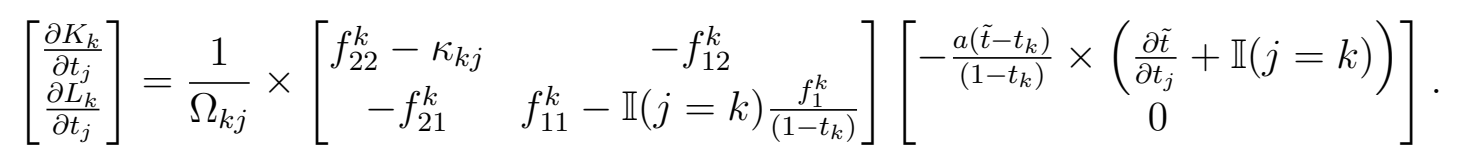

Consider now the effect of $t_{j}$ on $\tilde{t}$. Generalizing Equation D.6, we now have:

$$
\begin{aligned}
\frac{\partial \tilde{t}}{\partial t_{j}} & =\frac{K_{j}}{\sum_{k} K_{k}}-\frac{1}{\sum_{k} K_{k}} \sum_{k}\left[\left(\tilde{t}-t_{k}\right) \frac{\partial K_{k}}{\partial t_{j}}\right] \\
& =\frac{K_{j}}{\sum_{k} K_{k}}-\frac{1}{\sum_{k} K_{k}} \sum_{k} \frac{a\left(\tilde{t}-t_{k}\right)^{2}\left(\kappa_{k j}-f_{22}^{k}\right)}{\left(1-t_{k}\right) \Omega_{k j}} \times\left(\frac{\partial \tilde{t}}{\partial t_{j}}-\mathbb{I}(j=k)\right) .
\end{aligned}
$$

Solving for $\frac{\partial \tilde{t}}{\partial t_{j}}$ we now have:

$$
\frac{\partial \tilde{t}}{\partial t_{j}}=\frac{K_{j}+\frac{a\left(\tilde{t}-t_{j}\right)^{2}\left(\kappa_{j j}-f_{22}^{j}\right)}{\left(1-t_{j}\right) \Omega_{j j}}}{\sum_{k} K_{k}+\sum_{k} \frac{a\left(\tilde{t}-t_{k}\right)^{2}\left(\kappa_{k j}-f_{22}^{k}\right)}{\left(1-t_{k}\right) \Omega_{k j}}}
$$

Since $\kappa_{k j}-f_{22}^{k}>0$ and $\Omega_{k j}>0$, we know $1>\frac{\partial \tilde{t}}{\partial t_{j}}>0$. Note that if $f_{12}^{k}=f_{21}^{k}=0$, this equation reduces to Equation D.7.

From this equation and Equation D.9, we now have that, for $j \neq k$,

$$
\frac{\partial K_{k}}{\partial t_{j}}=\frac{a\left(\tilde{t}-t_{k}\right)\left(\kappa_{k j}-f_{22}^{k}\right)}{\left(1-t_{k}\right) \Omega_{k j}} \frac{\partial \tilde{t}}{\partial t_{j}}
$$

which confirms that the result of Proposition 3 holds in this setting. In addition, we now have the following implication of profit shifting for labor demand:

$$
\frac{\partial L_{k}}{\partial t_{j}}=\frac{a\left(\tilde{t}-t_{k}\right) f_{21}^{k}}{\left(1-t_{k}\right) \Omega_{k j}} \frac{\partial \tilde{t}}{\partial t_{j}}
$$


where $j \neq k$. Since $\Omega_{k j}>0$, we have

$$
\operatorname{sign}\left(\frac{\partial L_{k}}{\partial t_{j}}\right)=\operatorname{sign}\left(\left(\tilde{t}-t_{k}\right) f_{21}^{k}\right) .
$$

This implies labor in a high-tax country is a tax complement with the corporate rate in a tax haven if capital is a complement to labor in the high-tax country, i.e., $f_{21}^{k}>0$.

Finally, notice the following relation between the effects on capital and labor:

$$
\frac{\partial L_{k}}{\partial t_{j}}=\frac{f_{21}^{k}}{\kappa_{k j}-f_{22}^{k}} \frac{\partial K_{k}}{\partial t_{j}} .
$$

That is, we would expect to see a larger passthrough of capital to labor whenever capital and labor are highly complementary (large $f_{21}^{k}$ ), whevener capital has weak decreasing returns (small $f_{22}^{k}$ ), and whenever changes in labor demand have small wage effects ( $\operatorname{small} \kappa_{k j}$ ).

\section{D.5 Heterogeneous Profit Shifting Costs}

The model so far assumes that the cost of evasion is symmetric in all countries. As discussed in Section 2, lax regulations related to profit shifting and $§ 936$ meant that Puerto Rico was an especially desirable tax haven for US multinationals. Our model can incorporate this feature by allowing for heterogeneous costs of profit shifting across locations. This section shows that the results of Propositions 1-3 are robust to allowing for the parameter $a$ to vary by country.

Let $a_{j}$ be the value of $a$ for country $j$. The optimal profit shifting strategy is now:

$$
r_{j}=\bar{f}_{j}+a_{j}\left(\hat{t}-t_{j}\right)
$$

where $\hat{t}=\frac{\sum_{k} t_{k} K_{k} a_{k}}{\sum_{k} K_{k} a_{k}}$. This result is very similar to the one in Proposition 1 but notice that the "mean tax term" $\hat{t}$ also weights country's taxes by the parameters $a_{k}$. Intuitively, countries where profit shifting is more costly (lower values of $a_{j}$ ) will have smaller differences between reported and actual profitability. In addition, these countries will have a smaller contribution to the mean $\operatorname{tax}$.

We also obtain a similar result to Proposition 2. Equation D.4 now becomes:

$$
\left(1-t_{j}\right) f_{j}^{\prime}\left(K_{j}\right)-\rho+a_{j} \frac{\left(\hat{t}-t_{j}\right)^{2}}{2}=0 .
$$

This implies that countries where profit shifting is more costly (lower values of $a_{j}$ ) will see smaller effects on their user cost of capital.

With heterogeneous costs, the term $\frac{\partial \hat{t}}{\partial t_{j}}$ now includes the $a_{k}$ 's as well:

$$
\frac{\partial \hat{t}}{\partial t_{j}}=\frac{a_{j} K_{j}+\frac{a_{j}^{2}\left(\hat{t}-t_{j}\right)^{2}}{f_{j}^{\prime}\left(K_{j}\right)-\left(1-t_{j}\right) f_{j}^{\prime \prime}\left(K_{j}\right)}}{\sum_{k} a_{k} K_{k}+\sum_{k} \frac{a_{k}^{2}\left(\hat{\mathbb{I}}-t_{k}\right)^{2}}{\{k=j\} f_{k}^{\prime}\left(K_{k}\right)-\left(1-t_{k}\right) f_{k}^{\prime \prime}\left(K_{k}\right)}} .
$$


It is it still the case that $0<\frac{\partial \hat{t}}{\partial t_{j}}<1$ and the result of Proposition 3 still holds. We can further state that:

$$
\frac{\partial K_{i}}{\partial t_{j}} \propto a_{i}\left(\hat{t}-t_{i}\right)
$$

so that countries where profit shifting is more costly (lower values of $a_{i}$ ) will be subject to smaller tax complementarities. Similar arguments generalize the result of Proposition 4.

These results show that, all else equal, when a country $j$ has a low cost of profit shifting (higher $a_{j}$ ), tax complementarities on capital and employment will be stronger. This implies that the setting of $\S 936$ makes it likely that we can detect effects on domestic investment and employment.

\section{D.6 Discussion of Empirical Implications}

Consider now two examples that summarize the insights of Propositions 1-4 as applied to the elimination of $\S 936$.

Example 1 (US as a Low-Tax Country: $\tilde{t} \geq t_{U S}$ ). $§ 936$ would have the following effects:

- Profit shifting toward Puerto Rico $\left(r_{P}>\bar{f}_{P}\right)$ and the US $\left(r_{U S}>\bar{f}_{U S}\right)$.

- Profit shifting increases investment and employment globally.

- Profit shifting redirects investment and employment to the US.

Repealing $§ 936$ would have the following effects:

- Decrease profit shifting toward Puerto Rico, and increase shifting toward the US.

- Decrease investment and employment globally.

- Shift investment and employment away from Puerto Rico, and toward the US.

Notice that if $\tilde{t}=t_{U S},{ }^{73}$ and US is the country with the average tax, it would be the case that $\S 936$ or its repeal had no effect on US investment. Nonetheless, profit shifting toward Puerto Rico would mean that the US treasury would be reducing tax obligations of firms in other countries by paying for the US Corporations Possessions Tax Credit.

Example 2 (US as a High-Tax Country: $\left.\tilde{t}<t_{U S}\right) .{ }^{74}$

- Profit shifting toward Puerto Rico $\left(r_{P}>\bar{f}_{P}\right)$ and away from the $U S\left(r_{U S}<\bar{f}_{U S}\right)$.

\footnotetext{
${ }^{73} \mathrm{~A}$ convenient numerical example is the case when $K_{U S}=K_{C}=K_{P R}$ and $t_{C}=2 t_{U S}$

${ }^{74} \mathrm{~A}$ convenient numerical example is the case when $K_{U S}=K_{C}=K_{P R}$ and $t_{C}=t_{U S} / 2$. In this case $\tilde{t}=t_{U S} / 2$.
} 
- Profit shifting increases investment and employment globally.

- Profit shifting redirects investment and employment to the US.

Repealing $§ 936$ would have the following effects:

- Decrease profit shifting toward Puerto Rico, and increase shifting away from the US.

- Decrease investment and employment globally.

- Shift investment and employment away from Puerto Rico and the US.

Note that in this example profits are shifted away from other countries as well, such that the profits shifted to Puerto Rico may not represent a reduction in US tax obligations, but may represent obligations owed to other countries. However, as in the previous example, the US treasury would still be affected by the tax expenditure on the US Possessions Corporations tax credit.

These examples show that tax climates in other countries are an important consideration for whether tax changes, such as the repeal of $\S 936$, have positive or negative effects on the US economy. In particular, the view of the US as a high-tax country is consistent with our empirical results showing negative domestic effects of repealing $§ 936$ on the US economy.

\section{D.7 Additional Extensions}

The model abstracted away from dynamic considerations of investment. The model can be extended in this direction by adopting a framework such as in Auerbach (1989) or Auerbach and Hines (1987). If firms faced a dynamic investment decision and they viewed the repeal of $\S 936$ as permanent, they would respond by lowering investment and letting existing capital depreciate during the phase-out of the tax credits. Since labor is seen as a static input, the corresponding labor demand would match the dynamics of the capital stock.

Similarly, the model does not take into account the location of firms within the US. The empirical analysis on the effects on local labor markets uses the exposure of a given labor market to $\S 936$ to estimate the effects of the repeal of $\S 936$ at the local level. We can specialize the model by adding a location component to firms and couching the analysis of the reform in a model of local labor markets, as in Suárez Serrato and Zidar (2016). We may further estimate aggregate effects from regional variation using approaches such as those in Fajgelbaum et al. (2015) or Acemoglu and Restrepo (2017). Since these extensions would not change the main conclusions from the model in Section 3 or the empirical implications described in the previous section, we avoid needlessly complicating the presentation of the main model in the paper. 


\section{E Changes in Investment Flows and Capital Stocks}

The empirical results of Section 5 show that firms respond to the repeal of $\S 936$ by lowering the flow of capital investment. We present a stylized model of the capital stock to show how the domestic capital stock updates given the observed changes in investment. Capital stock is determined by a law of motion where capital in time $t$ is equal to the sum of non-depreciated capital from the previous period and investment from period $t$ :

$$
K_{t}=(1-\delta) K_{t-1}+I_{t}
$$

$\delta$ is the exogenous depreciation rate of capital. Investment is taken to be a multiple of the steady state capital stock, denoted by the zero subscript.

$$
I_{t}=\alpha K_{0}
$$

Assuming that the firm is in a steady state before the repeal of $\S 936$, capital is the same every period, and the investment rate $\alpha$ is equal to the depreciation rate $\delta$ :

$$
K_{0}=(1-\delta) K_{0}+\alpha K_{0} \Longrightarrow \alpha=\delta
$$

The empirical estimates presented in Tables 2 and 4 show that domestic investment decreases after the repeal of $\S 963$ through decreased total investment and decreased share of investment that is domestic. As discussed in Section 5, firms decrease domestic investment by 19.3-25.7\%. Assuming the upper range of our results, the new investment rate as $(1-0.26) \alpha$, the law of motion for capital becomes:

$$
K_{t}=(1-\delta) K_{t-1}+(1-0.26) \alpha K_{0}
$$

Figure A.9 plots the trajectory for the capital stock of three different types of general industrial capital. Note that the figure assumes $K_{0}=1$ as a normalization, and uses BEA (2018) estimates of depreciation values for different types of capital. The figure showcases short, medium, and long duration assets for the general industry category. Buildings, which depreciate relatively slowly with a depreciation rate of 0.025 , lose $5.8 \%$ of their value after 10 years. Machinery and Electronics (including computers) depreciate relatively faster — rates of 0.069 and 0.122 , respectively — and lose $13.2 \%$ and $18.96 \%$ of their stock within 10 years.

These results show that, while $§ 936$ has large and almost immediate effects on investment, the effects on the capital stock adjust slowly and lag the effects on investment depending on the depreciation rate. 


\section{F Heterogeneous Effects of Repealing $§ 936$ on Local Em- ployment Growth}

In this section we explore the potential for the repeal of $\S 936$ to have heterogeneous effects on employment growth across local labor markets. We build on the specification of Table 8, and we allow for interactions of the exposure variable with other policies or shocks. We present detailed results in Tables A.33 and A.34 where we include interactions with each of these variables.

Panel A of Figure A.20 shows the interaction terms between each variable and the exposure variable. The two variables with the largest positive interaction terms are the corporate income tax rate and job creation incentives from Bartik (2017). The intuition for a positive interaction with job incentives is that these incentives may help unemployed workers find jobs sooner, which may limit the effects of a negative shock. The intuition for a positive interaction term with the corporate tax rate follows from understanding that in the equilibrium of a tax competition game, states with lower taxes attract more mobile firms which would also be more responsive to the repeal of $\S 936$. The two largest negative interaction terms are for trade exposure to NAFTA and for the share of routine workers. The intuition for these effects is that it is harder for local labor markets to recover when they are hit with multiple economic shocks. ${ }^{75}$

Panel B of Figure A.20 shows how each of these interactions influence the marginal effect of exposure to $\S 936$ when these interaction terms take values above or below one standard deviation of the mean. The mean of the effects is about 8.0\%, which is slightly larger than the effect without interactions. However, when we examine the distribution of marginal effects, we find a median effect that is very close to when we do not include these controls or interactions.

We summarize the heterogeneity across all of these interactions by computing the marginal effect for all counties in the specification that includes all of the interactions. Panel $\mathrm{C}$ of Figure A.20 plots the distribution of marginal effects across counties and shows that some states had much larger sensitivity to the repeal of $§ 936$. In particular, states with zero corporate income taxes, such as Texas and Nevada, are more affected by the repeal of $\S 936$. However, this figure also shows considerable heterogeneity.

Finally, Panel D of Figure A.20 takes a different approach to characterizing the heterogeneity in effects and plots estimates of quantile regressions. These estimates show that the repeal of $\S 936$ had larger effects on counties that were growing faster. This implies that, while the repeal of $\S 936$ saw declines in growth across all counties, it also a led to a compression in the distribution of growth rates.

\footnotetext{
${ }^{75}$ Note that these interaction terms are not a form of bias for our main estimate. This specification controls for each variable and, as shown in Figure 13, controlling for both of these variables does not bias the main estimate.
} 


\section{Figure A.1: Employment in Puerto Rico by Industry}

\section{A. Total Employment in Puerto Rico}

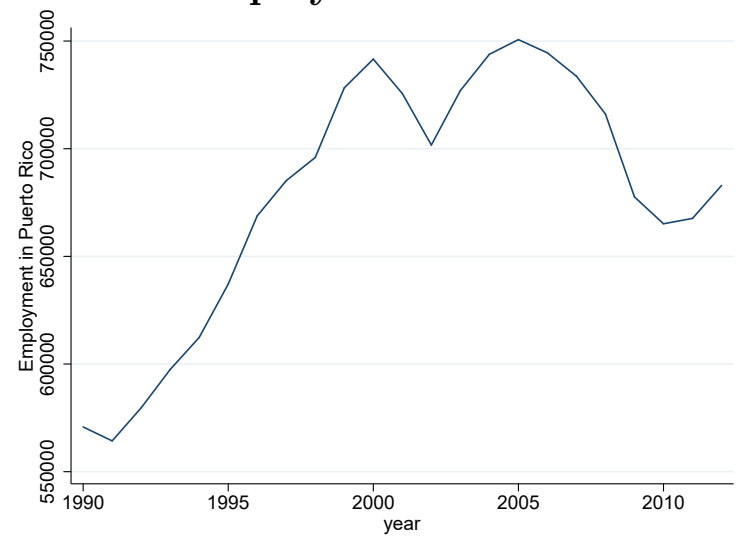

B. Employment in Puerto Rico by Industry
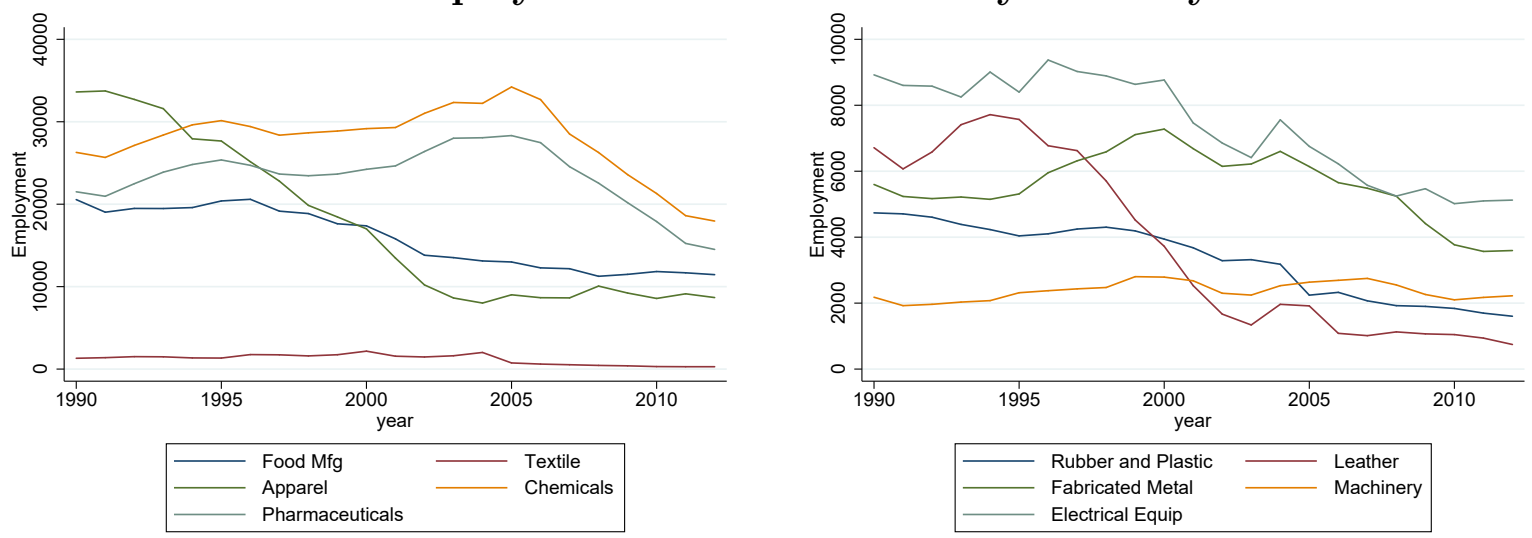

Notes: Author's calculations using data from NETS. This figure shows the total employment by all firms in Puerto Rico by industry from 1990 to 20012. Employment in Puerto Rico peaks in 2006 around 750,000 workers relative to 575,000 workers in 1990 . 


\section{Figure A.2: Exposure to $\S 936$ in 1995 by Establishments and Employment}

\section{A. Exposure to $\S 936$ at the County Level, Establishments}

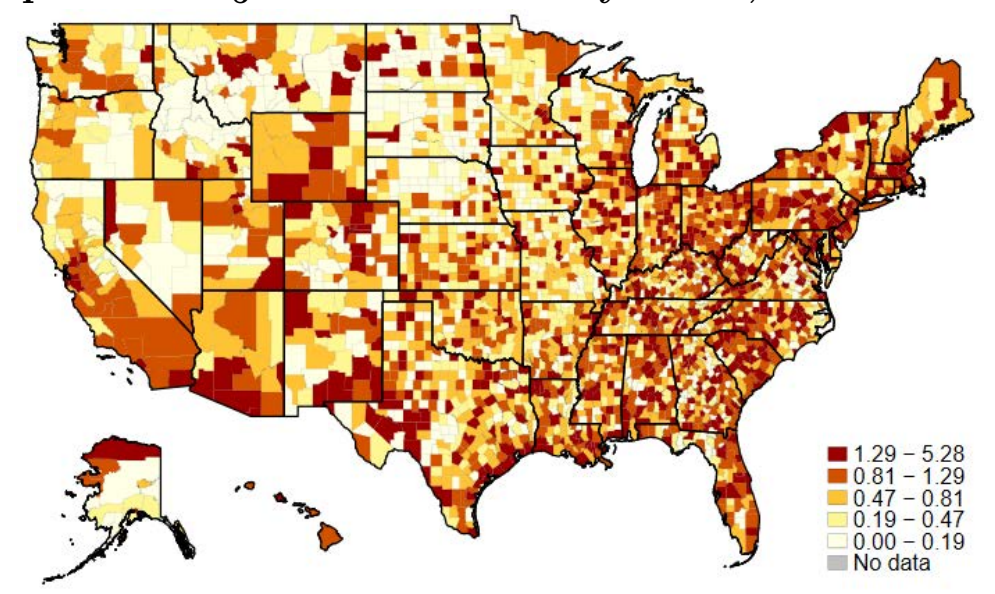

B. Exposure to $§ 936$ at the County Level, Employment

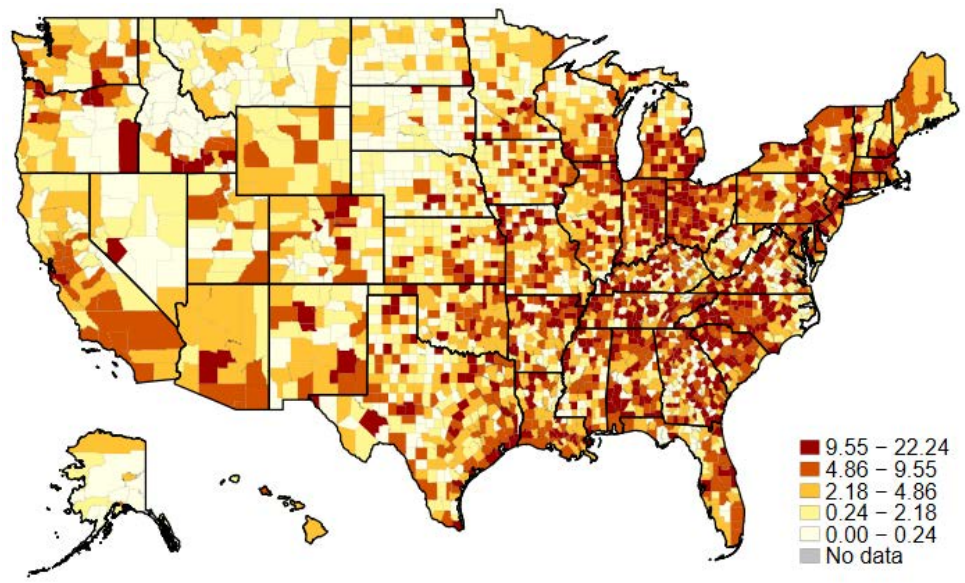

Notes: Author's calculations using data from NETS. This table shows the exposure variable calculated using employment instead of establishments. Panel A mirrors Figure 3 while panels B uses NETS employment data to generate links. For more information about the data and the exposure variable, see Section 4. This figure shows that the variation in exposure to Section 936 is robust to measurement, although we use the establishment definition in the main specifications because employment data in the NETS is likely subject to some mis-measurement (Barnatchez et al., 2017), the estimates of a regression using establishments links as an instrument for employment links are shown in Table A.12. 
Figure A.3: Distribution of Exposure to $\S 936$ in 1995

A. Exposure to $\S 936$ at the County Level

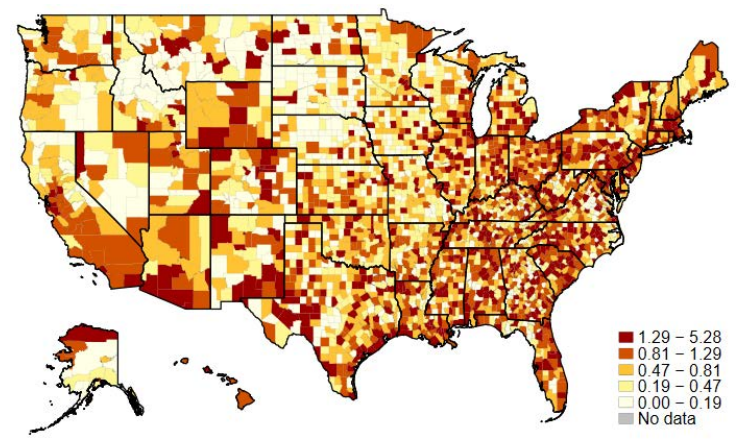

B. Exposure to $\S 936$ at the State Level

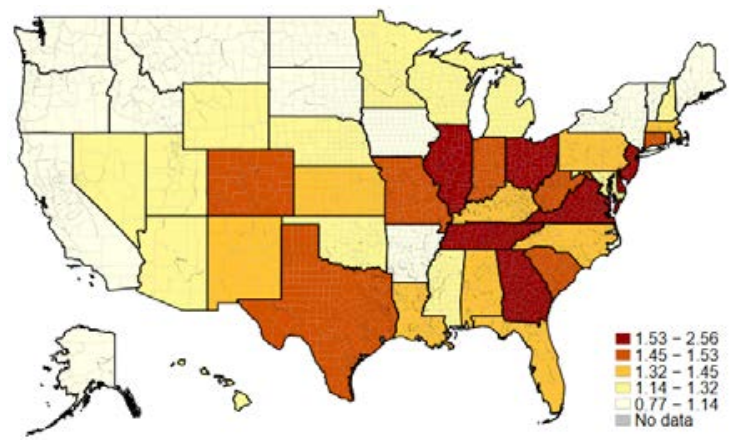

D. Exposure to $§ 936$ at the Commuting Zone Level

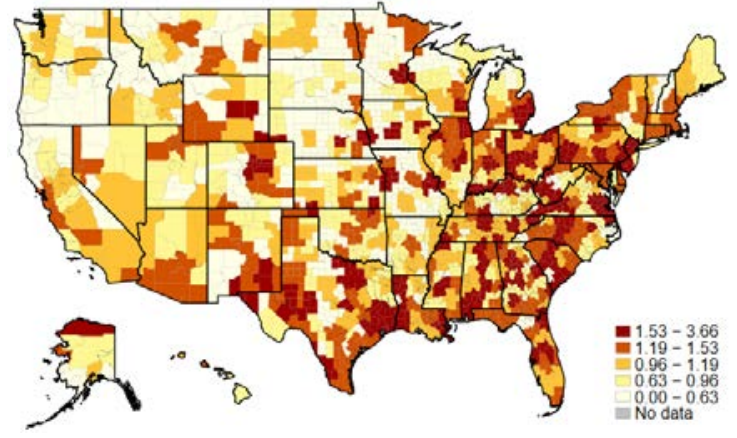

Notes: Author's calculations using data from NETS. This panel shows the establishment exposure to Section 936 aggregated to different geographic levels. Panel A mirrors Figure 3 while panels B, C, and D show the exposure at the state, conspuma, and commuting zone levels, respectively. For more information about the data and the exposure variable, see Section 4 . This figure shows that there is still variation in exposure to $§ 936$ even with higher levels of aggregation beyond counties, which are used as the main level of analysis. 


\section{Figure A.4: Change in Investment after §936 Repeal in Levels}

A. Investment

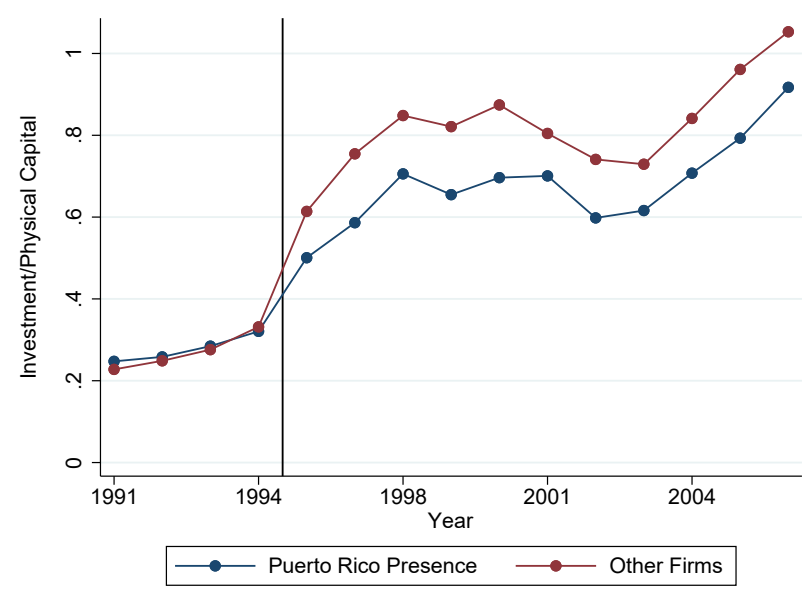

B. Percent Investment

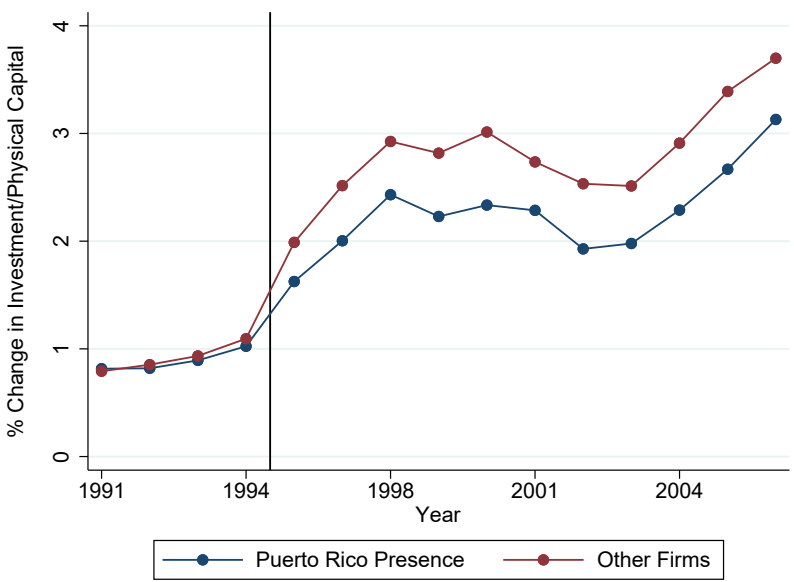

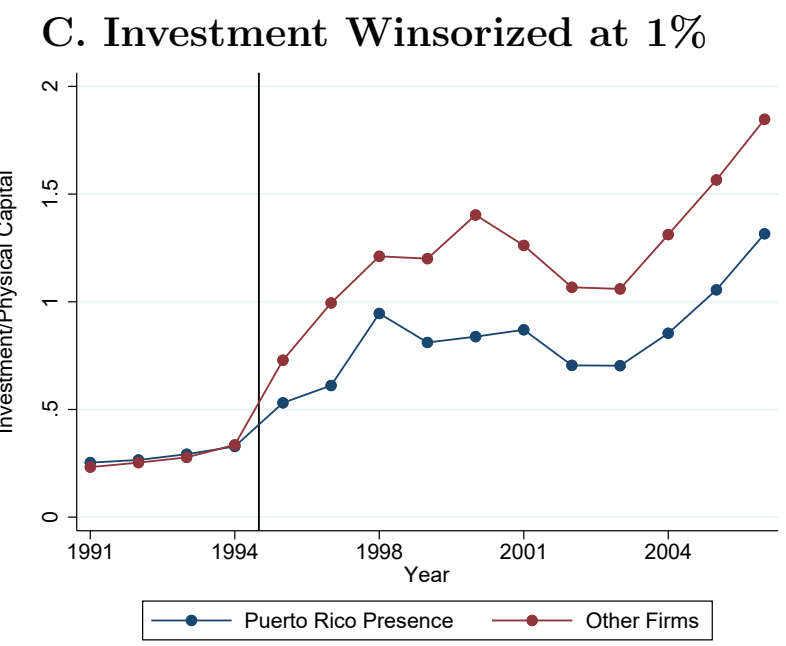

Notes: Author's calculations using data from COMPUSTAT. This figure shows level estimates of Equation 2 with three variations of the dependent variable. Exposure to $\S 936$ is an indicator at the firm level in all panels. In Panel A the dependent variable is investment divided by average plants, property, and equipment in 1990 to 1995 winsorized at the 5\% level. Panel B changes the dependent variable to be measured in percentage changes. Panel $\mathrm{C}$ uses the same dependent variable as Panel A with the investment winsorized at the $1 \%$ level. Blue lines span a $95 \%$ confidence interval. Standard errors are clustered at the firm level. 
Figure A.5: Effect of Repealing $§ 936$ on the Firm-Level Investment Rate: Percentage Change

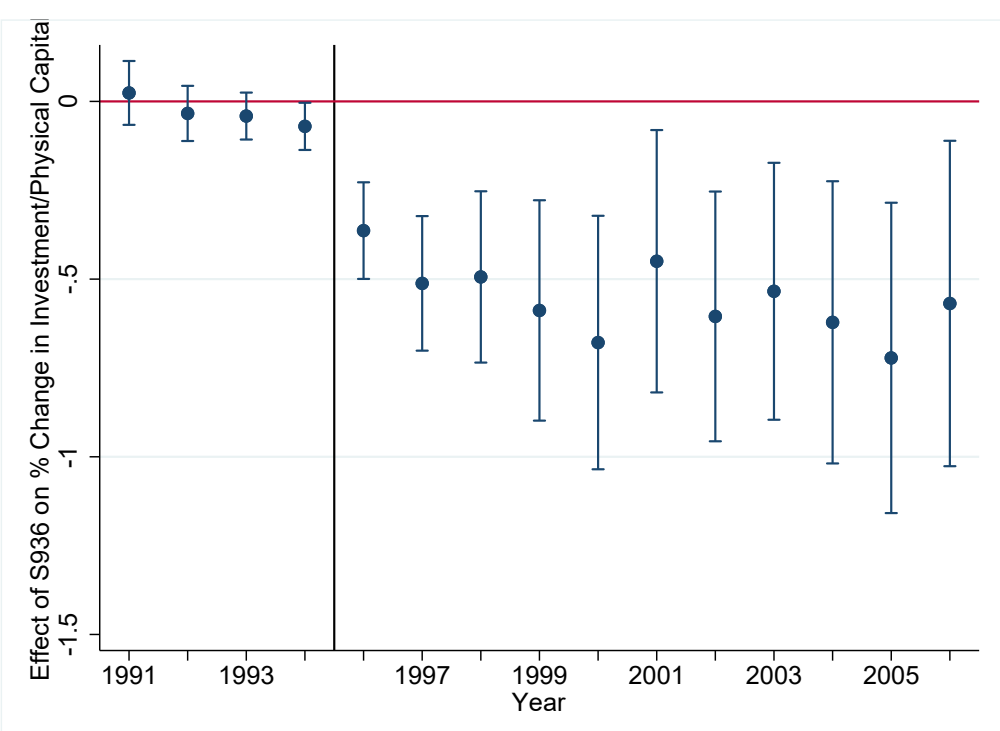

Notes: Author's calculations using data from COMPUSTAT. This figure shows estimates of Equation 2 where the dependent variable is the percent change in investment relative to the pre-period, and where exposure to $\S 936$ is an indicator at the firm level. Investment is defined as capital expenditures. Blue lines span a $95 \%$ confidence interval. Consistent with the hypothesis that multinationals decreased investment, we see that exposed firms saw a decrease in investment following the repeal of $\S 936$ relative to non-exposed firms. Point estimates and additional specifications are shown in Table A.5. Standard errors are clustered at the firm level. 


\section{Figure A.6: Effect of Repealing §936 on the Firm-Level Investment Rate: Winsorized at $1 \%$}

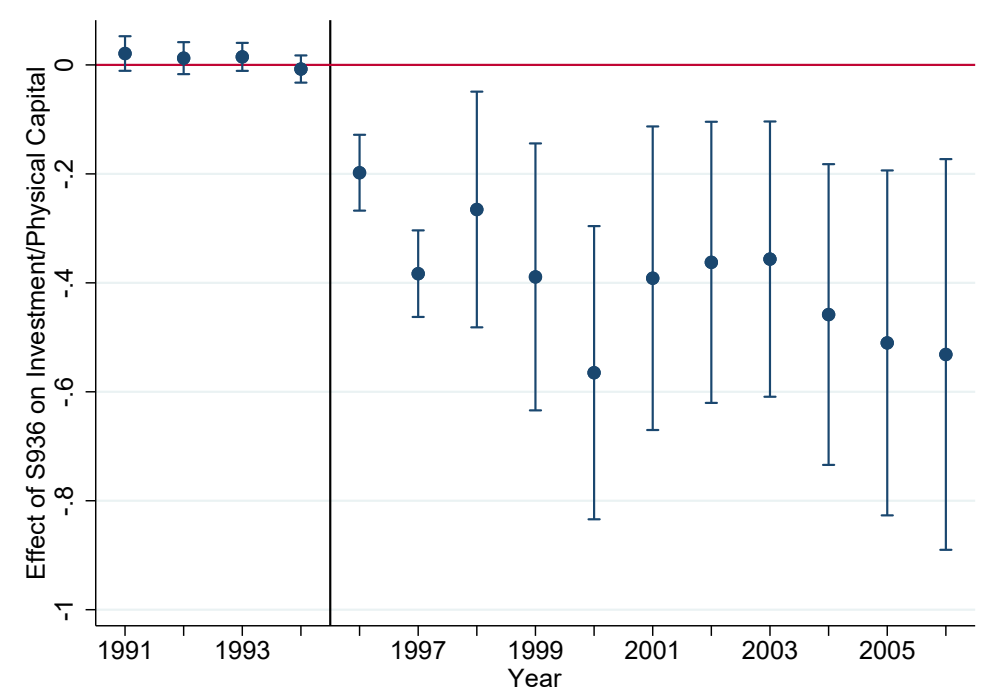

Notes: Author's calculations using data from COMPUSTAT. This figure shows estimates of Equation 2 where the dependent variable is investment divided by average capital in 1990 to 1995 and exposure to $\S 936$ is an indicator at the firm level. Investment is defined as capital expenditures and capital is defined as plants property and equipment. Blue lines span a 95\% confidence interval. Consistent with the hypothesis that multinationals decreased investment, we see that exposed firms saw a decrease in investment following the repeal of $\S 936$ relative to non-exposed firms. Point estimates and additional specifications are shown in Table A.6. Standard errors are clustered at the firm level. Investment divided by capital is winsorized at the $1 \%$ level. 
Figure A.7: Change in Investment after $§ 936$ Repeal with All Controls

A. Investment

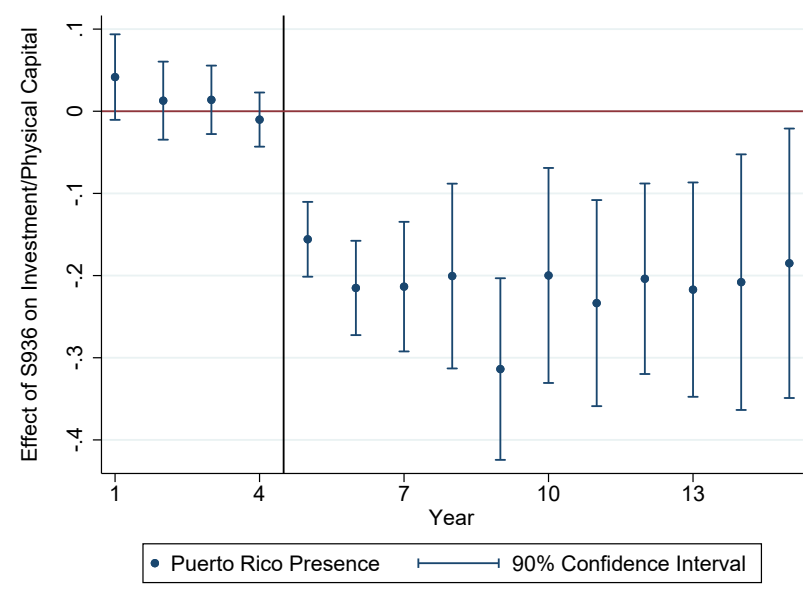

B. Percent Investment

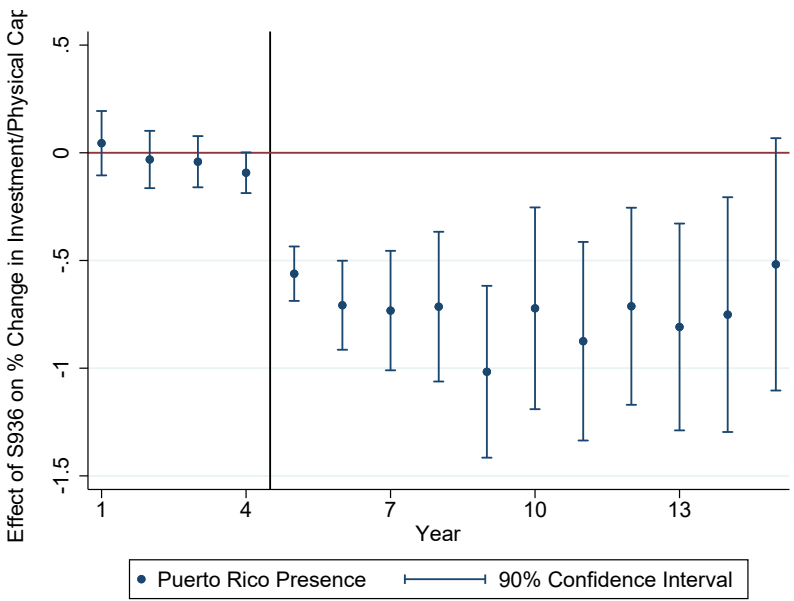

C. Investment Winsorized at $1 \%$

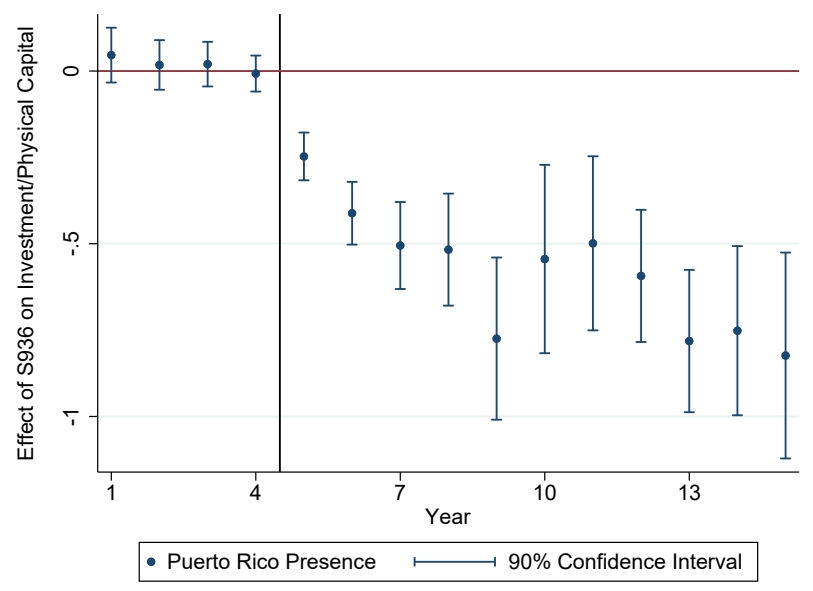

Notes: Author's calculations using data from COMPUSTAT. This figure shows level estimates of Equation 2 with three variations of the dependent variable and including all controls in specification (5) of Table 2. Exposure to $\S 936$ is an indicator at the firm level in all panels. In Panel A the dependent variable is investment divided by average plants, property, and equipment in 1990 to 1995 winsorized at the $5 \%$ level. Panel B changes the dependent variable to be measured in percentage changes. Panel $\mathrm{C}$ uses the same dependent variable as Panel A with the investment winsorized at the $1 \%$ level. Blue lines span a $95 \%$ confidence interval. Standard errors are clustered at the firm level. 


\section{Figure A.8: Change in Effective Federal Tax Rates after $§ 936$ Repeal}

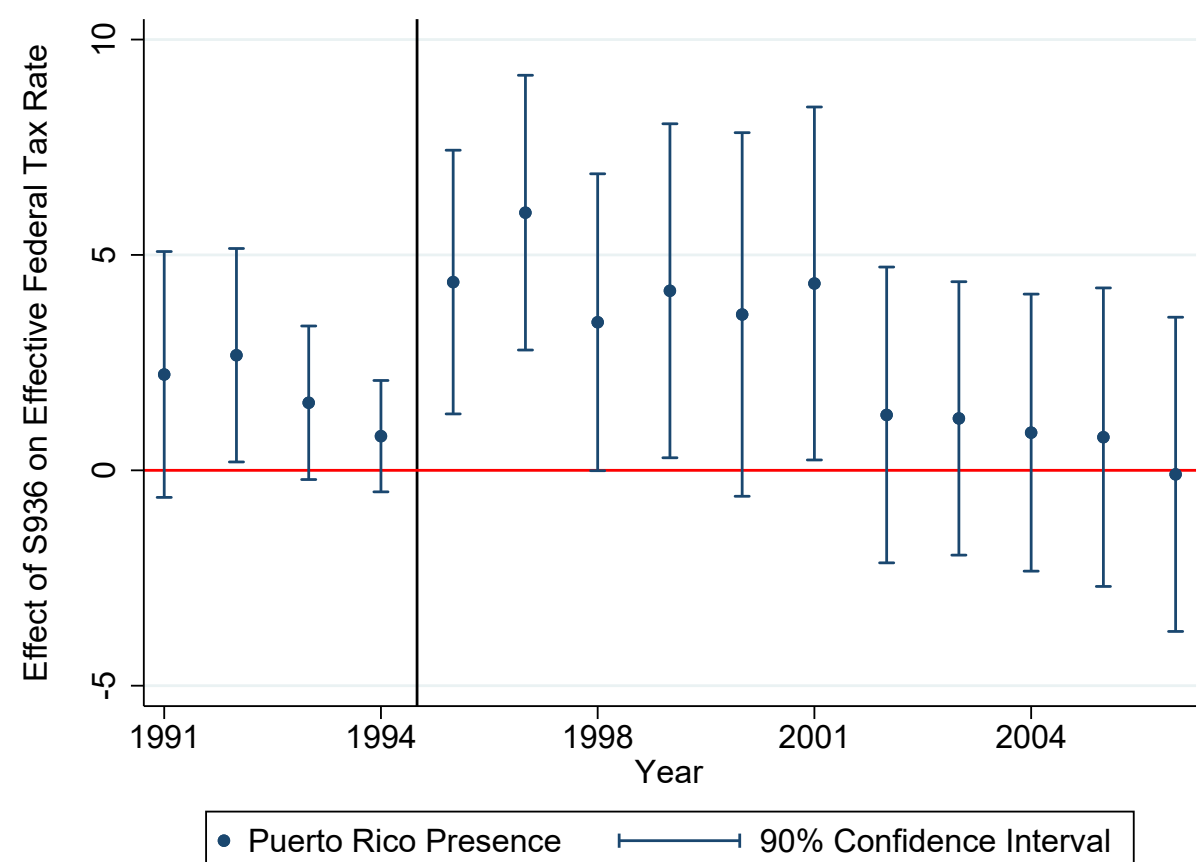

Notes: Author's calculations using data from COMPUSTAT. This figure shows estimates of Equation 2 where the dependent variable is federal cash taxes paid divided by global pretax income and where exposure to $\S 936$ is an indicator at the firm level. This specification uses the sample from specification (5) in Table 3. Blue lines span a 95\% confidence interval. Consistent with the hypothesis that multinationals increased federal tax liabilities, we see that exposed firms saw an increase in effective tax rates following the repeal of $\S 936$ relative to non-exposed firms. Standard errors are clustered at the firm level. 

Figure A.9: Effect of a $26 \%$ Decrease in Investment on Capital Stock by Type of
Capital

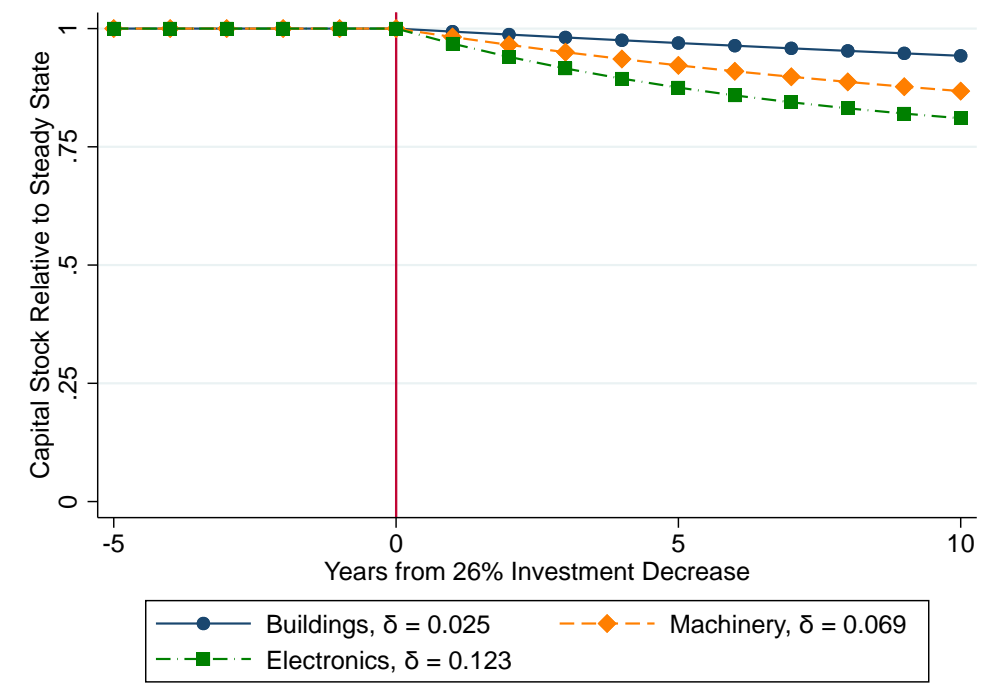

Notes: Author's calculations of the derivation shown in Appendix E calibrated using data from BEA (2018). This figure shows the trajectory of the capital stock for different types of capital at a general industrial firm. We assume the capital stock is in a steady state before year 0 and that investment decreases to $26 \%$ of its steady state value after the reform. Buildings, which depreciate relatively slowly with a depreciation rate of 0.025 , lose $5.8 \%$ of their value after 10 years. Machinery and electronics (including computers) depreciate relatively faster - rates of 0.069 and 0.122 , respectively - and lose $13.2 \%$ and $18.96 \%$ of their stock after 10 years. 
Figure A.10: NETS Employment Event Study, DFL Weights

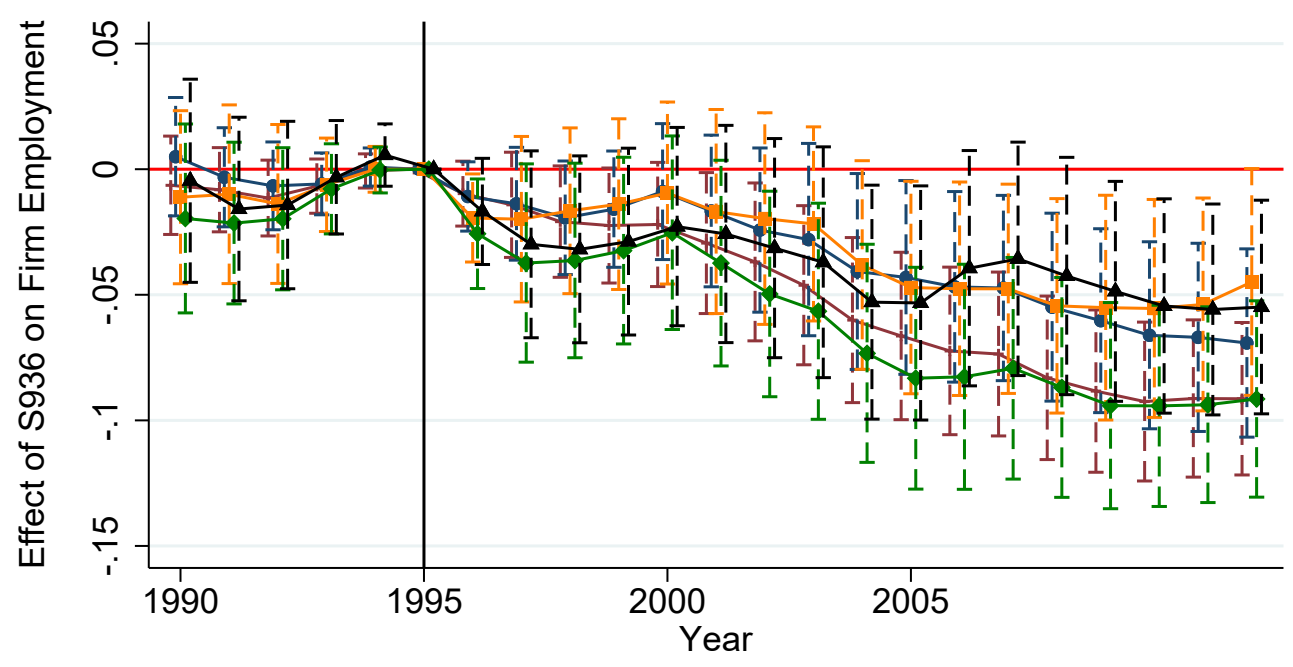

\begin{tabular}{|c|c|c|}
\hline & All Firms & $\vdash---\dashv 95 \% \mathrm{Cl}$ \\
\hline 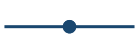 & All firms with FE & $\vdash---\dashv 95 \% \mathrm{Cl}$ \\
\hline & Major Sectors with FE & $\vdash---\dashv 95 \% \mathrm{Cl}$ \\
\hline 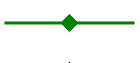 & Major Industries with FE & $\vdash--$ \\
\hline & Major Industries + DFL with FE & $\vdash-$ \\
\hline
\end{tabular}

Notes: Author's calculations using data from NETS. This figure shows the decline in employment at $\S 936$ exposed firms relative to similar control firms without exposure to $§ 936$. See Appendix A.3 for a description of the DFL weights used to create the control sample. Point estimates are displayed in Column (3) of Table A.10. See Section 5 for more discussion. Standard errors are clustered at the firm level. 
Figure A.11: Effects of Repealing of $\S 936$ on Number of Establishments in Affected Firms

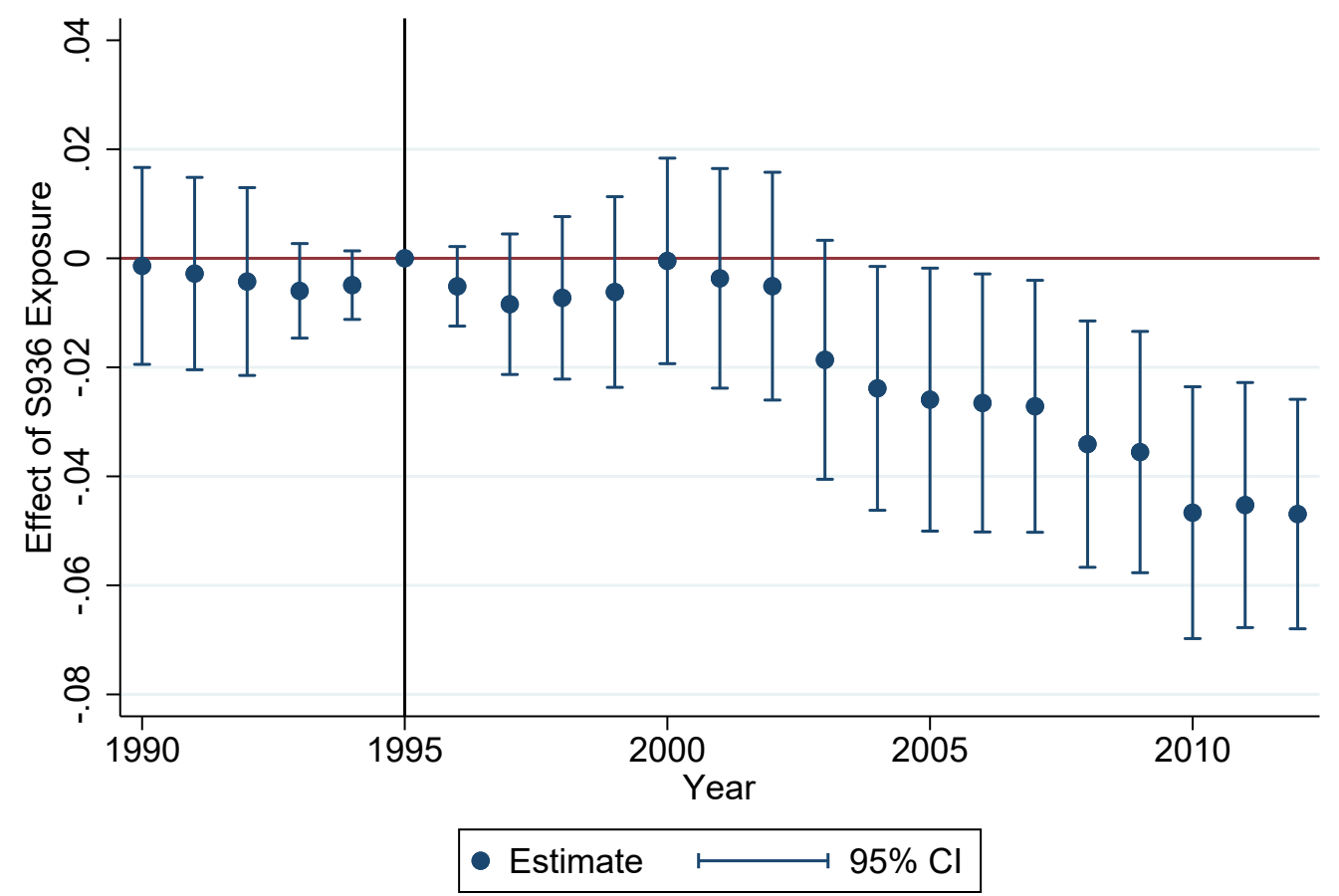

Notes: $\left(\right.$ Est $_{\mathrm{it}}-$ Est $\left._{\mathrm{i} 1995}\right) /$ Est $_{\mathrm{i} 1995}=\alpha_{\mathrm{t}}+\beta_{\mathrm{t}} \mathrm{S} 936$ Exposure $_{\mathrm{i}}+\varepsilon_{\mathrm{it}}$. SE's clustered by Firm.

Notes: Author's calculations using data from NETS. This figure shows the decline in establishments at $§ 936$ exposed firms relative to similar control firms without exposure to $\S 936$. See Appendix A.3 for a description of the procedure used to identify the comparison firms. By 2006, firms exposed to $\S 936$ had $2.7 \%$ less establishment growth than firms that were otherwise similar in 1995. See Section 5 for more discussion. Standard errors are clustered at the firm level. 


\section{Figure A.12: Relation Between Log Employment and Log Capital Expenditures}

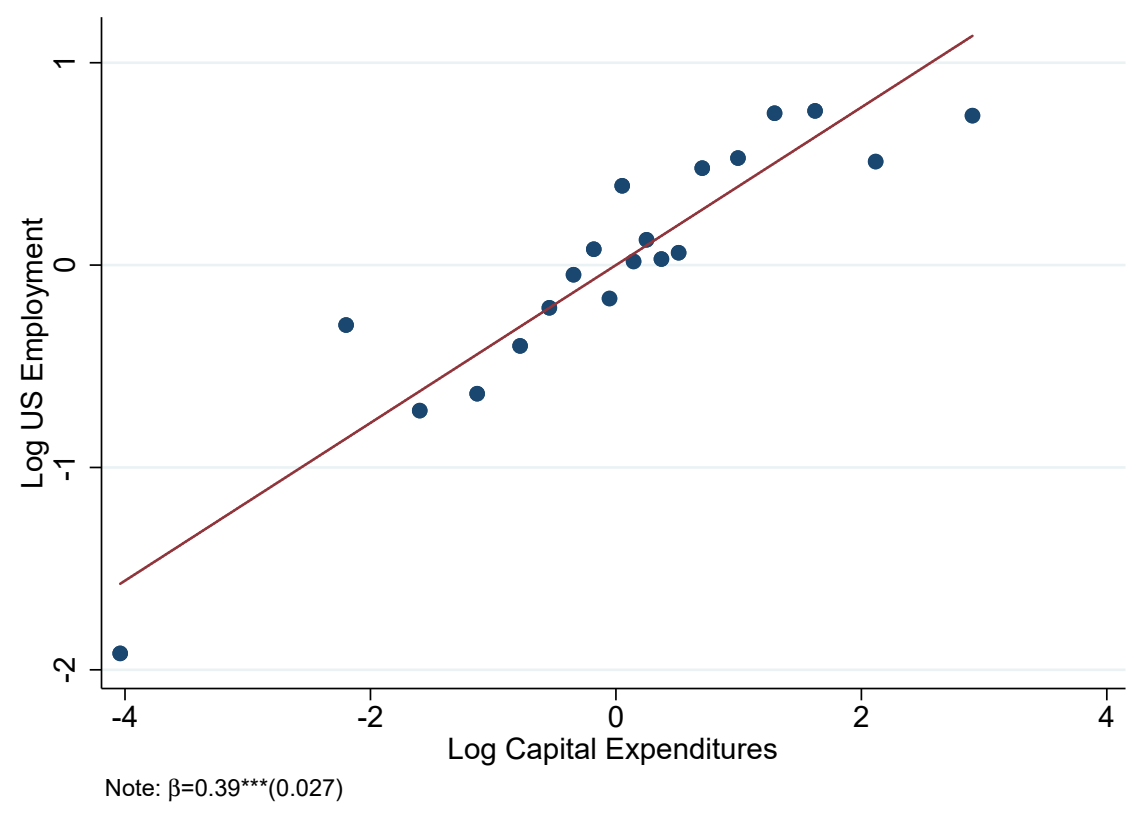

Notes: Author's calculations using data from COMPUSTAT and NETS. This figure plots the results of a regression of $\log$ US employment at the firm level on log capital expenditures. It shows that an increase in $1 \%$ of capital expenditures is associated with an increase in $0.39 \%$ in US employment. We use this estimated relation to benchmark the magnitudes of the employment and investment effects in Section 5. 
Figure A.13: Robustness Using Variable Definitions from Autor et al. (2013)

A. Effect of $\S 936$ Exposure on Employment-to-Pop Ratio in Manufacturing (\% change)

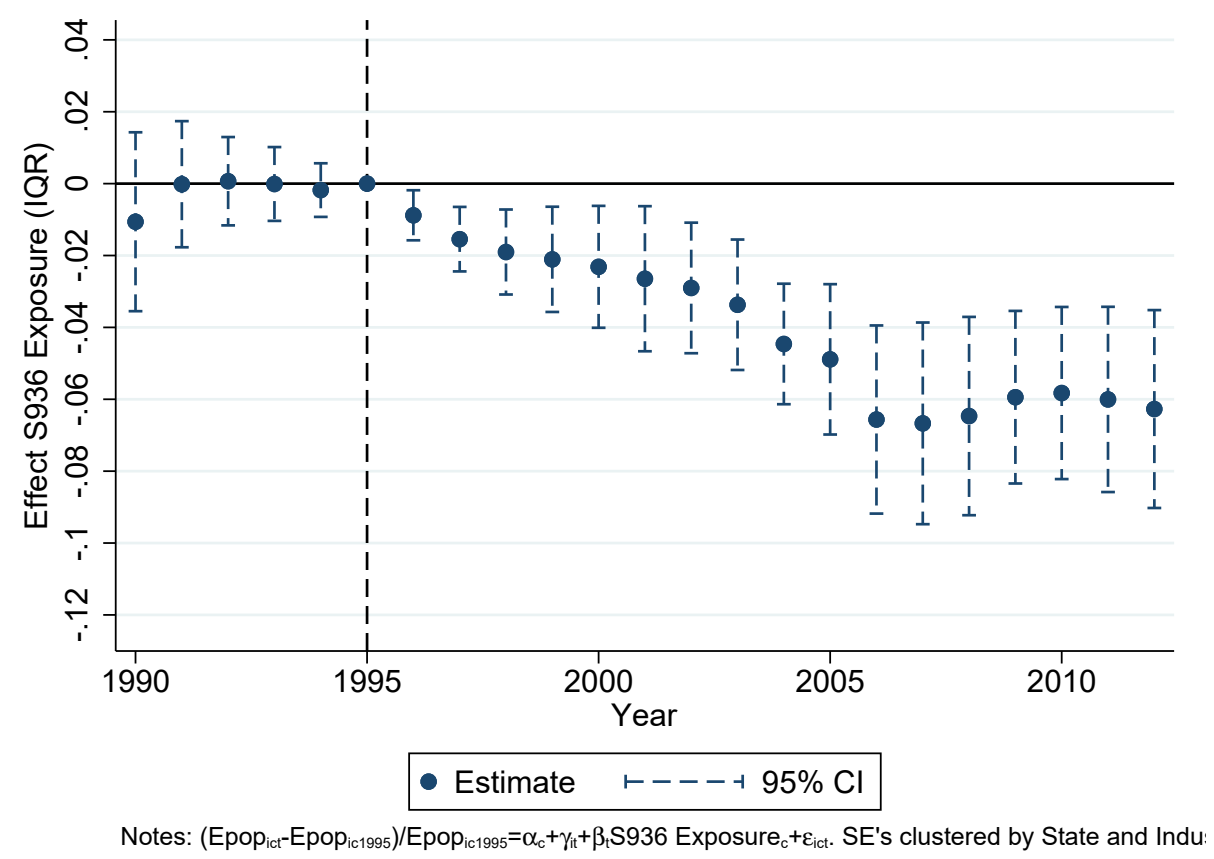

B. Effect of $§ 936$ Exposure on Employment-to-Pop Ratio in Manufacturing (level change)

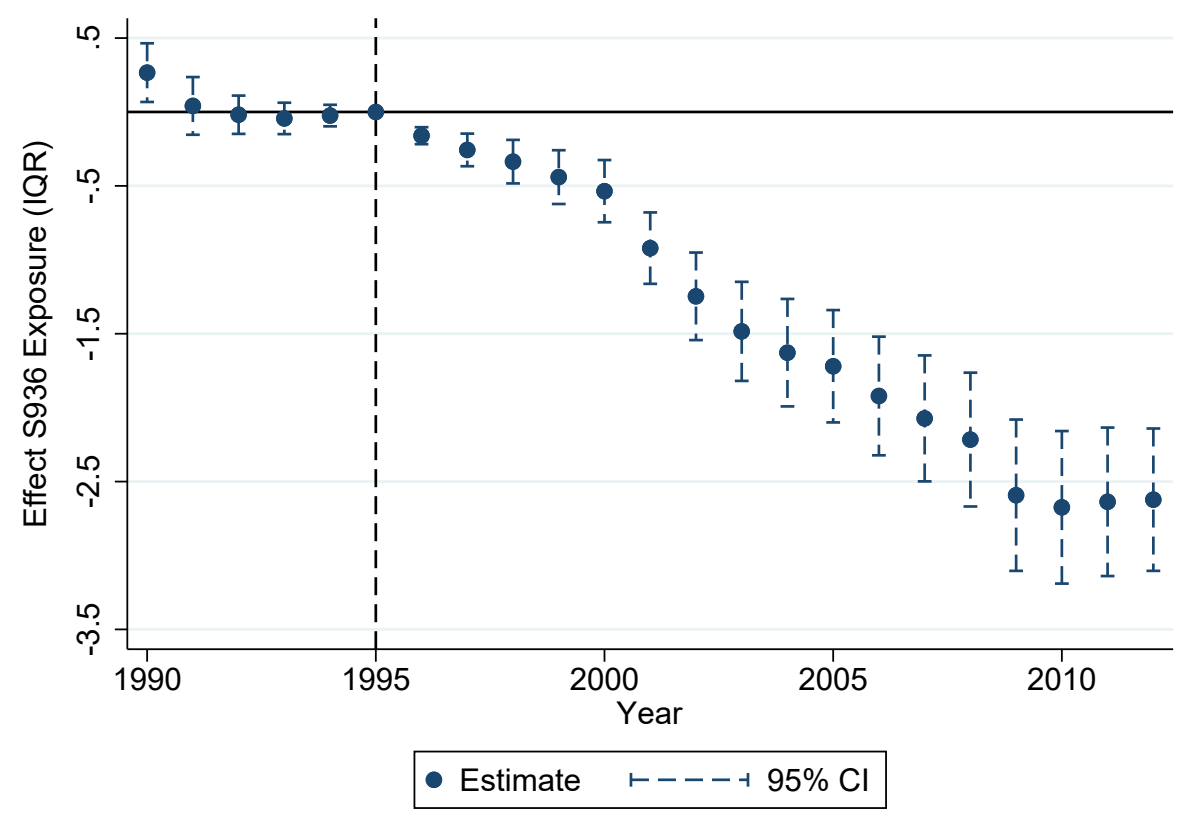

Notes: Epop $_{\mathrm{ict}}$-Epop $_{\mathrm{ic} 1995}=\alpha_{\mathrm{c}}+\gamma_{\mathrm{it}}+\beta_{\mathrm{t}} \mathrm{S} 936$ Exposure $_{\mathrm{c}}+\varepsilon_{\mathrm{ict}}$. SE's clustered by State and Industry.

Notes: Author's calculations using data from NETS, QCEW, and the Census. See Tables A.19 and A.20 for regression coefficients and more specifications. These figures estimate the effect that exposure to $\S 936$ has on the proportion of working age adults who work in the manufacturing sector. Autor et al. (2013) introduce this variable as a potential avenue for assigning dollar values to shocks that influence local labor markets. The top panel show that increasing $§ 936$ exposure from the $25^{\text {th }}$ percentile to the $75^{t h}$ percentile will decrease the percent of working age adults with manufacturing jobs by about $6 \%$ and the lower panel shows that proportion decreases by more than 2.5 percentage points. Standard errors are clustered at the state level. 
Figure A.14: Effect of Exposure to Section 936 on Employment at the County Level, State Time Trend

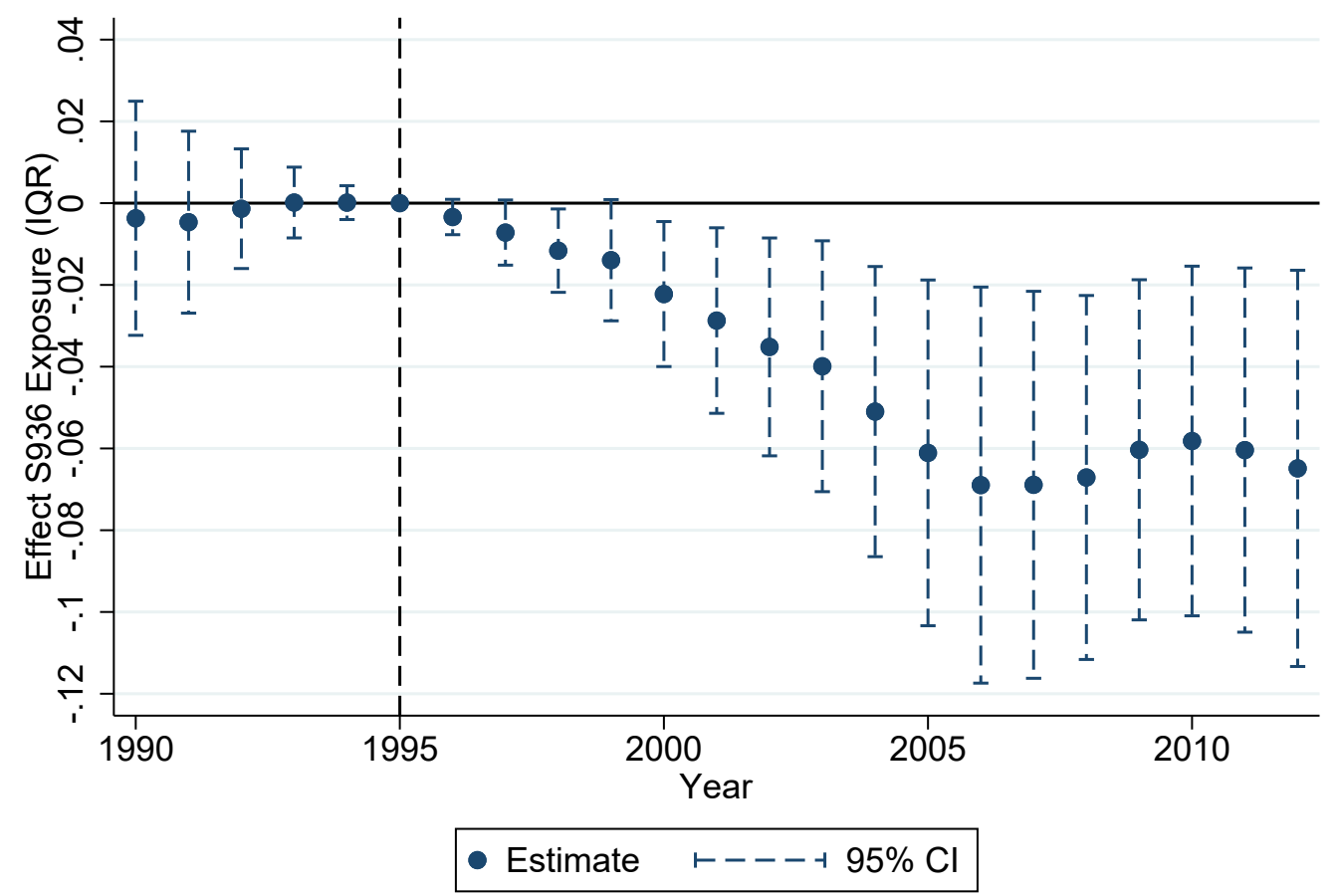

Notes: $\left(\mathrm{Emp}_{\mathrm{ict}}-\mathrm{Emp}_{\mathrm{ic} 1995}\right) / \mathrm{Emp}_{\mathrm{ic} 1995}=\alpha_{\mathrm{c}}+\gamma_{\mathrm{it}}+\beta_{\mathrm{t}} \mathrm{S} 936$ Exposure $_{\mathrm{c}}+\varepsilon_{\mathrm{ict}}$. SE's clustered by State and Industry.

Notes: Author's calculations using data from NETS and QCEW. This figure shows the coefficients for an event study of employment on exposure to $\S 936$ firms. This figure corresponds to Figure 10 with the inclusion of state-specific linear time trends. Standard errors are clustered at the state and industry levels. 
Figure A.15: Employment Effects of $§ 936$ Exposure, Robustness to Focusing Exposure on Largest Firms

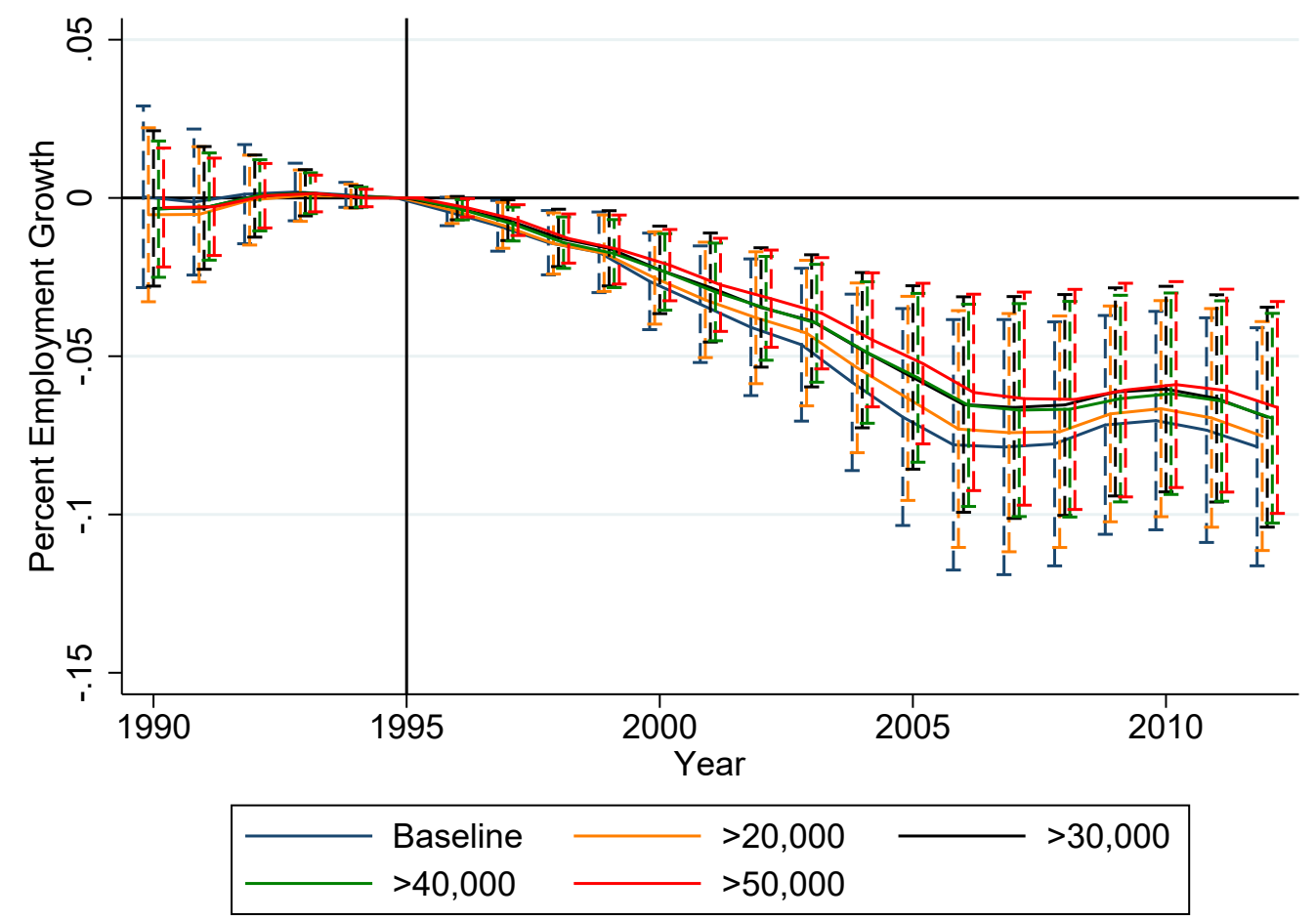

Notes: Author's calculations using data from NETS and QCEW. This figure shows the coefficients for an event study of employment on exposure to $\S 936$ firms where the set of connected firms are restricted to have a large number of employees-20,000, 30,000, 40,000, and 50,000, respectively. This figure corresponds to Figure 10 with the inclusion of shocks that are constructed of firms with a certain size. Standard errors are clustered at the state and industry levels. Standard errors and more details are shown in Table A.16. 


\section{Figure A.16: Heterogeneous Effects of Repealing of $\S 936$ on Employment by Sector, with Confidence Intervals}

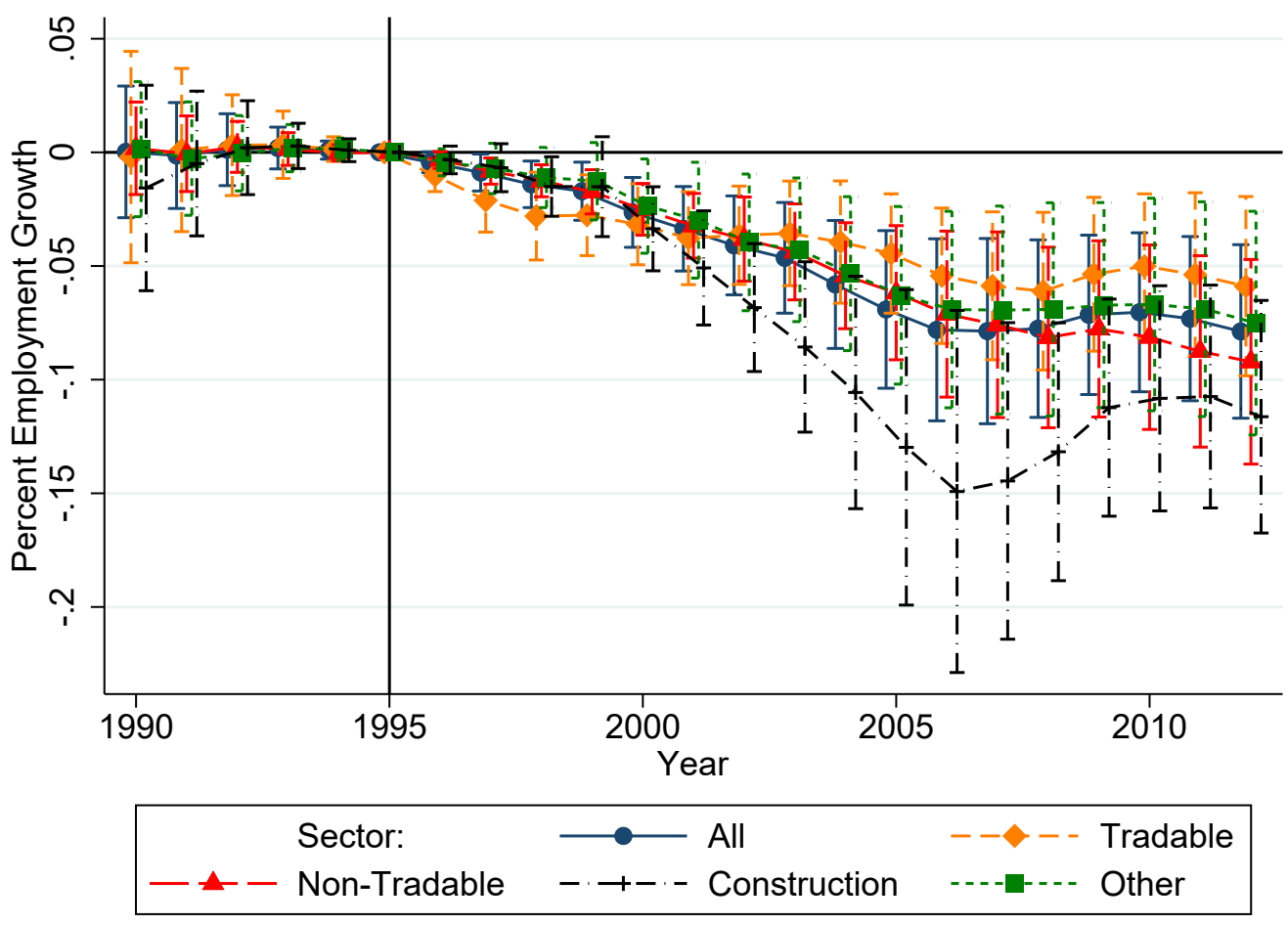

Notes: Author's calculations using data from NETS and QCEW and sector definitions from Mian and Sufi (2014). This figure shows the average effect and the heterogeneous effects by sector with confidence intervals corresponding to Figure 14. Estimates and standard errors are displayed in Table A.26. This figure highlights that the tradable sector sees a decline in employment before any of the other sectors. See Appendix A for a discussion of the data and Section 6 for a discussion of the results. Standard errors are clustered at the state and industry levels. Error bars show $95 \%$ confidence intervals. County observations are weighted according to employment in 1995. 
Figure A.17: Effects of Exposure to $§ 936$ on Adjusted Wages and Rental Costs

A. Wage Growth After 1990

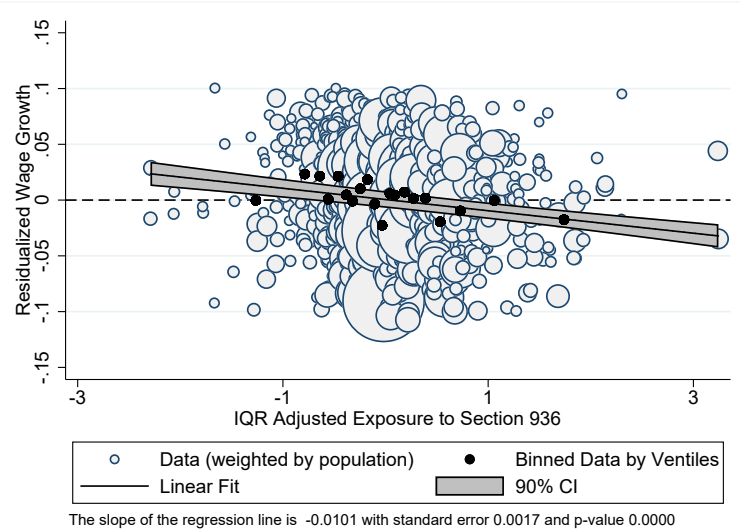

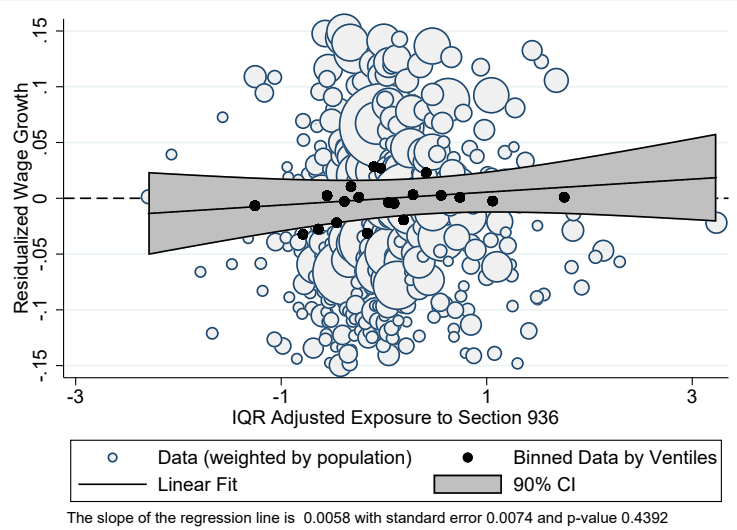

B. Low Skill Wage Growth After 1990

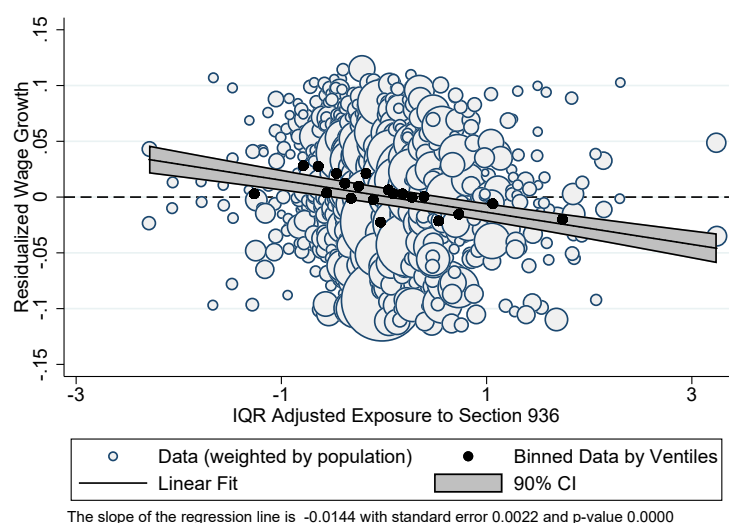

E. Low Skill Wage Growth Before 1990
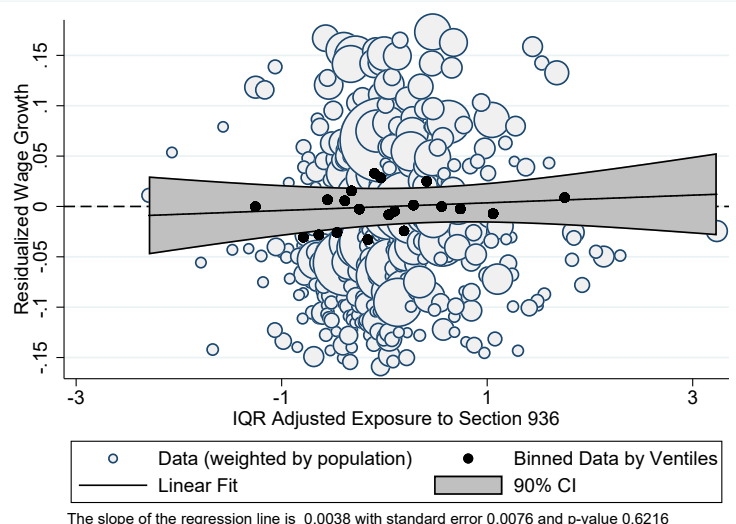

C. Rent Growth After 1990

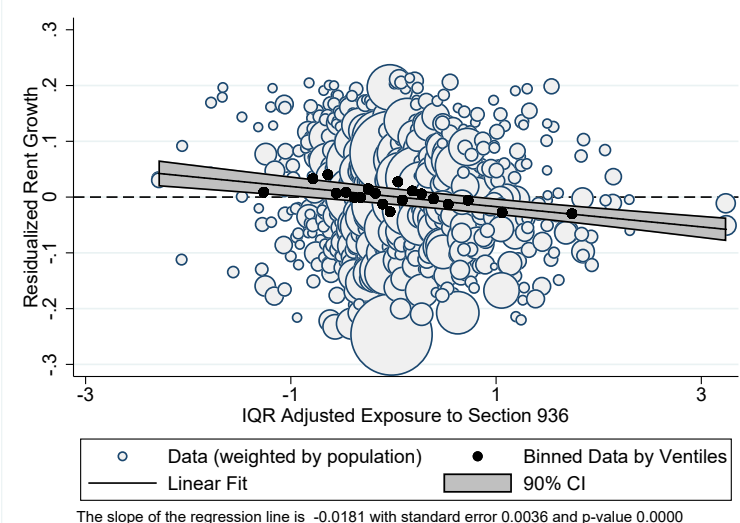

F. Rent Growth Before 1990

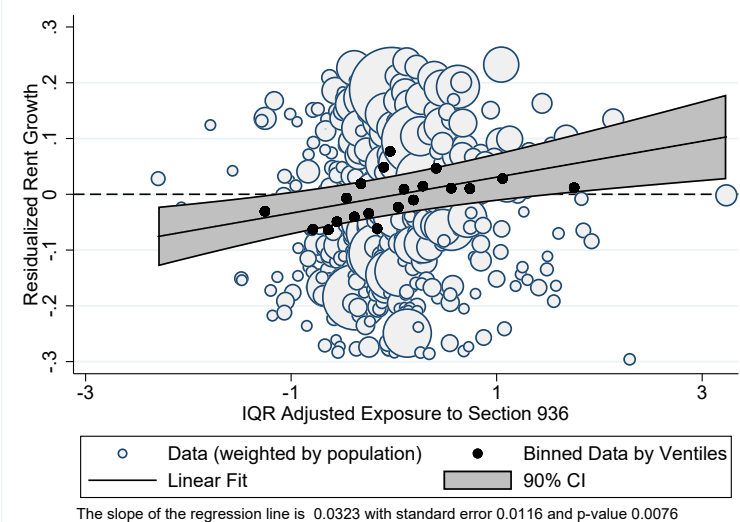

Notes: Author's calculations using data from NETS and Census. Exposure to $\S 936$ is residualized. This figure shows that exposure to $\S 936$ was not correlated with wage and rent growth before the repeal of $\S 936$. See Appendix A for a discussion of the data and Section 6 for a discussion of the results. 


\section{Figure A.18: Repealing §936 Reduced Firm Value of Exposed Firms}

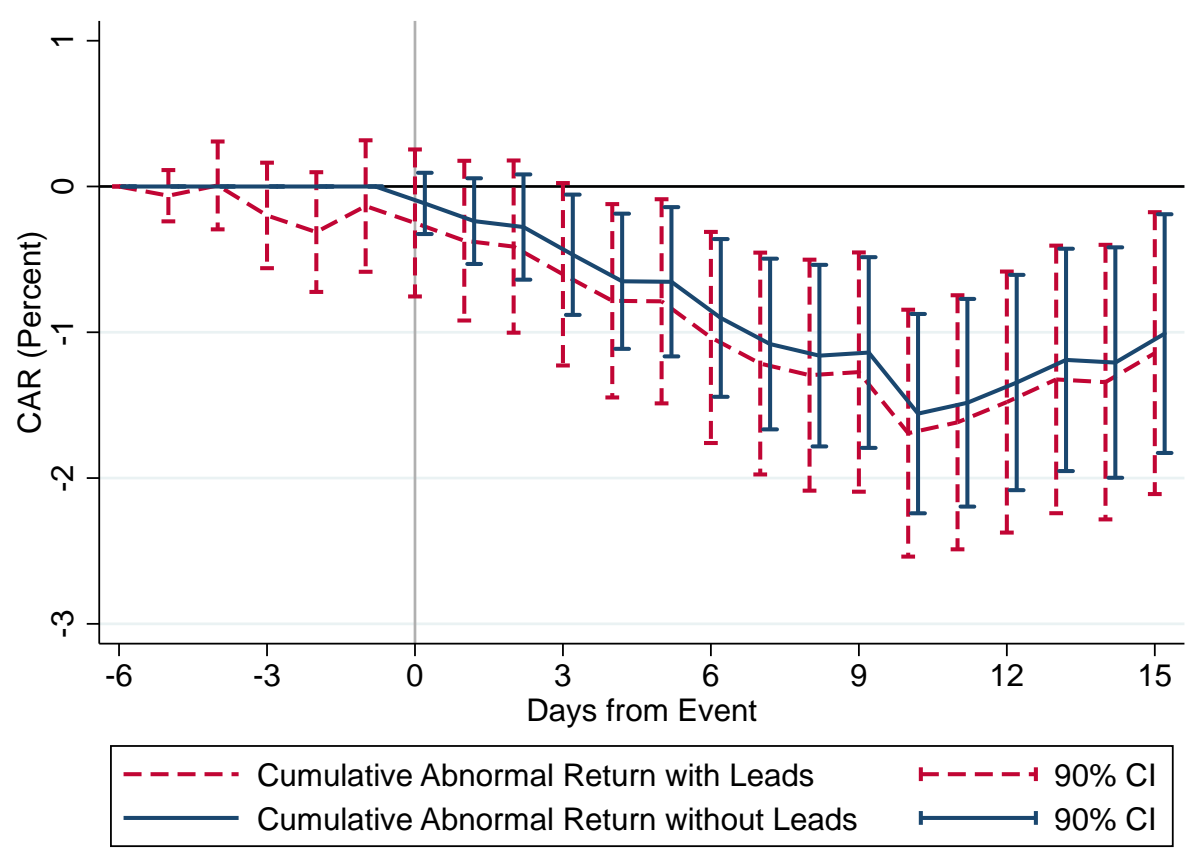

Notes: Author's calculations using data from COMPUSTAT and CRSP. The event study takes place on two dates regarding the repeal of the Possessions Tax Credit: February 16, 1993 and October 12, 1995. Cumulative abnormal returns are calculated for firms with exposure to the Possessions Tax Credit. For more information about the events see Appendix C. This plots the results of Table A.30 for all intermediate dates in $[-6,15]$. It shows that between days $(0,12)$ firms exposed to $\S 936$ experienced a CAR of $-1.4 \%$. The event study results are shown with additional specifications in Table A.31 that include interactions with firm characteristics. As a robustness check, Figure A.19 shows a specification that adjusts for the Fama and French (1993) 3 factors and momentum and finds a similar result. Standard errors are robust. 
Figure A.19: Repealing §936 Reduced Firm Value of Exposed Firms: Robustness CAPM Plus Fama-French Factors and Momentum

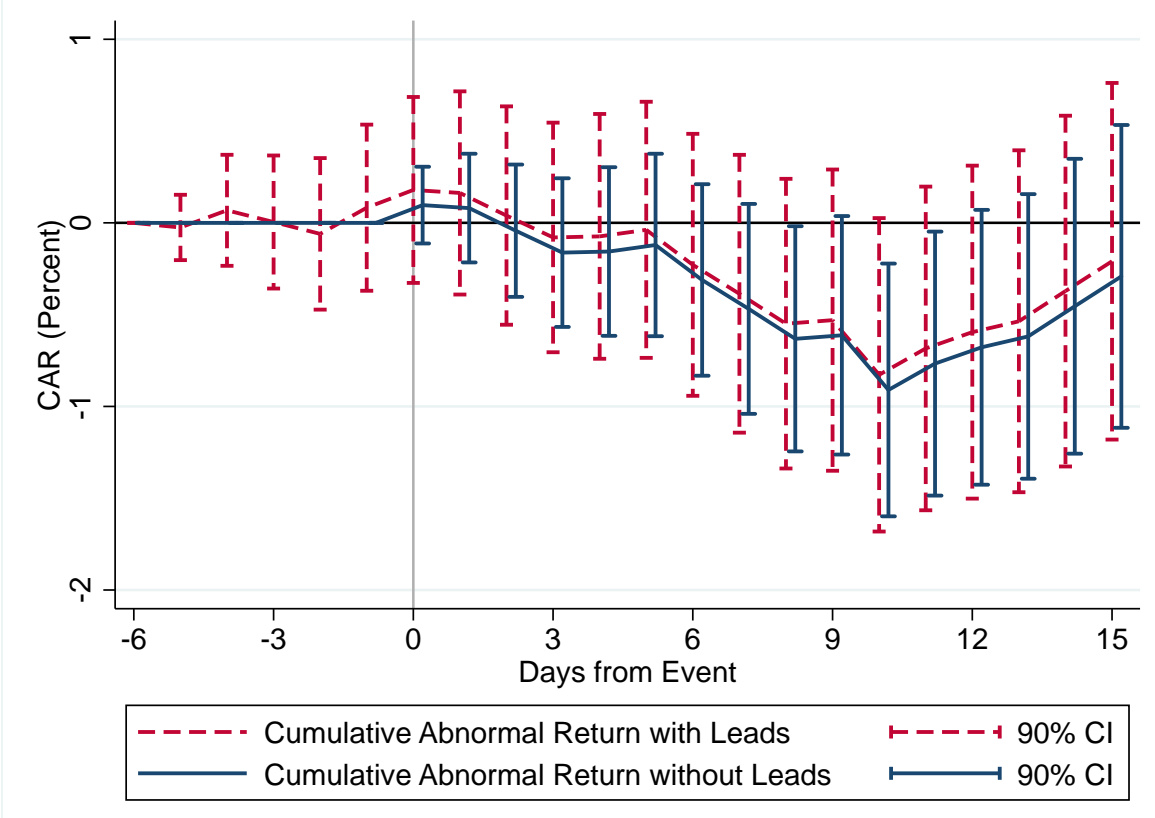

Notes: Author's calculations using data from COMPUSTAT and CRSP. This plots the results of Table A.30 for a wider range of dates. It shows that between days $(0,12)$ firms exposed to $\$ 936$ adjusting for the Fama and French (1993) 3 factors and momentum experienced a CAR of -.8\%. The primary specification without Fama-French Factors or Momentum is shown in Figure A.18. Standard errors are robust. 
Figure A.20: Heterogeneous Employment Effects of Repealing of $§ 936$

\section{A. Interaction Terms}

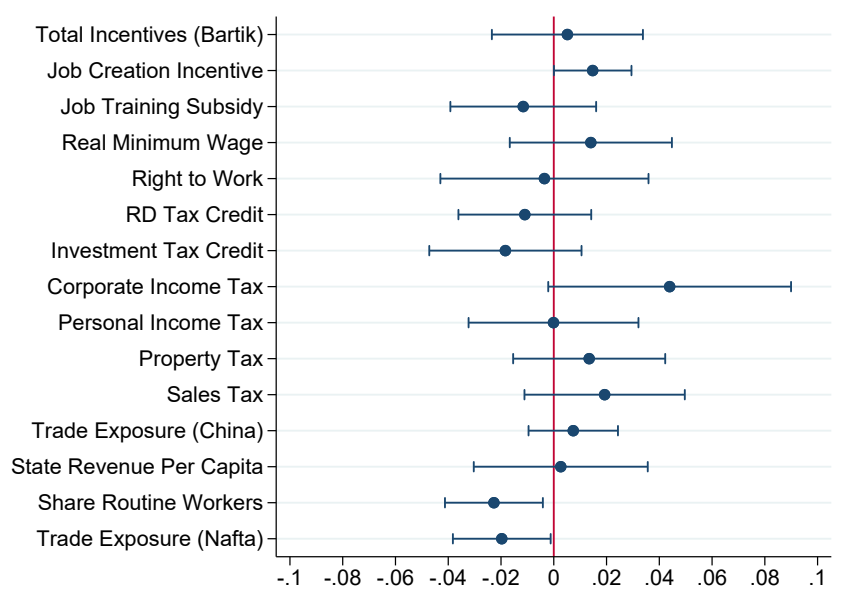

C. Geographic Distribution of Marginal Effects

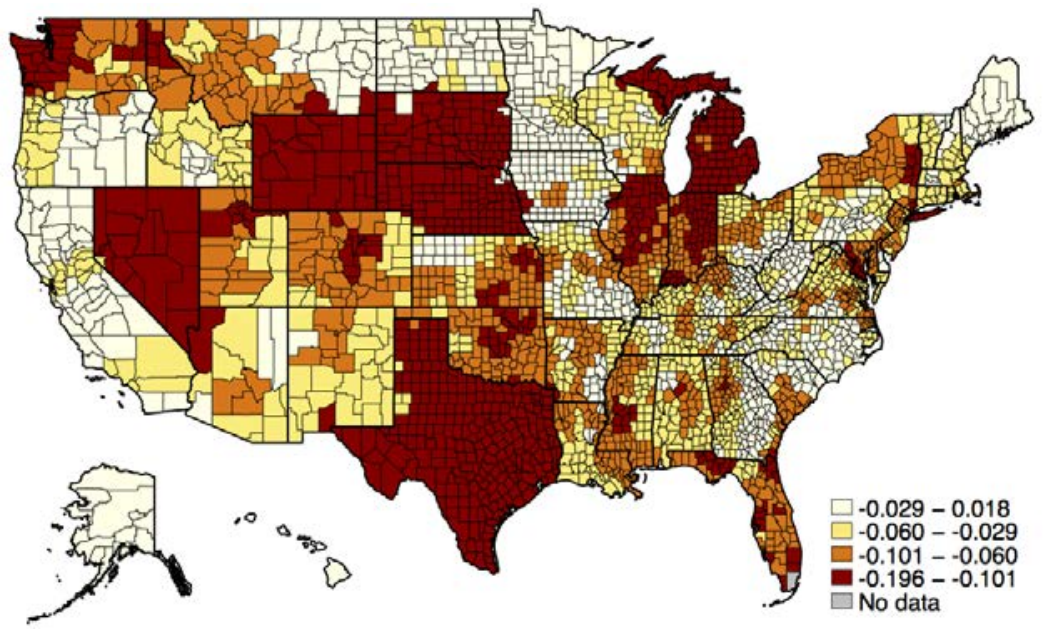

\section{B. Effects of Interactions on Marginal Effect}

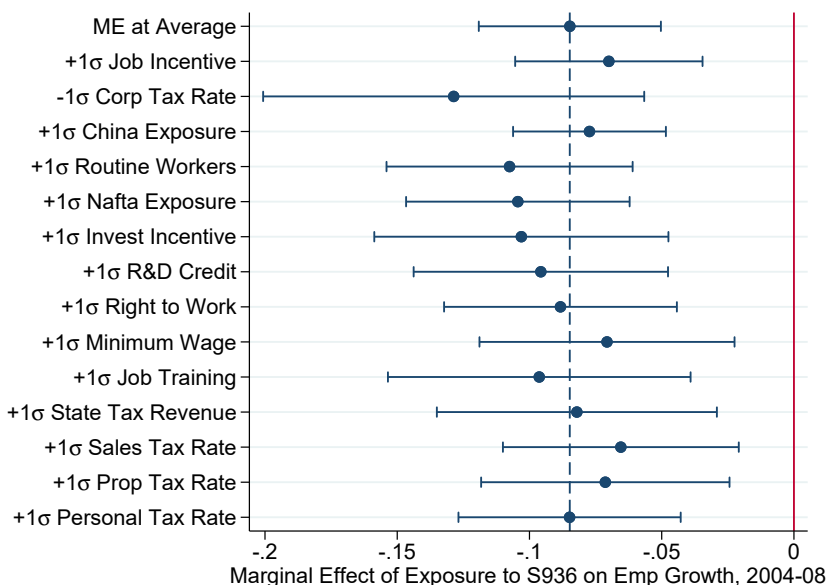

\section{Quantile Regression Estimates}

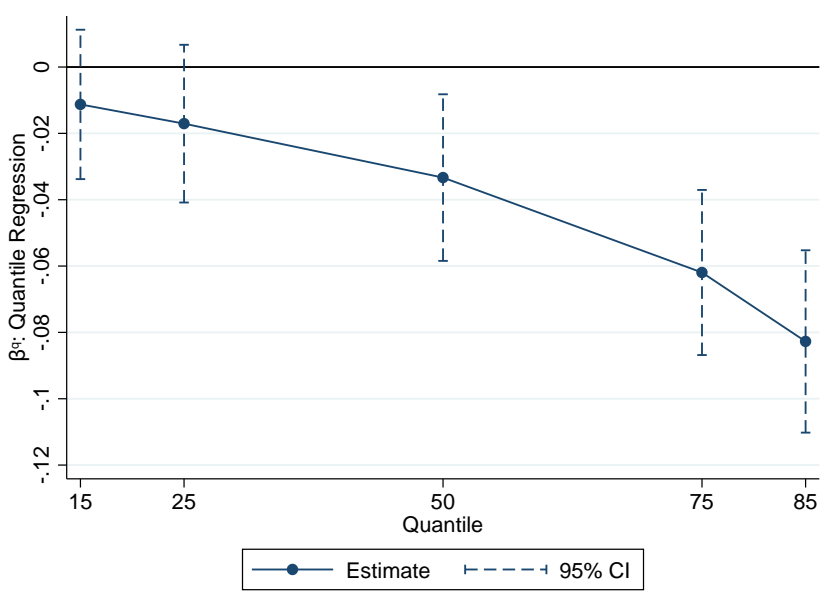

Notes: Author's calculations using data from NETS and QCEW. Panel A plots the individual interaction terms. Panel B plots the marginal effects evaluated at a one standard deviation change from the average. The marginal effect evaluated at the mean is about $8 \%$. The median effect across counties is close to the effect we find when we do not include these controls or interactions. Panel $\mathrm{C}$ plots the distribution of marginal effects across counties and shows that some states had much larger sensitivity to the repeal of $\S 936$. Panel D takes a different approach to characterizing the heterogeneity in effects and plots estimates of quantile regressions. These estimates show that the repeal of $\S 936$ had larger effects on counties that were growing faster. This implies that, while the repeal of $\S 936$ saw declines in growth across all counties, it also a led to a compression in the distribution of growth rates. ${ }^{*} p<0.1,{ }^{* *} p<0.05,{ }^{* * *} p<0.01$ 
Table A.1: Regressions of ETR on $§ 936$ Credits/Taxable Income

\begin{tabular}{lcccccc}
\hline \hline & $(1)$ & $(2)$ & $(3)$ & $(4)$ & $(5)$ & $(6)$ \\
\hline Possession Credits & -0.816 & -0.943 & -0.816 & & & \\
& $(0.252)$ & $(0.283)$ & $(0.314)$ & & & \\
& 0.004 & 0.003 & 0.016 & & & \\
Change in Possession Credits & & & & -0.771 & -0.718 & -0.767 \\
& & & & $(0.175)$ & $(0.225)$ & $(0.258)$ \\
& & & & 0.000 & 0.004 & 0.007 \\
\hline Year Fixed Effects & Yes & Yes & Yes & Yes & Yes & Yes \\
Industry Fixed Effects & Yes & Yes & Yes & & & \\
Net Income and Sales Controls & & Yes & Yes & & Yes & Yes \\
$\begin{array}{l}\text { Regression in First Differences } \\
\text { Taxable Income Weights }\end{array}$ & & & & Yes & Yes & Yes \\
Net Income Weights & Yes & & Yes & Yes & \\
\hline \hline
\end{tabular}

Notes: Author's calculations and data from SOI. This table shows regressions of effective tax rate on the US Possessions Tax credit in levels and in first differences. For each additional dollar of $\S 926$ credits, the effective tax rate goes down by 0.7 to 0.95 dollars in response. Standard errors clustered at the industry level are shown in parantheses with p-values below. Industries are weighted according to income before and after tax. For more information and discussion, see Appendix B. 
Table A.2: Firm Characteristics of the Firms with Compustat Data

\begin{tabular}{|c|c|c|c|c|c|c|}
\hline & \multicolumn{3}{|c|}{ S936 Firms } & \multicolumn{3}{|c|}{ All Control Firms } \\
\hline & Mean & $\mathrm{SD}$ & Count & Mean & $\mathrm{SD}$ & Count \\
\hline \multicolumn{7}{|l|}{ General Characteristics } \\
\hline Cash ETR & 0.351 & 0.302 & 263 & 0.482 & 0.427 & 11177 \\
\hline Federal Taxes Paid & 133.272 & 269.024 & 219 & 13.055 & 69.057 & 7654 \\
\hline Multinational & 0.973 & 0.161 & 263 & 0.970 & 0.170 & 11177 \\
\hline Net Operating Loss & 0.529 & 0.500 & 263 & 0.684 & 0.465 & 11177 \\
\hline Natural Log of Assets & 7.631 & 2.011 & 262 & 4.475 & 2.477 & 9907 \\
\hline \multicolumn{7}{|l|}{ Spending } \\
\hline Research and Development & 0.027 & 0.059 & 262 & 0.068 & 0.199 & 9629 \\
\hline Advertising & 0.012 & 0.036 & 262 & 0.008 & 0.052 & 9629 \\
\hline Capital Expenditures & 0.225 & 0.127 & 247 & 0.365 & 2.808 & 8339 \\
\hline \multicolumn{7}{|l|}{ Capital and Financing } \\
\hline Plants, Property, and Equipment & 0.286 & 0.187 & 260 & 0.270 & 0.258 & 9666 \\
\hline Leverage Ratio & 0.262 & 0.210 & 262 & 0.592 & 16.998 & 9907 \\
\hline Book to Debt Ratio & -0.001 & 0.021 & 139 & 0.020 & 0.370 & 1492 \\
\hline Intangibles & 0.101 & 0.121 & 211 & 0.061 & 0.129 & 8617 \\
\hline
\end{tabular}

Notes: This table reports the mean characteristics and firm counts with non-missing data from Compustat separately for $\S 936$ and control firms. 
Table A.3: Counties with Notable Section 936 Exposure in 1995

\begin{tabular}{lcccc}
\hline \hline Rank & County & S936 Est Exposure & County & S936 Emp Exposure \\
\hline 1 & Livingston County, Michigan & 0.003 & El Dorado County, California & 0.007 \\
2 & Sussex County, New Jersey & 0.004 & Sussex County, New Jersey & 0.008 \\
3 & Hernando County, Florida & 0.004 & San Luis Obispo County, California & 0.014 \\
4 & Kings County, New York & 0.004 & Bronx County, New York & 0.015 \\
5 & El Dorado County, California & 0.004 & Hernando County, Florida & 0.016 \\
6 & San Luis Obispo County, California & 0.004 & Livingston County, Michigan & 0.018 \\
7 & Bronx County, New York & 0.005 & Yakima County, Washington & 0.018 \\
8 & Tolland County, Connecticut & 0.005 & Whatcom County, Washington & 0.018 \\
9 & Marin County, California & 0.005 & Jackson County, Oregon & 0.019 \\
10 & Yavapai County, Arizona & 0.005 & Barnstable County, Massachusetts & 0.020 \\
448 & Mecklenburg County, North Carolina & 0.028 & Mercer County, New Jersey & 0.257 \\
449 & Vanderburgh County, Indiana & 0.029 & Durham County, North Carolina & 0.258 \\
450 & DuPage County, Illinois & 0.029 & Trumbull County, Ohio & 0.262 \\
451 & Hampton city, Virginia & 0.030 & Forsyth County, North Carolina & 0.267 \\
452 & Shelby County, Tennessee & 0.030 & Lake County, Illinois & 0.274 \\
453 & St. Louis city, Missouri & 0.030 & Brazoria County, Texas & 0.280 \\
454 & Bibb County, Georgia & 0.031 & Hartford County, Connecticut & 0.296 \\
455 & New Castle County, Delaware & 0.032 & Somerset County, New Jersey & 0.312 \\
456 & Henrico County, Virginia & 0.036 & Aiken County, South Carolina & 0.322 \\
457 & Bergen County, New Jersey & 0.037 & Genesee County, Michigan & 0.342 \\
\hline \hline
\end{tabular}

Notes: This table lists the top and bottom 10 counties in terms of exposure to Section 936 through percent of linked establishments (S936 Est Exposure) and percent of linked employment (S936 Emp Exposure). The sample of counties for inclusion in this table is restricted to those with more than 100,000 population in 1995. Data come from NETS (Walls \& Associates, 2012). 
Table A.4: Puerto Rico Link, Demographic Characteristics, and Economic Polices

\begin{tabular}{|c|c|c|c|c|c|}
\hline & $\begin{array}{c}(1) \\
\text { Min Wage }\end{array}$ & $\begin{array}{c}(2) \\
\text { Right to Work }\end{array}$ & $\begin{array}{c}(3) \\
\text { Pers. Income Tax }\end{array}$ & $\begin{array}{c}(4) \\
\text { Sales Tax }\end{array}$ & $\begin{array}{c}(5) \\
\text { Prop. Tax }\end{array}$ \\
\hline \multirow[t]{5}{*}{ Exposure to Section 936} & -0.174 & -0.050 & -0.009 & -0.081 & -0.008 \\
\hline & $(0.093)$ & $(0.084)$ & $(0.126)$ & $(0.115)$ & $(0.061)$ \\
\hline & 0.070 & 0.560 & 0.943 & 0.485 & 0.902 \\
\hline & $(1)$ & $(2)$ & $(3)$ & $(4)$ & $(5)$ \\
\hline & Corporate Tax & R\&D Credit & State Revenue/GDP & Trade Exposure (China) & Share of Routine Labor \\
\hline \multirow[t]{5}{*}{ Exposure to Section 936} & -0.033 & -0.103 & -0.123 & -0.042 & -0.003 \\
\hline & $(0.098)$ & $(0.078)$ & $(0.092)$ & $(0.032)$ & $(0.098)$ \\
\hline & 0.741 & 0.200 & 0.190 & 0.199 & 0.975 \\
\hline & $(1)$ & $(2)$ & $(3)$ & $(4)$ & $(5)$ \\
\hline & LFPR & $\%$ Retail & $\%$ Agriuclture & $\%$ Manuf. Durable & $\%$ Manuf. Non-Durable \\
\hline \multirow[t]{5}{*}{ Exposure to Section 936} & -0.007 & 0.090 & -0.049 & -0.052 & -0.011 \\
\hline & $(0.111)$ & $(0.093)$ & $(0.061)$ & $(0.070)$ & $(0.044)$ \\
\hline & 0.950 & 0.340 & 0.430 & 0.467 & 0.813 \\
\hline & $(1)$ & $(2)$ & $(3)$ & $(4)$ & $(5)$ \\
\hline & Capital Stock & $\%$ College & $\%$ Less HS & $\%$ White & $\%$ Black \\
\hline \multirow[t]{3}{*}{ Exposure to Section 936} & -0.141 & 0.282 & 0.029 & -0.110 & 0.080 \\
\hline & $(0.143)$ & $(0.124)$ & $(0.105)$ & $(0.308)$ & $(0.257)$ \\
\hline & 0.329 & 0.027 & 0.783 & 0.723 & 0.756 \\
\hline
\end{tabular}

Notes: This table shows correlations between the Exposure to Section 936 and other policy variables at the county level. Robust standard errors are shown in parentheses and p-values are displayed below standard errors. Exposure to Section 936 is calculated using data from NETS. Economic policies and other local characteristics come from the Bureau of Economic Analysis and the Bureau of Labor Statistics as gathered by Suárez Serrato and Wingender (2016), import exposure and routine labor shares come from Autor et al. (2016), and industry proportions are calculated from QCEW (2017). For more information on the calculation see Section 4 and for more information about the data see Appendix A. 
Table A.5: Effect of Repealing $§ 936$ on the Percent Change in Investment of Exposed Firms

\begin{tabular}{lcccccc}
\hline \hline Percent Change in Investment: $\frac{I}{I_{-} 1990-1995}-1$ & & & & & \\
& $(1)$ & $(2)$ & $(3)$ & $(4)$ & $(5)$ & $(6)$ \\
\hline Exposure to Section 936 X Post & -0.469 & -0.485 & -0.415 & -0.532 & -0.565 & -0.450 \\
& $(0.173)$ & $(0.173)$ & $(0.144)$ & $(0.168)$ & $(0.199)$ & $(0.178)$ \\
& 0.007 & 0.005 & 0.004 & 0.002 & 0.005 & 0.012 \\
\hline Observations & 78698 & 78681 & 78681 & 42615 & 35980 & 34725 \\
Sample Average I/K in 2006 Relative to 1995 & 4.197 & 4.197 & 4.197 & 3.560 & 3.587 & 3.664 \\
Percent of 2006 Average & $11.2 \%$ & $11.6 \%$ & $9.9 \%$ & $14.9 \%$ & $15.7 \%$ & $12.3 \%$ \\
Change in Effective Tax Rate & 5.727 & 5.727 & 5.727 & 4.653 & 6.010 & 6.010 \\
Semi-elasticity of Investment & 1.95 & 2.02 & 1.73 & 3.21 & 2.62 & 2.04 \\
\hline Year Fixed Effects & $\mathrm{Y}$ & $\mathrm{Y}$ & $\mathrm{Y}$ & $\mathrm{Y}$ & $\mathrm{Y}$ & $\mathrm{Y}$ \\
NAICS-by-Year Fixed Effects & & $\mathrm{Y}$ & $\mathrm{Y}$ & $\mathrm{Y}$ & $\mathrm{Y}$ & $\mathrm{Y}$ \\
Firm Fixed Effects & & & $\mathrm{Y}$ & $\mathrm{Y}$ & $\mathrm{Y}$ & $\mathrm{Y}$ \\
S936 Exposed Sector & & & & $\mathrm{Y}$ & $\mathrm{Y}$ & $\mathrm{Y}$ \\
S936 Exposed Industry & & & & & $\mathrm{Y}$ & $\mathrm{Y}$ \\
DFL Weights & & & & & & $\mathrm{Y}$ \\
\hline \hline
\end{tabular}

Notes: Author's calculations using data from COMPUSTAT. This table estimates Equation 2 where the dependent variable is the percent change in investment relative to investment in 19901995 winsorized at the $5 \%$ level. The estimates in this table correspond to a pooled version of the regression displayed in Figure A.5. These estimates reflect the percent change in investment at firms exposed to Section 936 after 1996 and show robustness to the variable measurement in the preferred specifications displayed in Table 2. See Section 5 for discussion and Appendix A for more information about the data and variables. Standard errors clustered at the firm level are shown in parentheses with p-values below. 
Table A.6: Effect of Repealing $§ 936$ on the Investment Relative to Capital of Exposed Firms, Winsorized at $1 \%$

\begin{tabular}{lcccccc}
\hline Change in Investment: $\frac{I}{K-1990-1995}$ & & & & & & \\
& $(1)$ & $(2)$ & $(3)$ & $(4)$ & $(5)$ & $(6)$ \\
\hline \multicolumn{1}{c}{ Exposure to Section 936 X Post } & -0.400 & -0.383 & -0.377 & -0.375 & -0.478 & -0.410 \\
& $(0.132)$ & $(0.130)$ & $(0.093)$ & $(0.095)$ & $(0.117)$ & $(0.086)$ \\
& 0.002 & 0.003 & 0.000 & 0.000 & 0.000 & 0.000 \\
\hline Observations & 79393 & 79376 & 79376 & 42734 & 36089 & 34821 \\
Sample Average I/K in 2006 & 2.066 & 2.066 & 2.066 & 1.472 & 1.591 & 1.636 \\
Percent of 2006 Average & $19.3 \%$ & $18.5 \%$ & $18.2 \%$ & $25.5 \%$ & $30.0 \%$ & $25.1 \%$ \\
Change in Effective Tax Rate & 5.727 & 5.727 & 5.727 & 4.653 & 6.010 & 6.010 \\
Semi-elasticity of Investment & 3.38 & 3.23 & 3.19 & 5.47 & 5.00 & 4.17 \\
\hline Year Fixed Effects & $\mathrm{Y}$ & $\mathrm{Y}$ & $\mathrm{Y}$ & $\mathrm{Y}$ & $\mathrm{Y}$ & $\mathrm{Y}$ \\
NAICS-by-Year Fixed Effects & & $\mathrm{Y}$ & $\mathrm{Y}$ & $\mathrm{Y}$ & $\mathrm{Y}$ & $\mathrm{Y}$ \\
Firm Fixed Effects & & & $\mathrm{Y}$ & $\mathrm{Y}$ & $\mathrm{Y}$ & $\mathrm{Y}$ \\
S936 Exposed Sector & & & & $\mathrm{Y}$ & $\mathrm{Y}$ & $\mathrm{Y}$ \\
S936 Exposed Industry & & & & & $\mathrm{Y}$ & $\mathrm{Y}$ \\
DFL Weights & & & & & & $\mathrm{Y}$ \\
\hline \hline
\end{tabular}

Notes: Author's calculations using data from COMPUSTAT. This table estimates Equation 2 where the dependent variable is investment divided by average capital in 1990-1995 winsorized at the $1 \%$ level. The estimates in this table correspond to a pooled version of the regression displayed in Figure A.6. These estimates reflect the percent change in investment at firms exposed to Section 936 after 1996. See Section 5 for more discussion and Appendix A for more information about the data and variables. The same regressions with the dependent variable winsorized at the 5\% level are shown in Table 2. Standard errors clustered at the firm level are shown in parentheses with p-values below. 
Table A.7: Effect of Repealing $§ 936$ on the Investment Relative to Capital of Exposed Firms:

Robustness to Controls

\begin{tabular}{|c|c|c|c|c|c|c|c|c|}
\hline Change in Investment: $\frac{1}{K_{-} 1990-1995}$ & (1) & $(2)$ & $(3)$ & $(4)$ & $(5)$ & (6) & (7) & (8) \\
\hline \multirow[t]{3}{*}{ Exposure to Section 936 X Post } & -0.119 & -0.118 & -0.132 & -0.105 & -0.142 & -0.144 & -0.150 & -0.181 \\
\hline & $(0.043)$ & $(0.043)$ & $(0.044)$ & $(0.043)$ & $(0.052)$ & $(0.052)$ & $(0.051)$ & $(0.048)$ \\
\hline & 0.006 & 0.006 & 0.002 & 0.015 & 0.007 & 0.006 & 0.003 & 0.000 \\
\hline Observations & 79376 & 79376 & 79393 & 79393 & 34821 & 34821 & 34821 & 34821 \\
\hline Sample Average I/K in 2006 & 1.174 & 1.174 & 1.174 & 1.174 & 1.018 & 1.018 & 1.018 & 1.018 \\
\hline Percent of 2006 Average & $10.1 \%$ & $10.1 \%$ & $11.3 \%$ & $9.0 \%$ & $14.0 \%$ & $14.1 \%$ & $14.8 \%$ & $17.8 \%$ \\
\hline Change in Effective Tax Rate & 5.727 & 5.727 & 5.727 & 5.727 & 6.010 & 6.010 & 6.010 & 6.010 \\
\hline Semi-elasticity of Investment & 1.77 & 1.76 & 1.97 & 1.57 & 2.33 & 2.35 & 2.46 & 2.96 \\
\hline 2 digit NAICS-by-Year Fixed Effects & $\mathrm{Y}$ & $\mathrm{Y}$ & & & $\bar{Y}$ & $\mathrm{Y}$ & & \\
\hline 3 digit NAICS-by-Year Fixed Effects & & & $\mathrm{Y}$ & $\mathrm{Y}$ & & & Y & Y \\
\hline Firm Fixed Effects & Y & $\mathrm{Y}$ & $\mathrm{Y}$ & $\mathrm{Y}$ & Y & Y & Y & Y \\
\hline Size Control (Employment) & $\mathrm{Y}$ & & $\mathrm{Y}$ & $\mathrm{Y}$ & $\mathrm{Y}$ & & Y & $\mathrm{Y}$ \\
\hline Size Control (Cubic in Revenue) & & & & $\mathrm{Y}$ & & & & $\mathrm{Y}$ \\
\hline S936 Exposed Sector & & & & & $\mathrm{Y}$ & Y & Y & $\mathrm{Y}$ \\
\hline S936 Exposed Industry & & & & & $\mathrm{Y}$ & Y & $\mathrm{Y}$ & $\mathrm{Y}$ \\
\hline DFL Weights & & & & & $\mathrm{Y}$ & $\mathrm{Y}$ & Y & $\mathrm{Y}$ \\
\hline
\end{tabular}

Notes: Author's calculations using data from COMPUSTAT. This table estimates Equation 2. This table shows that the results in Table 2 are robust to using different controls for industry and firm size. All columns control for firm fixed effects and firm size measured as the inverse hyperbolic sine of revenue. Columns (1) and (5) of this table correspond to columns (3) and (6) of Table 2. Columns (2) and (6) show we obtain similar results when we do not control for log-employment. Columns (3) and (7) show we obtain similar results when we control for 3-digit NAICS-by-year fixed effects instead of 2-digit NAICS-by-year fixed effects. Finally, columns (4) and (8) show we obtain similar results when we additionally control for a cubic polynomial in our revenue measure. See Section 5 for more discussion and Appendix A for more information about the data and variables. Standard errors clustered at the firm level are shown in parentheses with p-values below. 
Table A.8: Effect of Repealing $§ 936$ on the Federal Taxes Paid as a Percent of Pretax Income

\begin{tabular}{lcccccc}
\hline \hline & & & & & & \\
& $(1)$ & $(2)$ & $(3)$ & $(4)$ & $(5)$ & $(6)$ \\
\hline \multicolumn{1}{c}{ Exposure to Section 936 X Post } & 4.190 & 4.873 & 4.675 & 7.830 & 6.614 & 7.246 \\
& $(2.132)$ & $(2.119)$ & $(2.288)$ & $(3.286)$ & $(3.689)$ & $(3.383)$ \\
& 0.049 & 0.021 & 0.041 & 0.017 & 0.073 & 0.032 \\
\hline Observations & 33097 & 33074 & 33074 & 17314 & 14065 & 13187 \\
\hline Year Fixed Effects & $\mathrm{Y}$ & $\mathrm{Y}$ & $\mathrm{Y}$ & $\mathrm{Y}$ & $\mathrm{Y}$ & $\mathrm{Y}$ \\
NAICS-by-Year Fixed Effects & & $\mathrm{Y}$ & $\mathrm{Y}$ & $\mathrm{Y}$ & $\mathrm{Y}$ & $\mathrm{Y}$ \\
Fixed Effects & & & $\mathrm{Y}$ & $\mathrm{Y}$ & $\mathrm{Y}$ & $\mathrm{Y}$ \\
S936 Exposed Sector & & & & $\mathrm{Y}$ & $\mathrm{Y}$ & $\mathrm{Y}$ \\
S936 Exposed Industry & & & & $\mathrm{Y}$ & $\mathrm{Y}$ \\
DFL Weights & & & & & $\mathrm{Y}$ \\
\hline \hline
\end{tabular}

Notes: Author's calculations using data from COMPUSTAT. This table estimates a version of Equation 2 where the dependent variable is cash federal taxes paid divided by US pretax income. These estimates reflect the percent change in federal taxes paid as a percent of pretax income at firms exposed to Section 936 after 1995. The last column shows that federal taxes paid as a percent of US pretax income increased by 7.2pp at exposed firms after the repeal of $\S 936$. We use the share of revenue originating in the US as a proxy for the share of pretax income originating in the domestic market, which is $75 \%$ on average, and the sample is restricted to those firms with non-trivial pretax income. The estimated change in effective tax rate is similar to the tax increase estimates of 4.5-5.9pp discussed in Appendix B. See Section 5 and Appendix $\mathrm{B}$ for additional discussion and Appendix A for more information about the data and variables. Clustered standard errors at the firm level are shown in parentheses with p-values below. 
Table A.9: Change in Total Effective Tax Rate in Treated Firms

\begin{tabular}{lcccccc}
\hline \hline Change in Global Taxes Paid as a Percent of Pretax Income & & \\
& $(1)$ & $(2)$ & $(3)$ & $(4)$ & $(5)$ & $(6)$ \\
\hline \multicolumn{1}{c}{ Exposure to Section 936 X Post } & 2.446 & 2.681 & 3.262 & 4.264 & 5.642 & 5.156 \\
& $(1.652)$ & $(1.689)$ & $(1.993)$ & $(2.907)$ & $(2.948)$ & $(2.527)$ \\
& 0.139 & 0.112 & 0.102 & 0.143 & 0.056 & 0.041 \\
\hline Observations & 42235 & 42199 & 42199 & 21939 & 17604 & 16565 \\
Change in Effective Tax Rate & 5.727 & 5.727 & 5.727 & 4.653 & 6.010 & 6.010 \\
\hline Year Fixed Effects & $\mathrm{Y}$ & $\mathrm{Y}$ & $\mathrm{Y}$ & $\mathrm{Y}$ & $\mathrm{Y}$ & $\mathrm{Y}$ \\
NAICS-by-Year Fixed Effects & & $\mathrm{Y}$ & $\mathrm{Y}$ & $\mathrm{Y}$ & $\mathrm{Y}$ & $\mathrm{Y}$ \\
Firm Fixed Effects & & & $\mathrm{Y}$ & $\mathrm{Y}$ & $\mathrm{Y}$ & $\mathrm{Y}$ \\
S936 Exposed Sector & & & $\mathrm{Y}$ & $\mathrm{Y}$ & $\mathrm{Y}$ \\
S936 Exposed Industry & & & & $\mathrm{Y}$ & $\mathrm{Y}$ \\
DFL Weights & & & & & $\mathrm{Y}$ \\
\hline \hline
\end{tabular}

Notes: Author's calculations using data from NETS, SOI, and Compustat. This table shows the change in total (global) taxes paid as a percent of pretax income at exposed firms after the repeal of $\S 936$. This table estimates a version of Equation 2 where the dependent variable is global cash taxes paid divided by global pretax income. The last column shows that taxes paid as a percent of global pretax income increased by 5.1pp at exposed firms after the repeal of $\S 936$. The sample is restricted to those firms with non-trivial pretax income. The estimated change in effective tax rate is similar to the tax increase estimates of 4.5-5.9pp discussed in Appendix B. See Appendix B for additional discussion and Appendix A for more information about the data and variables. Clustered standard errors at the firm level are shown in parentheses with p-values below. 
Table A.10: Change in Employment at Exposed Firms Relative to Controls: Robustness

\begin{tabular}{|c|c|c|c|c|c|}
\hline & $(1)$ & $(2)$ & $(3)$ & $(4)$ & $(5)$ \\
\hline \multicolumn{6}{|l|}{ Exposure to Section 936} \\
\hline \multirow[t]{2}{*}{ X 1990} & -0.006 & 0.005 & -0.011 & -0.020 & -0.005 \\
\hline & $(0.010)$ & $(0.012)$ & $(0.018)$ & $(0.019)$ & $(0.021)$ \\
\hline \multirow[t]{2}{*}{ X 1991} & -0.008 & -0.003 & -0.010 & -0.021 & -0.016 \\
\hline & $(0.009)$ & $(0.010)$ & $(0.018)$ & $(0.016)$ & $(0.019)$ \\
\hline \multirow[t]{2}{*}{ X 1992} & -0.011 & -0.007 & -0.014 & -0.020 & -0.014 \\
\hline & $(0.008)$ & $(0.009)$ & $(0.016)$ & $(0.014)$ & $(0.017)$ \\
\hline \multirow[t]{2}{*}{ X 1993} & -0.007 & -0.006 & -0.006 & -0.008 & -0.003 \\
\hline & $(0.006)$ & $(0.006)$ & $(0.009)$ & $(0.009)$ & $(0.012)$ \\
\hline \multirow[t]{2}{*}{ X 1994} & -0.001 & 0.001 & -0.000 & -0.000 & 0.006 \\
\hline & $(0.003)$ & $(0.004)$ & $(0.005)$ & $(0.005)$ & $(0.006)$ \\
\hline \multirow[t]{2}{*}{ X 1996} & -0.010 & -0.011 & $-0.019^{*}$ & $-0.026^{*}$ & -0.017 \\
\hline & $(0.007)$ & $(0.007)$ & $(0.009)$ & $(0.011)$ & $(0.011)$ \\
\hline \multirow[t]{2}{*}{ X 1997} & -0.014 & -0.014 & -0.020 & -0.037 & -0.030 \\
\hline & $(0.011)$ & $(0.011)$ & $(0.017)$ & $(0.020)$ & $(0.019)$ \\
\hline \multirow[t]{2}{*}{ X 1998} & -0.021 & -0.019 & -0.017 & -0.036 & -0.032 \\
\hline & $(0.011)$ & $(0.012)$ & $(0.017)$ & $(0.020)$ & $(0.019)$ \\
\hline \multirow[t]{2}{*}{ X 1999} & -0.022 & -0.016 & -0.014 & -0.032 & -0.029 \\
\hline & $(0.012)$ & $(0.012)$ & $(0.017)$ & $(0.019)$ & $(0.019)$ \\
\hline \multirow[t]{2}{*}{ X 2000} & -0.022 & -0.009 & -0.009 & -0.025 & -0.023 \\
\hline & $(0.013)$ & $(0.014)$ & $(0.018)$ & $(0.020)$ & $(0.020)$ \\
\hline \multirow[t]{2}{*}{ X 2001} & $-0.029^{*}$ & -0.017 & -0.017 & -0.037 & -0.026 \\
\hline & $(0.014)$ & $(0.015)$ & $(0.021)$ & $(0.021)$ & $(0.022)$ \\
\hline \multirow[t]{2}{*}{ X 2002} & $-0.037^{*}$ & -0.024 & -0.020 & $-0.050^{*}$ & -0.031 \\
\hline & $(0.016)$ & $(0.017)$ & $(0.021)$ & $(0.021)$ & $(0.022)$ \\
\hline \multirow[t]{2}{*}{ X 2003} & $-0.046^{* *}$ & -0.028 & -0.022 & $-0.057^{*}$ & -0.037 \\
\hline & $(0.016)$ & $(0.020)$ & $(0.020)$ & $(0.022)$ & $(0.023)$ \\
\hline \multirow[t]{2}{*}{ X 2004} & $-0.060^{* * *}$ & $-0.041^{*}$ & -0.038 & $-0.073^{* * *}$ & $-0.053^{*}$ \\
\hline & $(0.017)$ & $(0.020)$ & $(0.021)$ & $(0.022)$ & $(0.024)$ \\
\hline \multirow[t]{2}{*}{ X 2005} & $-0.066^{* * *}$ & $-0.043^{*}$ & $-0.047^{*}$ & $-0.083^{* * *}$ & $-0.053^{*}$ \\
\hline & $(0.017)$ & $(0.020)$ & $(0.022)$ & $(0.023)$ & $(0.024)$ \\
\hline \multirow[t]{2}{*}{ X 2006} & $-0.072^{* * *}$ & $-0.047^{*}$ & $-0.048^{*}$ & $-0.083^{* * *}$ & -0.039 \\
\hline & $(0.017)$ & $(0.019)$ & $(0.022)$ & $(0.023)$ & $(0.024)$ \\
\hline \multirow[t]{2}{*}{ X 2007} & $-0.074^{* * *}$ & $-0.047^{*}$ & $-0.048^{*}$ & $-0.079^{* * *}$ & -0.036 \\
\hline & $(0.017)$ & $(0.019)$ & $(0.021)$ & $(0.023)$ & $(0.024)$ \\
\hline \multirow[t]{2}{*}{ X 2008} & $-0.083^{* * *}$ & $-0.055^{* *}$ & $-0.054^{*}$ & $-0.087^{* * *}$ & -0.043 \\
\hline & $(0.017)$ & $(0.019)$ & $(0.022)$ & $(0.022)$ & $(0.024)$ \\
\hline \multirow[t]{2}{*}{ X 2009} & $-0.088^{* * *}$ & $-0.060^{* *}$ & $-0.055^{*}$ & $-0.094^{* * *}$ & $-0.049^{*}$ \\
\hline & $(0.016)$ & $(0.019)$ & $(0.023)$ & $(0.021)$ & $(0.022)$ \\
\hline X 2010 & $-0.093^{* * *}$ & $-0.066^{* * *}$ & $-0.055^{*}$ & $-0.094^{* * *}$ & $-0.054^{*}$ \\
\hline & $(0.016)$ & $(0.019)$ & $(0.022)$ & $(0.020)$ & $(0.022)$ \\
\hline X 2011 & $-0.091^{* * *}$ & $-0.067^{* * *}$ & $-0.054^{*}$ & $-0.094^{* * *}$ & $-0.056^{* *}$ \\
\hline & $(0.016)$ & $(0.019)$ & $(0.022)$ & $(0.020)$ & $(0.021)$ \\
\hline X 2012 & $-0.091^{* * *}$ & $-0.069^{* * *}$ & -0.045 & $-0.091^{* * *}$ & $-0.055^{*}$ \\
\hline & $(0.015)$ & $(0.019)$ & $(0.023)$ & $(0.020)$ & $(0.022)$ \\
\hline Observations & 383893 & 383893 & 75026 & 66378 & 49910 \\
\hline Year Fixed Effects & $\mathrm{Y}$ & $\mathrm{Y}$ & $\mathrm{Y}$ & $\mathrm{Y}$ & $\mathrm{Y}$ \\
\hline NAICS-by-Year Fixed Effects & & $\mathrm{Y}$ & $\mathrm{Y}$ & $\mathrm{Y}$ & $\mathrm{Y}$ \\
\hline S936 Exposed Sector & & & Y & Y & Y \\
\hline S936 Exposed Industry & & & & $\mathrm{Y}$ & Y \\
\hline DFL Weights & & & & & Y \\
\hline
\end{tabular}

Notes: Author's calculations using data from NETS. This table shows the decline in employment at $\S 936$ exposed firms relative to similar control firms without exposure to $\S 936$ in the NETS. See Appendix A.4 for a description of the procedure used to generate DFL weights. See Section 5 for more discussion. Standard errors are clustered at the firm level. 
Table A.11: Change in Employment at Exposed Firms Relative to Controls, 20042008

\begin{tabular}{lccccc}
\hline \hline & $(1)$ & $(2)$ & $(3)$ & $(4)$ & $(5)$ \\
& All & Chemicals & Food & Electronics & Other \\
\hline Exposure to Section 936 & -0.071 & -0.141 & -0.000 & -0.134 & -0.064 \\
& $(0.017)$ & $(0.036)$ & $(0.052)$ & $(0.040)$ & $(0.018)$ \\
& 0.000 & 0.000 & 0.995 & 0.001 & 0.000 \\
\hline Observations & 83455 & 83455 & 83455 & 83455 & 83455 \\
\hline Year Fixed Effects & $\mathrm{Y}$ & $\mathrm{Y}$ & $\mathrm{Y}$ & $\mathrm{Y}$ & $\mathrm{Y}$ \\
\hline \hline
\end{tabular}

Notes: Author's calculations using data from NETS. This table shows the decline in employment by 2004-2008 at $\$ 936$ exposed firms relative to similar control firms without exposure to $§ 936$. See Appendix A.4 for a description of the procedure used to generate DFL weights. See Section 5 for more discussion. Standard errors are clustered at the firm level. 
Table A.12: Event Study on Employment at the County Level, Establishment Links Instrumenting for Employment Links

\begin{tabular}{|c|c|c|c|c|c|}
\hline Exposure to Section 936 & $(1)$ & $\overline{(2)}$ & $(3)$ & $(4)$ & $(5)$ \\
\hline \multirow[t]{2}{*}{ X 1990} & 0.000 & 0.000 & 0.000 & 0.010 & -0.008 \\
\hline & $(0.017)$ & $(0.017)$ & $(0.017)$ & $(0.012)$ & $(0.023)$ \\
\hline \multirow[t]{2}{*}{ X 1991} & -0.002 & -0.002 & -0.002 & 0.007 & -0.009 \\
\hline & $(0.014)$ & $(0.014)$ & $(0.014)$ & $(0.010)$ & $(0.019)$ \\
\hline \multirow[t]{2}{*}{ X 1992} & 0.001 & 0.001 & 0.001 & 0.006 & -0.003 \\
\hline & $(0.010)$ & $(0.009)$ & $(0.009)$ & $(0.007)$ & $(0.013)$ \\
\hline \multirow{2}{*}{ X 1993} & 0.002 & 0.002 & 0.002 & 0.004 & -0.001 \\
\hline & $(0.006)$ & $(0.006)$ & $(0.006)$ & $(0.004)$ & $(0.008)$ \\
\hline \multirow[t]{2}{*}{ X 1994} & 0.001 & 0.001 & 0.001 & 0.002 & 0.000 \\
\hline & $(0.002)$ & $(0.002)$ & $(0.002)$ & $(0.002)$ & $(0.003)$ \\
\hline \multirow[t]{2}{*}{ X 1996} & -0.005 & -0.005 & -0.005 & $-0.004^{*}$ & -0.006 \\
\hline & $(0.003)$ & $(0.003)$ & $(0.003)$ & $(0.002)$ & $(0.004)$ \\
\hline \multirow[t]{2}{*}{ X 1997} & $-0.011^{*}$ & $-0.010^{*}$ & $-0.010^{*}$ & $-0.010^{* *}$ & -0.011 \\
\hline & $(0.005)$ & $(0.005)$ & $(0.005)$ & $(0.004)$ & $(0.006)$ \\
\hline \multirow[t]{2}{*}{ X 1998} & $-0.017^{* *}$ & $-0.017^{* *}$ & $-0.017^{* *}$ & $-0.015^{* *}$ & $-0.018^{*}$ \\
\hline & $(0.006)$ & $(0.006)$ & $(0.006)$ & $(0.005)$ & $(0.008)$ \\
\hline \multirow[t]{2}{*}{ X 1999} & $-0.020^{* *}$ & $-0.020^{* *}$ & $-0.020^{* *}$ & $-0.019^{* *}$ & $-0.022^{*}$ \\
\hline & $(0.008)$ & $(0.008)$ & $(0.008)$ & $(0.006)$ & $(0.010)$ \\
\hline \multirow[t]{2}{*}{ X 2000} & $-0.031^{* *}$ & $-0.031^{* *}$ & $-0.031^{* *}$ & $-0.028^{* * *}$ & $-0.036^{* *}$ \\
\hline & $(0.009)$ & $(0.009)$ & $(0.009)$ & $(0.008)$ & $(0.012)$ \\
\hline \multirow[t]{2}{*}{ X 2001} & $-0.040^{* * *}$ & $-0.040^{* * *}$ & $-0.040^{* * *}$ & $-0.037^{* * *}$ & $-0.047^{* *}$ \\
\hline & $(0.011)$ & $(0.011)$ & $(0.011)$ & $(0.009)$ & $(0.015)$ \\
\hline \multirow[t]{2}{*}{ X 2002} & $-0.048^{* * *}$ & $-0.048^{* * *}$ & $-0.048^{* * *}$ & $-0.044^{* * *}$ & $-0.054^{* *}$ \\
\hline & $(0.013)$ & $(0.013)$ & $(0.013)$ & $(0.011)$ & $(0.017)$ \\
\hline \multirow[t]{2}{*}{ X 2003} & $-0.055^{* * *}$ & $-0.055^{* * *}$ & $-0.055^{* * *}$ & $-0.049^{* * *}$ & $-0.061^{* *}$ \\
\hline & $(0.014)$ & $(0.014)$ & $(0.014)$ & $(0.012)$ & $(0.019)$ \\
\hline \multirow[t]{2}{*}{ X 2004} & $-0.069^{* * *}$ & $-0.069^{* * *}$ & $-0.069^{* * *}$ & $-0.063^{* * *}$ & $-0.078^{* * *}$ \\
\hline & $(0.017)$ & $(0.017)$ & $(0.017)$ & $(0.014)$ & $(0.022)$ \\
\hline \multirow[t]{2}{*}{ X 2005} & $-0.082^{* * *}$ & $-0.082^{* * *}$ & $-0.082^{* * *}$ & $-0.073^{* * *}$ & $-0.095^{* * *}$ \\
\hline & $(0.021)$ & $(0.021)$ & $(0.021)$ & $(0.018)$ & $(0.027)$ \\
\hline \multirow[t]{2}{*}{ X 2006} & $-0.092^{* * *}$ & $-0.092^{* * *}$ & $-0.092^{* * *}$ & $-0.083^{* * *}$ & $-0.106^{* *}$ \\
\hline & $(0.024)$ & $(0.024)$ & $(0.024)$ & $(0.021)$ & $(0.031)$ \\
\hline \multirow[t]{2}{*}{ X 2007} & $-0.093^{* * *}$ & $-0.093^{* * *}$ & $-0.093^{* * *}$ & $-0.082^{* * *}$ & $-0.105^{* *}$ \\
\hline & $(0.024)$ & $(0.024)$ & $(0.024)$ & $(0.021)$ & $(0.031)$ \\
\hline \multirow[t]{2}{*}{ X 2008} & $-0.092^{* * *}$ & $-0.092^{* * *}$ & $-0.092^{* * *}$ & $-0.081^{* * *}$ & $-0.103^{* *}$ \\
\hline & $(0.023)$ & $(0.023)$ & $(0.023)$ & $(0.020)$ & $(0.030)$ \\
\hline \multirow[t]{2}{*}{ X 2009} & $-0.085^{* * *}$ & $-0.085^{* * *}$ & $-0.085^{* * *}$ & $-0.074^{* * *}$ & $-0.095^{* *}$ \\
\hline & $(0.021)$ & $(0.021)$ & $(0.021)$ & $(0.017)$ & $(0.027)$ \\
\hline \multirow[t]{2}{*}{ X 2010} & $-0.083^{* * *}$ & $-0.083^{* * *}$ & $-0.083^{* * *}$ & $-0.073^{* * *}$ & $-0.092^{* *}$ \\
\hline & $(0.021)$ & $(0.021)$ & $(0.021)$ & $(0.017)$ & $(0.027)$ \\
\hline \multirow[t]{2}{*}{ X 2011} & $-0.087^{* * *}$ & $-0.087^{* * *}$ & $-0.087^{* * *}$ & $-0.076^{* * *}$ & $-0.097^{* *}$ \\
\hline & $(0.021)$ & $(0.021)$ & $(0.021)$ & $(0.017)$ & $(0.028)$ \\
\hline X 2012 & $-0.093^{* * *}$ & $-0.093^{* * *}$ & $-0.093^{* * *}$ & $-0.081^{* * *}$ & $-0.106^{* * *}$ \\
\hline & $(0.023)$ & $(0.023)$ & $(0.023)$ & $(0.019)$ & $(0.029)$ \\
\hline Industry-by-Year Fixed Effects & Yes & Yes & Yes & Yes & Yes \\
\hline County Fixed Effects & & Yes & & Yes & Yes \\
\hline Industry-by-County Fixed Effects & & & Yes & & \\
\hline Winsorized Weights & & & & Yes & \\
\hline Drops Small County-Industries $(<1000)$ & & & & & Yes \\
\hline
\end{tabular}

Notes: This table displays estimates from regressions of employment on exposure to Section 936 interacted with year dummies corresponding to Table 6. Observations are county-industries in each year. Exposure to Section 936 comes from the NETS and employment comes from QCEW (2017). See Section 5 for discussion and Appendix A for more information about the data. Estimates are shown graphically in panel A of Figure 11. Standard errors clustered at the state and industry levels are shown in parentheses. ${ }^{*} p<0.05,{ }^{* *} p<0.01,{ }^{* * *} p<0.001$. Observations are weighted according to employêent in 1995. 
Table A.13: Event Study on Employment at the County Level, Large Retailers Removed from Links

\begin{tabular}{|c|c|c|c|c|c|}
\hline Exposure to Section 936 & $(1)$ & $\overline{(2)}$ & $(3)$ & $\overline{(4)}$ & $\overline{(5)}$ \\
\hline \multirow[t]{2}{*}{ X 1990} & 0.001 & 0.001 & 0.001 & 0.008 & -0.006 \\
\hline & $(0.015)$ & $(0.015)$ & $(0.015)$ & $(0.011)$ & $(0.019)$ \\
\hline \multirow[t]{2}{*}{ X 1991} & -0.001 & -0.001 & -0.001 & 0.005 & -0.007 \\
\hline & $(0.012)$ & $(0.012)$ & $(0.012)$ & $(0.009)$ & $(0.016)$ \\
\hline \multirow[t]{2}{*}{ X 1992} & 0.001 & 0.002 & 0.002 & 0.005 & -0.002 \\
\hline & $(0.008)$ & $(0.008)$ & $(0.008)$ & $(0.006)$ & $(0.011)$ \\
\hline \multirow[t]{2}{*}{ X 1993} & 0.002 & 0.002 & 0.002 & 0.004 & -0.000 \\
\hline & $(0.005)$ & $(0.005)$ & $(0.005)$ & $(0.004)$ & $(0.006)$ \\
\hline \multirow[t]{2}{*}{ X 1994} & 0.001 & 0.001 & 0.001 & 0.002 & 0.000 \\
\hline & $(0.002)$ & $(0.002)$ & $(0.002)$ & $(0.002)$ & $(0.003)$ \\
\hline \multirow[t]{2}{*}{ X 1996} & -0.004 & -0.004 & -0.004 & -0.004 & -0.005 \\
\hline & $(0.002)$ & $(0.002)$ & $(0.002)$ & $(0.002)$ & $(0.003)$ \\
\hline \multirow[t]{2}{*}{ X 1997} & $-0.009^{*}$ & $-0.009^{*}$ & $-0.009^{*}$ & $-0.009^{*}$ & -0.009 \\
\hline & $(0.004)$ & $(0.004)$ & $(0.004)$ & $(0.004)$ & $(0.005)$ \\
\hline \multirow[t]{2}{*}{ X 1998} & $-0.015^{* *}$ & $-0.014^{* *}$ & $-0.014^{* *}$ & $-0.014^{* *}$ & $-0.016^{*}$ \\
\hline & $(0.005)$ & $(0.005)$ & $(0.005)$ & $(0.005)$ & $(0.007)$ \\
\hline \multirow[t]{2}{*}{ X 1999} & $-0.018^{* *}$ & $-0.018^{*}$ & $-0.018^{* *}$ & $-0.018^{* *}$ & $-0.019^{*}$ \\
\hline & $(0.007)$ & $(0.007)$ & $(0.007)$ & $(0.006)$ & $(0.008)$ \\
\hline \multirow[t]{2}{*}{ X 2000} & $-0.027^{* *}$ & $-0.027^{* *}$ & $-0.027^{* *}$ & $-0.026^{* *}$ & $-0.030^{* *}$ \\
\hline & $(0.008)$ & $(0.008)$ & $(0.008)$ & $(0.008)$ & $(0.010)$ \\
\hline \multirow[t]{2}{*}{ X 2001} & $-0.034^{* * *}$ & $-0.034^{* * *}$ & $-0.034^{* * *}$ & $-0.033^{* * *}$ & $-0.040^{* *}$ \\
\hline & $(0.009)$ & $(0.010)$ & $(0.009)$ & $(0.009)$ & $(0.013)$ \\
\hline \multirow[t]{2}{*}{ X 2002} & $-0.042^{* * *}$ & $-0.042^{* * *}$ & $-0.042^{* * *}$ & $-0.040^{* * *}$ & $-0.046^{* *}$ \\
\hline & $(0.011)$ & $(0.011)$ & $(0.011)$ & $(0.011)$ & $(0.014)$ \\
\hline \multirow[t]{2}{*}{ X 2003} & $-0.047^{* * *}$ & $-0.047^{* * *}$ & $-0.047^{* * *}$ & $-0.044^{* * *}$ & $-0.052^{* *}$ \\
\hline & $(0.012)$ & $(0.012)$ & $(0.012)$ & $(0.012)$ & $(0.016)$ \\
\hline \multirow[t]{2}{*}{ X 2004} & $-0.059^{* * *}$ & $-0.059^{* * *}$ & $-0.059^{* * *}$ & $-0.056^{* * *}$ & $-0.066^{* * *}$ \\
\hline & $(0.014)$ & $(0.014)$ & $(0.014)$ & $(0.014)$ & $(0.019)$ \\
\hline \multirow[t]{2}{*}{ X 2005} & $-0.070^{* * *}$ & $-0.070^{* * *}$ & $-0.070^{* * *}$ & $-0.066^{* * *}$ & $-0.080^{* * *}$ \\
\hline & $(0.018)$ & $(0.018)$ & $(0.018)$ & $(0.017)$ & $(0.022)$ \\
\hline \multirow[t]{2}{*}{ X 2006} & $-0.079^{* * *}$ & $-0.079^{* * *}$ & $-0.079^{* * *}$ & $-0.075^{* * *}$ & $-0.089^{* *}$ \\
\hline & $(0.020)$ & $(0.020)$ & $(0.020)$ & $(0.019)$ & $(0.026)$ \\
\hline \multirow[t]{2}{*}{ X 2007} & $-0.080^{* * *}$ & $-0.080^{* * *}$ & $-0.080^{* * *}$ & $-0.075^{* * *}$ & $-0.089^{* *}$ \\
\hline & $(0.021)$ & $(0.021)$ & $(0.021)$ & $(0.019)$ & $(0.027)$ \\
\hline \multirow[t]{2}{*}{ X 2008} & $-0.079^{* * *}$ & $-0.079^{* * *}$ & $-0.079^{* * *}$ & $-0.074^{* * *}$ & $-0.087^{* *}$ \\
\hline & $(0.020)$ & $(0.020)$ & $(0.020)$ & $(0.018)$ & $(0.026)$ \\
\hline \multirow[t]{2}{*}{ X 2009} & $-0.073^{* * *}$ & $-0.073^{* * *}$ & $-0.073^{* * *}$ & $-0.068^{* * *}$ & $-0.080^{* *}$ \\
\hline & $(0.018)$ & $(0.018)$ & $(0.018)$ & $(0.016)$ & $(0.023)$ \\
\hline \multirow[t]{2}{*}{ X 2010} & $-0.072^{* * *}$ & $-0.072^{* * *}$ & $-0.072^{* * *}$ & $-0.067^{* * *}$ & $-0.078^{* *}$ \\
\hline & $(0.018)$ & $(0.018)$ & $(0.018)$ & $(0.016)$ & $(0.023)$ \\
\hline \multirow[t]{2}{*}{ X 2011} & $-0.075^{* * *}$ & $-0.075^{* * *}$ & $-0.075^{* * *}$ & $-0.070^{* * *}$ & $-0.082^{* *}$ \\
\hline & $(0.018)$ & $(0.018)$ & $(0.018)$ & $(0.017)$ & $(0.024)$ \\
\hline X 2012 & $-0.080^{* * *}$ & $-0.080^{* * *}$ & $-0.080^{* * *}$ & $-0.075^{* * *}$ & $-0.090^{* * *}$ \\
\hline & $(0.020)$ & $(0.020)$ & $(0.020)$ & $(0.018)$ & $(0.025)$ \\
\hline Industry-by-Year Fixed Effects & Yes & Yes & Yes & Yes & Yes \\
\hline County Fixed Effects & & Yes & & Yes & Yes \\
\hline Industry-by-County Fixed Effects & & & Yes & & \\
\hline Winsorized Weights & & & & Yes & \\
\hline Drops Small County-Industries $(<1000)$ & & & & & Yes \\
\hline
\end{tabular}

Notes: This table displays estimates from regressions of employment on exposure to Section 936 interacted with year dummies corresponding to Table 6. Observations are counties in each year.Exposure to Section 936 comes from the NETS and employment comes from QCEW (2017). See Section 6 for discussion and Appendix A for more information about the data. Estimates are shown graphically in panel B of Figure 11. Standard errors clustered at the state and industry levels are shown in parentheses. ${ }^{*} p<0.05,{ }^{* *} p<0.01,{ }^{* * *} p<0.001$. Observations are weighted according to employment in 1995. 108 
Table A.14: Event Study on Employment at the County Level, Firms without US Headquarters Removed from Links

\begin{tabular}{|c|c|c|c|c|c|}
\hline Exposure to Section 936 & $\overline{(1)}$ & $\overline{(2)}$ & $\overline{(3)}$ & $(4)$ & $(5)$ \\
\hline \multirow[t]{2}{*}{ X 1990} & 0.001 & 0.001 & 0.001 & 0.009 & -0.006 \\
\hline & $(0.015)$ & $(0.015)$ & $(0.015)$ & $(0.011)$ & $(0.020)$ \\
\hline \multirow[t]{2}{*}{ X 1991} & -0.001 & -0.001 & -0.001 & 0.006 & -0.007 \\
\hline & $(0.012)$ & $(0.012)$ & $(0.012)$ & $(0.009)$ & $(0.016)$ \\
\hline \multirow[t]{2}{*}{ X 1992} & 0.001 & 0.002 & 0.002 & 0.006 & -0.002 \\
\hline & $(0.008)$ & $(0.008)$ & $(0.008)$ & $(0.006)$ & $(0.011)$ \\
\hline \multirow[t]{2}{*}{ X 1993} & 0.002 & 0.002 & 0.002 & 0.004 & -0.000 \\
\hline & $(0.005)$ & $(0.005)$ & $(0.005)$ & $(0.004)$ & $(0.006)$ \\
\hline \multirow[t]{2}{*}{ X 1994} & 0.001 & 0.001 & 0.001 & 0.002 & 0.000 \\
\hline & $(0.002)$ & $(0.002)$ & $(0.002)$ & $(0.002)$ & $(0.003)$ \\
\hline \multirow[t]{2}{*}{ X 1996} & -0.005 & -0.005 & -0.005 & $-0.004^{*}$ & -0.005 \\
\hline & $(0.002)$ & $(0.002)$ & $(0.002)$ & $(0.002)$ & $(0.003)$ \\
\hline \multirow[t]{2}{*}{ X 1997} & $-0.010^{*}$ & $-0.010^{*}$ & $-0.010^{*}$ & $-0.009^{* *}$ & -0.010 \\
\hline & (0.004) & (0.004) & $(0.004)$ & $(0.003)$ & $(0.005)$ \\
\hline \multirow[t]{2}{*}{ X 1998} & $-0.015^{* *}$ & $-0.015^{* *}$ & $-0.015^{* *}$ & $-0.014^{* *}$ & $-0.016^{*}$ \\
\hline & $(0.005)$ & $(0.005)$ & $(0.005)$ & (0.004) & (0.007) \\
\hline \multirow[t]{2}{*}{ X 1999} & $-0.018^{* *}$ & $-0.018^{* *}$ & $-0.018^{* *}$ & $-0.018^{* *}$ & $-0.020^{*}$ \\
\hline & $(0.007)$ & (0.007) & $(0.007)$ & $(0.006)$ & (0.009) \\
\hline \multirow[t]{2}{*}{ X 2000} & $-0.028^{* * *}$ & $-0.028^{* *}$ & $-0.028^{* * *}$ & $-0.026^{* * *}$ & $-0.031^{* *}$ \\
\hline & $(0.008)$ & (0.008) & $(0.008)$ & (0.007) & $(0.010)$ \\
\hline \multirow[t]{2}{*}{ X 2001} & $-0.035^{* * *}$ & $-0.035^{* * *}$ & $-0.035^{* * *}$ & $-0.033^{* * *}$ & $-0.041^{* *}$ \\
\hline & $(0.010)$ & (0.010) & $(0.010)$ & (0.009) & (0.013) \\
\hline \multirow[t]{2}{*}{ X 2002} & $-0.043^{* * *}$ & $-0.043^{* * *}$ & $-0.043^{* * *}$ & $-0.039^{* * *}$ & $-0.047^{* *}$ \\
\hline & $(0.011)$ & $(0.011)$ & $(0.011)$ & $(0.010)$ & $(0.015)$ \\
\hline \multirow[t]{2}{*}{ X 2003} & $-0.048^{* * *}$ & $-0.048^{* * *}$ & $-0.048^{* * *}$ & $-0.044^{* * *}$ & $-0.053^{* *}$ \\
\hline & $(0.013)$ & $(0.013)$ & $(0.013)$ & $(0.011)$ & $(0.016)$ \\
\hline \multirow[t]{2}{*}{ X 2004} & $-0.060^{* * *}$ & $-0.060^{* * *}$ & $-0.060^{* * *}$ & $-0.055^{* * *}$ & $-0.067^{* * *}$ \\
\hline & $(0.015)$ & $(0.015)$ & $(0.015)$ & $(0.013)$ & $(0.019)$ \\
\hline \multirow[t]{2}{*}{ X 2005} & $-0.072^{* * *}$ & $-0.072^{* * *}$ & $-0.072^{* * *}$ & $-0.065^{* * *}$ & $-0.081^{* * *}$ \\
\hline & $(0.018)$ & $(0.018)$ & $(0.018)$ & $(0.016)$ & $(0.023)$ \\
\hline \multirow[t]{2}{*}{ X 2006} & $-0.081^{* * *}$ & $-0.081^{* * *}$ & $-0.081^{* * *}$ & $-0.073^{* * *}$ & $-0.091^{* *}$ \\
\hline & $(0.021)$ & $(0.021)$ & $(0.021)$ & $(0.018)$ & $(0.026)$ \\
\hline \multirow[t]{2}{*}{ X 2007} & $-0.081^{* * *}$ & $-0.081^{* * *}$ & $-0.081^{* * *}$ & $-0.073^{* * *}$ & $-0.090^{* *}$ \\
\hline & $(0.021)$ & $(0.021)$ & $(0.021)$ & $(0.018)$ & $(0.027)$ \\
\hline \multirow[t]{2}{*}{ X 2008} & $-0.080^{* * *}$ & $-0.080^{* * *}$ & $-0.080^{* * *}$ & $-0.071^{* * *}$ & $-0.088^{* *}$ \\
\hline & $(0.020)$ & $(0.020)$ & $(0.020)$ & $(0.017)$ & $(0.026)$ \\
\hline \multirow[t]{2}{*}{ X 2009} & $-0.074^{* * *}$ & $-0.074^{* * *}$ & $-0.074^{* * *}$ & $-0.065^{* * *}$ & $-0.081^{* *}$ \\
\hline & $(0.018)$ & $(0.018)$ & $(0.018)$ & $(0.015)$ & $(0.023)$ \\
\hline \multirow[t]{2}{*}{ X 2010} & $-0.073^{* * *}$ & $-0.073^{* * *}$ & $-0.073^{* * *}$ & $-0.064^{* * *}$ & $-0.079^{* *}$ \\
\hline & $(0.018)$ & $(0.018)$ & $(0.018)$ & $(0.015)$ & $(0.023)$ \\
\hline \multirow[t]{2}{*}{ X 2011} & $-0.076^{* * *}$ & $-0.076^{* * *}$ & $-0.076^{* * *}$ & $-0.068^{* * *}$ & $-0.083^{* *}$ \\
\hline & $(0.018)$ & $(0.018)$ & $(0.018)$ & $(0.015)$ & $(0.024)$ \\
\hline X 2012 & $-0.081^{* * *}$ & $-0.081^{* * *}$ & $-0.081^{* * *}$ & $-0.072^{* * *}$ & $-0.091^{* * *}$ \\
\hline & $(0.019)$ & $(0.019)$ & $(0.019)$ & $(0.016)$ & $(0.025)$ \\
\hline Industry-by-Year Fixed Effects & Yes & Yes & Yes & Yes & Yes \\
\hline County Fixed Effects & & Yes & & Yes & Yes \\
\hline Industry-by-County Fixed Effects & & & Yes & & \\
\hline Winsorized Weights & & & & Yes & \\
\hline Drops Small County-Industries $(<1000)$ & & & & & Yes \\
\hline
\end{tabular}

Notes: This table displays estimates from regressions of employment on exposure to Section 936 interacted with year dummies corresponding to Table 6. Exposure to Section 936 comes from the NETS and employment comes from QCEW (2017). See Section 5 for discussion and Appendix A for more information about the data. Estimates are shown graphically in panel B of Figure 11. Standard errors clustered at the state and industry levels are shown in parentheses. ${ }^{*} p<0.05,{ }^{* *} p<0.01,{ }^{* * *} p<0.001$. Observations are weighted according to employment in 1995. 
Table A.15: Event Study on Employment at the County Level, Links Only Counting Compustat Firms

\begin{tabular}{|c|c|c|c|c|c|}
\hline Exposure to Section 936 & $(1)$ & $\overline{(2)}$ & $(3)$ & $\overline{(4)}$ & $\overline{(5)}$ \\
\hline \multirow[t]{2}{*}{ X 1990} & 0.005 & 0.005 & 0.005 & 0.011 & 0.001 \\
\hline & $(0.013)$ & $(0.013)$ & $(0.013)$ & $(0.009)$ & $(0.018)$ \\
\hline \multirow[t]{2}{*}{ X 1991} & 0.004 & 0.004 & 0.004 & 0.010 & 0.001 \\
\hline & $(0.010)$ & $(0.010)$ & $(0.010)$ & $(0.007)$ & $(0.014)$ \\
\hline \multirow[t]{2}{*}{ X 1992} & 0.006 & 0.006 & 0.006 & 0.010 & 0.005 \\
\hline & $(0.007)$ & $(0.007)$ & $(0.007)$ & $(0.005)$ & $(0.010)$ \\
\hline \multirow[t]{2}{*}{ X 1993} & 0.005 & 0.005 & 0.005 & $0.007^{*}$ & 0.004 \\
\hline & $(0.004)$ & $(0.004)$ & $(0.004)$ & $(0.003)$ & $(0.006)$ \\
\hline \multirow[t]{2}{*}{ X 1994} & 0.003 & 0.003 & 0.003 & $0.004^{*}$ & 0.003 \\
\hline & $(0.002)$ & $(0.002)$ & $(0.002)$ & $(0.002)$ & $(0.003)$ \\
\hline \multirow[t]{2}{*}{ X 1996} & $-0.004^{*}$ & $-0.004^{*}$ & $-0.004^{*}$ & $-0.004^{*}$ & -0.005 \\
\hline & $(0.002)$ & $(0.002)$ & $(0.002)$ & $(0.002)$ & $(0.003)$ \\
\hline \multirow[t]{2}{*}{ X 1997} & $-0.009^{*}$ & $-0.009^{*}$ & $-0.009^{*}$ & $-0.009^{* *}$ & -0.009 \\
\hline & $(0.003)$ & $(0.003)$ & $(0.003)$ & $(0.003)$ & $(0.005)$ \\
\hline \multirow[t]{2}{*}{ X 1998} & $-0.014^{* *}$ & $-0.014^{* *}$ & $-0.014^{* *}$ & $-0.013^{* * *}$ & $-0.014^{*}$ \\
\hline & $(0.004)$ & $(0.004)$ & $(0.004)$ & $(0.004)$ & $(0.006)$ \\
\hline \multirow[t]{2}{*}{ X 1999} & $-0.016^{* *}$ & $-0.016^{* *}$ & $-0.016^{* *}$ & $-0.017^{* *}$ & $-0.016^{*}$ \\
\hline & $(0.005)$ & $(0.006)$ & $(0.005)$ & $(0.005)$ & $(0.007)$ \\
\hline \multirow[t]{2}{*}{ X 2000} & $-0.024^{* * *}$ & $-0.024^{* * *}$ & $-0.024^{* * *}$ & $-0.024^{* * *}$ & $-0.026^{* *}$ \\
\hline & $(0.006)$ & $(0.006)$ & $(0.006)$ & $(0.006)$ & $(0.009)$ \\
\hline \multirow[t]{2}{*}{ X 2001} & $-0.030^{* * *}$ & $-0.030^{* * *}$ & $-0.030^{* * *}$ & $-0.029^{* * *}$ & $-0.034^{* *}$ \\
\hline & $(0.008)$ & $(0.008)$ & $(0.008)$ & $(0.008)$ & $(0.011)$ \\
\hline \multirow[t]{2}{*}{ X 2002} & $-0.037^{* * *}$ & $-0.037^{* * *}$ & $-0.037^{* * *}$ & $-0.036^{* * *}$ & $-0.041^{* *}$ \\
\hline & $(0.010)$ & $(0.010)$ & $(0.010)$ & $(0.009)$ & $(0.013)$ \\
\hline \multirow[t]{2}{*}{ X 2003} & $-0.042^{* * *}$ & $-0.042^{* * *}$ & $-0.042^{* * *}$ & $-0.040^{* * *}$ & $-0.047^{* *}$ \\
\hline & $(0.011)$ & $(0.011)$ & $(0.011)$ & $(0.010)$ & $(0.015)$ \\
\hline \multirow[t]{2}{*}{ X 2004} & $-0.052^{* * *}$ & $-0.052^{* * *}$ & $-0.052^{* * *}$ & $-0.051^{* * *}$ & $-0.059^{* *}$ \\
\hline & $(0.012)$ & $(0.012)$ & $(0.012)$ & $(0.011)$ & $(0.017)$ \\
\hline \multirow[t]{2}{*}{ X 2005} & $-0.062^{* * *}$ & $-0.062^{* * *}$ & $-0.062^{* * *}$ & $-0.059^{* * *}$ & $-0.071^{* *}$ \\
\hline & $(0.015)$ & $(0.015)$ & $(0.015)$ & $(0.014)$ & $(0.021)$ \\
\hline \multirow[t]{2}{*}{ X 2006} & $-0.071^{* * *}$ & $-0.071^{* * *}$ & $-0.071^{* * *}$ & $-0.067^{* * *}$ & $-0.081^{* *}$ \\
\hline & $(0.017)$ & $(0.017)$ & $(0.017)$ & $(0.016)$ & $(0.024)$ \\
\hline \multirow[t]{2}{*}{ X 2007} & $-0.073^{* * *}$ & $-0.073^{* * *}$ & $-0.073^{* * *}$ & $-0.069^{* * *}$ & $-0.083^{* * *}$ \\
\hline & $(0.017)$ & $(0.017)$ & $(0.017)$ & $(0.016)$ & $(0.024)$ \\
\hline \multirow[t]{2}{*}{ X 2008} & $-0.072^{* * *}$ & $-0.072^{* * *}$ & $-0.072^{* * *}$ & $-0.068^{* * *}$ & $-0.080^{* * *}$ \\
\hline & $(0.016)$ & $(0.016)$ & $(0.016)$ & $(0.015)$ & $(0.022)$ \\
\hline \multirow[t]{2}{*}{ X 2009} & $-0.065^{* * *}$ & $-0.065^{* * *}$ & $-0.065^{* * *}$ & $-0.061^{* * *}$ & $-0.073^{* * *}$ \\
\hline & $(0.015)$ & $(0.015)$ & $(0.015)$ & $(0.013)$ & $(0.021)$ \\
\hline \multirow[t]{2}{*}{ X 2010} & $-0.065^{* * *}$ & $-0.065^{* * *}$ & $-0.065^{* * *}$ & $-0.062^{* * *}$ & $-0.072^{* *}$ \\
\hline & $(0.015)$ & $(0.015)$ & $(0.015)$ & $(0.013)$ & $(0.021)$ \\
\hline \multirow[t]{2}{*}{ X 2011} & $-0.068^{* * *}$ & $-0.068^{* * *}$ & $-0.068^{* * *}$ & $-0.064^{* * *}$ & $-0.077^{* * *}$ \\
\hline & $(0.015)$ & $(0.015)$ & $(0.015)$ & $(0.014)$ & $(0.021)$ \\
\hline X 2012 & $-0.073^{* * *}$ & $-0.073^{* * *}$ & $-0.073^{* * *}$ & $-0.069^{* * *}$ & $-0.084^{* * *}$ \\
\hline & $(0.016)$ & $(0.016)$ & $(0.016)$ & $(0.015)$ & $(0.022)$ \\
\hline Industry-by-Year Fixed Effects & Yes & Yes & Yes & Yes & Yes \\
\hline County Fixed Effects & & Yes & & Yes & Yes \\
\hline Industry-by-County Fixed Effects & & & Yes & & \\
\hline Winsorized Weights & & & & Yes & \\
\hline Drops Small County-Industries $(<1000)$ & & & & & Yes \\
\hline
\end{tabular}

Notes: This table displays estimates from regressions of employment on exposure to Section 936 interacted with year dummies corresponding to Table 6. Exposure to Section 936 comes from the NETS and employment comes from QCEW (2017). See Section 5 for discussion and Appendix A for more information about the data. Estimates are shown graphically in panel B of Figure 11. Standard errors clustered at the state and industry levels are shown in parentheses. ${ }^{*} p<0.05,{ }^{* *} p<0.01,{ }^{* * *} p<0.001$. Observations are weighted according to employment in 1995. 
Table A.16: Local Labor Market Impact Robustness to Focusing Exposure on Largest Firms

\begin{tabular}{|c|c|c|c|c|c|}
\hline Exposure to Section 936 & $\overline{(1)}$ & $\overline{(2)}$ & $\overline{(3)}$ & $\overline{(4)}$ & 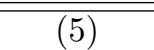 \\
\hline \multirow[t]{2}{*}{ X 1990} & 0.000 & -0.005 & -0.003 & -0.004 & -0.003 \\
\hline & $(0.015)$ & $(0.014)$ & $(0.013)$ & $(0.011)$ & $(0.010)$ \\
\hline \multirow[t]{2}{*}{ X 1991} & -0.001 & -0.005 & -0.003 & -0.003 & -0.003 \\
\hline & $(0.012)$ & $(0.011)$ & $(0.010)$ & $(0.009)$ & $(0.008)$ \\
\hline \multirow[t]{2}{*}{ X 1992} & 0.001 & -0.001 & 0.001 & 0.001 & 0.001 \\
\hline & $(0.008)$ & $(0.007)$ & $(0.007)$ & $(0.006)$ & $(0.005)$ \\
\hline \multirow[t]{2}{*}{ X 1993} & 0.002 & 0.001 & 0.002 & 0.001 & 0.001 \\
\hline & $(0.005)$ & $(0.004)$ & $(0.004)$ & $(0.003)$ & $(0.003)$ \\
\hline \multirow[t]{2}{*}{ X 1994} & 0.001 & 0.001 & 0.000 & 0.000 & -0.000 \\
\hline & $(0.002)$ & $(0.002)$ & $(0.002)$ & $(0.002)$ & $(0.001)$ \\
\hline \multirow[t]{2}{*}{ X 1996} & -0.004 & -0.004 & -0.003 & $-0.004^{*}$ & $-0.003^{*}$ \\
\hline & $(0.002)$ & $(0.002)$ & $(0.002)$ & $(0.002)$ & $(0.001)$ \\
\hline \multirow[t]{2}{*}{ X 1997} & $-0.009^{*}$ & $-0.009^{*}$ & $-0.007^{*}$ & $-0.008^{* *}$ & $-0.007^{* *}$ \\
\hline & $(0.004)$ & $(0.004)$ & $(0.003)$ & (0.003) & $(0.002)$ \\
\hline \multirow[t]{2}{*}{ X 1998} & $-0.014^{* *}$ & $-0.014^{* *}$ & $-0.013^{* *}$ & $-0.014^{* *}$ & $-0.013^{* *}$ \\
\hline & $(0.005)$ & $(0.005)$ & $(0.005)$ & (0.004) & $(0.004)$ \\
\hline \multirow[t]{2}{*}{ X 1999} & $-0.017^{*}$ & $-0.017^{* *}$ & $-0.016^{*}$ & $-0.018^{* *}$ & $-0.016^{* *}$ \\
\hline & $(0.006)$ & $(0.006)$ & $(0.006)$ & $(0.005)$ & $(0.006)$ \\
\hline \multirow[t]{2}{*}{ X 2000} & $-0.026^{* *}$ & $-0.025^{* *}$ & $-0.023^{* *}$ & $-0.023^{* * *}$ & $-0.021^{* * *}$ \\
\hline & $(0.008)$ & $(0.007)$ & (0.007) & $(0.006)$ & $(0.006)$ \\
\hline \multirow[t]{2}{*}{ X 2001} & $-0.034^{* * *}$ & $-0.032^{* *}$ & $-0.028^{* *}$ & $-0.030^{* * *}$ & $-0.027^{* * *}$ \\
\hline & $(0.009)$ & $(0.009)$ & (0.009) & (0.008) & (0.008) \\
\hline \multirow[t]{2}{*}{ X 2002} & $-0.041^{* * *}$ & $-0.038^{* * *}$ & $-0.035^{* * *}$ & $-0.035^{* * *}$ & $-0.032^{* * *}$ \\
\hline & $(0.011)$ & (0.011) & (0.010) & (0.008) & $(0.008)$ \\
\hline \multirow[t]{2}{*}{ X 2003} & $-0.046^{* * *}$ & $-0.043^{* * *}$ & $-0.039^{* * *}$ & $-0.040^{* * *}$ & $-0.036^{* * *}$ \\
\hline & $(0.012)$ & $(0.012)$ & (0.011) & (0.009) & $(0.009)$ \\
\hline \multirow[t]{2}{*}{ X 2004} & $-0.058^{* * *}$ & $-0.054^{* * *}$ & $-0.048^{* * *}$ & $-0.049^{* * *}$ & $-0.045^{* * *}$ \\
\hline & $(0.014)$ & $(0.014)$ & $(0.013)$ & $(0.011)$ & $(0.011)$ \\
\hline \multirow[t]{2}{*}{ X 2005} & $-0.069^{* * *}$ & $-0.063^{* * *}$ & $-0.057^{* * *}$ & $-0.057^{* * *}$ & $-0.052^{* * *}$ \\
\hline & $(0.017)$ & $(0.016)$ & $(0.015)$ & $(0.014)$ & $(0.013)$ \\
\hline \multirow[t]{2}{*}{ X 2006} & $-0.078^{* * *}$ & $-0.073^{* * *}$ & $-0.065^{* * *}$ & $-0.066^{* * *}$ & $-0.061^{* * *}$ \\
\hline & $(0.020)$ & $(0.019)$ & $(0.017)$ & $(0.016)$ & $(0.016)$ \\
\hline \multirow[t]{2}{*}{ X 2007} & $-0.079^{* * *}$ & $-0.074^{* * *}$ & $-0.066^{* * *}$ & $-0.067^{* * *}$ & $-0.063^{* * *}$ \\
\hline & $(0.021)$ & $(0.019)$ & $(0.018)$ & $(0.017)$ & $(0.017)$ \\
\hline \multirow[t]{2}{*}{ X 2008} & $-0.078^{* * *}$ & $-0.074^{* * *}$ & $-0.065^{* * *}$ & $-0.067^{* * *}$ & $-0.064^{* * *}$ \\
\hline & $(0.020)$ & $(0.019)$ & $(0.018)$ & $(0.017)$ & $(0.018)$ \\
\hline \multirow[t]{2}{*}{ X 2009} & $-0.072^{* * *}$ & $-0.068^{* * *}$ & $-0.061^{* * *}$ & $-0.063^{* * *}$ & $-0.061^{* * *}$ \\
\hline & (0.018) & $(0.017)$ & $(0.017)$ & (0.017) & $(0.017)$ \\
\hline \multirow[t]{2}{*}{ X 2010} & $-0.070^{* * *}$ & $-0.067^{* * *}$ & $-0.060^{* * *}$ & $-0.062^{* * *}$ & $-0.059^{* * *}$ \\
\hline & $(0.018)$ & $(0.017)$ & (0.017) & $(0.016)$ & $(0.017)$ \\
\hline \multirow[t]{2}{*}{ X 2011} & $-0.073^{* * *}$ & $-0.069^{* * *}$ & $-0.063^{* * *}$ & $-0.064^{* * *}$ & $-0.061^{* * *}$ \\
\hline & $(0.018)$ & $(0.018)$ & $(0.017)$ & $(0.016)$ & $(0.016)$ \\
\hline \multirow[t]{2}{*}{ X 2012} & $-0.079^{* * *}$ & $-0.075^{* * *}$ & $-0.069^{* * *}$ & $-0.070^{* * *}$ & $-0.066^{* * *}$ \\
\hline & $(0.019)$ & $(0.018)$ & $(0.018)$ & $(0.017)$ & $(0.017)$ \\
\hline Industry-by-Year Fixed Effects & Yes & Yes & Yes & Yes & Yes \\
\hline County Fixed Effects & Yes & Yes & Yes & Yes & Yes \\
\hline
\end{tabular}

Notes: This table reports the estimates from a regression of local employment growth on exposure to $\S 936$ firms of varying size restrictions. The estimates shown in this table correspond to Equation 6 and the baseline estimates in Table 6. Column (1) in this table matches Column (2) in Table 6. Columns (2) to (5) run the same regression where the set of firms that are allowed to have connections with Puerto Rico are restricted to larger firms. The $\S 936$ exposure shocks are all normalized to share the same standard deviation. Column (2) restricts the shock to only include firms with more than 20,000 workers. The restriction is increased to 30,000 workers in Column (3), 40,000 workers in Column (4) and 50,000 workers in Column (5). Results are shown graphically in Figure A.15. Standard errors shbthn in parentheses are clustered at the state and industry levels. 
Table A.17: Event Study on Employment Growth, Exposure to $§ 936$ Defined using 1993 Firm Networks

\begin{tabular}{|c|c|c|c|c|c|}
\hline Exposure to Section 936 & $\overline{(1)}$ & $(2)$ & $(3)$ & $(4)$ & $(5)$ \\
\hline \multirow[t]{2}{*}{ X 1990} & 0.002 & 0.002 & 0.002 & 0.008 & -0.005 \\
\hline & $(0.015)$ & $(0.015)$ & $(0.015)$ & $(0.012)$ & $(0.019)$ \\
\hline \multirow[t]{2}{*}{ X 1991} & -0.001 & -0.001 & -0.001 & 0.004 & -0.007 \\
\hline & $(0.012)$ & $(0.012)$ & $(0.012)$ & (0.010) & $(0.016)$ \\
\hline \multirow[t]{2}{*}{ X 1992} & 0.001 & 0.001 & 0.001 & 0.004 & -0.002 \\
\hline & $(0.008)$ & $(0.008)$ & (0.008) & (0.006) & (0.011) \\
\hline \multirow[t]{2}{*}{ X 1993} & 0.002 & 0.002 & 0.002 & 0.003 & -0.000 \\
\hline & $(0.005)$ & $(0.005)$ & $(0.005)$ & $(0.004)$ & $(0.006)$ \\
\hline \multirow[t]{2}{*}{ X 1994} & 0.001 & 0.001 & 0.001 & 0.002 & 0.001 \\
\hline & $(0.002)$ & $(0.002)$ & $(0.002)$ & $(0.002)$ & $(0.003)$ \\
\hline \multirow[t]{2}{*}{ X 1996} & -0.004 & -0.004 & -0.004 & -0.004 & -0.005 \\
\hline & $(0.002)$ & $(0.002)$ & $(0.002)$ & (0.002) & $(0.003)$ \\
\hline \multirow[t]{2}{*}{ X 1997} & $-0.009^{*}$ & $-0.009^{*}$ & $-0.009^{*}$ & $-0.008^{*}$ & -0.009 \\
\hline & $(0.004)$ & (0.004) & $(0.004)$ & $(0.004)$ & $(0.005)$ \\
\hline \multirow[t]{2}{*}{ X 1998} & $-0.015^{*}$ & $-0.015^{*}$ & $-0.015^{*}$ & $-0.013^{*}$ & $-0.016^{*}$ \\
\hline & $(0.006)$ & $(0.006)$ & $(0.006)$ & $(0.005)$ & $(0.007)$ \\
\hline \multirow{2}{*}{ X 1999} & $-0.018^{*}$ & $-0.018^{*}$ & $-0.018^{*}$ & $-0.017^{*}$ & $-0.020^{*}$ \\
\hline & $(0.007)$ & $(0.007)$ & $(0.007)$ & $(0.007)$ & (0.009) \\
\hline \multirow[t]{2}{*}{ X 2000} & $-0.027^{* *}$ & $-0.027^{* *}$ & $-0.027^{* *}$ & $-0.025^{* *}$ & $-0.031^{* *}$ \\
\hline & $(0.008)$ & $(0.008)$ & $(0.008)$ & $(0.008)$ & $(0.011)$ \\
\hline \multirow{2}{*}{ X 2001} & $-0.034^{* *}$ & $-0.034^{* *}$ & $-0.034^{* *}$ & $-0.032^{* *}$ & $-0.039^{* *}$ \\
\hline & $(0.010)$ & $(0.010)$ & $(0.010)$ & $(0.010)$ & $(0.013)$ \\
\hline \multirow[t]{2}{*}{ X 2002} & $-0.041^{* * *}$ & $-0.041^{* * *}$ & $-0.041^{* * *}$ & $-0.038^{* * *}$ & $-0.045^{* *}$ \\
\hline & $(0.011)$ & $(0.011)$ & $(0.011)$ & $(0.011)$ & $(0.014)$ \\
\hline \multirow[t]{2}{*}{ X 2003} & $-0.046^{* * *}$ & $-0.046^{* * *}$ & $-0.046^{* * *}$ & $-0.043^{* * *}$ & $-0.050^{* *}$ \\
\hline & $(0.012)$ & $(0.012)$ & $(0.012)$ & $(0.012)$ & $(0.016)$ \\
\hline \multirow[t]{2}{*}{ X 2004} & $-0.057^{* * *}$ & $-0.057^{* * *}$ & $-0.057^{* * *}$ & $-0.054^{* * *}$ & $-0.063^{* * *}$ \\
\hline & $(0.014)$ & $(0.014)$ & $(0.014)$ & $(0.013)$ & $(0.018)$ \\
\hline \multirow[t]{2}{*}{ X 2005} & $-0.067^{* * *}$ & $-0.067^{* * *}$ & $-0.067^{* * *}$ & $-0.063^{* * *}$ & $-0.076^{* * *}$ \\
\hline & $(0.017)$ & $(0.017)$ & $(0.017)$ & $(0.016)$ & $(0.021)$ \\
\hline \multirow[t]{2}{*}{ X 2006} & $-0.077^{* * *}$ & $-0.077^{* * *}$ & $-0.077^{* * *}$ & $-0.071^{* * *}$ & $-0.086^{* *}$ \\
\hline & $(0.020)$ & $(0.020)$ & $(0.020)$ & $(0.019)$ & $(0.025)$ \\
\hline \multirow[t]{2}{*}{ X 2007} & $-0.077^{* * *}$ & $-0.077^{* * *}$ & $-0.077^{* * *}$ & $-0.071^{* * *}$ & $-0.085^{* *}$ \\
\hline & $(0.021)$ & $(0.021)$ & $(0.021)$ & (0.019) & $(0.026)$ \\
\hline \multirow[t]{2}{*}{ X 2008} & $-0.077^{* * *}$ & $-0.077^{* * *}$ & $-0.077^{* * *}$ & $-0.071^{* * *}$ & $-0.084^{* *}$ \\
\hline & $(0.020)$ & $(0.020)$ & $(0.020)$ & (0.019) & $(0.026)$ \\
\hline \multirow[t]{2}{*}{ X 2009} & $-0.072^{* * *}$ & $-0.072^{* * *}$ & $-0.072^{* * *}$ & $-0.066^{* * *}$ & $-0.079^{* *}$ \\
\hline & (0.019) & $(0.019)$ & $(0.019)$ & (0.017) & $(0.024)$ \\
\hline \multirow[t]{2}{*}{ X 2010} & $-0.071^{* * *}$ & $-0.071^{* * *}$ & $-0.071^{* * *}$ & $-0.065^{* * *}$ & $-0.077^{* *}$ \\
\hline & $(0.019)$ & $(0.019)$ & $(0.019)$ & $(0.017)$ & $(0.024)$ \\
\hline \multirow[t]{2}{*}{ X 2011} & $-0.074^{* * *}$ & $-0.074^{* * *}$ & $-0.074^{* * *}$ & $-0.069^{* * *}$ & $-0.081^{* *}$ \\
\hline & $(0.020)$ & $(0.020)$ & $(0.020)$ & $(0.018)$ & $(0.025)$ \\
\hline X 2012 & $-0.080^{* * *}$ & $-0.080^{* * *}$ & $-0.080^{* * *}$ & $-0.073^{* * *}$ & $-0.089^{* *}$ \\
\hline & $(0.021)$ & $(0.021)$ & $(0.021)$ & $(0.019)$ & $(0.027)$ \\
\hline Industry-by-Year Fixed Effects & Yes & Yes & Yes & Yes & Yes \\
\hline County Fixed Effects & & Yes & & Yes & Yes \\
\hline Industry-by-County Fixed Effects & & & Yes & & \\
\hline Winsorized Weights & & & & Yes & \\
\hline Drops Small County-Industries $(<1000)$ & & & & & Yes \\
\hline
\end{tabular}

Notes: This table displays estimates of Equation 5, which are shown in Figure 11. Observations are county-industries in each year. Exposure to Section 936 comes from the NETS and employment growth comes from QCEW (2017). In this table, exposure to $\S 936$ is defined using the set of firms with establishments in Puerto Rico in 1993 as a robustness check to Table 6. See Section 5 for discussion and Appendix A for more information about the data. Standard errors clustered at the state and industry levels are shown in parentheses. Observations are weighted by employment in $1995 .{ }^{*} p<0.05,{ }^{* *} p<0.01,12^{* *} p<0.001$. 
Table A.18: Event Study on Employment Growth, Exposure to $§ 936$ Defined using 1993 Firm Networks with Firms also Present in 1995

\begin{tabular}{|c|c|c|c|c|c|}
\hline Exposure to Section 936 & $\overline{(1)}$ & $(2)$ & $(3)$ & $(4)$ & $(5)$ \\
\hline \multirow[t]{2}{*}{ X 1990} & 0.000 & 0.000 & 0.000 & 0.007 & -0.007 \\
\hline & $(0.015)$ & $(0.015)$ & $(0.015)$ & (0.011) & $(0.019)$ \\
\hline \multirow[t]{2}{*}{ X 1991} & -0.001 & -0.001 & -0.001 & 0.004 & -0.008 \\
\hline & $(0.012)$ & $(0.012)$ & $(0.012)$ & (0.009) & $(0.016)$ \\
\hline \multirow[t]{2}{*}{ X 1992} & 0.001 & 0.001 & 0.001 & 0.005 & -0.003 \\
\hline & $(0.008)$ & $(0.008)$ & $(0.008)$ & $(0.006)$ & (0.011) \\
\hline \multirow[t]{2}{*}{ X 1993} & 0.002 & 0.002 & 0.002 & 0.004 & -0.001 \\
\hline & $(0.005)$ & $(0.005)$ & $(0.005)$ & $(0.004)$ & $(0.006)$ \\
\hline \multirow[t]{2}{*}{ X 1994} & 0.001 & 0.001 & 0.001 & 0.002 & 0.000 \\
\hline & $(0.002)$ & $(0.002)$ & $(0.002)$ & $(0.002)$ & $(0.003)$ \\
\hline \multirow[t]{2}{*}{ X 1996} & -0.004 & -0.004 & -0.004 & -0.004 & -0.005 \\
\hline & $(0.002)$ & $(0.002)$ & $(0.002)$ & $(0.002)$ & $(0.003)$ \\
\hline \multirow[t]{2}{*}{ X 1997} & $-0.009^{*}$ & $-0.009^{*}$ & $-0.009^{*}$ & $-0.008^{*}$ & -0.009 \\
\hline & $(0.004)$ & (0.004) & $(0.004)$ & $(0.003)$ & $(0.005)$ \\
\hline \multirow[t]{2}{*}{ X 1998} & $-0.014^{* *}$ & $-0.014^{* *}$ & $-0.014^{* *}$ & $-0.013^{* *}$ & $-0.015^{*}$ \\
\hline & $(0.005)$ & $(0.005)$ & $(0.005)$ & $(0.005)$ & $(0.007)$ \\
\hline \multirow[t]{2}{*}{ X 1999} & $-0.017^{*}$ & $-0.017^{*}$ & $-0.017^{*}$ & $-0.017^{* *}$ & $-0.018^{*}$ \\
\hline & $(0.006)$ & $(0.007)$ & $(0.007)$ & $(0.006)$ & $(0.008)$ \\
\hline \multirow[t]{2}{*}{ X 2000} & $-0.026^{* *}$ & $-0.026^{* *}$ & $-0.026^{* *}$ & $-0.025^{* *}$ & $-0.029^{* *}$ \\
\hline & $(0.008)$ & $(0.008)$ & $(0.008)$ & $(0.007)$ & $(0.010)$ \\
\hline \multirow[t]{2}{*}{ X 2001} & $-0.034^{* * *}$ & $-0.034^{* * *}$ & $-0.034^{* * *}$ & $-0.032^{* * *}$ & $-0.039^{* *}$ \\
\hline & $(0.009)$ & (0.009) & $(0.009)$ & (0.009) & $(0.012)$ \\
\hline \multirow[t]{2}{*}{ X 2002} & $-0.041^{* * *}$ & $-0.041^{* * *}$ & $-0.041^{* * *}$ & $-0.039^{* * *}$ & $-0.045^{* *}$ \\
\hline & $(0.011)$ & $(0.011)$ & $(0.011)$ & $(0.011)$ & $(0.014)$ \\
\hline \multirow[t]{2}{*}{ X 2003} & $-0.046^{* * *}$ & $-0.046^{* * *}$ & $-0.046^{* * *}$ & $-0.044^{* * *}$ & $-0.051^{* *}$ \\
\hline & $(0.012)$ & $(0.012)$ & $(0.012)$ & $(0.012)$ & $(0.016)$ \\
\hline \multirow[t]{2}{*}{ X 2004} & $-0.058^{* * *}$ & $-0.058^{* * *}$ & $-0.058^{* * *}$ & $-0.056^{* * *}$ & $-0.065^{* * *}$ \\
\hline & $(0.014)$ & $(0.014)$ & $(0.014)$ & $(0.014)$ & $(0.018)$ \\
\hline \multirow[t]{2}{*}{ X 2005} & $-0.069^{* * *}$ & $-0.069^{* * *}$ & $-0.069^{* * *}$ & $-0.065^{* * *}$ & $-0.078^{* * *}$ \\
\hline & $(0.017)$ & $(0.018)$ & $(0.017)$ & $(0.017)$ & $(0.022)$ \\
\hline \multirow[t]{2}{*}{ X 2006} & $-0.078^{* * *}$ & $-0.078^{* * *}$ & $-0.078^{* * *}$ & $-0.074^{* * *}$ & $-0.088^{* *}$ \\
\hline & $(0.020)$ & $(0.020)$ & $(0.020)$ & $(0.019)$ & $(0.026)$ \\
\hline \multirow[t]{2}{*}{ X 2007} & $-0.079^{* * *}$ & $-0.079^{* * *}$ & $-0.079^{* * *}$ & $-0.074^{* * *}$ & $-0.087^{* *}$ \\
\hline & $(0.021)$ & $(0.021)$ & $(0.021)$ & $(0.019)$ & $(0.026)$ \\
\hline \multirow[t]{2}{*}{ X 2008} & $-0.078^{* * *}$ & $-0.078^{* * *}$ & $-0.078^{* * *}$ & $-0.073^{* * *}$ & $-0.085^{* *}$ \\
\hline & $(0.020)$ & $(0.020)$ & $(0.020)$ & (0.018) & $(0.025)$ \\
\hline \multirow[t]{2}{*}{ X 2009} & $-0.072^{* * *}$ & $-0.072^{* * *}$ & $-0.072^{* * *}$ & $-0.067^{* * *}$ & $-0.078^{* *}$ \\
\hline & $(0.018)$ & $(0.018)$ & $(0.018)$ & $(0.016)$ & $(0.023)$ \\
\hline \multirow[t]{2}{*}{ X 2010} & $-0.070^{* * *}$ & $-0.070^{* * *}$ & $-0.070^{* * *}$ & $-0.066^{* * *}$ & $-0.076^{* *}$ \\
\hline & $(0.018)$ & $(0.018)$ & $(0.018)$ & $(0.016)$ & $(0.023)$ \\
\hline \multirow[t]{2}{*}{ X 2011} & $-0.073^{* * *}$ & $-0.073^{* * *}$ & $-0.073^{* * *}$ & $-0.069^{* * *}$ & $-0.080^{* *}$ \\
\hline & $(0.018)$ & $(0.018)$ & $(0.018)$ & $(0.016)$ & $(0.024)$ \\
\hline X 2012 & $-0.079^{* * *}$ & $-0.079^{* * *}$ & $-0.079^{* * *}$ & $-0.074^{* * *}$ & $-0.087^{* * *}$ \\
\hline & $(0.019)$ & $(0.019)$ & $(0.019)$ & $(0.018)$ & $(0.025)$ \\
\hline Industry-by-Year Fixed Effects & Yes & Yes & Yes & Yes & Yes \\
\hline County Fixed Effects & & Yes & & Yes & Yes \\
\hline Industry-by-County Fixed Effects & & & Yes & & \\
\hline Winsorized Weights & & & & Yes & \\
\hline Drops Small County-Industries $(<1000)$ & & & & & Yes \\
\hline
\end{tabular}

Notes: This table displays estimates of Equation 5, which are shown in Figure 11. Observations are county-industries in each year. Exposure to Section 936 comes from the NETS and employment growth comes from QCEW (2017). In this table, exposure to $\S 936$ is defined using the set of firms with establishments in Puerto Rico in 1993 and in 1995 as a robustness check to Table 6. See Section 5 for discussion and Appendix A for more information about the data. Standard errors clustered at the state and industry levels are shown in parentheses. Observations are weighted by employment in $1995 .{ }^{*} p<0.0533^{* *} p<0.01,{ }^{* * *} p<0.001$. 
Table A.19: Event Study on the Ratio of Manufacturing Employment to Working Age Population at the County Level, Percentage Change

\begin{tabular}{|c|c|c|c|c|c|}
\hline Exposure to Section 936 & $(1)$ & $\overline{(2)}$ & $(3)$ & $(4)$ & $\overline{(5)}$ \\
\hline \multirow[t]{2}{*}{ X 1990} & -0.011 & -0.011 & 0.015 & -0.005 & -0.011 \\
\hline & $(0.013)$ & $(0.013)$ & $(0.010)$ & $(0.012)$ & $(0.013)$ \\
\hline \multirow[t]{2}{*}{ X 1991} & -0.000 & -0.000 & $0.018^{*}$ & 0.004 & -0.000 \\
\hline & $(0.009)$ & $(0.009)$ & $(0.008)$ & $(0.008)$ & $(0.009)$ \\
\hline \multirow{2}{*}{ X 1992} & 0.001 & 0.001 & 0.010 & 0.004 & 0.001 \\
\hline & $(0.006)$ & $(0.006)$ & $(0.006)$ & $(0.006)$ & $(0.006)$ \\
\hline \multirow[t]{2}{*}{ X 1993} & -0.000 & -0.000 & 0.003 & 0.002 & -0.000 \\
\hline & $(0.005)$ & $(0.005)$ & $(0.005)$ & $(0.005)$ & $(0.005)$ \\
\hline \multirow[t]{2}{*}{ X 1994} & -0.002 & -0.002 & -0.002 & -0.001 & -0.002 \\
\hline & $(0.004)$ & $(0.004)$ & $(0.003)$ & $(0.004)$ & $(0.004)$ \\
\hline \multirow[t]{2}{*}{ X 1996} & $-0.009^{*}$ & $-0.009^{*}$ & -0.001 & $-0.009^{* *}$ & $-0.009^{*}$ \\
\hline & $(0.004)$ & $(0.004)$ & $(0.003)$ & $(0.003)$ & $(0.004)$ \\
\hline \multirow[t]{2}{*}{ X 1997} & $-0.015^{* *}$ & $-0.015^{* *}$ & -0.005 & $-0.016^{* * *}$ & $-0.015^{* *}$ \\
\hline & $(0.005)$ & $(0.005)$ & $(0.004)$ & $(0.004)$ & $(0.005)$ \\
\hline \multirow[t]{2}{*}{ X 1998} & $-0.019^{* *}$ & $-0.019^{* *}$ & $-0.009^{*}$ & $-0.019^{* * *}$ & $-0.019^{* *}$ \\
\hline & $(0.006)$ & $(0.006)$ & $(0.005)$ & $(0.005)$ & $(0.006)$ \\
\hline \multirow[t]{2}{*}{ X 1999} & $-0.021^{* *}$ & $-0.021^{* *}$ & $-0.015^{* *}$ & $-0.022^{* *}$ & $-0.021^{* *}$ \\
\hline & $(0.007)$ & $(0.007)$ & $(0.006)$ & $(0.006)$ & $(0.007)$ \\
\hline \multirow[t]{2}{*}{ X 2000} & $-0.023^{*}$ & $-0.023^{*}$ & $-0.016^{*}$ & $-0.025^{* * *}$ & $-0.023^{*}$ \\
\hline & $(0.009)$ & $(0.009)$ & $(0.007)$ & $(0.007)$ & $(0.009)$ \\
\hline \multirow[t]{2}{*}{ X 2001} & $-0.026^{*}$ & $-0.026^{*}$ & -0.016 & $-0.029^{* *}$ & $-0.026^{*}$ \\
\hline & $(0.010)$ & $(0.010)$ & (0.009) & $(0.008)$ & $(0.010)$ \\
\hline \multirow[t]{2}{*}{ X 2002} & $-0.029^{* *}$ & $-0.029^{* *}$ & $-0.022^{*}$ & $-0.030^{* * *}$ & $-0.029^{* *}$ \\
\hline & $(0.009)$ & $(0.009)$ & $(0.008)$ & $(0.008)$ & $(0.009)$ \\
\hline \multirow[t]{2}{*}{ X 2003} & $-0.034^{* * *}$ & $-0.034^{* * *}$ & $-0.029^{* *}$ & $-0.035^{* * *}$ & $-0.034^{* * *}$ \\
\hline & $(0.009)$ & $(0.009)$ & $(0.009)$ & $(0.008)$ & $(0.009)$ \\
\hline \multirow[t]{2}{*}{ X 2004} & $-0.045^{* * *}$ & $-0.045^{* * *}$ & $-0.037^{* * *}$ & $-0.047^{* * *}$ & $-0.045^{* * *}$ \\
\hline & $(0.009)$ & $(0.009)$ & $(0.009)$ & $(0.008)$ & $(0.009)$ \\
\hline \multirow[t]{2}{*}{ X 2005} & $-0.049^{* * *}$ & $-0.049^{* * *}$ & $-0.040^{* * *}$ & $-0.051^{* * *}$ & $-0.049^{* * *}$ \\
\hline & $(0.011)$ & $(0.011)$ & $(0.010)$ & $(0.009)$ & $(0.011)$ \\
\hline \multirow[t]{2}{*}{ X 2006} & $-0.066^{* * *}$ & $-0.066^{* * *}$ & $-0.050^{* * *}$ & $-0.069^{* * *}$ & $-0.066^{* * *}$ \\
\hline & $(0.013)$ & $(0.013)$ & $(0.012)$ & $(0.012)$ & $(0.013)$ \\
\hline \multirow[t]{2}{*}{ X 2007} & $-0.067^{* * *}$ & $-0.067^{* * *}$ & $-0.050^{* * *}$ & $-0.070^{* * *}$ & $-0.067^{* * *}$ \\
\hline & $(0.014)$ & $(0.014)$ & $(0.012)$ & $(0.013)$ & $(0.014)$ \\
\hline \multirow[t]{2}{*}{ X 2008} & $-0.065^{* * *}$ & $-0.065^{* * *}$ & $-0.047^{* * *}$ & $-0.068^{* * *}$ & $-0.065^{* * *}$ \\
\hline & $(0.014)$ & $(0.014)$ & $(0.012)$ & $(0.013)$ & $(0.014)$ \\
\hline \multirow[t]{2}{*}{ X 2009} & $-0.059^{* * *}$ & $-0.059^{* * *}$ & $-0.039^{* * *}$ & $-0.061^{* * *}$ & $-0.059^{* * *}$ \\
\hline & $(0.012)$ & $(0.012)$ & $(0.011)$ & $(0.012)$ & $(0.012)$ \\
\hline \multirow[t]{2}{*}{ X 2010} & $-0.058^{* * *}$ & $-0.058^{* * *}$ & $-0.042^{* * *}$ & $-0.060^{* * *}$ & $-0.058^{* * *}$ \\
\hline & $(0.012)$ & $(0.012)$ & $(0.010)$ & $(0.012)$ & $(0.012)$ \\
\hline \multirow{2}{*}{ X 2011} & $-0.060^{* * *}$ & $-0.060^{* * *}$ & $-0.046^{* * *}$ & $-0.063^{* * *}$ & $-0.060^{* * *}$ \\
\hline & $(0.013)$ & $(0.013)$ & $(0.011)$ & $(0.012)$ & $(0.013)$ \\
\hline X 2012 & $-0.063^{* * *}$ & $-0.063^{* * *}$ & $-0.050^{* * *}$ & $-0.066^{* * *}$ & $-0.063^{* * *}$ \\
\hline & $(0.014)$ & $(0.014)$ & $(0.011)$ & $(0.013)$ & $(0.014)$ \\
\hline Year Fixed Effects & Yes & Yes & Yes & Yes & Yes \\
\hline County Fixed Effects & & Yes & & Yes & Yes \\
\hline Year-by-State Fixed Effects & & & Yes & & \\
\hline Winsorized Weights & & & & Yes & \\
\hline Drops Small County-Industries $(<1000)$ & & & & & Yes \\
\hline
\end{tabular}

Notes: This table displays estimates from regressions of percentage change in percent of working age population working in manufacturing on exposure to Section 936 interacted with year dummies corresponding to Table 6 . This regression is designed after the analysis of Autor et al. (2013). Exposure to Section 936 comes from the NETS and employment comes from QCEW (2017). See Section 5 for discussion and Appendix A for more information about the data. Standard errors clustered at the state and industry levels are shown in parentheses. ${ }^{*} p<0.05$, ** $p<0.01,{ }^{* * *} p<0.001$. Observations are welighted by employment in 1995 . 
Table A.20: Event Study on the Ratio of Manufacturing Employment to Working Age Population at the County Level, Percentage Points

\begin{tabular}{|c|c|c|c|c|c|}
\hline Exposure to Section 936 & $(1)$ & $(2)$ & $(3)$ & $(4)$ & $(5)$ \\
\hline \multirow[t]{2}{*}{ X 1990} & $0.266^{*}$ & $0.266^{*}$ & $0.456^{* * *}$ & $0.302^{* *}$ & $0.266^{*}$ \\
\hline & $(0.101)$ & $(0.101)$ & $(0.129)$ & $(0.097)$ & $(0.102)$ \\
\hline \multirow[t]{2}{*}{ X 1991} & 0.041 & 0.041 & 0.224 & 0.071 & 0.041 \\
\hline & $(0.100)$ & $(0.100)$ & $(0.113)$ & $(0.096)$ & $(0.100)$ \\
\hline \multirow{2}{*}{ X 1992} & -0.019 & -0.019 & 0.102 & 0.009 & -0.019 \\
\hline & $(0.066)$ & $(0.066)$ & $(0.078)$ & $(0.064)$ & $(0.066)$ \\
\hline \multirow[t]{2}{*}{ X 1993} & -0.044 & -0.044 & 0.008 & -0.031 & -0.044 \\
\hline & $(0.054)$ & $(0.054)$ & $(0.050)$ & $(0.054)$ & $(0.054)$ \\
\hline \multirow{2}{*}{ X 1994} & -0.024 & -0.024 & -0.009 & -0.021 & -0.024 \\
\hline & $(0.037)$ & $(0.037)$ & $(0.030)$ & $(0.038)$ & $(0.037)$ \\
\hline \multirow[t]{2}{*}{ X 1996} & $-0.161^{* * *}$ & $-0.161^{* * *}$ & -0.061 & $-0.160^{* * *}$ & $-0.161^{* * *}$ \\
\hline & $(0.029)$ & $(0.029)$ & $(0.032)$ & $(0.029)$ & $(0.029)$ \\
\hline \multirow[t]{2}{*}{ X 1997} & $-0.257^{* * *}$ & $-0.257^{* * *}$ & $-0.113^{*}$ & $-0.256^{* * *}$ & $-0.257^{* * *}$ \\
\hline & $(0.056)$ & $(0.056)$ & $(0.047)$ & $(0.056)$ & $(0.056)$ \\
\hline \multirow[t]{2}{*}{ X 1998} & $-0.336^{* * *}$ & $-0.336^{* * *}$ & $-0.172^{* *}$ & $-0.335^{* * *}$ & $-0.337^{* * *}$ \\
\hline & $(0.075)$ & $(0.075)$ & $(0.051)$ & $(0.075)$ & $(0.075)$ \\
\hline \multirow[t]{2}{*}{ X 1999} & $-0.441^{* * *}$ & $-0.441^{* * *}$ & $-0.287^{* * *}$ & $-0.436^{* * *}$ & $-0.441^{* * *}$ \\
\hline & $(0.093)$ & $(0.093)$ & $(0.050)$ & $(0.095)$ & $(0.093)$ \\
\hline \multirow[t]{2}{*}{ X 2000} & $-0.536^{* * *}$ & $-0.536^{* * *}$ & $-0.346^{* * *}$ & $-0.545^{* * *}$ & $-0.537^{* * *}$ \\
\hline & $(0.107)$ & $(0.107)$ & $(0.067)$ & $(0.108)$ & $(0.108)$ \\
\hline \multirow[t]{2}{*}{ X 2001} & $-0.921^{* * *}$ & $-0.921^{* * *}$ & $-0.609^{* * *}$ & $-0.912^{* * *}$ & $-0.923^{* * *}$ \\
\hline & $(0.123)$ & $(0.123)$ & $(0.076)$ & $(0.124)$ & $(0.123)$ \\
\hline \multirow[t]{2}{*}{ X 2002} & $-1.247^{* * *}$ & $-1.247^{* * *}$ & $-0.894^{* * *}$ & $-1.223^{* * *}$ & $-1.249^{* * *}$ \\
\hline & $(0.151)$ & $(0.151)$ & $(0.096)$ & $(0.152)$ & $(0.151)$ \\
\hline \multirow[t]{2}{*}{ X 2003} & $-1.484^{* * *}$ & $-1.484^{* * *}$ & $-1.122^{* * *}$ & $-1.455^{* * *}$ & $-1.486^{* * *}$ \\
\hline & $(0.171)$ & $(0.171)$ & $(0.116)$ & $(0.171)$ & $(0.171)$ \\
\hline \multirow[t]{2}{*}{ X 2004} & $-1.628^{* * *}$ & $-1.628^{* * *}$ & $-1.231^{* * *}$ & $-1.602^{* * *}$ & $-1.631^{* * *}$ \\
\hline & $(0.185)$ & $(0.185)$ & $(0.130)$ & $(0.186)$ & $(0.186)$ \\
\hline \multirow[t]{2}{*}{ X 2005} & $-1.720^{* * *}$ & $-1.720^{* * *}$ & $-1.291^{* * *}$ & $-1.698^{* * *}$ & $-1.723^{* * *}$ \\
\hline & $(0.194)$ & (0.194) & $(0.134)$ & $(0.196)$ & $(0.194)$ \\
\hline \multirow[t]{2}{*}{ X 2006} & $-1.921^{* * *}$ & $-1.921^{* * *}$ & $-1.411^{* * *}$ & $-1.902^{* * *}$ & $-1.924^{* * *}$ \\
\hline & $(0.205)$ & $(0.205)$ & $(0.141)$ & $(0.209)$ & $(0.205)$ \\
\hline \multirow[t]{2}{*}{ X 2007} & $-2.073^{* * *}$ & $-2.073^{* * *}$ & $-1.528^{* * *}$ & $-2.055^{* * *}$ & $-2.076^{* * *}$ \\
\hline & $(0.217)$ & $(0.217)$ & $(0.148)$ & $(0.223)$ & $(0.218)$ \\
\hline \multirow[t]{2}{*}{ X 2008} & $-2.216^{* * *}$ & $-2.216^{* * *}$ & $-1.613^{* * *}$ & $-2.194^{* * *}$ & $-2.220^{* * *}$ \\
\hline & $(0.231)$ & $(0.231)$ & $(0.158)$ & $(0.236)$ & $(0.231)$ \\
\hline \multirow[t]{2}{*}{ X 2009} & $-2.592^{* * *}$ & $-2.592^{* * *}$ & $-1.862^{* * *}$ & $-2.559^{* * *}$ & $-2.596^{* * *}$ \\
\hline & $(0.261)$ & $(0.261)$ & $(0.179)$ & $(0.265)$ & $(0.262)$ \\
\hline \multirow[t]{2}{*}{ X 2010} & $-2.674^{* * *}$ & $-2.674^{* * *}$ & $-1.967^{* * *}$ & $-2.643^{* * *}$ & $-2.678^{* * *}$ \\
\hline & $(0.263)$ & $(0.263)$ & $(0.181)$ & $(0.267)$ & $(0.264)$ \\
\hline \multirow[t]{2}{*}{ X 2011} & $-2.637^{* * *}$ & $-2.637^{* * *}$ & $-1.958^{* * *}$ & $-2.613^{* * *}$ & $-2.641^{* * *}$ \\
\hline & $(0.256)$ & $(0.256)$ & $(0.176)$ & $(0.260)$ & $(0.257)$ \\
\hline X 2012 & $-2.623^{* * *}$ & $-2.623^{* * *}$ & $-1.981^{* * *}$ & $-2.602^{* * *}$ & $-2.627^{* * *}$ \\
\hline & $(0.246)$ & $(0.246)$ & $(0.168)$ & $(0.249)$ & $(0.246)$ \\
\hline Year Fixed Effects & Yes & Yes & Yes & Yes & Yes \\
\hline County Fixed Effects & & Yes & & Yes & Yes \\
\hline Year-by-State Fixed Effects & & & Yes & & \\
\hline Winsorized Weights & & & & Yes & \\
\hline Drops Small County-Industries $(<1000)$ & & & & & Yes \\
\hline
\end{tabular}

Notes: This table displays estimates from regressions of change in percent of working age population working in manufacturing on exposure to Section 936 interacted with year dummies corresponding to Table 6. This regression is designed after the analysis of Autor et al. (2013). Exposure to Section 936 comes from the NETS and employment comes from QCEW (2017). See Section 5 for further discussion and Appendix A for more information about the data. Standard errors clustered at the state and industry levels are shown in parentheses. ${ }^{*} p<0.1,{ }^{* *} p<0.05$, *** $p<0.01$. Observations are weighted by employment in 1995 . 
Table A.21: Event Study on Employment at the County Level, State Fixed Effects and Time Trends

\begin{tabular}{|c|c|c|c|c|c|}
\hline Exposure to Section 936 & $(1)$ & $(2)$ & $(3)$ & $(4)$ & $(5)$ \\
\hline \multirow[t]{2}{*}{ X 1990} & 0.005 & $\begin{array}{c}-0.004 \\
\end{array}$ & -0.004 & 0.003 & -0.013 \\
\hline & $(0.012)$ & $(0.015)$ & $(0.015)$ & $(0.016)$ & $(0.021)$ \\
\hline \multirow[t]{2}{*}{ X 1991} & 0.004 & -0.005 & -0.005 & 0.001 & -0.012 \\
\hline & $(0.008)$ & $(0.011)$ & $(0.011)$ & $(0.009)$ & $(0.017)$ \\
\hline \multirow[t]{2}{*}{ X 1992} & 0.007 & -0.001 & -0.001 & 0.002 & -0.006 \\
\hline & $(0.005)$ & $(0.007)$ & $(0.007)$ & $(0.006)$ & $(0.011)$ \\
\hline \multirow[t]{2}{*}{ X 1993} & $0.009^{*}$ & 0.000 & 0.000 & 0.002 & -0.003 \\
\hline & $(0.003)$ & $(0.004)$ & $(0.004)$ & $(0.004)$ & $(0.006)$ \\
\hline \multirow[t]{2}{*}{ X 1994} & $0.009^{*}$ & 0.000 & 0.000 & 0.001 & -0.001 \\
\hline & $(0.004)$ & $(0.002)$ & $(0.002)$ & $(0.002)$ & $(0.003)$ \\
\hline \multirow[t]{2}{*}{ X 1996} & 0.005 & -0.003 & -0.003 & -0.003 & -0.004 \\
\hline & $(0.005)$ & $(0.002)$ & $(0.002)$ & $(0.003)$ & $(0.003)$ \\
\hline \multirow[t]{2}{*}{ X 1997} & 0.001 & -0.007 & -0.007 & -0.007 & -0.007 \\
\hline & $(0.006)$ & $(0.004)$ & $(0.004)$ & $(0.005)$ & $(0.007)$ \\
\hline \multirow[t]{2}{*}{ X 1998} & -0.003 & $-0.012^{*}$ & $-0.012^{*}$ & -0.011 & -0.012 \\
\hline & $(0.006)$ & $(0.005)$ & $(0.005)$ & $(0.007)$ & $(0.012)$ \\
\hline \multirow[t]{2}{*}{ X 1999} & -0.005 & -0.014 & -0.014 & -0.014 & -0.014 \\
\hline & $(0.007)$ & $(0.007)$ & $(0.008)$ & $(0.008)$ & $(0.011)$ \\
\hline \multirow[t]{2}{*}{ X 2000} & -0.014 & $-0.022^{*}$ & $-0.022^{*}$ & $-0.021^{*}$ & $-0.024^{*}$ \\
\hline & $(0.008)$ & $(0.009)$ & $(0.009)$ & $(0.010)$ & $(0.010)$ \\
\hline \multirow[t]{2}{*}{ X 2001} & -0.020 & $-0.029^{*}$ & $-0.029^{*}$ & $-0.027^{*}$ & $-0.032^{*}$ \\
\hline & $(0.010)$ & $(0.011)$ & $(0.012)$ & $(0.012)$ & $(0.013)$ \\
\hline \multirow[t]{2}{*}{ X 2002} & $-0.026^{*}$ & $-0.035^{*}$ & $-0.035^{*}$ & $-0.034^{*}$ & $-0.037^{*}$ \\
\hline & $(0.012)$ & $(0.013)$ & $(0.014)$ & $(0.016)$ & $(0.015)$ \\
\hline \multirow[t]{2}{*}{ X 2003} & $-0.031^{*}$ & $-0.040^{*}$ & $-0.040^{*}$ & $-0.038^{*}$ & $-0.042^{*}$ \\
\hline & $(0.014)$ & $(0.015)$ & $(0.016)$ & $(0.017)$ & $(0.018)$ \\
\hline \multirow{2}{*}{ X 2004} & $-0.042^{*}$ & $-0.051^{* *}$ & $-0.051^{* *}$ & $-0.049^{*}$ & $-0.055^{* *}$ \\
\hline & $(0.017)$ & $(0.018)$ & $(0.018)$ & $(0.020)$ & $(0.020)$ \\
\hline \multirow[t]{2}{*}{ X 2005} & $-0.052^{*}$ & $-0.061^{* *}$ & $-0.061^{* *}$ & $-0.058^{* *}$ & $-0.067^{* *}$ \\
\hline & $(0.020)$ & $(0.021)$ & $(0.022)$ & $(0.021)$ & $(0.024)$ \\
\hline \multirow[t]{2}{*}{ X 2006} & $-0.060^{*}$ & $-0.069^{* *}$ & $-0.069^{* *}$ & $-0.065^{* *}$ & $-0.075^{*}$ \\
\hline & $(0.023)$ & $(0.024)$ & $(0.025)$ & $(0.022)$ & $(0.031)$ \\
\hline \multirow[t]{2}{*}{ X 2007} & $-0.060^{*}$ & $-0.069^{* *}$ & $-0.069^{* *}$ & $-0.064^{* *}$ & $-0.074^{*}$ \\
\hline & $(0.023)$ & $(0.024)$ & $(0.024)$ & $(0.022)$ & $(0.030)$ \\
\hline \multirow[t]{2}{*}{ X 2008} & $-0.058^{* *}$ & $-0.067^{* *}$ & $-0.067^{* *}$ & $-0.063^{* *}$ & $-0.070^{*}$ \\
\hline & $(0.022)$ & $(0.022)$ & $(0.023)$ & $(0.022)$ & $(0.030)$ \\
\hline \multirow[t]{2}{*}{ X 2009} & $-0.052^{*}$ & $-0.060^{* *}$ & $-0.060^{* *}$ & $-0.056^{*}$ & $-0.063^{*}$ \\
\hline & $(0.021)$ & $(0.021)$ & $(0.021)$ & $(0.022)$ & $(0.029)$ \\
\hline \multirow[t]{2}{*}{ X 2010} & $-0.049^{*}$ & $-0.058^{* *}$ & $-0.058^{*}$ & $-0.054^{*}$ & -0.059 \\
\hline & $(0.022)$ & $(0.022)$ & $(0.022)$ & $(0.024)$ & $(0.030)$ \\
\hline X 2011 & $-0.052^{*}$ & $-0.061^{*}$ & $-0.060^{*}$ & $-0.057^{*}$ & -0.062 \\
\hline & $(0.023)$ & $(0.023)$ & $(0.023)$ & $(0.026)$ & $(0.033)$ \\
\hline X 2012 & $-0.056^{*}$ & $-0.065^{*}$ & $-0.065^{*}$ & $-0.060^{*}$ & -0.068 \\
\hline & $(0.025)$ & $(0.025)$ & $(0.025)$ & $(0.028)$ & $(0.036)$ \\
\hline Industry-by-Year Fixed Effects & Yes & Yes & Yes & Yes & Yes \\
\hline State Fixed Effects & Yes & Yes & Yes & Yes & Yes \\
\hline State Time Trends & Yes & Yes & Yes & Yes & Yes \\
\hline County Fixed Effects & & Yes & Yes & Yes & Yes \\
\hline County-by-Industry Fixed Effects & & & Yes & Yes & \\
\hline Winsorized Weights & & & & Yes & \\
\hline Drops Small County-Industries $(<1000)$ & & & & & Yes \\
\hline
\end{tabular}

Notes: This table displays estimates from regressions of employment on exposure to Section 936 interacted with year dummies corresponding to Table 6. Observations are counties in each year.Exposure to Section 936 comes from the NETS and employment comes from QCEW (2017). See Section 6 for discussion and Appendix A for more information about the data. Estimates are shown graphically in panel $\mathrm{C}$ of Figure 11. Stapfdard errors clustered at the state and industry levels are shown in parentheses. ${ }^{*} p<0.05,{ }^{* *} p<0.01,{ }^{* * *} p<0.001$. Observations are weighted according to employment in 1995. 
Table A.22: Event Study on Employment at the County Level, Fake Shock

\begin{tabular}{|c|c|c|c|c|c|}
\hline Exposure to Section 936 & $(1)$ & $(2)$ & $(3)$ & $(4)$ & $(5)$ \\
\hline \multirow[t]{2}{*}{ X 1990} & $-0.017^{*}$ & $-0.017^{*}$ & $-0.018^{*}$ & $-0.017^{*}$ & $-0.031^{*}$ \\
\hline & $(0.009)$ & $(0.009)$ & $(0.009)$ & $(0.009)$ & $(0.015)$ \\
\hline \multirow[t]{2}{*}{ X 1991} & -0.010 & -0.010 & -0.010 & -0.010 & -0.018 \\
\hline & $(0.007)$ & $(0.007)$ & $(0.007)$ & $(0.007)$ & $(0.012)$ \\
\hline \multirow[t]{2}{*}{ X 1992} & -0.005 & -0.005 & -0.006 & -0.005 & -0.009 \\
\hline & $(0.005)$ & $(0.005)$ & $(0.005)$ & $(0.005)$ & $(0.008)$ \\
\hline \multirow[t]{2}{*}{ X 1993} & -0.004 & -0.004 & -0.004 & -0.004 & -0.007 \\
\hline & $(0.003)$ & $(0.003)$ & $(0.003)$ & $(0.003)$ & $(0.006)$ \\
\hline \multirow[t]{2}{*}{ X 1994} & -0.001 & -0.001 & -0.001 & -0.001 & -0.003 \\
\hline & $(0.002)$ & $(0.002)$ & $(0.002)$ & $(0.002)$ & $(0.003)$ \\
\hline \multirow[t]{2}{*}{ X 1996} & 0.000 & 0.000 & 0.001 & 0.000 & 0.001 \\
\hline & $(0.002)$ & $(0.002)$ & $(0.002)$ & $(0.002)$ & $(0.003)$ \\
\hline \multirow[t]{2}{*}{ X 1997} & 0.002 & 0.002 & 0.002 & 0.002 & 0.005 \\
\hline & $(0.003)$ & $(0.003)$ & $(0.004)$ & $(0.003)$ & $(0.006)$ \\
\hline \multirow[t]{2}{*}{ X 1998} & 0.004 & 0.004 & 0.004 & 0.004 & 0.009 \\
\hline & $(0.005)$ & $(0.005)$ & $(0.005)$ & $(0.005)$ & $(0.009)$ \\
\hline \multirow[t]{2}{*}{ X 1999} & 0.004 & 0.004 & 0.004 & 0.004 & 0.012 \\
\hline & $(0.006)$ & $(0.006)$ & $(0.006)$ & $(0.006)$ & $(0.010)$ \\
\hline \multirow[t]{2}{*}{ X 2000} & 0.004 & 0.004 & 0.004 & 0.004 & 0.015 \\
\hline & $(0.006)$ & $(0.006)$ & $(0.006)$ & $(0.006)$ & $(0.011)$ \\
\hline \multirow{2}{*}{ X 2001} & -0.001 & -0.001 & -0.001 & -0.001 & 0.009 \\
\hline & $(0.008)$ & $(0.008)$ & (0.008) & (0.008) & $(0.014)$ \\
\hline \multirow{2}{*}{ X 2002} & -0.002 & -0.002 & -0.002 & -0.002 & 0.009 \\
\hline & $(0.009)$ & $(0.009)$ & (0.009) & (0.009) & $(0.015)$ \\
\hline \multirow[t]{2}{*}{ X 2003} & -0.003 & -0.003 & -0.003 & -0.003 & 0.005 \\
\hline & $(0.009)$ & $(0.009)$ & $(0.009)$ & $(0.009)$ & $(0.016)$ \\
\hline \multirow[t]{2}{*}{ X 2004} & -0.005 & -0.005 & -0.005 & -0.005 & 0.005 \\
\hline & $(0.010)$ & $(0.010)$ & $(0.010)$ & $(0.010)$ & (0.017) \\
\hline \multirow[t]{2}{*}{ X 2005} & -0.011 & -0.011 & -0.011 & -0.011 & 0.001 \\
\hline & $(0.012)$ & $(0.012)$ & $(0.012)$ & $(0.012)$ & $(0.019)$ \\
\hline \multirow[t]{2}{*}{ X 2006} & -0.008 & -0.008 & -0.008 & -0.008 & 0.007 \\
\hline & $(0.013)$ & $(0.013)$ & $(0.013)$ & $(0.013)$ & $(0.022)$ \\
\hline \multirow[t]{2}{*}{ X 2007} & -0.003 & -0.003 & -0.003 & -0.003 & 0.014 \\
\hline & $(0.012)$ & $(0.012)$ & $(0.012)$ & $(0.012)$ & $(0.022)$ \\
\hline \multirow[t]{2}{*}{ X 2008} & -0.000 & -0.000 & -0.000 & -0.000 & 0.018 \\
\hline & (0.011) & $(0.011)$ & (0.011) & $(0.011)$ & $(0.022)$ \\
\hline \multirow[t]{2}{*}{ X 2009} & 0.002 & 0.002 & 0.002 & 0.002 & 0.022 \\
\hline & $(0.011)$ & $(0.011)$ & (0.011) & $(0.011)$ & $(0.022)$ \\
\hline \multirow[t]{2}{*}{ X 2010} & 0.005 & 0.005 & 0.005 & 0.005 & 0.025 \\
\hline & $(0.011)$ & $(0.011)$ & $(0.011)$ & $(0.011)$ & $(0.022)$ \\
\hline \multirow[t]{2}{*}{ X 2011} & 0.010 & 0.010 & 0.010 & 0.010 & 0.034 \\
\hline & $(0.011)$ & $(0.011)$ & $(0.011)$ & $(0.011)$ & $(0.024)$ \\
\hline X 2012 & 0.013 & 0.013 & 0.013 & 0.013 & 0.038 \\
\hline & $(0.012)$ & $(0.012)$ & $(0.012)$ & $(0.012)$ & $(0.026)$ \\
\hline Industry-by-Year Fixed Effects & Yes & Yes & Yes & Yes & Yes \\
\hline County Fixed Effects & & Yes & & Yes & Yes \\
\hline Industry-by-County Fixed Effects & & & Yes & & \\
\hline Winsorized Weights & & & & Yes & \\
\hline Drops Small County-Industries $(<1000)$ & & & & & Yes \\
\hline
\end{tabular}

Notes: This table displays estimates from regressions of employment on a placebo for exposure to Section 936 interacted with year dummies corresponding to Table 6. Observations are counties in each year. The placebo for exposure to Section 936 comes from a matched sample of firms in the NETS that do not have establishments in Puerto Rico and employment comes from QCEW (2017). See Section 6 for discussion and Appendix A for more information about the data. Estimates are shown graphically in panel A of Figure 12. Standard errors clustered at the state and industry levels are shown in parentheses. ${ }^{*} p<0.05,{ }^{* *} p<0.01,{ }^{* * *} p<0.001$. Observations are weighted according to emploximent in 1995. 
Table A.23: Event Study on Employment at the County Level, Pharmaceuticals Exposure

\begin{tabular}{|c|c|c|c|c|c|}
\hline Exposure to Pharmaceuticals & $(1)$ & $(2)$ & $\overline{(3)}$ & $(4)$ & $(5)$ \\
\hline \multirow[t]{2}{*}{ X 1990} & $0.011^{*}$ & $0.011^{*}$ & $0.012^{* *}$ & $0.012^{* *}$ & $0.010^{*}$ \\
\hline & $(0.004)$ & $(0.004)$ & $(0.004)$ & $(0.004)$ & $(0.004)$ \\
\hline \multirow[t]{2}{*}{ X 1991} & 0.007 & 0.007 & 0.007 & $0.007^{*}$ & 0.005 \\
\hline & $(0.004)$ & (0.004) & $(0.003)$ & $(0.003)$ & $(0.004)$ \\
\hline \multirow[t]{2}{*}{ X 1992} & 0.005 & 0.005 & $0.005^{*}$ & $0.005^{*}$ & 0.004 \\
\hline & $(0.002)$ & $(0.002)$ & $(0.002)$ & $(0.002)$ & $(0.002)$ \\
\hline \multirow[t]{2}{*}{ X 1993} & 0.003 & 0.003 & 0.003 & 0.003 & 0.002 \\
\hline & $(0.002)$ & $(0.002)$ & $(0.002)$ & $(0.002)$ & $(0.002)$ \\
\hline \multirow[t]{2}{*}{ X 1994} & 0.001 & 0.001 & 0.001 & 0.001 & 0.001 \\
\hline & $(0.001)$ & $(0.001)$ & $(0.001)$ & $(0.001)$ & $(0.001)$ \\
\hline \multirow[t]{2}{*}{ X 1996} & 0.001 & 0.001 & 0.001 & 0.001 & 0.002 \\
\hline & $(0.001)$ & (0.001) & $(0.001)$ & $(0.001)$ & $(0.001)$ \\
\hline \multirow{2}{*}{ X 1997} & 0.003 & 0.003 & 0.003 & 0.002 & 0.003 \\
\hline & $(0.002)$ & $(0.002)$ & $(0.002)$ & $(0.002)$ & $(0.002)$ \\
\hline \multirow[t]{2}{*}{ X 1998} & 0.004 & 0.004 & 0.004 & 0.003 & 0.005 \\
\hline & $(0.002)$ & $(0.002)$ & $(0.002)$ & $(0.002)$ & $(0.003)$ \\
\hline \multirow[t]{2}{*}{ X 1999} & 0.005 & 0.005 & 0.005 & 0.004 & 0.005 \\
\hline & $(0.003)$ & $(0.003)$ & $(0.003)$ & $(0.003)$ & $(0.003)$ \\
\hline \multirow[t]{2}{*}{ X 2000} & 0.006 & 0.006 & 0.006 & 0.005 & 0.007 \\
\hline & $(0.004)$ & $(0.004)$ & $(0.004)$ & $(0.003)$ & $(0.004)$ \\
\hline \multirow[t]{2}{*}{ X 2001} & $0.009^{*}$ & $0.009^{*}$ & $0.009^{*}$ & $0.008^{*}$ & $0.009^{*}$ \\
\hline & $(0.004)$ & $(0.004)$ & $(0.004)$ & $(0.004)$ & $(0.004)$ \\
\hline \multirow[t]{2}{*}{ X 2002} & 0.006 & 0.006 & 0.006 & 0.005 & 0.007 \\
\hline & $(0.004)$ & $(0.004)$ & $(0.004)$ & $(0.004)$ & $(0.004)$ \\
\hline \multirow[t]{2}{*}{ X 2003} & $0.007^{* *}$ & $0.007^{* *}$ & $0.007^{* *}$ & $0.006^{*}$ & $0.009^{* *}$ \\
\hline & $(0.003)$ & $(0.003)$ & $(0.003)$ & $(0.003)$ & $(0.003)$ \\
\hline \multirow[t]{2}{*}{ X 2004} & 0.007 & 0.007 & 0.007 & 0.006 & $0.009^{*}$ \\
\hline & $(0.004)$ & $(0.004)$ & $(0.004)$ & $(0.004)$ & $(0.004)$ \\
\hline \multirow[t]{2}{*}{ X 2005} & 0.006 & 0.006 & 0.006 & 0.004 & 0.008 \\
\hline & $(0.004)$ & $(0.004)$ & $(0.004)$ & $(0.004)$ & $(0.004)$ \\
\hline \multirow[t]{2}{*}{ X 2006} & 0.006 & 0.006 & 0.006 & 0.004 & 0.009 \\
\hline & $(0.005)$ & $(0.005)$ & $(0.004)$ & $(0.005)$ & $(0.005)$ \\
\hline \multirow[t]{2}{*}{ X 2007} & 0.007 & 0.007 & 0.007 & 0.005 & $0.010^{*}$ \\
\hline & $(0.005)$ & $(0.005)$ & $(0.005)$ & $(0.005)$ & $(0.005)$ \\
\hline \multirow[t]{2}{*}{ X 2008} & 0.007 & 0.007 & 0.007 & 0.006 & 0.011 \\
\hline & $(0.005)$ & $(0.005)$ & $(0.005)$ & $(0.005)$ & $(0.005)$ \\
\hline \multirow[t]{2}{*}{ X 2009} & 0.008 & 0.008 & 0.008 & 0.006 & 0.011 \\
\hline & $(0.005)$ & $(0.005)$ & $(0.005)$ & $(0.005)$ & $(0.005)$ \\
\hline \multirow[t]{2}{*}{ X 2010} & 0.007 & 0.007 & 0.007 & 0.005 & 0.010 \\
\hline & $(0.005)$ & $(0.005)$ & $(0.005)$ & $(0.005)$ & $(0.005)$ \\
\hline \multirow[t]{2}{*}{ X 2011} & 0.006 & 0.006 & 0.006 & 0.005 & 0.009 \\
\hline & $(0.005)$ & $(0.005)$ & $(0.005)$ & $(0.006)$ & $(0.005)$ \\
\hline X 2012 & 0.007 & 0.007 & 0.007 & 0.006 & 0.010 \\
\hline & $(0.006)$ & $(0.006)$ & $(0.006)$ & $(0.006)$ & $(0.006)$ \\
\hline Industry-by-Year Fixed Effects & Yes & Yes & Yes & Yes & Yes \\
\hline County Fixed Effects & & Yes & & Yes & Yes \\
\hline Industry-by-County Fixed Effects & & & Yes & & \\
\hline Winsorized Weights & & & & Yes & \\
\hline Drops Small County-Industries $(<1000)$ & & & & & Yes \\
\hline
\end{tabular}

Notes: This table displays estimates from regressions of employment on exposure to Pharmaceuticals interacted with year dummies corresponding to Table 6. Observations are counties in each year. Data regarding the exposure to Pharmaceuticals and data on employment both come from QCEW (2017). See Section 6 for discussion and Appendix A for more information about the data. Estimates are shown graphically in panel B of Figure 12. Standard errors clustered at the state and industry levels are shown in parentheses. ${ }^{*} p<0.05,{ }^{* *} p<0.01,{ }^{* * *} p<0.001$. Observations are weighted according to employident in 1995. 
Table A.24: Effects of Repealing $§ 936$ on Employment Growth at the County Level: Robustness Part 1

\begin{tabular}{|c|c|c|c|c|c|c|c|c|c|}
\hline & (1) & $\overline{(2)}$ & $(3)$ & $(4)$ & $(5)$ & $(6)$ & $\overline{(7)}$ & $(8)$ & $(9)$ \\
\hline Exposure to Section 936 & $\begin{array}{c}-0.072 \\
(0.018)\end{array}$ & $\begin{array}{c}-0.083 \\
(0.018)\end{array}$ & $\begin{array}{l}-0.080 \\
(0.021)\end{array}$ & $\begin{array}{l}-0.079 \\
(0.021)\end{array}$ & $\begin{array}{c}-0.074 \\
(0.021)\end{array}$ & $\begin{array}{c}-0.068 \\
(0.018)\end{array}$ & $\begin{array}{c}-0.079 \\
(0.022)\end{array}$ & $\begin{array}{c}-0.078 \\
(0.018)\end{array}$ & $\begin{array}{c}-0.074 \\
(0.019)\end{array}$ \\
\hline & 0.000 & 0.000 & 0.000 & 0.001 & 0.001 & 0.000 & 0.001 & 0.000 & 0.000 \\
\hline Total Incentives (Bartik) & & $\begin{array}{c}-0.045 \\
(0.011) \\
0.000\end{array}$ & & & & & & & \\
\hline Job Creation Incentive & & & $\begin{array}{c}-0.003 \\
(0.003) \\
0.357\end{array}$ & & & & & & \\
\hline Job Training Subsidy & & & & $\begin{array}{c}0.005 \\
(0.017) \\
0.775\end{array}$ & & & & & \\
\hline Real Minimum Wage & & & & & $\begin{array}{c}0.001 \\
(0.011) \\
0007\end{array}$ & & & & \\
\hline Right to Work & & & & & & $\begin{array}{c}0.045 \\
(0.014) \\
0.002\end{array}$ & & & \\
\hline RD Tax Credit & & & & & & & $\begin{array}{c}0.003 \\
(0.010) \\
0.752\end{array}$ & & \\
\hline Investment Tax Credit & & & & & & & & $\begin{array}{c}-0.032 \\
(0.014) \\
0.027\end{array}$ & \\
\hline Corporate Income Tax & & & & & & & & & $\begin{array}{c}-0.022 \\
(0.016) \\
0.174\end{array}$ \\
\hline Year Fixed Effects & Yes & Yes & Yes & Yes & Yes & Yes & Yes & Yes & Yes \\
\hline Industry Fixed Effects & Yes & Yes & Yes & Yes & Yes & Yes & Yes & Yes & Yes \\
\hline
\end{tabular}

Notes: Estimates in this table build on results shown in Table 6. The estimates in each column come from a regression of employment growth from QCEW on exposure to Section 936 and other local characteristics. State level policy data come from BEA and BLS data gathered by Suárez Serrato and Wingender (2016). All specifications include year, industry, and state fixed effects. See Section 6 for discussion and Appendix A for more information about the data. Standard errors clustered at the state and industry levels are shown in parentheses. Observations are weighted according to employment in 1995. 
Table A.25: Effects of Repealing $§ 936$ on Employment Growth at the County Level: Robustness Part 2

\begin{tabular}{|c|c|c|c|c|c|c|c|c|c|c|}
\hline & $(1)$ & $\overline{(2)}$ & $(3)$ & $(4)$ & $(5)$ & $(6)$ & $(7)$ & $(8)$ & $(9)$ & $(10)$ \\
\hline Exposure to Section 936 & $\begin{array}{l}-0.072 \\
(0.018)\end{array}$ & $\begin{array}{l}-0.069 \\
(0.017)\end{array}$ & $\begin{array}{l}-0.073 \\
(0.021)\end{array}$ & $\begin{array}{l}-0.077 \\
(0.021)\end{array}$ & $\begin{array}{l}-0.073 \\
(0.018)\end{array}$ & $\begin{array}{l}-0.076 \\
(0.019)\end{array}$ & $\begin{array}{l}-0.071 \\
(0.019)\end{array}$ & $\begin{array}{l}-0.069 \\
(0.017)\end{array}$ & $\begin{array}{l}-0.072 \\
(0.017)\end{array}$ & $\begin{array}{l}-0.068 \\
(0.016)\end{array}$ \\
\hline & 0.000 & 0.000 & 0.001 & 0.001 & 0.000 & 0.000 & 0.001 & 0.000 & 0.000 & 0.000 \\
\hline Personal Income Tax & & $\begin{array}{c}-0.033 \\
(0.012) \\
0.010\end{array}$ & & & & & & & $\begin{array}{c}-0.008 \\
(0.017) \\
0.640\end{array}$ & $\begin{array}{c}-0.008 \\
(0.016) \\
0.641\end{array}$ \\
\hline Property Tax & & & $\begin{array}{c}-0.026 \\
(0.012) \\
0.038\end{array}$ & & & & & & $\begin{array}{c}-0.023 \\
(0.014) \\
0.115\end{array}$ & $\begin{array}{c}-0.023 \\
(0.015) \\
0.127\end{array}$ \\
\hline Sales Tax & & & & $\begin{array}{c}0.008 \\
(0.011) \\
0.463\end{array}$ & & & & & $\begin{array}{c}0.009 \\
(0.022) \\
0.698\end{array}$ & $\begin{array}{c}0.006 \\
(0.022) \\
0.794\end{array}$ \\
\hline Trade Exposure (China) & & & & & $\begin{array}{c}-0.008 \\
(0.013) \\
0.551\end{array}$ & & & & $\begin{array}{c}0.007 \\
(0.012) \\
0.569\end{array}$ & $\begin{array}{c}0.019 \\
(0.013) \\
0.135\end{array}$ \\
\hline State Revenue Per Capita & & & & & & $\begin{array}{c}-0.026 \\
(0.014) \\
0.061\end{array}$ & & & $\begin{array}{c}-0.002 \\
(0.017) \\
0.898\end{array}$ & $\begin{array}{c}0.004 \\
(0.018) \\
0.825\end{array}$ \\
\hline Share Routine Workers & & & & & & & $\begin{array}{c}-0.013 \\
(0.014) \\
0.344\end{array}$ & & $\begin{array}{c}0.014 \\
(0.011) \\
0.218\end{array}$ & $\begin{array}{c}0.033 \\
(0.013) \\
0.017\end{array}$ \\
\hline Trade Exposure (Nafta) & & & & & & & & $\begin{array}{c}0.008 \\
(0.019) \\
0674\end{array}$ & $\begin{array}{c}-0.001 \\
(0.015) \\
0.970\end{array}$ & $\begin{array}{c}-0.012 \\
(0.014) \\
0381\end{array}$ \\
\hline Total Incentives (Bartik) & & & & & & & & & $\begin{array}{c}-0.043 \\
(0.012) \\
0.001\end{array}$ & $\begin{array}{c}-0.044 \\
(0.012)\end{array}$ \\
\hline Job Creation Incentive & & & & & & & & & $\begin{array}{l}0.006 \\
(0.014)\end{array}$ & $\begin{array}{c}0.010 \\
(0.014)\end{array}$ \\
\hline Job Training Subsidy & & & & & & & & & $\begin{array}{c}0.670 \\
-0.010 \\
(0.020) \\
0.610\end{array}$ & $\begin{array}{c}0.456 \\
-0.011 \\
(0.020) \\
0.568\end{array}$ \\
\hline Real Minimum Wage & & & & & & & & & $\begin{array}{l}-0.006 \\
(0.009)\end{array}$ & $\begin{array}{c}-0.008 \\
(0.009)\end{array}$ \\
\hline Right to Work & & & & & & & & & $\begin{array}{c}0.522 \\
0.047 \\
(0.024)\end{array}$ & $\begin{array}{c}0.382 \\
0.041 \\
(0.022)\end{array}$ \\
\hline RD Tax Credit & & & & & & & & & $\begin{array}{c}0.001 \\
0.011 \\
(0.010)\end{array}$ & $\begin{array}{c}0.008 \\
(0.011)\end{array}$ \\
\hline Investment Tax Credit & & & & & & & & & $\begin{array}{c}0.293 \\
0.003 \\
(0.018)\end{array}$ & $\begin{array}{c}0.402 \\
0.002 \\
(0.018)\end{array}$ \\
\hline Corporate Income Tax & & & & & & & & & $\begin{array}{c}-0.013 \\
(0.017) \\
0.459\end{array}$ & $\begin{array}{c}-0.012 \\
(0.016) \\
0.458\end{array}$ \\
\hline Year Fixed Effects & Yes & Yes & Yes & Yes & Yes & Yes & Yes & Yes & Yes & Yes \\
\hline $\begin{array}{l}\text { Industry Fixed Effects } \\
\text { Firm Size Dist. Cont. }\end{array}$ & Yes & Yes & Yes & Yes & Yes & Yes & Yes & Yes & Yes & $\begin{array}{l}\text { Yes } \\
\text { Yes }\end{array}$ \\
\hline
\end{tabular}

Notes: See Section 6 for discussion of regressions and Appendix A for more information about the data. Standard errors clustered at the state and industry levels are shown in parentheses. Observations are weighted according to employment in 1995. 
Table A.26: Event Study on Employment Growth at the County Level, Heterogeneous Effects by Sector

\begin{tabular}{|c|c|c|c|c|c|}
\hline Exposure to Section 936 & $\begin{array}{c}(1) \\
\text { Average Effect }\end{array}$ & $\begin{array}{c}(2) \\
\text { Tradable }\end{array}$ & $\begin{array}{c}(3) \\
\text { Non-Tradable }\end{array}$ & $\begin{array}{c}(4) \\
\text { Other }\end{array}$ & $\begin{array}{c}(5) \\
\text { Construction }\end{array}$ \\
\hline X 1990 & $\begin{array}{c}0.000 \\
(0.015)\end{array}$ & $\begin{array}{l}-0.002 \\
(0.024)\end{array}$ & $\begin{array}{c}0.002 \\
(0.010)\end{array}$ & $\begin{array}{c}0.001 \\
(0.015)\end{array}$ & $\begin{array}{l}-0.016 \\
(0.023)\end{array}$ \\
\hline X 1991 & $\begin{array}{l}-0.001 \\
(0.012)\end{array}$ & $\begin{array}{c}0.001 \\
(0.018)\end{array}$ & $\begin{array}{l}-0.001 \\
(0.008)\end{array}$ & $\begin{array}{l}-0.003 \\
(0.013)\end{array}$ & $\begin{array}{l}-0.005 \\
(0.016)\end{array}$ \\
\hline X 1992 & $\begin{array}{c}0.001 \\
(0.008)\end{array}$ & $\begin{array}{c}0.003 \\
(0.011)\end{array}$ & $\begin{array}{c}0.002 \\
(0.006)\end{array}$ & $\begin{array}{l}-0.000 \\
(0.008)\end{array}$ & $\begin{array}{c}0.002 \\
(0.011)\end{array}$ \\
\hline X 1993 & $\begin{array}{c}0.002 \\
(0.005)\end{array}$ & $\begin{array}{c}0.003 \\
(0.008)\end{array}$ & $\begin{array}{c}0.001 \\
(0.004)\end{array}$ & $\begin{array}{c}0.002 \\
(0.005)\end{array}$ & $\begin{array}{c}0.003 \\
(0.005)\end{array}$ \\
\hline X 1994 & $\begin{array}{c}0.001 \\
(0.002) \\
\end{array}$ & $\begin{array}{c}0.001 \\
(0.003)\end{array}$ & $\begin{array}{l}-0.000 \\
(0.002)\end{array}$ & $\begin{array}{c}0.001 \\
(0.002) \\
\end{array}$ & $\begin{array}{c}0.001 \\
(0.003) \\
\end{array}$ \\
\hline X 1996 & $\begin{array}{l}-0.004 \\
(0.002)\end{array}$ & $\begin{array}{l}-0.010^{*} \\
(0.004)\end{array}$ & $\begin{array}{l}-0.003 \\
(0.002)\end{array}$ & $\begin{array}{l}-0.004 \\
(0.003)\end{array}$ & $\begin{array}{l}-0.003 \\
(0.003)\end{array}$ \\
\hline X 1997 & $\begin{array}{l}-0.009^{*} \\
(0.004)\end{array}$ & $\begin{array}{c}-0.021^{* *} \\
(0.007)\end{array}$ & $\begin{array}{l}-0.008^{*} \\
(0.003)\end{array}$ & $\begin{array}{l}-0.007 \\
(0.006)\end{array}$ & $\begin{array}{l}-0.007 \\
(0.005)\end{array}$ \\
\hline X 1998 & $\begin{array}{c}-0.014^{* *} \\
(0.005)\end{array}$ & $\begin{array}{c}-0.028^{* *} \\
(0.010)\end{array}$ & $\begin{array}{c}-0.013^{* *} \\
(0.004)\end{array}$ & $\begin{array}{l}-0.011 \\
(0.007)\end{array}$ & $\begin{array}{l}-0.015^{*} \\
(0.007)\end{array}$ \\
\hline X 1999 & $\begin{array}{l}-0.017^{*} \\
(0.007)\end{array}$ & $\begin{array}{c}-0.028^{* *} \\
(0.009)\end{array}$ & $\begin{array}{c}-0.017^{* *} \\
(0.005)\end{array}$ & $\begin{array}{l}-0.013 \\
(0.009)\end{array}$ & $\begin{array}{l}-0.015 \\
(0.011)\end{array}$ \\
\hline X 2000 & $\begin{array}{c}-0.026^{* *} \\
(0.008)\end{array}$ & $\begin{array}{c}-0.032^{* *} \\
(0.009)\end{array}$ & $\begin{array}{c}-0.025^{* *} \\
(0.006)\end{array}$ & $\begin{array}{c}-0.024^{*} \\
(0.011)\end{array}$ & $\begin{array}{c}-0.034^{* *} \\
(0.009)\end{array}$ \\
\hline X 2001 & $\begin{array}{c}-0.034^{* * *} \\
(0.009)\end{array}$ & $\begin{array}{c}-0.038^{* *} \\
(0.010)\end{array}$ & $\begin{array}{c}-0.032^{* *} \\
(0.007)\end{array}$ & $\begin{array}{c}-0.030^{*} \\
(0.013)\end{array}$ & $\begin{array}{c}-0.051^{* *} \\
(0.013)\end{array}$ \\
\hline X 2002 & $\begin{array}{c}-0.041^{* * *} \\
(0.011)\end{array}$ & $\begin{array}{c}-0.036^{* *} \\
(0.011)\end{array}$ & $\begin{array}{c}-0.038^{* *} \\
(0.009)\end{array}$ & $\begin{array}{l}-0.040^{*} \\
(0.015)\end{array}$ & $\begin{array}{c}-0.068^{* * *} \\
(0.014)\end{array}$ \\
\hline X 2003 & $\begin{array}{c}-0.046^{* * *} \\
(0.012)\end{array}$ & $\begin{array}{c}-0.036^{* *} \\
(0.012)\end{array}$ & $\begin{array}{c}-0.044^{* *} \\
(0.011)\end{array}$ & $\begin{array}{l}-0.043^{*} \\
(0.016)\end{array}$ & $\begin{array}{c}-0.086^{* * *} \\
(0.019)\end{array}$ \\
\hline X 2004 & $\begin{array}{c}-0.058^{* * *} \\
(0.014)\end{array}$ & $\begin{array}{c}-0.039^{* *} \\
(0.014)\end{array}$ & $\begin{array}{c}-0.054^{* *} \\
(0.012)\end{array}$ & $\begin{array}{c}-0.053^{* *} \\
(0.017)\end{array}$ & $\begin{array}{c}-0.106^{* *} \\
(0.026)\end{array}$ \\
\hline X 2005 & $\begin{array}{c}-0.069^{* * *} \\
(0.018)\end{array}$ & $\begin{array}{c}-0.045^{* *} \\
(0.013)\end{array}$ & $\begin{array}{c}-0.062^{* *} \\
(0.015)\end{array}$ & $\begin{array}{c}-0.063^{* *} \\
(0.020)\end{array}$ & $\begin{array}{c}-0.130^{* *} \\
(0.035)\end{array}$ \\
\hline X 2006 & $\begin{array}{c}-0.078^{* * *} \\
(0.020)\end{array}$ & $\begin{array}{c}-0.054^{* *} \\
(0.015)\end{array}$ & $\begin{array}{c}-0.071^{* *} \\
(0.019)\end{array}$ & $\begin{array}{c}-0.069^{* *} \\
(0.022)\end{array}$ & $\begin{array}{r}-0.149^{* *} \\
(0.041)\end{array}$ \\
\hline X 2007 & $\begin{array}{c}-0.079^{* * *} \\
(0.021)\end{array}$ & $\begin{array}{c}-0.059^{* *} \\
(0.017)\end{array}$ & $\begin{array}{c}-0.076^{* *} \\
(0.021)\end{array}$ & $\begin{array}{c}-0.069^{* *} \\
(0.023)\end{array}$ & $\begin{array}{r}-0.145^{* *} \\
(0.036)\end{array}$ \\
\hline X 2008 & $\begin{array}{c}-0.078^{* * *} \\
(0.020)\end{array}$ & $\begin{array}{c}-0.061^{* *} \\
(0.018)\end{array}$ & $\begin{array}{c}-0.081^{* *} \\
(0.020)\end{array}$ & $\begin{array}{c}-0.069^{* *} \\
(0.024)\end{array}$ & $\begin{array}{c}-0.132^{* * *} \\
(0.029)\end{array}$ \\
\hline X 2009 & $\begin{array}{c}-0.071^{* * *} \\
(0.018)\end{array}$ & $\begin{array}{c}-0.054^{* *} \\
(0.017)\end{array}$ & $\begin{array}{c}-0.078^{* *} \\
(0.020)\end{array}$ & $\begin{array}{c}-0.067^{* *} \\
(0.023)\end{array}$ & $\begin{array}{c}-0.112^{* * *} \\
(0.024)\end{array}$ \\
\hline X 2010 & $\begin{array}{c}-0.070^{* * *} \\
(0.018)\end{array}$ & $\begin{array}{c}-0.050^{* *} \\
(0.016)\end{array}$ & $\begin{array}{c}-0.081^{* *} \\
(0.021)\end{array}$ & $\begin{array}{c}-0.067^{* *} \\
(0.024)\end{array}$ & $\begin{array}{c}-0.108^{* *} \\
(0.025)\end{array}$ \\
\hline X 2011 & $\begin{array}{c}-0.073^{* * *} \\
(0.018)\end{array}$ & $\begin{array}{c}-0.054^{* *} \\
(0.018)\end{array}$ & $\begin{array}{c}-0.088^{* *} \\
(0.021)\end{array}$ & $\begin{array}{c}-0.069^{* *} \\
(0.024)\end{array}$ & $\begin{array}{c}-0.107^{* *} \\
(0.025)\end{array}$ \\
\hline X 2012 & $\begin{array}{c}-0.079^{* * *} \\
(0.019)\end{array}$ & $\begin{array}{c}-0.059^{* *} \\
(0.020)\end{array}$ & $\begin{array}{c}-0.092^{* *} \\
(0.023)\end{array}$ & $\begin{array}{c}-0.075^{* *} \\
(0.025) \\
\end{array}$ & $\begin{array}{c}-0.116^{* * *} \\
(0.026) \\
\end{array}$ \\
\hline Industry-by-Year Fixed Effects & Yes & Yes & Yes & Yes & Yes \\
\hline County Fixed Effects & Yes & Yes & Yes & Yes & Yes \\
\hline
\end{tabular}

Notes: This table displays estimates from regressions of employment growth on exposure to Section 936 interacted with year dummies corresponding to Table 6. The second to fifth columns show the heterogeneous effects by industry using definitions from Mian and Sufi (2014). Exposure to Section 936 comes from the NETS and employment growth comes from QCEW (2017). See Section 6 for discussion and Appendix A for more information about the data. The estimates are shown graphically in Figure 14. Standard errors clustered at the state and industry levels are shown in parentheses. ${ }^{*} p<0.05,{ }^{* *} p<0.01,{ }^{* * *} p<0.001$. Observations are weighted according to employment in 1995. 
Table A.27: Effects of Repealing $§ 936$ on Wages, Rental Costs, and Home Values: Robustness to Not Adjusting for Changes in Observable Characteristics

\begin{tabular}{|c|c|c|c|c|c|}
\hline & $(1)$ & $(2)$ & $(3)$ & (4) & (5) \\
\hline \multicolumn{6}{|c|}{ Stacked Differences After 1990} \\
\hline & \multicolumn{3}{|c|}{ Wages } & \multirow[b]{2}{*}{ Rent } & \multirow[b]{2}{*}{ Home Value } \\
\hline & All & High Skill & Low Skill & & \\
\hline \multirow[t]{3}{*}{ Exposure to Section 936} & -0.010 & -0.002 & -0.017 & -0.019 & -0.035 \\
\hline & $(0.002)$ & $(0.002)$ & $(0.003)$ & $(0.003)$ & $(0.007)$ \\
\hline & 0.000 & 0.375 & 0.000 & 0.000 & 0.000 \\
\hline Observations & 984 & 984 & 984 & 984 & 984 \\
\hline Year Fixed Effects & Yes & Yes & Yes & Yes & Yes \\
\hline State Fixed Effects & Yes & Yes & Yes & Yes & Yes \\
\hline \multicolumn{6}{|l|}{ Differences Before 1990} \\
\hline & \multicolumn{3}{|c|}{ Wages } & \multirow[b]{2}{*}{ Rent } & \multirow[b]{2}{*}{ Home Value } \\
\hline & All & High Skill & Low Skill & & \\
\hline \multirow[t]{3}{*}{ Exposure to Section 936} & 0.005 & -0.004 & 0.000 & 0.021 & 0.029 \\
\hline & $(0.008)$ & $(0.004)$ & $(0.007)$ & $(0.010)$ & $(0.023)$ \\
\hline & 0.505 & 0.387 & 0.958 & 0.045 & 0.212 \\
\hline Observations & 492 & 492 & 492 & 492 & 492 \\
\hline Year Fixed Effects & Yes & Yes & Yes & Yes & Yes \\
\hline State Fixed Effects & Yes & Yes & Yes & Yes & Yes \\
\hline
\end{tabular}

Notes: This table shows additional estimates associated with Table 9. Estimates in this table come from regressions of economic outcomes at the conspuma level on the exposure to Section 936. Exposure to Section 936 comes from the NETS and conspuma level outcomes come from the Census (Ruggles et al., 2010). The outcome data in this table are not adjusted for differences in observable characteristics. See Section 6 for more discussion and Appendix A for more information about the data. Standard errors clustered at the state level are shown in parentheses. Observations are weighted according to population. 
Table A.28: Effects of Repealing $§ 936$ on Government Transfer Payments Per Capita, 1990-1995

\begin{tabular}{|c|c|c|c|c|c|c|c|}
\hline & $\begin{array}{c}\text { Total } \\
\text { Transfers } \\
(1)\end{array}$ & $\begin{array}{c}\text { Unem- } \\
\text { ployment } \\
\text { Benefits } \\
(2)\end{array}$ & $\begin{array}{c}\text { Income } \\
\text { Replace- } \\
\text { ment } \\
(3)\end{array}$ & $\begin{array}{c}\text { Educ- } \\
\text { ation } \\
\text { Benefits } \\
(4)\end{array}$ & $\begin{array}{c}\text { Retire- } \\
\text { ment and } \\
\text { Disability } \\
(5)\end{array}$ & $\begin{array}{c}\text { Medicare } \\
\text { Benefits } \\
(6)\end{array}$ & $\begin{array}{c}\text { Public } \\
\text { Medical } \\
\text { Benefits } \\
(7)\end{array}$ \\
\hline \multicolumn{8}{|c|}{ Panel A. Percent change in transfers per capita relative to 1995} \\
\hline \multirow[t]{2}{*}{ Exposure to Section 936} & $\begin{array}{l}-0.002 \\
(0.002)\end{array}$ & $\begin{array}{c}0.023 \\
(0.017)\end{array}$ & $\begin{array}{l}-0.001 \\
(0.005)\end{array}$ & $\begin{array}{c}0.001 \\
(0.009)\end{array}$ & $\begin{array}{l}-0.003 \\
(0.002)\end{array}$ & $\begin{array}{l}-0.003 \\
(0.003)\end{array}$ & $\begin{array}{l}-0.004 \\
(0.006)\end{array}$ \\
\hline & 0.356 & 0.196 & 0.914 & 0.886 & 0.214 & 0.330 & 0.488 \\
\hline \multicolumn{8}{|c|}{ Panel B. Dollar change in transfers per capita relative to 1995} \\
\hline \multirow[t]{2}{*}{ Exposure to Section 936} & $\begin{array}{c}14.982 \\
(18.979)\end{array}$ & $\begin{array}{c}0.893 \\
(1.883)\end{array}$ & $\begin{array}{c}5.815 \\
(5.050)\end{array}$ & $\begin{array}{l}-0.404 \\
(0.714)\end{array}$ & $\begin{array}{l}-1.808 \\
(4.126)\end{array}$ & $\begin{array}{c}2.957 \\
(4.940)\end{array}$ & $\begin{array}{c}8.633 \\
(14.574)\end{array}$ \\
\hline & 0.434 & 0.637 & 0.255 & 0.574 & 0.663 & 0.552 & 0.556 \\
\hline Sample Proportion of Transfers & $96.9 \%$ & $3.1 \%$ & $10.7 \%$ & $1.6 \%$ & $46.2 \%$ & $19.4 \%$ & $15.4 \%$ \\
\hline Sample Transfers Per Capita & $2,793.9$ & 88.8 & 307.4 & 47.6 & $1,330.4$ & 559.7 & 443.2 \\
\hline Year Fixed Effects & Yes & Yes & Yes & Yes & Yes & Yes & Yes \\
\hline
\end{tabular}

Notes: Estimates in this table come from regressions of government transfers in each category at the county level on the exposure to Section 936. The upper panel shows the results with the dependent variable measured in percent change of category transfers per capita while the lower panel shows results with the dependent variable measured in change in dollars per capita. Exposure to Section 936 comes from the NETS and county level transfers comes from the BEA local area personal income accounts (Bureau of Economic Analysis, 2018). Column (1) includes all transfers in columns (2) to (7), which does not include veteran's benefits. None of the specifications for this period find significant differences in transfer payments before the repeal of $\S 936$. See Appendix A for more information about the data. Clustered standard errors are shown in parentheses with p-values displayed below. Analogous regressions for the 2004-2008 period are shown in Table 10. 
Table A.29: Probit Regressions of Probability of Being in Puerto Rico at Firm Level

\begin{tabular}{|c|c|c|c|c|c|}
\hline & $(1)$ & $(2)$ & $(3)$ & $(4)$ & $(5)$ \\
\hline \multicolumn{6}{|l|}{$\overline{\mathrm{PR}}$} \\
\hline \multirow[t]{3}{*}{$\ln$ (Assets) } & 0.935 & 0.941 & 0.888 & 0.901 & 0.919 \\
\hline & $(0.063)$ & $(0.067)$ & $(0.061)$ & $(0.066)$ & $(0.063)$ \\
\hline & 0.000 & 0.000 & 0.000 & 0.000 & 0.000 \\
\hline \multirow[t]{3}{*}{ NAICS 3254 (Pharma) } & 0.098 & 0.123 & 0.225 & 0.223 & 0.225 \\
\hline & $(0.033)$ & $(0.042)$ & $(0.042)$ & $(0.031)$ & $(0.033)$ \\
\hline & 0.003 & 0.003 & 0.000 & 0.000 & 0.000 \\
\hline \multirow[t]{3}{*}{ ETR } & & -0.067 & -0.055 & -0.058 & -0.063 \\
\hline & & $(0.041)$ & $(0.041)$ & $(0.046)$ & $(0.045)$ \\
\hline & & 0.102 & 0.176 & 0.204 & 0.164 \\
\hline \multirow[t]{3}{*}{ Any Research \& Development } & & & 0.148 & 0.135 & 0.137 \\
\hline & & & $(0.060)$ & $(0.066)$ & $(0.067)$ \\
\hline & & & 0.013 & 0.042 & 0.040 \\
\hline \multirow{3}{*}{ Gross Profit / Operating Assets } & & & & 0.140 & 0.142 \\
\hline & & & & $(0.040)$ & $(0.038)$ \\
\hline & & & & 0.000 & 0.000 \\
\hline \multirow{3}{*}{ Long-term Debt / Assets } & & & & -0.015 & -0.014 \\
\hline & & & & $(0.067)$ & $(0.067)$ \\
\hline & & & & 0.824 & 0.835 \\
\hline \multirow{3}{*}{ Any Advertising } & & & & & -0.084 \\
\hline & & & & & $(0.144)$ \\
\hline & & & & & 0.559 \\
\hline Observations & 8945 & 8945 & 8945 & 8945 & 8945 \\
\hline 3 Digit NAICS Industry Fixed Effects & Yes & Yes & Yes & Yes & Yes \\
\hline
\end{tabular}

Notes: Author's calculations and data from COMPUSTAT. This table displays probit estimates of the probability of having any establishments in Puerto Rico in 1995 on firm characteristics. Continuous covariates $\ln$ (Assets), ETR, Gross Profit / Operating Assets, and Long-term Debt / Assets are normalized to z-scores so the estimated coefficients can be interpreted as the marginal effect of a standard deviation change. 
Table A.30: Event Study Results on Firm Value

\begin{tabular}{|c|c|c|c|c|c|c|c|}
\hline & $(0,0)$ & $(0,3)$ & $(0,6)$ & $(0,9)$ & $(0,12)$ & $(0,15)$ & $(-5,15)$ \\
\hline \multicolumn{8}{|c|}{ Pooled CAPM } \\
\hline \multirow[t]{3}{*}{ Event } & -0.141 & -0.447 & -0.970 & -1.191 & -1.431 & -1.078 & -1.250 \\
\hline & $(0.130)$ & $(0.252)$ & $(0.330)$ & $(0.399)$ & $(0.450)$ & $(0.501)$ & $(0.593)$ \\
\hline & 0.280 & 0.076 & 0.003 & 0.003 & 0.001 & 0.031 & 0.035 \\
\hline \multicolumn{8}{|c|}{ Pooled Fama-French 3 Factors Plus Momentum } \\
\hline \multirow[t]{3}{*}{ Event } & 0.061 & -0.207 & -0.478 & -0.774 & -0.825 & -0.342 & -0.255 \\
\hline & $(0.128)$ & $(0.250)$ & $(0.320)$ & $(0.399)$ & $(0.458)$ & $(0.505)$ & $(0.597)$ \\
\hline & 0.634 & 0.408 & 0.135 & 0.052 & 0.072 & 0.499 & 0.669 \\
\hline \multicolumn{8}{|c|}{ February 16, 1993 Event CAPM } \\
\hline \multirow[t]{3}{*}{ Event } & -0.440 & -1.302 & -1.851 & -2.027 & -2.292 & -1.882 & -2.433 \\
\hline & $(0.207)$ & $(0.413)$ & $(0.535)$ & $(0.647)$ & $(0.712)$ & $(0.780)$ & $(0.919)$ \\
\hline & 0.034 & 0.002 & 0.001 & 0.002 & 0.001 & 0.016 & 0.008 \\
\hline \multicolumn{8}{|c|}{ 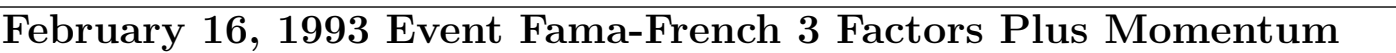 } \\
\hline \multirow[t]{3}{*}{ Event } & 0.056 & -0.757 & -0.662 & -1.090 & -1.220 & -0.616 & -1.108 \\
\hline & $(0.200)$ & $(0.407)$ & $(0.511)$ & $(0.623)$ & $(0.693)$ & $(0.762)$ & $(0.900)$ \\
\hline & 0.780 & 0.063 & 0.195 & 0.080 & 0.078 & 0.419 & 0.218 \\
\hline \multicolumn{8}{|c|}{ October 12, 1995 CAPM } \\
\hline \multirow[t]{3}{*}{ Event } & 0.074 & 0.306 & -0.150 & -0.406 & -0.616 & -0.315 & -0.130 \\
\hline & $(0.167)$ & (0.301) & $(0.396)$ & $(0.478)$ & $(0.560)$ & $(0.636)$ & (0.758) \\
\hline & 0.656 & 0.311 & 0.704 & 0.396 & 0.271 & 0.621 & 0.864 \\
\hline \multicolumn{8}{|c|}{ October 12, 1995 Fama-French 3 Factors Plus Momentum } \\
\hline \multirow[t]{3}{*}{ Event } & 0.064 & 0.252 & -0.319 & -0.464 & -0.419 & -0.072 & 0.589 \\
\hline & $(0.167)$ & (0.308) & $(0.402)$ & $(0.501)$ & $(0.595)$ & $(0.665)$ & $(0.784)$ \\
\hline & 0.700 & 0.414 & 0.427 & 0.354 & 0.482 & 0.914 & 0.453 \\
\hline Observations & 21,105 & 21,732 & 22.359 & 22.986 & 23,613 & 24,240 & 24,240 \\
\hline
\end{tabular}

Notes: Estimates in this table are average Cumulative Abnormal Return (CAR) for an equally weighted portfolio of publicly traded US firms with establishments in Puerto Rico between 1990 and 1996. Each column corresponds to an event study where the range of dates in the event period are equal to the title of the column where the event is defined to be day 0 . The first panel uses CAPM to estimate expected returns while the second panel uses Fama-French 3 factors plus momentum (Fama and French, 1993). Robust standard errors are more conservative than standard errors clustered at the firm or date level. The included firms come from manually matching firms in NETS and COMPUSTAT. Stock return data come from CRSP Stocks (19901996). See Appendix C for discussion and Appendix A for more information about the data. Robust standard errors are shown in parentheses and p-values are displayed below standard errors. 
Table A.31: Event Study Results on Firm Value with Heterogeneous Effects

\begin{tabular}{|c|c|c|c|c|c|c|}
\hline & (1) & $(2)$ & $(3)$ & (4) & $(5)$ & (6) \\
\hline \multirow[t]{3}{*}{ Exposure to Section 936} & -1.523 & -1.521 & -1.515 & -1.513 & -1.527 & \\
\hline & $(0.362)$ & $(0.361)$ & $(0.360)$ & $(0.355)$ & $(0.356)$ & \\
\hline & 0.000 & 0.000 & 0.000 & 0.000 & 0.000 & \\
\hline \multirow[t]{3}{*}{ February 16, 1993} & & & & & & -2.577 \\
\hline & & & & & & $(0.520)$ \\
\hline & & & & & & 0.000 \\
\hline \multirow[t]{3}{*}{ October 12, 1995} & & & & & & -0.559 \\
\hline & & & & & & $(0.467)$ \\
\hline & & & & & & 0.232 \\
\hline \multirow[t]{3}{*}{ Research \& Development } & -0.467 & -0.390 & -0.387 & -0.387 & -0.379 & -0.372 \\
\hline & $(0.075)$ & $(0.090)$ & $(0.094)$ & $(0.094)$ & $(0.097)$ & $(0.083)$ \\
\hline & 0.000 & 0.000 & 0.000 & 0.000 & 0.000 & 0.000 \\
\hline \multirow[t]{3}{*}{ Gross Profit / Operating Assets } & & 0.709 & 1.019 & 1.018 & 1.033 & 0.749 \\
\hline & & $(0.421)$ & $(0.432)$ & $(0.432)$ & $(0.434)$ & $(0.379)$ \\
\hline & & 0.093 & 0.019 & 0.019 & 0.018 & 0.049 \\
\hline \multirow[t]{3}{*}{ Any Advertising } & & & -0.806 & -0.801 & -0.647 & -0.603 \\
\hline & & & $(0.470)$ & $(0.462)$ & $(0.440)$ & $(0.400)$ \\
\hline & & & 0.087 & 0.084 & 0.142 & 0.133 \\
\hline \multirow[t]{3}{*}{ Change in ETR } & & & & -0.053 & 0.026 & -0.062 \\
\hline & & & & $(0.485)$ & $(0.449)$ & $(0.398)$ \\
\hline & & & & 0.914 & 0.955 & 0.876 \\
\hline \multirow[t]{3}{*}{ Relative PR Employment } & & & & & -0.967 & -0.762 \\
\hline & & & & & $(0.755)$ & $(0.628)$ \\
\hline & & & & & 0.201 & 0.225 \\
\hline Observations & 406 & 406 & 406 & 406 & 406 & 406 \\
\hline Industry Fixed Effects & Yes & Yes & Yes & Yes & Yes & Yes \\
\hline
\end{tabular}

Notes: This table estimates the heterogeneous effects of the event study using a two step process. Counterfactual returns for the event period are predicted using a regression on the 100 days of trading before the event. The dependent variable for regressions in this table is the $[0,10]$ day cumulative abnormal return for stocks of firms with exposure to Section 936. Independent variables other than exposure to Section 936 and its interactions with dates are normalized to be mean zero and scaled to standard deviations for interpretation. Two digit industry NAICS controls are included in all specifications. Data for firm financial characteristics come from Compustat (Capital IQ, 1980-2014) and daily stock return data are obtained from CRSP (CRSP Stocks, 1990-1996). The corresponding regressions controlling for the Fama-French factors plus momentum are shown in Table A.32. See Appendix $\mathrm{C}$ for discussion and Appendix A for more information about the data. Robust standard errors are shown in parentheses and p-values are displayed below standard errors. 
Table A.32: Event Study Results on Firm Value with Heterogeneous Effects and Fama-French Controls

\begin{tabular}{|c|c|c|c|c|c|c|}
\hline & (1) & $(2)$ & (3) & (4) & $(5)$ & (6) \\
\hline Exposure to Section 936 & $\begin{array}{l}-0.867 \\
(0.331)\end{array}$ & $\begin{array}{l}-0.867 \\
(0.331)\end{array}$ & $\begin{array}{l}-0.858 \\
(0.328)\end{array}$ & $\begin{array}{l}-0.857 \\
(0.323)\end{array}$ & $\begin{array}{l}-0.866 \\
(0.326)\end{array}$ & \\
\hline & 0.009 & 0.009 & 0.009 & 0.008 & 0.008 & \\
\hline February 16, 1993 & & & & & & $\begin{array}{c}-1.344 \\
(0.470) \\
0.004\end{array}$ \\
\hline October 12, 1995 & & & & & & $\begin{array}{c}-0.479 \\
(0.439) \\
0.275\end{array}$ \\
\hline Research \& Development & $\begin{array}{l}-0.313 \\
(0.051)\end{array}$ & $\begin{array}{c}-0.276 \\
(0.073)\end{array}$ & $\begin{array}{c}-0.273 \\
(0.077)\end{array}$ & $\begin{array}{c}-0.273 \\
(0.077)\end{array}$ & $\begin{array}{l}-0.268 \\
(0.078)\end{array}$ & $\begin{array}{l}-0.260 \\
(0.067)\end{array}$ \\
\hline & 0.000 & 0.000 & 0.000 & 0.000 & 0.001 & 0.000 \\
\hline Gross Profit / Operating Assets & & $\begin{array}{c}0.339 \\
(0.360)\end{array}$ & $\begin{array}{c}0.767 \\
(0.381)\end{array}$ & $\begin{array}{c}0.766 \\
(0.382)\end{array}$ & $\begin{array}{c}0.776 \\
(0.382)\end{array}$ & $\begin{array}{c}0.644 \\
(0.351)\end{array}$ \\
\hline & & 0.347 & 0.045 & 0.046 & 0.043 & 0.067 \\
\hline Any Advertising & & & $\begin{array}{c}-1.112 \\
(0.417)\end{array}$ & $\begin{array}{l}-1.109 \\
(0.410)\end{array}$ & $\begin{array}{c}-1.008 \\
(0.393)\end{array}$ & $\begin{array}{l}-0.898 \\
(0.374)\end{array}$ \\
\hline & & & 0.008 & 0.007 & 0.011 & 0.017 \\
\hline Change in ETR & & & & $\begin{array}{l}-0.043 \\
(0.447)\end{array}$ & $\begin{array}{c}0.008 \\
(0.424)\end{array}$ & $\begin{array}{c}-0.062 \\
(0.376)\end{array}$ \\
\hline Relative PR Employment & & & & 0.924 & $\begin{array}{c}0.984 \\
-0.631 \\
(0.729) \\
0.387\end{array}$ & $\begin{array}{c}0.868 \\
-0.508 \\
(0.604) \\
0.401\end{array}$ \\
\hline Observations & 406 & 406 & 406 & 406 & 406 & 406 \\
\hline Industry Fixed Effects & Yes & Yes & Yes & Yes & Yes & Yes \\
\hline
\end{tabular}

Notes : This table estimates the heterogeneous effects of the event study using a two step process. Counterfactual returns for the event period are predicted using a regression on the 100 days of trading before the event. The dependent variable for regressions in this table is the $[0,10]$ day cumulative abnormal return for stocks of firms with exposure to Section 936 . Independent variables other than exposure to Section 936 and its interactions with dates are normalized to be mean zero and scaled to standard deviations for interpretation. Two digit industry NAICS controls are included in all specifications. Data for firm financial characteristics come from Compustat (Capital IQ, 1980-2014) and daily stock return data are obtained from CRSP (CRSP Stocks, 1990-1996). The corresponding regressions without controlling for the Fama-French factors plus momentum are shown in Table A.31. See Section 5 for more discussion and Appendix A for more information about the data. Robust standard errors are shown in parentheses and p-values are displayed below standard errors. 
Table A.33: Effects of Repealing $§ 936$ on Employment Growth at the County Level: Interactions Part 1

\begin{tabular}{|c|c|c|c|c|c|c|c|c|c|}
\hline & $\overline{(1)}$ & $\overline{(2)}$ & $\overline{(3)}$ & $\overline{(4)}$ & $\overline{(5)}$ & $\overline{(6)}$ & $\overline{(7)}$ & $\overline{(8)}$ & $\overline{(9)}$ \\
\hline Exposure to Section 936 & -0.072 & -0.075 & -0.072 & -0.072 & -0.068 & -0.073 & -0.073 & -0.073 & -0.074 \\
\hline & $(0.017)$ & $(0.016)$ & $(0.017)$ & $(0.017)$ & $(0.017)$ & $(0.016)$ & $(0.017)$ & $(0.017)$ & $(0.015)$ \\
\hline & 0.000 & 0.000 & 0.000 & 0.000 & 0.000 & 0.000 & 0.000 & 0.000 & 0.000 \\
\hline \multicolumn{10}{|c|}{ Interaction of Exposure with: } \\
\hline Total Incentives (Bartik) & & $\begin{array}{c}-0.011 \\
(0.010) \\
0.284\end{array}$ & & & & & & & \\
\hline Job Creation Incentive & & & $\begin{array}{c}0.002 \\
(0.003) \\
0.394\end{array}$ & & & & & & \\
\hline Job Training Subsidy & & & & $\begin{array}{c}0.009 \\
(0.007) \\
0.180\end{array}$ & & & & & \\
\hline Real Minimum Wage & & & & & $\begin{array}{c}0.020 \\
(0.016) \\
0.206\end{array}$ & & & & \\
\hline Right to Work & & & & & & $\begin{array}{c}-0.012 \\
(0.009) \\
0.188\end{array}$ & & & \\
\hline RD Tax Credit & & & & & & & $\begin{array}{c}-0.004 \\
(0.010) \\
0.678\end{array}$ & & \\
\hline Investment Tax Credit & & & & & & & & $\begin{array}{c}-0.002 \\
(0.004) \\
0.593\end{array}$ & \\
\hline Corporate Income Tax & & & & & & & & & $\begin{array}{c}0.040 \\
(0.017) \\
0.021\end{array}$ \\
\hline Year Fixed Effects & Yes & Yes & Yes & Yes & Yes & Yes & Yes & Yes & Yes \\
\hline Industry Fixed Effects & Yes & Yes & Yes & Yes & Yes & Yes & Yes & Yes & Yes \\
\hline Includes all Controls & Yes & Yes & Yes & Yes & Yes & Yes & Yes & Yes & Yes \\
\hline
\end{tabular}

Notes: Estimates in this table build on results shown in Tables 8 and A.24. The estimates in each column come from a regression of employment growth from QCEW on exposure to Section 936 and other local characteristics. All specifications include year, industry, and state fixed effects in addition to all listed controls. Displayed estimates are for the interaction of the listed control and exposure to Section 936. See Appendix F for discussion and Appendix A for more information about the data. Standard errors clustered at the state and industry levels are shown in parentheses. Observations are weighted according to employment in 1995. 
Table A.34: Effects of Repealing $§ 936$ on Employment Growth at the County Level: Interactions Part 2

\begin{tabular}{|c|c|c|c|c|c|c|c|c|c|}
\hline & $(1)$ & $(2)$ & $(3)$ & $(4)$ & $(5)$ & $(6)$ & $(7)$ & $(8)$ & $(9)$ \\
\hline Exposure to Section 936 & $\begin{array}{l}-0.072 \\
(0.017)\end{array}$ & $\begin{array}{c}-0.075 \\
(0.018)\end{array}$ & $\begin{array}{c}-0.072 \\
(0.017)\end{array}$ & $\begin{array}{l}-0.069 \\
(0.017)\end{array}$ & $\begin{array}{c}-0.075 \\
(0.018)\end{array}$ & $\begin{array}{c}-0.073 \\
(0.017)\end{array}$ & $\begin{array}{l}-0.075 \\
(0.019)\end{array}$ & $\begin{array}{l}-0.077 \\
(0.018)\end{array}$ & $\begin{array}{c}-0.085 \\
(0.018)\end{array}$ \\
\hline & 0.000 & 0.000 & 0.000 & 0.000 & 0.000 & 0.000 & 0.000 & 0.000 & 0.000 \\
\hline \multicolumn{10}{|c|}{ Interaction of Exposure with: } \\
\hline Personal Income Tax & & $\begin{array}{c}0.015 \\
(0.013) \\
0.277\end{array}$ & & & & & & & $\begin{array}{c}-0.000 \\
(0.019) \\
0.996\end{array}$ \\
\hline Property Tax & & & $\begin{array}{c}0.001 \\
(0.014) \\
0.971\end{array}$ & & & & & & $\begin{array}{c}0.013 \\
(0.017) \\
0.438\end{array}$ \\
\hline Sales Tax & & & & $\begin{array}{c}0.020 \\
(0.014) \\
0.152\end{array}$ & & & & & $\begin{array}{c}0.019 \\
(0.018) \\
0.292\end{array}$ \\
\hline Trade Exposure (China) & & & & & $\begin{array}{c}0.013 \\
(0.007) \\
0.077\end{array}$ & & & & $\begin{array}{c}0.007 \\
(0.010) \\
0.467\end{array}$ \\
\hline State Revenue Per Capita & & & & & & $\begin{array}{c}0.012 \\
(0.009) \\
0.186\end{array}$ & & & $\begin{array}{c}0.003 \\
(0.020) \\
0.893\end{array}$ \\
\hline Share Routine Workers & & & & & & & $\begin{array}{c}-0.014 \\
(0.009) \\
0.151\end{array}$ & & $\begin{array}{c}-0.023 \\
(0.011) \\
0.046\end{array}$ \\
\hline Trade Exposure (Nafta) & & & & & & & & $\begin{array}{c}-0.014 \\
(0.008) \\
0.106\end{array}$ & $\begin{array}{c}-0.020 \\
(0.011) \\
0.081\end{array}$ \\
\hline Total Incentives (Bartik) & & & & & & & & & $\begin{array}{c}0.005 \\
(0.017) \\
0.763\end{array}$ \\
\hline Job Creation Incentive & & & & & & & & & $\begin{array}{c}0.015 \\
(0.009) \\
0.099\end{array}$ \\
\hline Job Training Subsidy & & & & & & & & & $\begin{array}{c}-0.012 \\
(0.016) \\
0.485\end{array}$ \\
\hline Real Minimum Wage & & & & & & & & & $\begin{array}{c}0.014 \\
(0.018) \\
0.446\end{array}$ \\
\hline Right to Work & & & & & & & & & $\begin{array}{c}-0.004 \\
(0.023) \\
0.881\end{array}$ \\
\hline RD Tax Credit & & & & & & & & & $\begin{array}{c}-0.011 \\
(0.015) \\
0467\end{array}$ \\
\hline Investment Tax Credit & & & & & & & & & $\begin{array}{c}-0.018 \\
(0.017) \\
0.291\end{array}$ \\
\hline Corporate Income Tax & & & & & & & & & $\begin{array}{c}0.044 \\
(0.027) \\
0.116\end{array}$ \\
\hline Year Fixed Effects & Yes & Yes & Yes & Yes & Yes & Yes & Yes & Yes & Yes \\
\hline Industry Fixed Effects & Yes & Yes & Yes & Yes & Yes & Yes & Yes & Yes & Yes \\
\hline Includes all Controls & Yes & Yes & Yes & Yes & Yes & Yes & Yes & Yes & Yes \\
\hline
\end{tabular}

Notes: See Apendix F for discussion of regressions and Appendix A for more information about the data. These estimates of interaction terms between $\S 936$ exposure and other county characteristics build on the regressions shown in Table A.33. Standard errors clustered at the state and industry levels are shown in parenthesk89vith p-values below. Observations are weighted according to employment in 1995. 
Table A.35: Quantile Regression Estimates of the Effects of Repealing §936 on Employment Growth at the County Level

\begin{tabular}{lccccc}
\hline \hline & $(1)$ & & & & \\
& $\mathrm{q} 15$ & $\mathrm{q} 25$ & $\mathrm{q} 50$ & $\mathrm{q} 75$ & $\mathrm{q} 85$ \\
\hline Exposure to Section 936 & -0.011 & -0.017 & -0.033 & -0.062 & -0.083 \\
& $(0.011)$ & $(0.012)$ & $(0.013)$ & $(0.013)$ & $(0.014)$ \\
& 0.327 & 0.159 & 0.009 & 0.000 & 0.000 \\
\hline Year Fixed Effects & $\mathrm{Y}$ & $\mathrm{Y}$ & $\mathrm{Y}$ & $\mathrm{Y}$ & $\mathrm{Y}$ \\
State Fixed Effects & $\mathrm{Y}$ & $\mathrm{Y}$ & $\mathrm{Y}$ & $\mathrm{Y}$ & $\mathrm{Y}$ \\
Industry Fixed Effects & $\mathrm{Y}$ & $\mathrm{Y}$ & $\mathrm{Y}$ & $\mathrm{Y}$ & $\mathrm{Y}$ \\
& & & & & \\
\hline \hline
\end{tabular}

Notes: Author's calculations and data from NETS and QCEW. This table shows quantile regression estimates of Equation 5. See Appendix F for discussion of regressions and Appendix A for more information about the data. Standard errors clustered at the state and industry levels are shown in parentheses with p-values below. 